\title{
On your marks: revising, testing and integrating stage models of smoking initiation
}

Citation for published version (APA):

Kremers, S. P. J. (2002). On your marks: revising, testing and integrating stage models of smoking initiation. [Doctoral Thesis, Maastricht University]. Universiteit Maastricht. https://doi.org/10.26481/dis.20020301sk

Document status and date:

Published: 01/01/2002

DOI:

10.26481/dis.20020301sk

Document Version:

Publisher's PDF, also known as Version of record

\section{Please check the document version of this publication:}

- A submitted manuscript is the version of the article upon submission and before peer-review. There can be important differences between the submitted version and the official published version of record.

People interested in the research are advised to contact the author for the final version of the publication, or visit the DOI to the publisher's website.

- The final author version and the galley proof are versions of the publication after peer review.

- The final published version features the final layout of the paper including the volume, issue and page numbers.

Link to publication

\footnotetext{
General rights rights.

- You may freely distribute the URL identifying the publication in the public portal. please follow below link for the End User Agreement:

www.umlib.nl/taverne-license

Take down policy

If you believe that this document breaches copyright please contact us at:

repository@maastrichtuniversity.nl

providing details and we will investigate your claim.
}

Copyright and moral rights for the publications made accessible in the public portal are retained by the authors and/or other copyright owners and it is a condition of accessing publications that users recognise and abide by the legal requirements associated with these

- Users may download and print one copy of any publication from the public portal for the purpose of private study or research.

- You may not further distribute the material or use it for any profit-making activity or commercial gain

If the publication is distributed under the terms of Article $25 \mathrm{fa}$ of the Dutch Copyright Act, indicated by the "Taverne" license above, 


\section{On your marks: \\ Revising, testing and integrating \\ stage models of smoking initiation}

We don't know anything.

Herman Brood 



\section{On your marks: Revising, testing and integrating stage models of smoking initiation}

\section{PROEFSCHRIFT}

ter verkrijging van de graad van doctor aan de Universiteit Maastricht, op gezag van de Rector Magnificus,

Prof. Dr. A. C. Nieuwenhuijzen Kruseman, volgens het besluit van het College van Decanen, in het openbaar te verdedigen op vrijdag 1 maart 2002 om 12.00 uur door

Stef Petrus Jacobus Kremers 
Promotor:

Prof. Dr. H. de Vries

Co-promotor:

Dr. A. N. Mudde

\section{Beoordelingscommissie:}

Prof. Dr. N. K. de Vries (voorzitter)

Prof. Dr. Ir. J. Brug

Prof. Dr. R. C. M. E. Engels (Katholieke Universiteit Nijmegen)

Prof. Dr. R. A. Knibbe

Prof. Dr. W. F. Velicer (University of Rhode Island, United States of America)

ISBN: $90-5681-125-8$

Cover Design by Silvia Smits

Printed by Unigraphic Maastricht

The study presented in this thesis was performed at the Maastricht Health Research Institute for Prevention and Care (HEALTH), which participates in the Netherlands School of Primary Care Research (CaRe), acknowledged in 1995 by the Royal Dutch Academy of Science (KNAW).

All studies were conducted with financial support from the European Community, Fund for Tobacco Research and Information (Regulation (EC) No 2427/93). Financial support by the Netherlands Heart Foundation for the publication of this thesis is gratefully acknowledged. 


\title{
CONTENTS
}

\section{Chapter 1 \\ Introduction}

7

\section{PART 1 MOTIVATIONAL STAGES OF SMOKING INITIATION Chapter 2}

Subtypes within the precontemplation stage of adolescent smoking acquisition 33

\section{Chapter 3}

Four motivational stages of smoking initiation: predictive validity 45

\section{PART 2 BEHAVIOURAL STAGES OF SMOKING INITIATION}

\section{Chapter 4}

'Kicking the initiation': Do adolescent ex-smokers differ from other groups within the initiation continuum?

55

\section{Chapter 5}

Operationalising Flay's stage model of adolescent smoking initiation:

A longitudinal test

69

\section{PART 3 INTEGRATION OF MOTIVATIONAL AND BEHAVIOURAL STAGES}

\section{Chapter 6}

Model of Unmotivated Smoking Initiation of Children and Adolescents (MUSICA):

Development and testing of a stage model of adolescent smoking initiation

85

\section{Chapter 7 \\ General Discussion \\ 103}

\author{
Notes \\ 120 \\ References \\ 121 \\ Summary \\ 138 \\ Samenvatting \\ 142 \\ Acknowledgements \\ 146 \\ Curriculum Vitae \\ 147
}





\section{Chapter 1 Introduction}

Rule 162.2: 'At all international meetings, the commands of the starter in his own language shall [...] be "On your marks", "Set", and when all competitors are "Set", the gun shall be fired, or approved starting apparatus activated'

International Association of Athletics Federations, 2000

\section{GENERAL INTRODUCTION}

As a result of rule 162.2 of the rules book of the International Amateur Athletic Federation, athletes all over the world start their sprints identically, following three distinct stages. First, each athlete assumes a position completely within his allocated lane and behind the starting line. Both hands and one knee are in contact with the ground and both feet in contact with the starting blocks. Second, at the "Set" command, each competitor immediately rises to his final starting position retaining the contact of the hands with the ground and of the feet with the foot plates of the blocks (International Association of Athletics Federations, 2000). Third, at the report of the starter's gun, athletes commence their starting motion. Of course, slight differences in techniques may be observed, but there is a general sequence in the stages of starting, with rules necessitating athletes to start in a prescribed fashion.

However, where there are no general rules, such a sequence of stages in the starting behaviour is often less obvious. Approximately $40 \%$ of adolescents in the Western World take up smoking. Before they start to smoke on a regular basis, they appear to go through a sequence of stages. A valid study of the determinants of regular smoking requires information with regard to the smoking initiation continuum. Up to now, no generally accepted measure of this continuum exists. The studies presented in this thesis address this issue. Two widespread theories on the process of smoking initiation are refined, tested and integrated. To keep up the analogy of athletics: while many previous studies may have made a false start studying adolescent smoking behaviour and its determinants, this thesis should be viewed as a step towards a valid model of the smoking initiation process.

Studies of adolescent smoking initiation may profit from an accepted model of this process, and applying such a model may improve insights into the population under study. Determinant studies may be able to separate the effects from the causes of stage transitions. Interventions can then be tailored to specific risk groups, and the content of interventions can be adjusted to the most salient causes of stage transitions.

The studies in this thesis have been conducted in the context of the ESFA project (European Smoking prevention Framework Approach; De Vries et al., submitted). ESFA was a five-year European smoking prevention project that combined intervention and research. It was implemented at seven locations in the European 
Community, and started in February 1997. The participating countries were Denmark, Finland, the Netherlands, Portugal, Spain and the United Kingdom. The intervention in Spain was divided over two locations (Madrid and Barcelona) because of language differences. The Tobacco Research and Information Fund of the European Commission financed $71 \%$ of the costs of the project. The remaining costs of programme development were covered by the seven participating locations. ESFA aimed to develop, implement and evaluate a comprehensive smoking prevention programme. If proven successful, the approach is to be disseminated to other EC member states. Since several European countries participated in the project, a large cross-cultural data set was created which proved to be an outstanding source of information for generating and examining the hypotheses of the present thesis.

This introductory chapter starts by briefly discussing the health effects of smoking, and goes on to outline the social cognitive theories most widely used to study adolescent smoking behaviour. It then summarises the empirical findings of determinant studies on the subject of adolescent smoking in a theoretical context, and elaborates on stage models of health behaviour. The next section describes and discusses two stage models of adolescent smoking initiation. One is a motivational stage model that originated from the stages of change construct (Prochaska \& DiClemente, 1983), while the other is a behavioural stage model by Flay and colleagues (Flay, 1993; Flay, D’Avernas, Best, Kersell \& Ryan, 1983; U. S. Department of Health and Human Services [USDHHS], 1994). This leads to the aim of the present thesis. The studies described in this thesis intended to refine, test and integrate two stage models of adolescent smoking initiation. Several research designs that are able to test stage models are described. The final section of the chapter presents an outline of the thesis.

\section{HEALTH EFFECTS OF SMOKING}

Every day, smoking kills more people than AIDS, alcohol, drug abuse, car crashes, suicides, and fires combined (Lynch \& Bonnie, 1994). Ever since Christopher Columbus returned from his journeys with some leaves of the tobacco plant, its use has spread all over the world, and politicians, physicians, journalists, scientists and the public have struggled with the health and social consequences of smoking (Kaufman \& Feiden, 1999). Medical evidence of the harm done by smoking has been accumulating for 200 years, initially in relation to cancers of the lip and mouth, and then in relation to cardiovascular disease and lung cancer (Doll, 1998). The evidence was generally ignored until five case-control studies linking smoking to the development of lung cancer were published in 1950 (Doll \& Hill, 1950; Levin, Goldstein \& Gerhardt, 1950; Mills \& Porter, 1950; Schrek. Baker, Ballard \& Dolgoff, 1950; Wynder \& Graham, 1950; see also Peto et al., 2000). The modern era of the study of smoking had begun (Doll, 1998).

Numerous studies on the health effects of smoking have shown, for instance, that men who smoke increase their risk of death from lung cancer more than 22 -fold, while women who smoke increase this risk nearly 12-fold (Centers for Disease Control 
and Prevention [CDC], 1993). Smoking triples the risk of dying from heart disease among the middle-aged (CDC, 1993). On average, smokers die nearly seven years younger than nonsmokers (USDHHS, 1994). About half of all cigarette smokers will eventually be killed by their habit (Doll, Peto, Wheatley, Gray \& Sutherland, 1994). Among young people, the short-term health effects of smoking include damage to the respiratory system, while long-term health consequences are aggravated by the fact that most young people who smoke regularly continue to smoke throughout adulthood (USDHHS, 1994). The younger people start smoking cigarettes, the more likely they are to become strongly addicted to nicotine (USDHHS, 1994). Moreover, tobacco is generally the first drug used by young people who enter a sequence of drug use that may include alcohol, marijuana and harder drugs (Kandel \& Faust, 1975; USDHHS, 1994).

It is estimated that world-wide about 3 million smokers a year die from smoking (Peto, Lopez, Boreham, Thun \& Heath, 1994). Tobacco is responsible for approximately $14 \%$ of all deaths in Europe (Haglund, 2000). In the Netherlands, smoking accounts for over 18,000 deaths annually (Dutch Foundation on Smoking and Health, 1999). Almost $90 \%$ of today's adult smokers started to smoke as teenagers. Between the ages of 11 and 18 years, the percentage of daily smokers among the Dutch population increases from 0 to $38 \%$ (Dutch Foundation on Smoking and Health, 2000). Today, approximately $34 \%$ of the Dutch population aged 15 years and older smoke; $37 \%$ of them are men, $31 \%$ women (Dutch Foundation on Smoking and Health, 2000). Sweden is the only European country which has reached the WHO goal of $80 \%$ nonsmokers by the year 2000 (Haglund, 2000).

Recognising the crucial period of adolescence in the development of smoking behaviour, many studies have tried to explain the onset of adolescent smoking. If we know why adolescents start smoking, we can make attempts to prevent them from taking up the habit. Usually, and preferably, these studies are based on theoretical models. Numerous theories have been developed that try to explain adolescent smoking initiation (see Lettieri, Sayers \& Pearson, 1980; Petraitis, Flay \& Miller, 1995 for reviews). Theories have been presented, for instance, by sociologists, social psychologists and theorists focusing on personality or biology. The application of psychosocial theories to the area of adolescent smoking behaviour was pioneered by the conceptual and pilot work of Leventhal (1968), Bandura (1977), Evans and colleagues (Evans et al., 1978), McAllister and colleagues (McAllister, Perry \& Maccoby,1979) and McGuire (1984). The theoretical approach provided a major breakthrough in the understanding of smoking initiation and development (USDHHS, 1994). In order to understand the origin of the research questions in the studies presented in this thesis, it is useful to give some insight into the psychosocial theories of health behaviour that have been applied most widely to study adolescent smoking behaviour.

\section{INTENTIONAL MODELS OF HEALTH BEHAVIOUR}

Whereas in the beginning of the 20th century, behaviour was vicwed as a more or less passive response to the environment (e.g., Pavlov, 1927; Skinner, 1938), the 
perspective changed to an interactive viewpoint in the early fifties (e.g., Kelly, 1955; Lewin, 1951). In the latter perspective, individuals process information from the environment and rationally decide whether to act or not. The theories that have emerged from this perspective focus primarily on the intention to adopt or modify behaviour. Ajzen \& Fishbein (1980) argued that the measure of intention should be a precise measure of the likelihood that a person will engage in a particular behaviour. Thus, a respondent might be asked to indicate the subjective probability that she will smoke a cigarette in the next year, as follows: 'I intend to smoke a cigarette in the next year', with answering categories ranging from 'extremely probable', through 'quite probable' and 'slightly probable' to 'slightly improbable', 'quite improbable', and 'extremely improbable'. Intention to either adopt a new behaviour or to continue the existing behaviour is always the result of a deliberation process (Gebhardt, 1997). This intention is assumed to be the primary, if not the only determinant of behaviour, and models that share this assumption are labelled 'intentional' models of health behaviour. Some intentional theories that have been used in adolescent smoking research are the Theory of Reasoned Action (TRA; Fishbein \& Ajzen, 1975), the Social Learning Theory (SLT; Bandura, 1977), the Theory of Planned Behaviour (TPB; Ajzen, 1988), the ASE model (De Vries, Dijkstra \& Kuhlman, 1988) and the Theory of Triadic Influence (TTI; Flay \& Petraitis, 1994).

The intentional focus is not the only aspect shared by the theories. Three main clusters of cognitive constructs can be identified (see also Petraitis et al., 1995). First, the models describe attitudinal constructs. This construct refers to adolescents' expectations and evaluations about a particular health behaviour. Second, social or interpersonal clusters are recognised. They include modelling, normative beliefs, and perceived support or pressures. Third, self-efficacy is generally viewed as a factor that influences health behaviour. This factor refers to the perception of control over a specific behaviour.

The Theory of Reasoned Action (Fishbein \& Ajzen, 1975) is an exception in that it does not include the self-efficacy construct. However, after the introduction of the self-efficacy concept by Bandura (1977) in his Social Learning Theory, Ajzen (1985) acknowledged the necessity to add a similar concept to his theory of reasoned action. He therefore proposed a new theory, the Theory of Planned Behaviour, which included the concept of perceived behavioural control. The ASE model (De Vries et al., 1988) and the Theory of Triadic Influence (Flay \& Petraitis, 1994) may be regarded as integrative theories in that they integrate relevant aspects of the TRA, SLT and TPB in order to provide a broad perspective on health behaviour. Moreover, the ASE model and TTI emphasise distal levels of influence in addition to the proximal influences of attitudes, social influence and self-efficacy. These integrative models will be briefly outlined below.

\section{Integrative models}

The ASE model (De Vries et al., 1988) was originally proposed as an adaptation of the Theory of Reasoned Action (Fishbein \& Ajzen, 1975), and has evolved into an integrative health behaviour model (De Vries \& Mudde, 1998; Figure 1.1). The Theory of Triadic Influence (Flay \& Petraitis, 1994; Figure 1.2) is the result of an integration of existing theories of adolescent substance use. Both models state that 
behaviour is a function of a person's intention, and combine cognitive-affective aspects with social cognitive influences, concepts of social interaction and intrapersonal characteristics in order to predict and explain these intentions (note I). The three clusters of attitudes, social influences and self-efficacy are recognised, as well as distinct levels of influence.

Figure 1.1. The ASE Model (De Vries et al., 1988; De Vries \& Mudde, 1998)

PREDISPOSING FACTORS

PROXIMAL FACTORS

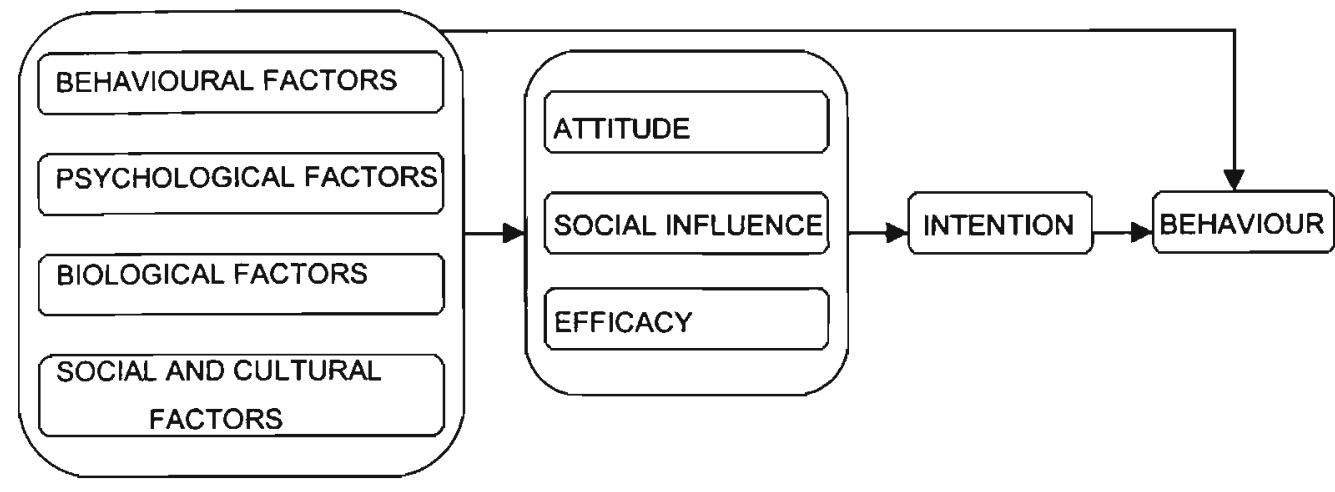

The TTI assumes that proximal influences should be measured by a multiplicative function, as originally proposed by Fishbein \& Ajzen (1980). In contrast, the ASE model postulates that all concepts should be entered separately into regression equations (De Vries \& Mudde, 1998). Several studies support this postulate (De Vries, Lechner \& Kremers, in preparation; Gagné \& Godin, 2000; Lechner, 1997), in that they have shown that the various multiplicative functions do not have additional explanatory value over the measurement of the beliefs. The ASE model distinguishes two types of attitudinal dimensions: cognitive and emotional consequences. Further, three types of proximal social influences are distinguished; social norms, direct pressure or support, and perceived behaviour of others. In the TTI, the latter concept is viewed as a distal social concept, as proposed by Bandura in his social learning theory. Several clusters of self-efficacy are distinguished in the ASE model (see also De Vries \& Mudde, 1998).

In the ASE model, the impact of the proximal factors is assumed to be moderated by four distal types of influence: behavioural factors (e.g., acquisition of skills and previous experience with the same and related behaviours), psychological factors (e.g., self-esteem, anxiety, depressed affect), biological factors (e.g., gender, age, hereditary variables), and social and cultural variables (e.g., parenting styles, social climate, socio-economic status) (De Vries \& Mudde, 1998). Whereas the ASE model describes proximal and distal influences, the TTI additionally distinguishes ultimate levels of influence. Ultimate influences are beyond the personal control of 
Figure 1.2. Theory of Triadic Influence (Flay \& Petraltls, 1994)

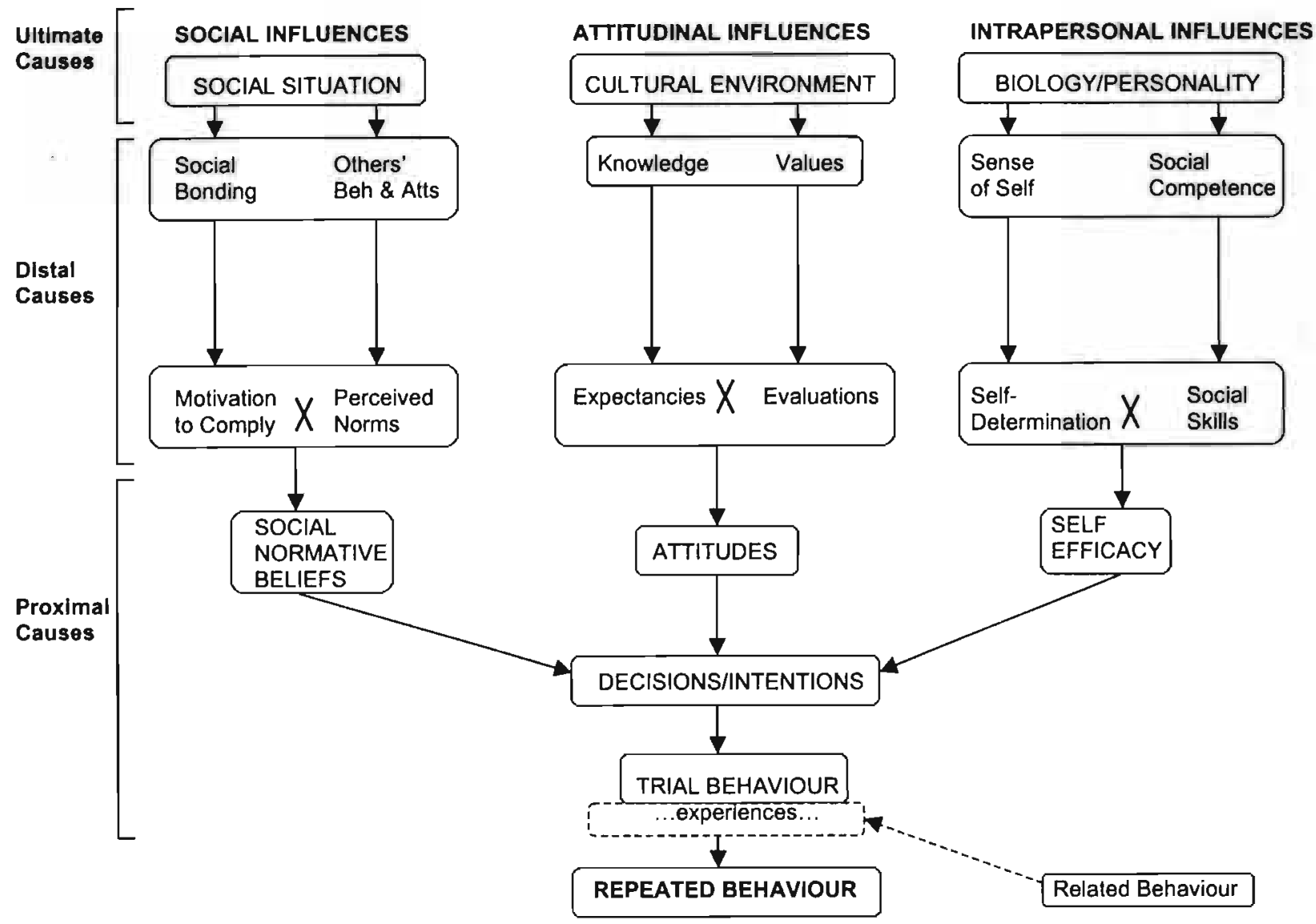


individuals. For example, neighbourhood crime problems, parental divorce and parenting styles are viewed as ultimate influences, while personality traits like aggressiveness and neuroticism, as well as genetic factors, also belong to this level. Both the ASE model and the TTI postulate that constructs from the proximal levels of influence mediate the effects of the more distal constructs. On the other hand, it has been acknowledged that behaviours that have become habitual may have direct effects on future behaviour (De Vries, Backbier, Kok \& Dijkstra, 1995; De Vries \& Mudde, 1998) and may thus bypass the cognitive process (Aarts \& Dijksterhuis, 2000; Trafimow, 2000; Triandis 1977; 1980; Verplanken \& Aarts, 1999). The TTI distinguishes trial behaviour from the repeated use of substances. Initial trial experiences may cause an individual to continue or quit the use of the substance.

\section{ASSOCIATIONS WITH ADOLESCENT SMOKING BEHAVIOUR}

The United States Surgeon General's 1994 report on smoking and health presented an analysis of psychosocial risk factors for smoking, based on a literature review by Conrad, Flay \& Hill (1992). Tyas \& Pederson (1998) extended the time frame of this review to 1996. In order to provide a complete overview, the reviews were updated for the present thesis by means of a search of computerised databases (MedLine and PsychLit) from 1997-2001, as well as an inspection of journals that are not filed in computerised databases but are known to publish studies of adolescent smoking, and a careful examination of the citations and references in known studies and reviews of adolescent smoking. The studies reviewed include both cross-sectional and longitudinal designs. Consequently, this thesis speaks of associations with adolescent smoking behaviour, rather than determinants (note 2). The empirical findings with regard to proximal associations are summarised in Figure 1.3, using the ASE model as a framework. For a more detailed overview the reader is referred to the reviews by Conrad et al. (1992) and Tyas and Pederson (1998).

Intention to smoke is found to be highly associated with future smoking behaviour. Conrad, Flay and Hill (1992) found that intention to smoke was significantly associated with onset in $89 \%$ of the studies. Special features of an adolescent's intention to smoke are the concepts of susceptibility to smoking (Pierce, Choi, Gilpin, Farkas \& Merritt, 1996; Pierce, Farkas, Evans \& Gilpin, 1995) and the intentional or motivational stages of change (Prochaska \& DiClemente, 1983). Research has shown that susceptibility to smoking (i.e., the absence of a firm commitment to nonsmoking) was strongly associated with moving towards both experimentation (Pierce et al., 1996) and established smoking (Choi, Pierce, Gilpin, Farkas \& Berry, 1997). Research that applied the stages of change construct to adolescent smoking acquisition showed that the stages were associated with cognitive risk factors (Elder et al., 1990; Kelley, Denny \& Young, 1999; Pallonen, 1998; Pallonen, Prochaska, Velicer, Prokhorov \& Smith, 1998; Stern, Prochaska, Velicer \& Elder, 1987; Werch \& DiClemente, 1994). This topic will be elaborated in more detail in the sections and chapters below.

Positive attitudes toward smoking have been found to be associated with an increased likelihood of smoking (e.g., Botvin, Baker, Goldberg, Dusenbury \& Botvin, 
will execute the behaviour under study. For example, if a person scores high on a 'pro' of a particular behaviour, this person is more likely to execute this behaviour than a person with lower scores. Since the equation is identical for each subject under study, a linear model is assumed to underlie it. Figure 1.4a graphically represents a typical linear model.

Figure 1.4a. Graphical representation of a linear model

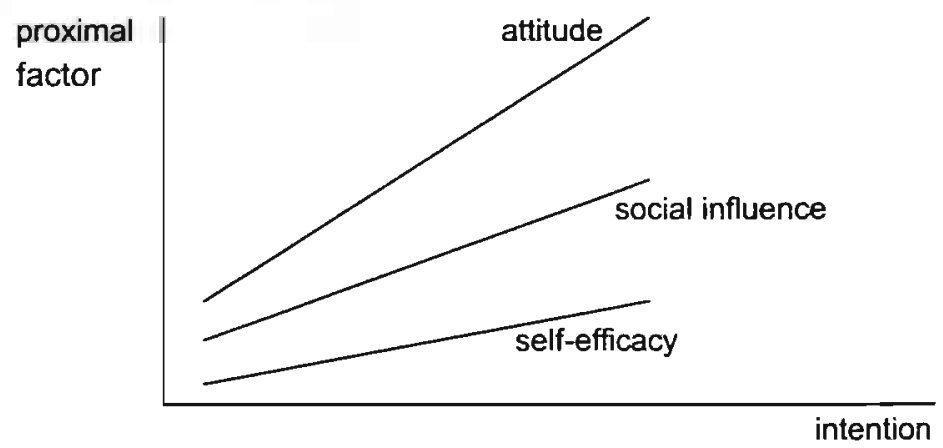

However, some behaviours may not be accurately predicted by a single equation. Two individuals who act differently may need a different prediction equation. Even two persons who are motivated differently towards acting in a certain way may be best described by different prediction equations. As a result of this insight, stage models of health behaviour are increasingly used in health psychology (Sutton, 2000). Stage thcories present a temporal dimension, which is largely ignored by other theories of change. Behaviour change is often construed as an event, such as quitting smoking, drinking, or over-eating (Velicer, Prochaska, Fava, Norman \& Redding, 1998). In contrast, stage models assume behaviour change to be a dynamic process that involves movement through a set of defined, qualitatively distinct, stages (Weinstein et al., 1998). Figure 1.4b shows an example of a curve ('the $\varnothing$-pattern') that indicates an underlying stage model (see also De Vries \& Backbier, 1994).

Figure 1.4b . Graphical representation of a stage model (b; the Ø-pattern)

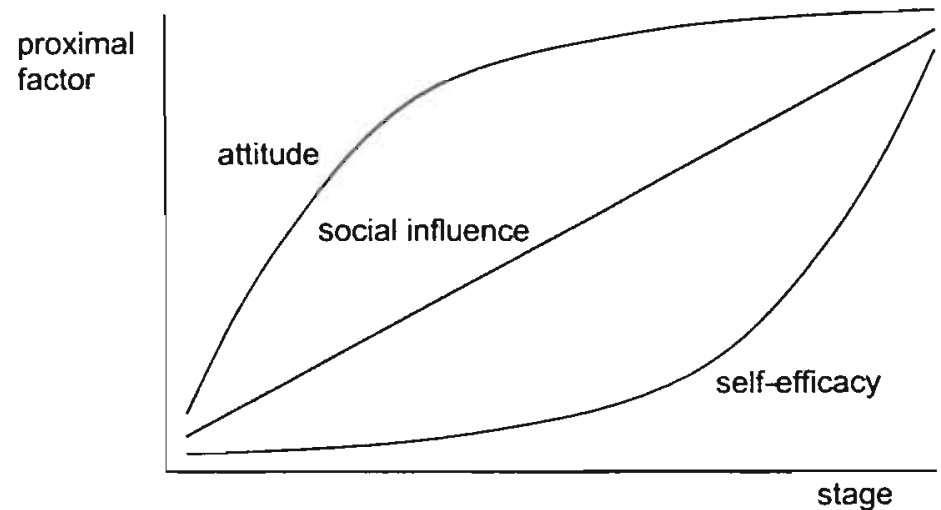


Weinstein and colleagues (1998) defined four properties of a stage theory of health behaviour. First, any stage theory includes a classification system that assigns each individual to one of a limited number of categories. Each health behaviour stage includes people who differ relatively little from each other, while differences between people in different stages are relatively large. Second, stage theories have a sequential nature. People are assumed to pass through a particular stage in order to enter the next. The third defining property states that people in the same stage face similar barriers before they can progress to the next stage, while different stages involve different barriers. Health behaviour theories that do not meet these four defining criteria should not be labelled stage processes. In such theories, the concept of stages would be superfluous, and the behaviour could just as well be described as linear.

A number of stage-based theories have been proposed in the health literature. Stage theories can be divided into health behaviour related stage theories and general stage theories. Stage models that address a particular health behaviour have been applied in the areas of AIDS prevention (Catania, Kegeles \& Coates, 1990; Martin, 1995) and delay in seeking medical care (Safer, Tharps, Jackson \& Leventhal, 1979; Andersen, Cacioppo \& Roberts, 1995). General stage theories in current use in health psychology include the Transtheoretical model (TTM; Prochaska \& DiClemente, 1983), the Precaution Adoption Process Model (PAPM; Weinstein, 1988; Weinstein \& Sandman, 1992), the Health Action Process Approach (HAPA; Schwarzer, 1992; Schwarzer \& Fuchs, 1996), and the Health Behaviour Goal Model (HBGM; Gebhardt, 1997). Generally, each of these models distinguishes a pre-contemplative, a contemplative, a preparative and an active and/or maintenance stage, although the exact definitions of each of these stages may differ (see also Gebhardt, 1997). The 'stages of change' construct in the Transtheoretical model is by far the most widely used stage theory of health behaviour change (Sutton, 2000). This model is described in the next section.

\section{Stages of Change}

The stages of change construct (SCC) was developed in the early 1980s (Prochaska \& DiClemente, 1982; 1983; Figure 1.5). The SCC is the key construct of the Transtheoretical Model (TTM), and construes change as a process involving progtess through a series of five stages. Precontemplation is the stage in which people do not intend to take action within the foreseeable future, typically operationalised as the next six months (Velicer et al., 1998). People may be in this stage because they are uninformed or under-informed about the consequences of their behaviour. They may also be in this stage because they are not aware of the fact that behaviour change might be desirable. Contemplation is the stage in which people intend to change within the next six months. They are assumed to be more aware of the advantages of behaviour change, but are also accurately aware of the disadvantages. Preparation is the stage in which people intend to take action within the next month. These individuals typically have a plan of action, such as talking to an expert, or buying a self-help book. Action is the stage in which people have made specific overt modifications to their life-styles within the past six months. In this stage, caution against relapse is critical. Maintenance is the stage in which people are working to stabilise the behaviour change. Regression occurs when individuals revert to an earlier stage of change 
(Velicer et al., 1998). Relapse is one form of regression, involving regression from action or maintenance to an earlier stage. Note that in early publications of the SCC, the latter concept was viewed as a separate stage (e.g., Prochaska \& DiClemente, 1983; Prochaska, DiClemente, Velicer, Ginpil \& Norcross, 1985).

\section{Figure 1.5. Stages of change construct}

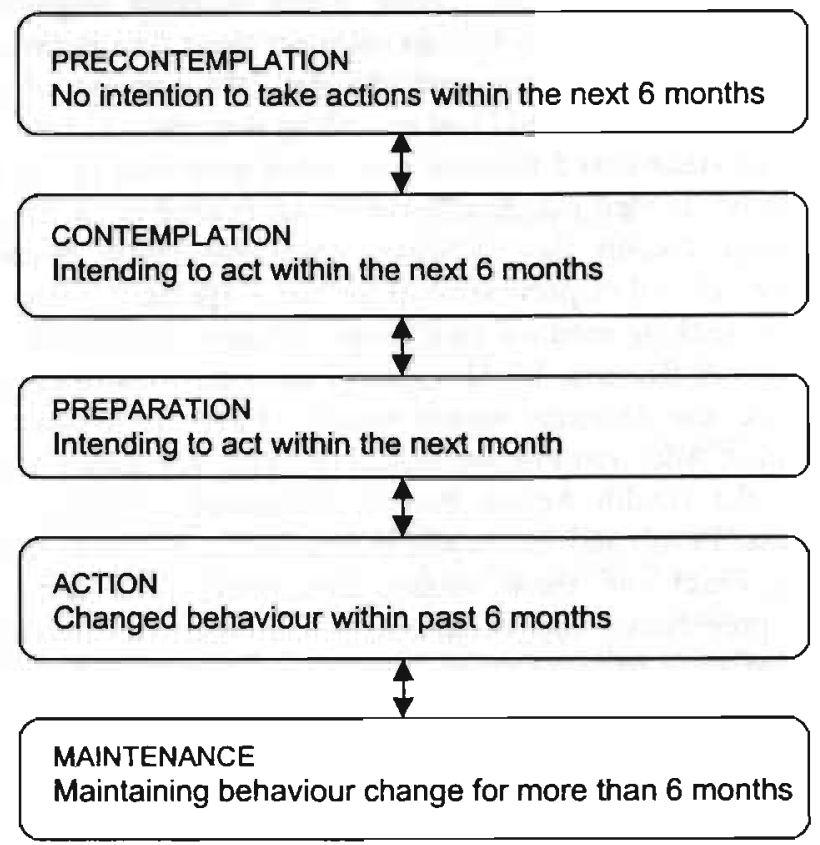

The findings of several studies suggest that the stages of change not only differ because of differences in intentions, but also because of differences in the impact of the cognitive determinants (Velicer, Norman, Fava \& Prochaska, 1999). Cognitive determinants, referred to as dynamic constructs in the TTM, have been shown to differ between the various stages of change (Velicer et al., 1999; Prochaska \& DiClemente, 1984; Prochaska, Velicer, Guadagnoli, Rossi \& DiClemente, 1991). The dynamic constructs in the TTM consist of pros (perceived advantages), cons (perceived disadvantages), and temptations (perceived self-efficacy) with regard to the behaviour in question.

Individuals mostly recycle through the stages, i.e., they pass through the various stages a number of times before actual behaviour change takes place. Ten processes of change have been identified to represent the cognitive and behavioural strategies that people use when they move through the various stages (Prochaska, Velicer, DiClemente \& Fava, 1988). The cognitive, or experiental, processes include consciousness raising, self-reevaluation, self-liberation, environmental reevaluation, and emotional arousal and dramatic relief. The behavioural processes include counter-conditioning, stimulus control, reinforcement management, helping 
relationships, and social liberation. Prochaska and DiClemente (1983) have argued that the relative importance of each process is stage-dependent.

\section{STAGE MODELS OF ADOLESCENT SMOKING INITIATION}

This paragraph reviews the current models of the stage process of adolescent smoking initiation. Although many researchers have assumed a stage-like progression of smoking initiation, two major lines of research can be identified that have assessed this continuum (Werch \& Anzalone, 1995). One is a line of research that has its origin in the stages of change construct (Prochaska \& DiClemente, 1983), which focuses mainly on changes in the motivational (or intentional) stages of smoking initiation. The second line of research originated from the early work of Leventhal and Cleary (1980), and focuses on the behavioural stages of initiation. The sections below elaborate on the status of evidence in both lines of research.

\section{Motivational stages of adolescent smoking acquisition}

As was described in the section on associations with adolescent smoking behaviour, intention to smoke is highly associated with future smoking behaviour. Because of the strength of this association, several researchers have used intentions to smoke as an outcome measure in their studies (USDHHS, 1994). This was especially the case in populations where smoking prevalence is low, such as pre-adolescents. These studies were mostly based on Fishbein and Ajzen's Theory of Reasoned Action (1975) and assessed the adolescents' plans to start smoking in the next year, or some time in the future (e.g., Evans, 1983; Evans, Rozelle \& Maxwell, 1981; Page \& Gold, 1983; Sherman, 1982; Tucker, 1984). Note that intentional outcome measures have a linear nature.

Recognising the stage-like process of health behaviour change, Prochaska \& DiClemente (1983) developed a standardised stage measure of individuals' intentions or motivations, labelled the stages of change construct (SCC), which was described in the previous section. Although the SCC emerged from research on adult smoking cessation, it has been applied to a wide variety of problem behaviours (Prochaska et al., 1994).

The SCC has also been applied to adolescent smoking acquisition (Elder et al., 1990; Kelley et al., 1999; Pallonen, 1998; Pallonen et al., 1998; Stern et al., 1987; Werch \& DiClemente, 1994) and can be regarded as the mirror image of the cessation model (Stern et al., 1987). The SCC distinguishes three motivational stages of smoking acquisition (Pallonen et al., 1998), defined as acquisition precontemplation (aPC; no intentions to start smoking within the next 6 months), acquisition contemplation ( $\mathrm{aC}$; thinking about starting to smoke within the next 6 months) and acquisition preparation (aP; thinking about starting to smoke within the next 30 days). Additionally, the model assumes stages of action (having smoked during the past 6 months) and maintenance (having smoked for more than 6 months). The McMOS model (Werch \& Anzalone, 1995; Werch \& DiClemente, 1994) is based on the SCC, and combines the five acquisition stages of change with the five 'regular' stages of cessation, forming a ten-stage model. The model has been applied mostly to the 
acquisition of alcohol use (Werch, 1997; Werch, 2001; Werch, Carlson, Pappas, Dunn \& Williams, 1997; Werch et al., 1995) and drug use (Werch, Meers \& Farrell, 1993; Werch, Ross, Anzalone \& Meers, 1994).

Since the SCC provides a standardised measure of individual motivations, this construct has received increasing attention. Cross-sectional research on the stages of smoking acquisition has shown that the various stages differ with regard to cognitive characteristics. Acquisition precontemplators were shown to have the least risky cognitive characteristics (Pallonen et al., 1998; Stern et al., 1987; Werch et al., 1993; 1994). They saw fewer advantages of smoking and more disadvantages of smoking (Pallonen et al., 1998; Stern et al., 1987) and they had greater motivation to avoid tobacco (Werch et al., 1993; 1994) than those in the more advanced stages. Furthermore, they had a stronger belief that they could refrain from smoking in difficult situations, for instance when a friend offers a cigarette. Acquisition contemplators had some cognitive characteristics that were less risky than those of acquisition preparators (Pallonen et al., 1998; Werch et al., 1993).

\section{Status of evidence}

The SCC has had a large impact on health promotion. It has become one of the most prominent and popular conceptual resources in the field (Whitelaw, Baldwin, Bunton \& Flynn, 2000). The ability of the SCC to segment populations and direct compatible interventions to them are attractive features (Whitelaw et al., 2000). To illustrate its popularity, a review of the stages of change construct by Whitelaw and colleagues identified 239 empirical studies using the stages of change construct. The use of the SCC increased from 4 studies in 1985, through 11 studies in 1992 and 31 studies in 1995 , to 54 in 1997.

An advantage of studying adolescent smoking initiation using the SCC is that similar measures can be used for both adolescent smoking acquisition and cessation. Thus, the SCC provides a concise and theory-based approach to adolescent smoking (Pallonen et al., 1998). Another feature of the SCC of smoking acquisition that may have face validity is that subjects can move in both directions between the stages or recycle several times through the stages. Other (behavioural) stage theories appear to assume that smoking is a linear developmental process where one stage necessarily leads to the next (Pallonen et al., 1998). Unfortunately, the possibility of recycling through the stages has not been investigated to date. This would require a longitudinal design, and no longitudinal test of the SCC of smoking acquisition has yet been conducted.

In their review of the SCC, Whitelaw and colleagues (2000) suggest that many studies that empirically test the construct are attempting to present evidence supporting the SCC. However, doubts have been raised about the authority of these studies and thus the assumption of valid evidence (Whitelaw et al., 2000; Sutton, 2001). Bandura (1997) has questioned whether the model is a 'true' stage model at all. The subdivision of the various stages by using time frames may be arbitrary rather than a reflection of qualitative stage transformation. Moreover, Bandura (1997) stated that genuine stage progression does not permit recycling through stages. Sutton (2001), however, has postulated that it is unrealistic to insist on an irreversible sequence for stages of change of addictive behaviours. The validity of self-reported stages has also been questioned. 
Lechner and colleagues (Lechner, Brug, De Vries, Van Assema \& Mudde, 1998), for example, have shown that different methods of dietary assessment classify subjects into different stages. Many subjects would be classified as being in 'precontemplation' according to one classification, whereas the traditional classification would result in an assignment to the 'maintenance' stage. Further, the external validity has been questioned with respect to its transfer to other behaviours than smoking cessation, such as drug use, exercise and healthy diet (Clarke and Eves, 1997).

With regard to smoking initiation, the prevalence of acquisition precontemplators among the nonsmoking adolescent population has been found to be over 90\% (Aveyard et al., 1999; Pallonen et al., 1998). Since a large percentage of adolescents will eventually start smoking, the precontemplating group might be diverse with regard to predictors of smoking initiation. In this respect, the stages of change construct might not comply with the first defining property proposed by Weinstein and colleagues (1998), that states that stages should include people with relatively small differences between each other.

Further, the time frame of the SCC may not be applicable to adolescents. Unlike adults, adolescents might not plan as much as six months ahead. The period of adolescence is characterised by many and rapid social and personal changes. For every individual, there are a few critical moments in adolescence in which certain health behaviours crop up as significant topics and they must decide whether to act or not (Engels, Knibbe \& Drop, 1999). Moreover, the motivation-behaviour link may not be very strong in adolescence. This might be particularly true for those who have given little consideration to the consequences of specific behaviour (Bagozzi \& Yi, 1989), or for those who are unwilling to make the effort to come to a deliberate decision (Fazio, 1985). Many adolescents say they do not want to start smoking, but many of them still do take up the habit. Measuring the motivation to start smoking at some time in the future might not distinguish between children who have really thought consciously about being nonsmokers and those who have not rationally decided not to smoke. Therefore, the concept of 'non-susceptibility' was introduced by Pierce and colleagues (1995). The move to start smoking may be influenced by the absence of a firm decision not to smoke (Choi et al., 1997; Pierce et al., 1996; Unger, Johnson, Stoddard, Nezami \& Chou, 1997).

Finally, some researchers have recognised some deficits in the applicability of the SCC to the experimental nature of adolescent smoking acquisition. Kelley and colleagues (1999) added one stage to the model, that of recontemplation, representing those individuals who have tried a substance but are not planning to try it again. They found the recontemplation stage to be the second largest stage in adolescent smoking initiation, after the precontemplation stage.

In conclusion, although the stages of change approach to adolescent smoking behaviour seems to be a useful starting point, the applicability of the construct as such to the process of adolescent smoking initiation needs to be evaluated. The primary shortcoming is that research has mostly been limited to cross-sectional studies on stage placement. Further, past definitions have not clearly delineated and tested the roles of variations in the strength of intention and time frames in measuring and understanding the motivational acquisition stages of smoking behaviour (see also Werch, 2001). 


\section{Behavioural stages of adolescent smoking}

Since evidence relating smoking to the development of lung cancer started accumulating in the 1950s (Doll \& Hill, 1950; Levin et al., 1950; Mills \& Porter, 1950; Schrek et al., 1950; Wynder \& Graham, 1950) researchers have initiated sociological and epidemiological studies on smoking behaviour. Many surveys were carried out in the late 1950s and early 1960s (Borgatta \& Evans, 1968). In 1968, Salber and colleagues stated that 'a considerable number of cross-sectional epidemiological studies have been undertaken of the general population, of groups deemed to be of particular relevance, such as adolescents, and perhaps most often of groups convenient to survey' (Salber, Freeman \& Abelin, 1968; p. 129). In this particular publication however, the authors take a new stand, in stating that crosssectional epidemiological surveys do not provide sufficient insight into the aetiology of smoking. "Rather, longitudinal studies with "process" or "dynamic" data are required to understand the career of the smoker' (Salber et al., 1968; p. 130).

These and other observations of smoking behaviour in the late 1960s and early 1970s (e.g., Dunn, 1973) have informed theory construction on the definition of stages of adolescent smoking initiation in the early 1980s (Flay et al., 1983; Hirschman et al., 1984; Leventhal \& Cleary, 1980). Leventhal and Cleary (1980) suggested that the developmental history of a smoker moves through several stages. The stages of their model are: 1) preparation for smoking, 2) initiation and initial trials, 3) becoming a smoker (experimenting and adopting the habit), and 4) maintenance or addiction.

Flay and colleagues (1983) essentially agreed with the basic premise of stages, and provided further elaborations of the stages suggested by Leventhal \& Cleary. The basic stages were described and summarised in Flay (1993) and the 1994 Surgeon General's Report (USDHHS, 1994; Figure 1.6), and empirically tested by Flay, Hu \& Richardson (1998). The model by Flay (1993) may be viewed as the leading theory of the adolescent smoking initiation continuum. During the first or never smoked stage, beliefs are formed about the utility of smoking. At this stage, the adolescent may see smoking as functional. This perceived functionality can be expressed as offering opportunities to appear mature, cope with stress, bond with a new peer group, or display independence (Perry, Murray \& Klepp, 1987; USDHHS, 1994). The second or trying stage encompasses the first few cigarettes that an adolescent smokes. Situations that encourage trying usually involve peers. The perception of the physiological effects of smoking (negative or positive) and the degree of social reinforcement of these trials determine whether an adolescent proceeds to the next stage, experimentation, which includes repeated but irregular smoking. This stage is characterised by a gradual increase in the frequency of smoking and in the variety of situations in which cigarettes are consumed. Smoking is generally a response to external stimuli, such as being at a party or being offered a cigarette by a friend. These influences will not yet have prompted a regular pattern of use. In the fourth stage, regular use, an adolescent smokes on a regular basis, usually at least weekly. Some smoke every weekend at parties or other gatherings; some smoke on most weekdays on the way to or from school. The final stage, nicotine dependence and addiction, is characterised by a physiological need for nicotine. These adolescents may develop cravings, smoke cigarettes daily and experience withdrawal symptoms (see also USDHHS, 1994). 
Figure 1.6. Smoking initiation process

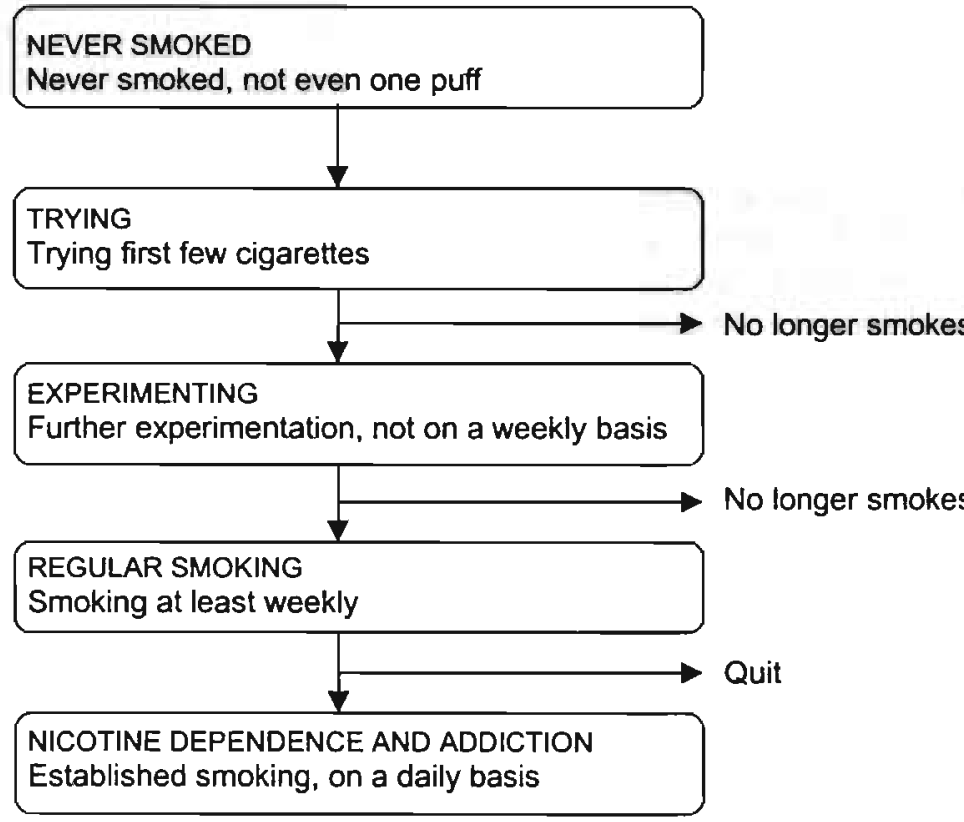

Research on the correlates of psychosocial variables with the various stages of smoking initiation has shown that the stages differ with regard to the likelihood of future smoking behaviour (Flay et al., 1998). Never smokers were found to have certain psychosocial characteristics, indicating that they were least likely to take up future smoking behaviour. For example, never smokers perceived many disadvantages of smoking and they had few friends who had tried smoking. Triers could be distinguished from experimenters on the basis of psychosocial characteristics, with experimenters being more likely to take up smoking in the future. Regular smokers had the most risky psychosocial characteristics. They perceived many advantages of smoking and they had a high level of intention to continue smoking. Additionally, Flay and colleagues (1998) examined which factors predicted stage transition. The most important correlates of transition from trial to experimental use included friends' smoking and approval, cigarette offers by friends, smoking intentions, school level, and alcohol and marijuana use. The significant predictors of transitions from experimental use to regular use included only parental smoking and family conflicts (Flay et al., 1998).

\section{Status of evidence}

The stage model by Flay and colleagues has face validity (Robinson, Klesges, Zbikowski \& Glaser, 1997) and it has been accepted as the leading theory on the process of smoking initiation by the American Surgeon General (USDHHS, 1994). However, except for the single determinant study described above (Flay et al., 1998), the model has never been validated as such in longitudinal research. Although in 
comparison to earlier models of initiation, the model presents an increased accuracy in the operationalisation of stages (Werch \& Anzalone, 1998), one reason for the lack of empirical tests of the model may be that stage definitions are sometimes unclear, contradictory and unfalsifiable. The lack of consistent operational definitions of smoking stages has resulted in a failed attempt to identify unique predictors of stage transitions in a review on studies of determinants of adolescent smoking initiation (Mayhew, Flay \& Mott, 2000). For instance, the trying stage has been defined as trying the first 'few' cigarettes (e.g., Mayhew et al., 2000, p. S63; USDHHS, 1994, p. 126), but also as the first two or three cigarettes (e.g., Flay, 1993), though it has been operationalised as having smoked 'all or part of one cigarette' (Flay et al., 1998).

The behavioural stage model of smoking initiation does not define a stage of exsmoking. Research by Chassin and colleagues (Chassin, Presson, Pitts \& Sherman, 2000; Chassin, Presson, Rose \& Sherman, 1991; Chassin, Presson, Sherman \& Edwards, 1990) on the natural history of cigarette smoking from adolescence to adulthood has shown that a group of adolescent 'nonpersistent smokers' can be distinguished. These adolescents decide to be nonsmokers after having tried or experimented with smoking. For this section of the adolescent population, smoking represents only a period of benign experimentation and adolescent rebellion, rather than a persistent smoking behaviour (Chassin et al., 1991; 2000), indicating that not all adolescents advance beyond trying or experimenting. Approximately $50 \%-67 \%$ of persons who try smoking do not proceed to regular patterns of use (Centers for Disease Control and Prevention [CDC], 1998; USDHHS, 1994). In addition, the subject of adolescent smoking cessation is receiving more and more scientific interest (Houston, Kolbe \& Eriksen, 1998). Since quitting becomes more difficult as smokers progress through the continuum (CDC, 1998), it is well conceivable that stages of initiation are recycled as a result of quitting behaviour. Flay has acknowledged that adolescents may quit after trying, experimenting or regular smoking, by postulating that the probability of advancing from one stage to another is always less than one (Flay, 1993). In empirical settings, however, nonsmoking deciders and quitters have usually been categorised in any of the three stages preceding regular smoking (i.e., never smoked, tried, or experimented; Mayhew et al., 2000). In the most recent empirical study on different stages of adolescent smoking by Flay and colleagues (Flay et al., 1998), exsmokers were divided over the groups of triers and experimenters.

Other stage models of smoking initiation based on the work by Leventhal and Flay have since been introduced. Rowe and colleagues (Rowe, Chassin, Presson \& Edwards, 1992) have introduced an 'epidemic' model of smoking initiation, later termed the Contagion Model. This model describes smoking behaviour as progression through four stages, from a 'nonsmoker' stage (adolescents who are immune to experimentation as well as those adolescents who are susceptible), to an 'exposed' stage (those who have smoked a few cigarettes but are not regular smokers), and an 'infected' stage (consisting of regular smokers). This model also identifies a 'recovered' stage, consisting of those who have kicked the habit (Thomton, Douglas \& Houghton, 1999). Studies that have applied the contagion model have shown the usefulness of studying adolescent smoking initiation as a stage-like process (Rowe et al., 1992; Thornton et al., 1999). However, difficulties with regard to the operationalisation of stages remain. 
Measurement strategies in adolescent smoking research have rarely been developed as a result of theories on the smoking initiation continuum. Instead, measurement strategies have often driven stage definitions (Mayhew et al., 2000). Studies have frequently used existing data-sets, and defined stages of initiation on the basis of the available data. For example, triers have been defined as those adolescents 'having tried smoking only once' (Murray, Swan, Johnson \& Bewley, 1983), or smoking 'no more than once per month' (Rowe, Chassin, Presson \& Sherman, 1996). Experimenters have been defined as those smoking 'less than weekly' (Santi, Cargo, Brown, Best \& Cameron, 1994), or those having smoked 'one to one-hundred cigarettes in lifetime but not in the last 30 days' (Wang, Fitzhugh, Eddy, Fu \& Tumer, 1997).

A valid and reliable measure of stages is paramount to the future of adolescent smoking research (Mayhew et al., 2000). Only this will allow empirical findings to reliably inform theory development and subsequently guide the development of prevention efforts (Mayhew et al., 2000). Although the smoking initiation process proposed by Flay and colleagues has face validity, the model needs to be tested on its usefulness and validity in adolescent smoking behaviour research.

\section{Conclusion}

While a considerable amount of research into the stages of health behaviour has been conducted, there appears to be a need for research on the developmental stages of smoking acquisition. Although limited, there is evidence supporting the validity of stages of smoking acquisition. Advances have been made in recognising the complexity of smoking initiation. Only the two models described in this section (the behavioural model based on the work by Leventhal and Cleary (1980) and the motivational model based on the SCC by Prochaska \& DiClemente, 1983) were concluded to show potential in a review of stage models of drug use (Werch \& Anzalone, 1995). However, this review also concluded that additional research is essential to further test and refine the various components of the motivational and behavioural stage models. Werch (2001) recommends that new motivational stage definitions and corresponding measures should be developed and tested, including those which examine variations in past experimental behaviour, strength of intention, and the time frame for each stage. The studies in the present thesis aim to meet these recommendations. The next section outlines the overall goals of the thesis and the methods used to achieve these goals.

\section{OVERALL GOALS AND METHODS}

The overall aim of the thesis is to propose refinements of the two stage models of the adolescent smoking initiation process described in the previous sections. For this purpose, a number of studies were conducted to test the refined models. Additionally, the two models were combined into one integrated model, which has been defined and tested. 
Figure 1.7 Inductive (a) and deductive (b) reasoning and the empirical cycle (c)

a. Induction

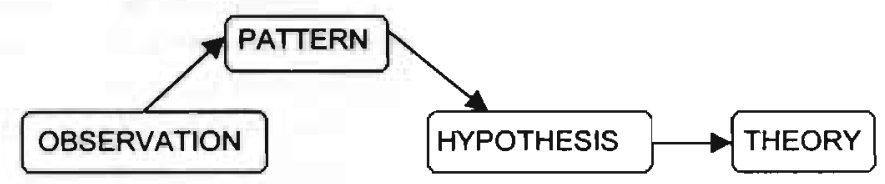

b. Deduction

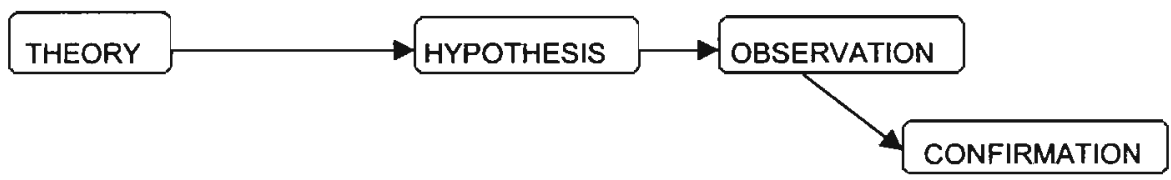

c. Empirical cycle

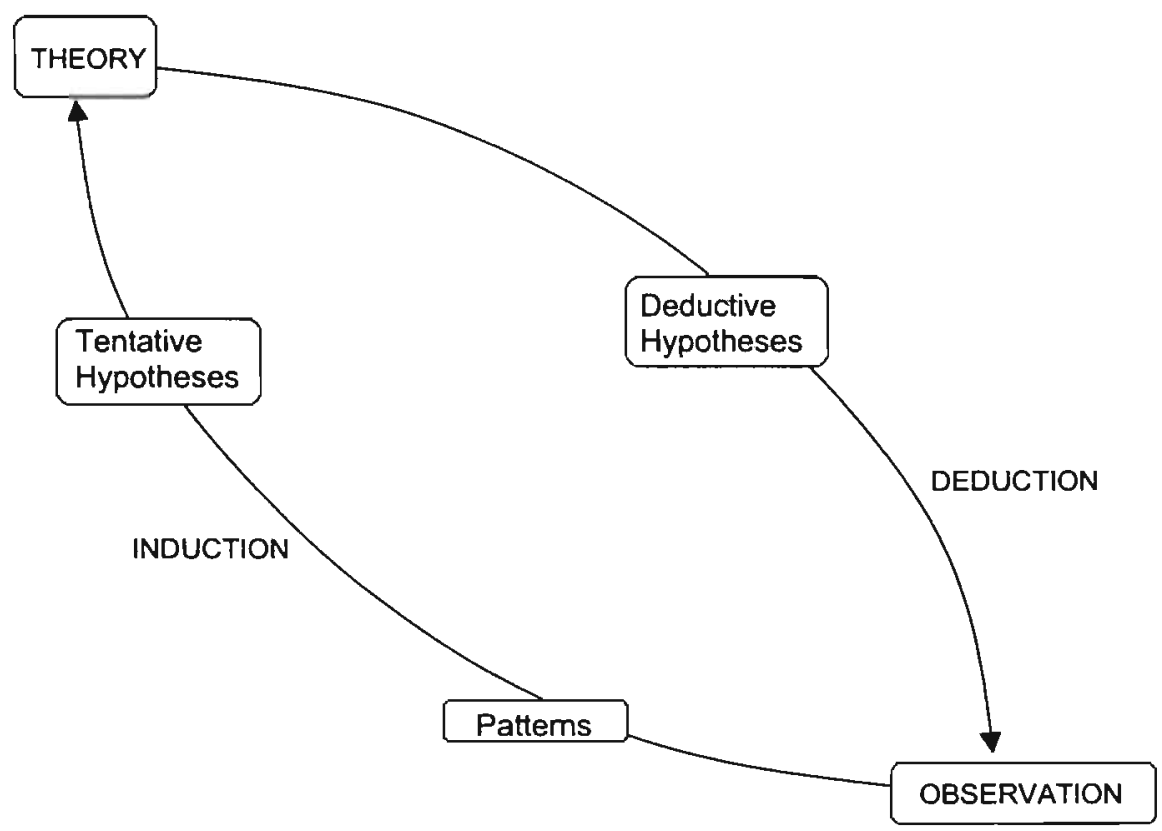




\section{Developing and testing models}

In developing and testing theoretical models, two broad lines of reasoning are commonly applied: induction and deduction (Trochim, 2001). Inductive reasoning moves from specific observations to broader generalisations and theories (Figure 1.7a). Specific observations and measures are used to detect patterns and regularities, and tentative hypotheses are formulated in order to explore the object under study. Finally, general conclusions are drawn or general theories developed. Deductive reasoning, by contrast, moves from a general theory to specific observations (Figure 1.7b). A theory is narrowed down to specific testable hypotheses, after which data (observations) are gathered to test the hypotheses. The specific observations lead to a confirmation or falsification of the original theory. Inductive research is more open-ended and exploratory, whereas deductive reasoning is narrower in nature and is concerned with testing hypotheses. Most social research involves both inductive and deductive reasoning processes at some stage in the project (Trochim, 2001). In fact, Figures 1.7a and $1.7 \mathrm{~b}$ can be easily combined into a single, circular shape that continually cycles from theories to observations and back to theories (Figure 1.7c). Thus, the validity of models can be assessed.

There are several criteria for testing the validity of a measure. Reliability is a necessary condition for validity (McDowell \& Newell, 1987), and is concerned with measurement error. Unreliability can be seen as the discrepancies that would arise if a measurement were repeated many times (McDowell \& Newell, 1987). For example, the same form of test can be administered on two or more separate occasions to the same group of people (Test-retest). However, this approach is often not practical, as repeated measurements are likely to influence examinees. Internal consistency is another indicator of reliability. If respondents' answers to a number of questions are inconsistent, this may be interpreted as reflecting an unreliable set of items. Face validity refers to the validity of a model at face value. Face validity is often defined as 'making common sense', being persuasive and appearing logical to the reader (Lacity \& Jansen, 1994). Content validity indicates how adequately the instrument reflects the aims of the model (McDowell \& Newell, 1987). This criterion is usually established by content experts, while qualitative tests of linguistic clarity are used to test whether the phrasing of the questions is clear (e.g., Vroom, 1994). The measures used in the present thesis are examined with regard to internal consistency, face validity and content validity.

If there is already an accepted method to measure the concept in question, a criterion or 'gold standard' is used to evaluate the new measure against the existing one. This procedure is known as criterion, correlational or concurrent validation (McDowell \& Newell, 1987). However, as shown in the previous sections, no accepted measure of the smoking initiation process exists. In this situation, evidence from several validation procedures must be assembled, a process known as construct validation (McDowell \& Newell, 1987). Since the concept of construct validation of stage models will be the main criterium of validity in the present thesis, it will be described in more detail in the next section. 


\section{Testing the construct validity of stage models}

Weinstein and colleagues (1998) describe three types of research design that can be applied in a non-experimental setting to test the validity of stage theories (see also Sutton, 2001). The first involves a cross-sectional comparison of people in different stages, the second an assessment of the predictive validity of the stages, and the third evaluates the predictors of transitions.

\section{CROSS-SECTIONAL COMPARISON OF PEOPLE IN DIFFERENT STAGES}

In this research design, people in different stages are compared in terms of variables that the theories say should differ across stages (Weinstein et al., 1998). Participants are classified into stages and mean scores on theoretically relevant variables are computed. It is expected that stages that are more remote from an unhealthy behaviour have a score indicating less risky behaviour than stages assumed to be closer to displaying the unhealthy behaviour. If this result is indeed found, it can be interpreted as a first indication of a possible underlying stage model. Overall, cross-sectional comparisons provide a weak test of stage ideas (see also Sutton, 2000), though this research design does have the power to provide some initial insights, making it an ideal design to inductively examine the baseline validity of a stage model. This research design will be applied in Chapters 2 and 4.

\section{PREDICTIVE VALIDITY OF STAGES}

A second research design that can be used to test the validity of a stage model is a longitudinal examination of stage sequences. Most studies to date have assessed transitions from pre-action stages to action (Weinstein et al., 1998; e.g., De Vries \& Mudde, 1998; DiClemente et al., 1991; Dijkstra, Roijackers \& De Vries, 1998; Weinstein \& Sandman, 1992). If people who have displayed the behaviour of interest during a follow-up period come predominantly from a stage that is assumed to be closest to action, this can be interpreted as support for a stage model (Sutton, 2001; Weinstein et al., 1998). However, a gradual pattern of transitions may also suggest a linear process. Since labelling a pattern of transition probabilities as 'gradual' or 'abrupt' is somewhat subjective, sequence data is not conclusive (Weinstein et al., 1998). Nevertheless, after a cross-sectional comparison, studying stage sequences can be viewed as a second step towards assessing the validity of a stage model. Stage sequences are studied in Chapters 3 and 5.

\section{PREDICTORS OF TRANSITION}

Third, prospective studies can be used to test the assumption that different predictors are involved in different stages (De Vries \& Mudde, 1998; Weinstein et al., 1998). In this design, theoretically relevant variables measured at Time 1 are used as independent variables in order to predict forward or backward stage transition at Time 2. In linear models, predictors of progress are independent of where an individual stands on the continuum. Thus, a longitudinal study of linear models would not find different predictors at different stages (Sutton, 2001; Weinstein et al., 1998). The observation that predictors vary with the stage is an indicator of a stage-based process. Predictors of progression are studied in Chapter 6 of the present thesis. 
Although the models in the present thesis have been tested according to the methodologies described above, it must be kept in mind that validity cannot be proven definitively. It is an ongoing process, in which testing often contributes to our understanding of the construct, after which new predictions are made and tested (McDowell \& Newell, 1987).

\section{OUTLINE OF THE THESIS}

The present thesis consists of three parts, graphically represented in Figure 1.8. All parts have identical constructions, namely that of a cross-sectional study that is merely inductive by nature, followed by a longitudinal study that deductively examines the validity of the proposed model.

In the first part of the thesis, the Stages of Change Construct is applied to smoking initiation. Chapter 2 provides a cross-sectional examination of the data, and critically reviews previous research on this subject. This leads to an examination of possible subtypes within the acquisition precontemplation stage: committers, immotives, and progressives. Adolescents in each of these stages are compared with regard to scores on attitudes, social influences and self-efficacy. In Chapter 3, the findings of the cross-sectional study are examined in a longitudinal design. Using the control group of the ESFA study, it was studied whether motivational stage of initiation is predictive of future regular smoking behaviour.

The second part of the thesis examines the existing theory of behavioural stages of smoking initiation. A model is proposed that is based on the model by Flay and colleagues (Flay, 1993; Flay, et al., 1983; USDHHS, 1994), but distinguishes two additional stages of nonsmoking; nonsmoking deciders and quitters. Chapter 4 reports on an explorative study, using cross-sectional data, which examines whether the inclusion of two extra stages of current nonsmoking could be a useful refinement of the stage model. Chapter 5 discusses the theory and its measuring instrument longitudinally. The development and use of the measure is explained, and the predictive validity of the various stages with regard to future daily smoking is reported over a 12 months follow-up period.

The third part, consisting of Chapter 6, focuses on the integration of the motivational and behavioural stages of smoking initiation. This chapter explores the usefulness of integrating the two lines of research and proposes an integrated model. Prevalence rates within an integrated framework are observed, hypotheses are constructed and the model is tested longitudinally.

Chapter 7 starts with a summary of the results of the studies presented, and addresses the shortcomings and implications of the studies. 
Figure 1.8. Scheme of empirical (re)cycling in the present thesis

Refinement of Stages of Change

\section{PART 1 MOTIVATIONAL STAGES}

Construct to smoking initiation

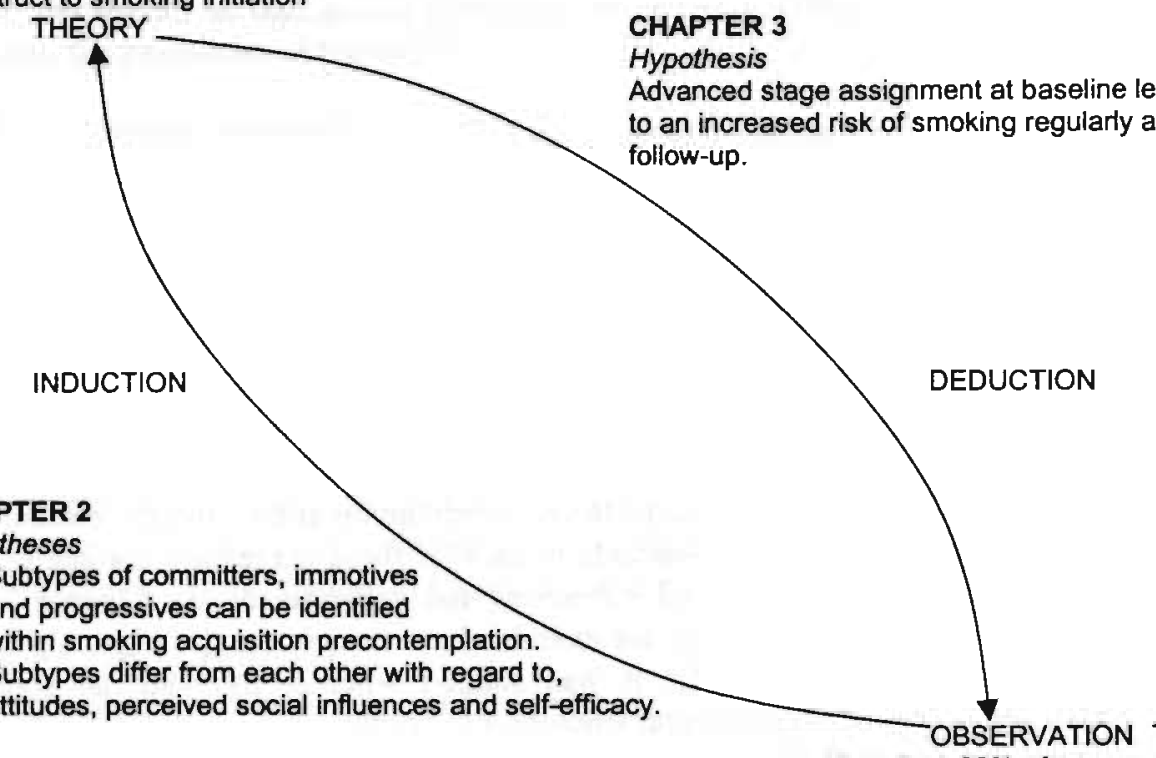

\section{CHAPTER 2}

Hypotheses

1. Subtypes of committers, immotives and progressives can be identified

within smoking acquisition precontemplation.

2. Subtypes differ from each other with regard to, attitudes, perceived social influences and self-efficacy.

More than $90 \%$ of nonsmokers classified as precontemplators

\section{PART 2 BEHAVIOURAL STAGES}

Refinement of Flay's theory of the smoking initiation process

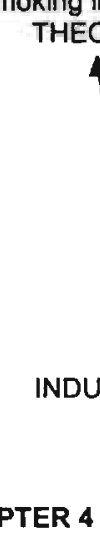

\section{CHAPTER 4}

Hypotheses

1. Original stages of never smokers. triers, experimenters and regular smokers can be distinguished as separate stages.

2. Nonsmoking deciders and quitters can be distinguished from the other stages, based on their cognitive characteristics.

\section{CHAPTER 5}

Hypothesis

Advanced stage assignment at baseline leads to increased risk of smoking daily at follow-up. lo inc 
Figure 1.8 (continued). Scheme of empirical (re)cycling in the present thesis

Construction of Model of

\section{PART 3 INTEGRATION}

Unmotivated Smoking Initiation

of Children and Adolescents

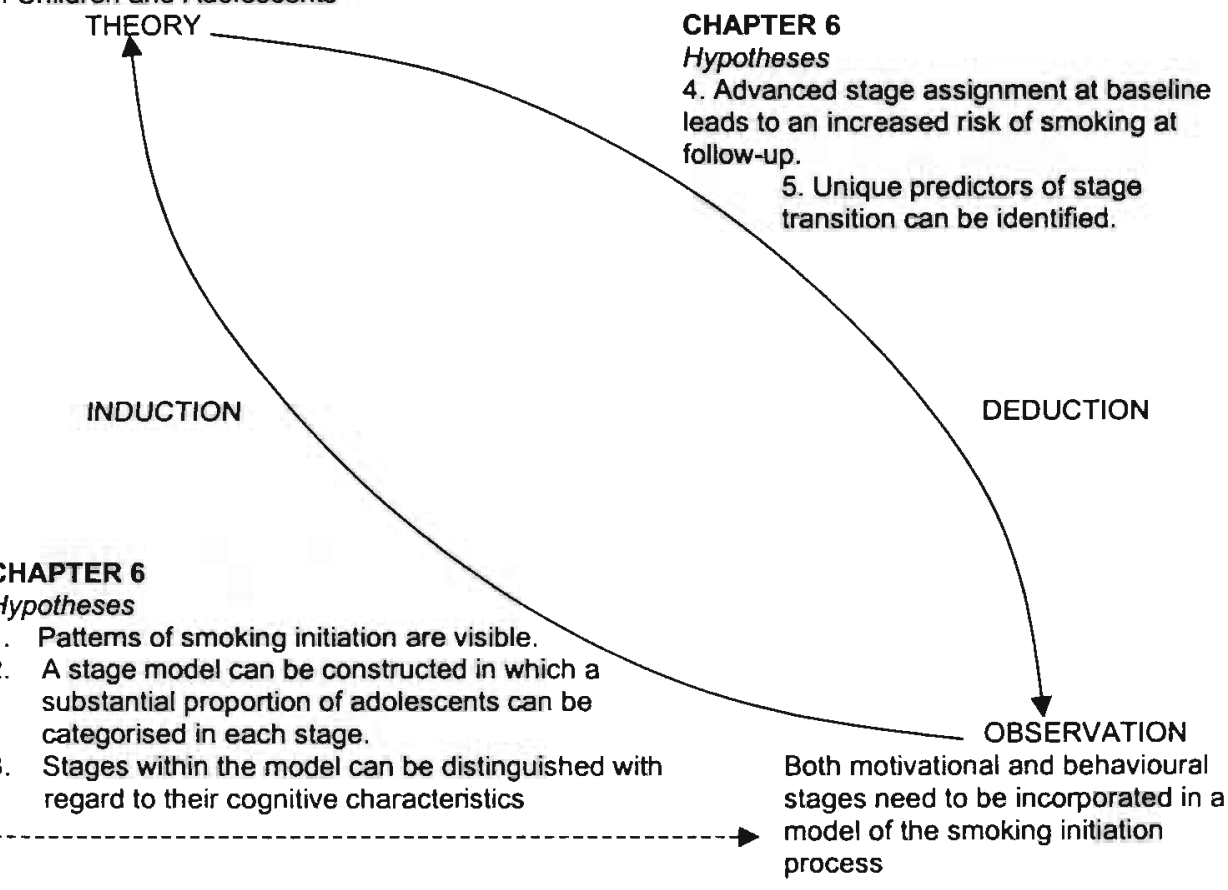




\section{Part 1}

\section{Motivational stages of smoking initiation}

Until one is committed, there is hesitancy, the chance to draw back, always ineffectiveness.

W. H. Murray

(The Scottish Himalayan Expedition) 


\section{Chapter 2}

\section{Subtypes within the precontemplation stage of adolescent smoking acquisition}

\section{ABSTRACT}

The present study examined the existence of three possible subtypes within the precontemplation stage of smoking acquisition: committers, immotives and progressives. The sample of the study included young people from six European countries (mean age 13 years) who had never smoked regularly ( $n=21535$ ). A crosssectional design was used to assess cognitive determinants of smoking behaviour: attitudes towards smoking, perceived social influences and self-efficacy to remain a nonsmoker. Adolescents within the various stages of smoking acquisition were compared with regard to standardised T-scores on these risk factors. The results showed that adolescents in the three subgroups of precontemplation differed from each other on every cognitive determinant tested, revealing a higher risk to start smoking among progressives than among immotives. Immotives revealed a higher risk to start smoking than committers. It is concluded that the use of subtypes within acquisition precontemplation in research on adolescent smoking may be a promising tool for investigating the initiation continuum and for improving the quality of both the implementation and evaluation of prevention programs.

Published as:

Kremers S.P.J., Mudde A.N., \& De Vries H. (2001a). Subtypes within the precontemplation stage of adolescent smoking acquisition. Addictive Behaviors, 26 , 237-251. 
Although the Stages of Change Construct (SCC; Prochaska \& DiClemente, 1983) was originally developed to study adult smoking cessation within the Transtheoretical Model of Change (TTM; Prochaska \& DiClemente, 1983; DiClemente \& Prochaska, 1982; DiClemente et al, 1991), it has also been applied to adolescent smoking cessation and acquisition (Elder et al., 1990; Kelley et al., 1999; Pallonen, 1998; Pallonen et al., 1998; Stern et al., 1987; Werch \& DiClemente, 1994). The TTM of smoking acquisition can be regarded as the miror image of the cessation model (Stern et al., 1987). The SCC distinguishes three stages of smoking acquisition (Pallonen et al., 1998), defined as acquisition precontemplation (aPC; no intentions to start smoking in the next 6 months), acquisition contemplation ( $\mathrm{aC}$; thinking about starting to smoke in the next 6 months) and acquisition preparation (aP; thinking about starting to smoke in the next 30 days).

Especially among early adolescents, a large majority of the population is in the precontemplation stage of smoking acquisition. The prevalence of acquisition precontemplators within the nonsmoking adolescent population has been found to be over 90\% (Aveyard et al., 1999; Pallonen et al., 1998). Since a large percentage of adolescents eventually will start smoking, the precontemplating group might be diverse with regard to predictors of smoking initiation. The possibility to provide finer discriminations makes identification of subtypes within a large group of precontemplators desirable (Crittenden, Manfredi, Lacey, Warnecke \& Parsons, 1994). Finer discriminations within acquisition precontemplators enable the possibility to provide accurate health education messages to a target group of nonsmoking adolescents.

Identification of possible subgroups within the precontemplation stage has been the subject of recent research on adult smoking cessation (Crittenden et al., 1994; Dijkstra, Bakker \& De Vries, 1997; Dijkstra et al., 1998; Norman, Velicer, Fava \& Prochaska, 2000; Velicer, Hughes, Fava, Prochaska \& DiClemente, 1995). Two clearly interpretable subgroups within precontemplation have been identified. Velicer and colleagues (1995) identified a subgroup of precontemplators 'clearly ready to move to the contemplation stage' which was labelled 'progressives'. A subgroup of precontemplating smokers who plan not to quit within the next five years has been labelled 'immotives' (Dijkstra et al., 1997; Velicer et al., 1995). Consequently, immotives are thought to be more remote from contemplation than the progressive subgroup. Norman and colleagues (2000) recently replicated and externally validated the existence of these subtypes within a representative sample of adult smokers. Perhaps the distinction between immotives and progressives could also be made for the acquisition stages of adolescent smoking.

A third possible subgroup within acquisition precontemplation may consist of adolescents who have a strong commitment not to smoke. The concept of commitment to nonsmoking, labelled as 'non-susceptibility', is introduced by Pierce and colleagues (Pierce et al., 1995). The move to start smoking may be influenced by the absence of a firm decision not to smoke (Choi et al., 1997; Pierce et al., 1996; Unger et al., 1997). Measuring the intention to start smoking at some time in the future might not distinguish the children who have really thought consciously about being a nonsmoker 
from those who have not rationally decided not to smoke. Where immotives also plan never to start smoking, but lack the strong decision not to smoke, adolescents who are firmly committed to nonsmoking ('committers') might be more remote from the contemplation stage than immotives.

Over the past decades, much effort has been put into explaining and predicting adolescent smoking initiation (Conrad et al., 1992; Tyas \& Pederson, 1998). In their review of theories of adolescent substance use, Petraitis and colleagues conclude that attitudinal, social and self-efficacy components are useful motivational (proximal) determinants to predict and explain adolescent smoking behaviour (Petraitis et al., 1995). All other levels of influence are believed to exert little effect on adolescent substance use unless they first affect these substance-specific cognitions (Petraitis et al., 1995). For example, the Attitude-Social influence-Efficacy (ASE) model (De Vries et al., 1988; De Vries \& Mudde, 1998) proved to be of value in explaining and predicting adolescent smoking behaviour (De Vries et al., 1988; 1995; Mudde, Kremers \& De Vries, 1999).

Findings in several studies suggest that the stages of change not only differ because of differences in intentions to smoke, but also because of differences in the impact of the cognitive determinants of smoking (Velicer, Norman, Fava \& Prochaska, 1999). Cognitive determinants, referred to as dynamic constructs in the TTM, have been shown to differ between the various stages of change of smoking cessation (Prochaska \& DiClemente, 1984; Prochaska, Velicer, Guadagnoli, Rossi \& DiClemente, 1991; Velicer et al., 1999). Findings in studies using the ASE model have resembled these differences, despite the use of different cognitive constructs (De Vries \& Backbier, 1994; De Vries, Mudde, Dijkstra \& Willemsen, 1998; Dijkstra, De Vries \& Bakker, 1996; Dijkstra, De Vries, Roijackers \& Mudde, 1997).

The objective of the present paper is to investigate the identification of the concepts of commitment, immotiveness and progressiveness as different subtypes within the precontemplation stage of adolescent smoking acquisition. The usefulness of a more detailed description of the acquisition precontemplation stage was tested by assessing differences between the various subgroups regarding cognitive predictors of smoking behaviour. It was hypothesised that adolescents in the commitment stage would score higher than immotives with regard to nonsmoking attitudes, perccive less negative social influences with regard to smoking and have higher self-efficacy with regard to refraining from smoking. Immotives are expected to show the same pattern when compared to progressives.

\section{METHODS}

\section{Participants and recruitment}

In the present study, seventh graders in a large international sample of European adolescents $(n=23304)$ were measured cross-sectionally. This study is part of a larger, ongoing prospective study of the ESFA project (European Smoking prevention Framework Approach; De Vries et al., submitted). Seven sites in six European Union member states (Finland, Denmark, the United Kingdom, the Netherlands, Barcelona (Spain), Madrid (Spain) and Portugal) participate in this project. Data were collected at 
school, using self-administered questionnaires. The questionnaire was based on a review of the literature and earlier work regarding adolescent smoking behaviour over the last 15 years (De Vries et al., 1988; De Vries \& Kok, 1986; De Vries et al., 1994; Dijkstra, Mesters, De Vries, Van Breukelen \& Parcel, 1999). Due to missing or incomplete data on key variables on smoking behaviour 219 cases $(0.9 \%)$ were excluded from analyses.

Of the total sample, $7.6 \%$ lived in Denmark, $12.0 \%$ in Finland, $17.0 \%$ in the Netherlands, $13.1 \%$ in Portugal, $8.6 \%$ in Barcelona, $13.8 \%$ in Madrid and $27.9 \%$ lived in the United kingdom. The mean age of the respondents was 13.3 years $(\mathrm{SD}=0.7)$, and $50.1 \%$ were males.

\section{MEASURES}

\section{Current smoking status}

Adolescents were to pick a statement that best described them, out of a set of specific smoking related statements. Responses were cross validated using an algorithm, consisting of concepts measuring current smoking and lifetime smoking. A primary measure of regular use is smoking, on the average, at least once a week or with greater frequency (Flay, 1993; Sussman, Dent, Burton, Stacy \& Flay, 1995; U.S. Department of Health and Human Services, 1994). Consequently, smoking behaviour was classified into four stages:

(1) Never smokers were defined as those who reported never having smoked a cigarette, not even one puff $(n=14671 ; 63 \%)$.

(2) Experimenters were defined as those who reported having tried smoking or having experimented with cigarettes, but not smoking weekly $(n=6864 ; n=29.5 \%)$.

(3) Regular smokers were defined as those who reported smoking at least once a week $(n=1300 ; 5.6 \%)$.

(4) Quitters were defined as those who reported to have quit smoking after having smoked at least once a week $(n=469 ; 2.0 \%)$.

\section{Stages of smoking acquisition}

Regular smokers and quitters were excluded from analyses of the acquisition stages. Subsequently, respondents were classified as acquisition preparators $(n=529 ; 2.5 \%)$ if they indicated that they intended to start smoking within the next month and as acquisition contemplators $(n=29 ; 0.1 \%)$ if they planned to start within the next six months (but not within the next month). The algorithm corresponds with that used by Pallonen and colleagues (1998) to assess smoking acquisition stages, and parallels the algorithm used for adult smoking cessation (Prochaska \& DiClemente, 1984; Prochaska, DiClemente \& Norcross, 1993). Within the group who did not intend to start smoking within the next six months (acquisition precontemplators), three subtypes were distinguished: those who intended to start smoking within the next five years (progressives, $n=668 ; 3.1 \%$ ), those who did not intend to start within the next five years but lacked a strong decision never to start smoking (immotives, $n=12492$; $58.0 \%$ ), and those who indicated to be sure to never start smoking and definitely not 
intending to smoke in the next year and definitely not intending to smoke in the future (committers, $\mathrm{n}=7817 ; 36.3 \%$ ).

\section{Determinants of smoking behaviour}

Based on a pretest at all participating sites, 12 items on smoking related beliefs were measured on a 7-point scale. One item, referring to sociability of smoking, was excluded from the analyses because of ambiguous translations into several languages. Separate principal component analyses were performed to identify factors. Subsequently, alpha factoring with direct oblimin rotation was used to discover which common factors are consistently found when repeated samples of variables are taken from the population of variables (Tabachnick \& Fidell, 1996). This revealed two stable factors: the pros of smoking and the cons of smoking (Table 2.1). The item assessing the belief that smoking would help to be slim did not load uniquely on any factor and was therefore removed from the analysis. Consequently, both subscales consisted of 5 items. The items on the pros of smoking refer to expected positive outcomes of smoking. The cons of smoking refer to expected negative outcomes of smoking. Scales of pros and cons of smoking consisted of sumscores.

Three components of social influence were assessed in the present study: social pressure to smoke, social norm, and perceived behaviour of the social environment. Pressure to smoke from people in the environment was operationalised by 8 items with five answering categories. For example: Have you ever felt pressure to smoke from your mother? Answering possibilities were very often (4), often (3), sometimes (2), a few times (1), and never (0). Factor analysis indicated two stable factors: pressure from friends and pressure from others (Table 2.1). The 'friends' subscale consisted of 3 items, while the 'others' subscale contained 5 items. Social norm was assessed using 8 items with 7 answering categories on perceptions of individuals whether important others think they should smoke or not. Important others included in this study were mother, father, brother(s), sister(s), friends, best friend, people in same school year, and teachers. For example; My best friend thinks that I definitely should smoke (-3) to definitely should not smoke (3). Two meaningful factors were suggested by factor analysis: social norm of parents and social norm of others (Table 2.1). The third component within the concept of social influence analysed in this study was perceived behaviour of the social environment. Perceived behaviour was measured by asking whether mother, father, brother(s), sister(s) and best friend smoked or not. For example: Does your father smoke? $(n o=0$, yes $=1)$. Unlike the other components within social influence, this concept was not treated as a scale. In order to gain more detailed information of the discrete impact of the several important others, perceived behaviour was analysed separately for each measured person in the social environment.

Self-efficacy was measured by 12 items on a 7-point scale, derived from a validated instrument by Lawrance (1988). The items refer to the respondents' perception of their ability to refrain from smoking when they are in certain situations with friends, when they have certain emotions and when they have certain opportunities to smoke. Factor analysis indeed revealed these subscales although the item 'when you are at the shops with friends', which was originally intended as an opportunity item, turned out to be more closely correlated with the friends subscale (Table 2.1). Demographics included in the study were country, gender and age. 
Table 2.1. Factors among the proximal determlnants of smoking initiation $(n=21535)$

\begin{tabular}{|c|c|c|c|}
\hline \multirow{2}{*}{$\begin{array}{l}\text { Items } \\
\text { Attltude } \\
(-3,+3)\end{array}$} & \multicolumn{3}{|l|}{ Factors } \\
\hline & $\begin{array}{l}\text { Pros of } \\
\text { smoking } \\
(\alpha=.62)\end{array}$ & $\begin{array}{l}\text { Cons of } \\
\text { smoking } \\
(\alpha=66)\end{array}$ & \\
\hline My friends will pay me more attention & .45 & & \\
\hline I seem more confident in company & .50 & & \\
\hline It is easier to be part of the crowd & .48 & & \\
\hline it helps to clam my nerves & .54 & & \\
\hline It will make me feel relaxed & .50 & & \\
\hline It helps me to be slim & & & \\
\hline It is bad for my health & & .57 & \\
\hline I will be sorry that I ever started smoking & & .47 & \\
\hline It is stupid of me & & .66 & \\
\hline It tastes homible & & .40 & \\
\hline I consider my behaviour to be wrong & & .61 & \\
\hline $\begin{array}{l}\text { Social Norm } \\
(-3,+3)\end{array}$ & $\begin{array}{l}\text { Parents } \\
(\alpha=.80)\end{array}$ & $\begin{array}{l}\text { Others } \\
(\alpha=.75)\end{array}$ & \\
\hline Father & .79 & & \\
\hline Mother & .82 & & \\
\hline Brother & & .41 & \\
\hline Sister & & $.39^{*}$ & \\
\hline Best friend & & .73 & \\
\hline Friends & & .78 & \\
\hline People in school year & & .67 & \\
\hline Teachers & & .47 & \\
\hline $\begin{array}{l}\text { Social Pressure } \\
(0,4)\end{array}$ & $\begin{array}{l}\text { Friends } \\
(\alpha=.74)\end{array}$ & $\begin{array}{l}\text { Others } \\
(\alpha=.74)\end{array}$ & \\
\hline Best friend & .60 & & \\
\hline Friends & .86 & & \\
\hline People in school year & .66 & & \\
\hline Father & & .74 & \\
\hline Mother & & .68 & \\
\hline Brother & & .59 & \\
\hline Sister & & .52 & \\
\hline Teachers & & .51 & \\
\hline $\begin{array}{l}\text { Self-efficacy } \\
(-3,+3)\end{array}$ & $\begin{array}{l}\text { Friends } \\
(\alpha=.93)\end{array}$ & $\begin{array}{l}\text { Opportunities } \\
(\alpha=95)\end{array}$ & $\begin{array}{l}\text { Emotions } \\
(\alpha=.96)\end{array}$ \\
\hline When with others who smoke & .84 & & \\
\hline When with friends who smoke & .89 & & \\
\hline When you are offered a cigarette & .89 & & \\
\hline When friends offer you a cigarette & .90 & & \\
\hline When you are at the shops with friends & .82 & & \\
\hline When you are watching TV & & .94 & \\
\hline When you are doing homework & & .96 & \\
\hline When you are on the way home from school & & .90 & \\
\hline When you feel upset & & & .90 \\
\hline When you feel depressed & & & .94 \\
\hline When you feel nervous & & & .93 \\
\hline When you are worried & & & .91 \\
\hline
\end{tabular}

Note. Highest loadings per item $(>.40)$ are shown. "Although factor loading <.40, this item has been included in the analysis. 


\section{Statistical analyses}

Two sets of analyses were performed. Firstly, the five groups within the smoking acquisition continuum were compared on demographics and experimenting behaviour, using chi-square analysis for discrete variables and F-tests for continuous variables. In the case of significant main effects, variables were included in analyses as covariates. Secondly, the five groups were compared with respect to proximal determinants of smoking behaviour. Standardised T-scores were computed with a mean of 50 and a standard deviation of 10 , and contrasts between the five groups were computed using the Tukey-HSD method.

Table 2.2. Demographics among the five stages of smoking acquisition $(n=21535)$

\begin{tabular}{|c|c|c|c|c|c|c|}
\hline$\%$ of total & $\begin{array}{l}\mathrm{Cm} \\
36.3 \%\end{array}$ & $\operatorname{lm} 58.0 \%$ & $\begin{array}{l}\mathrm{Pg} \\
3.1 \%\end{array}$ & $\begin{array}{l}C \\
0.1 \%\end{array}$ & $\begin{array}{l}P \\
2.5 \%\end{array}$ & sign \\
\hline Gender (\% within gender) & & & & & & $p<.001$ \\
\hline Male & 40.1 & 54.8 & 2.8 & 0.1 & 2.2 & \\
\hline Female & 32.6 & 61.2 & 3.4 & 0.2 & 2.7 & \\
\hline $\begin{array}{l}\text { Mean Age (years) } \\
\text { (SD) }\end{array}$ & $\begin{array}{l}13.2 \\
(0.6)\end{array}$ & $\begin{array}{l}13.2 \\
(0.7)\end{array}$ & $\begin{array}{l}13.2 \\
(0.7)\end{array}$ & $\begin{array}{l}13.2 \\
(0.6)\end{array}$ & $\begin{array}{l}13.3 \\
(0.8)\end{array}$ & $p<.001$ \\
\hline Country ( $\%$ within country) & & & & & & $p<.001$ \\
\hline Denmark & 41.5 & 52.7 & 2.7 & 0.2 & 2.8 & \\
\hline Finland & 31.5 & 64.7 & 2.3 & 0.0 & 1.5 & \\
\hline The Netherlands & 32.0 & 63.9 & 2.9 & 0.0 & 1.2 & \\
\hline Portugal & 28.9 & 67.1 & 1.3 & 0.1 & 2.7 & \\
\hline Spain (Barcelona) & 16.5 & 71.9 & 8.4 & 0.3 & 2.9 & \\
\hline Spain (Madrid) & 36.7 & 55.9 & 3.0 & 0.2 & 2.4 & \\
\hline United Kingdom & 49.1 & 45.4 & 2.9 & 0.2 & 2.4 & \\
\hline Smoking behaviour ( $\%$ within beh.) & & & & & & $p<.001$ \\
\hline Never smoker & 45.7 & 52.2 & 0.9 & 0.0 & 1.1 & \\
\hline Experimenter & 16.1 & 70.4 & 7.8 & 0.4 & 5.3 & \\
\hline
\end{tabular}

Note. $\mathrm{Cm}=$ committers; $\mathrm{Im}=$ immotives; $\mathrm{Pg}=$ progressives; $\mathrm{C}=$ contemplators; $\mathrm{P}=$ preparators.

Significance tests are based on chi-square analysis for gender, country and smoking behaviour, and on a F-test for age.

\section{RESULTS}

\section{Demographics and experimenting behaviour within stages}

The distribution of adolescents over the five stage groups - committers, immotives, progressives, contemplators, preparators - did differ significantly for gender, age, country and experimental smoking behaviour (Table 2.2). Girls seemed to be more clearly progressing towards smoking than boys. There were hardly any differences in age distribution between the groups. In comparison to the other sites in our study, Barcelonese adolescents tended not to commit themselves to nonsmoking, while the adolescents from the UK appeared to commit themselves to nonsmoking most of all participants. Almost half of them reported to be absolutely sure that they would never 
start smoking. Both never smokers and experimenters were most likely to be immotive. However, compared to experimenters, more never smokers were committed to nonsmoking. Furthermore, adolescents who had experimented with cigarettes were far more commonly found within the progressive stage of acquisition precontemplation than those who had never smoked even one puff.

In view of the differences between the various groups, the analyses on attitudes, social influence and self-efficacy were corrected for gender, age, country and experimenting behaviour.

\section{Cognitive determinants of smoking behaviour}

Next, the five groups were compared on the motivational determinants measured. Table 2.3 shows the standardised T-scores of factors within the concepts of attitude, social norm, social pressure, perceived behaviour of the social environment and selfefficacy. We will first focus on the subtypes within acquisition precontemplation. For this stage, standardised $\mathrm{T}$-scores showed a pattern that is consistent with the hypotheses. Tukey-HSD contrasts revealed that committers scored significantly lower than immotives on the pros of smoking, the perceived pressure to smoke and the perceived behaviour of the social environment, and that they scored higher on the cons of smoking, the perceived social norm and on self-efficacy. Similarly, the group of immotives differed significantly from the progressive subgroup on all concepts. Although Table 2.3 is based on a significance level of $\mathrm{p}<.05$, additional analysis revealed that all differences between the subgroups within precontemplation were significant on a level of $p<.001$.

Cognitive structures on pros and cons of smoking differed considerably between adolescents in the various subgroups of acquisition precontemplation. Whereas the committers' score on the cons of smoking was higher than that of the pros of smoking, the cons score declined across the subgroups, while that of the pros increased. The pros of smoking slightly outweighed the cons in the immotive subtype. The trend of a declining score on pros and an increasing score on cons continued when the immotive and progressive subgroups were compared. In the progressive subgroup, the score on pros of smoking was clearly higher than the score on cons.

Social pressure seemed to be a particularly important social influence as individuals move from immotive to progressive. Best friend's smoking scored lowest of all perceived behaviour variables in committers and highest in progressives, making this the most salient perceived behaviour factor. The perceived pressure from friends was more salient than the perceived pressure from others. Results with regard to the subtypes within precontemplation revealed considerable differences between the three subtypes in the social norm towards nonsmoking.

Self-efficacy in situations with friends was the self-efficacy scale that seemed to yield the greatest differences between the subtypes. The score on self-efficacy in situations with friends was highest in the commitment stage and lowest among the progressives. Opportunity self-efficacy appeared to differ between the subtypes least among all self-efficacy factors. 
Table 2.3. Standardised $T$-scores per stage (mean=50; $S D=10$ ) of the proximal determinants of smoking behaviour $(n=21535)$

\begin{tabular}{|c|c|c|c|c|c|c|}
\hline $\mathbf{n}$ & $\begin{array}{l}\mathrm{Cm} \\
7817\end{array}$ & $\begin{array}{l}\operatorname{lm} \\
12492\end{array}$ & $\begin{array}{l}\mathrm{Pg} \\
668\end{array}$ & $\begin{array}{l}\text { C } \\
29\end{array}$ & $\begin{array}{l}P \\
529\end{array}$ & $\begin{array}{l}\text { Tukey-HSD } \\
\text { Contrasts }\end{array}$ \\
\hline $\begin{array}{l}\text { Attitude } \\
\text { Pros of smoking } \\
\text { Cons of smoking }\end{array}$ & $\begin{array}{l}48.1 \\
52.9\end{array}$ & $\begin{array}{l}50.8 \\
49.0\end{array}$ & $\begin{array}{l}55.3 \\
41.6\end{array}$ & $\begin{array}{l}56.0 \\
40.1\end{array}$ & $\begin{array}{l}53.2 \\
42.9\end{array}$ & $\begin{array}{l}\mathrm{Cm}<\mathrm{Im}<\mathrm{Pg}, \mathrm{C}, \mathrm{P} ; \mathrm{Pg}>\mathrm{P} \\
\mathrm{Cm}>\mathrm{Im}>\mathrm{Pg}, \mathrm{C}, \mathrm{P}\end{array}$ \\
\hline $\begin{array}{l}\text { Social norm } \\
\text { Parents } \\
\text { Others }\end{array}$ & $\begin{array}{l}52.1 \\
52.7\end{array}$ & $\begin{array}{l}49.1 \\
48.8\end{array}$ & $\begin{array}{l}45.2 \\
44.1\end{array}$ & $\begin{array}{l}42.0 \\
44.6\end{array}$ & $\begin{array}{l}46.5 \\
46.4\end{array}$ & $\begin{array}{l}C m>I m>P g, C, P \\
C m>I m>P g, C, P ; P g<P\end{array}$ \\
\hline $\begin{array}{l}\text { Social pressure } \\
\text { Friends } \\
\text { Others }\end{array}$ & $\begin{array}{l}49.0 \\
49.2\end{array}$ & $\begin{array}{l}50.2 \\
50.1\end{array}$ & $\begin{array}{l}56.1 \\
54.2\end{array}$ & $\begin{array}{l}52.1 \\
56.0\end{array}$ & $\begin{array}{l}53.3 \\
53.4\end{array}$ & $\begin{array}{l}\mathrm{Cm}<1 \mathrm{~m}<\mathrm{Pg}, \mathrm{C}, \mathrm{P} ; \mathrm{Pg}>\mathrm{P} \\
\mathrm{Cm}<\mathrm{lm}<\mathrm{Pg}, \mathrm{C}, \mathrm{P}\end{array}$ \\
\hline $\begin{array}{l}\text { Smoking behaviour } \\
\text { social onvironment } \\
\text { Mother } \\
\text { Father } \\
\text { Brother(s) } \\
\text { Sister(s) } \\
\text { Best friend }\end{array}$ & $\begin{array}{l}49.7 \\
49.3 \\
49.2 \\
49.4 \\
49.2\end{array}$ & $\begin{array}{l}50.1 \\
50.3 \\
50.3 \\
50.2 \\
50.0\end{array}$ & $\begin{array}{l}51.6 \\
52.0 \\
52.9 \\
52.4 \\
54.8\end{array}$ & $\begin{array}{l}52.6 \\
50.6 \\
52.1 \\
49.2 \\
52.3\end{array}$ & $\begin{array}{l}50.9 \\
51.4 \\
51.4 \\
51.6 \\
56.3\end{array}$ & $\begin{array}{l}\mathrm{Cm}<\mathrm{Im}<\mathrm{Pg}, \mathrm{P} \\
\mathrm{Cm}<\mathrm{Im}<\mathrm{Pg}, \mathrm{P} \\
\mathrm{Cm}<\mathrm{Im}<\mathrm{Pg}, \mathrm{P} ; \mathrm{Pg}>\mathrm{P} \\
\mathrm{Cm}<\mathrm{Im}<\mathrm{Pg}, \mathrm{P} \\
\mathrm{Cm}<\mathrm{Im}<\mathrm{Pg}, \mathrm{P} ; \mathrm{Cm}<\mathrm{C}\end{array}$ \\
\hline $\begin{array}{l}\text { Self-efficacy } \\
\text { Friend } \\
\text { Opportunity } \\
\text { Emotion }\end{array}$ & $\begin{array}{l}54.0 \\
52.8 \\
53.4\end{array}$ & $\begin{array}{l}48.3 \\
48.8 \\
48.6\end{array}$ & $\begin{array}{l}41.0 \\
44.0 \\
42.5\end{array}$ & $\begin{array}{l}40.9 \\
47.7 \\
42.7\end{array}$ & $\begin{array}{l}41.9 \\
45.2 \\
43.4\end{array}$ & $\begin{array}{l}\mathrm{Cm}>\mathrm{Im}>\mathrm{Pg}, \mathrm{C}, \mathrm{P} \\
\mathrm{Cm}>\mathrm{Im}>\mathrm{Pg}, \mathrm{P} ; \mathrm{Cm}>\mathrm{C} \\
\mathrm{Cm}>\mathrm{im}>\mathrm{Pg}, \mathrm{C}, \mathrm{P}\end{array}$ \\
\hline
\end{tabular}

Note. $\mathrm{Cm}=$ committers; Im=immotives; $\mathrm{Pg}=$ progressives; $\mathrm{C}=$ contemplators; $\mathrm{P}=$ preparators.

$\mathrm{Cm}<\mathrm{Im}$ : Committers score significantly lower $(p<.05)$ than immotives.

If precontemplation was considered as one large group, standardised T-scores of precontemplation on all variables would be between 49.9 and 50.2. Differences on every motivational determinant within precontemplation would not have been apparent. For example, the apparent differences between the subgroups in the weighing of pros and cons of smoking did not show up when the acquisition precontemplation stage was viewed as one homogenous group; they were only revealed when subgroups were distinguished. Furthermore, the lowest score of all perceived behaviour factors on best friend's smoking in the committers subgroup and the highest score on this variable in the progressive subgroup would have been levelled out. Moreover, a distinction between the various subgroups revealed that the greatest cognitive changes in every proximal determinant of smoking behaviour seem to occur within the immotive subtype.

The findings for contemplating and preparating adolescents were less clear. Tscores did not differ significantly $(p<.05)$ between these two stages on any motivational determinant. Moreover, contemplators did not differ from the progressive subtype of precontemplation on any of the tested variables. Contemplators did not differ significantly from any other stage with regard to smoking behaviour of the social environment, except for the significant difference with committers on the best friend-variable. Preparators differed from committers and immotives on every determinant, and they differed from progressives with regard to pros of smoking, 
social norm of others, social pressure of friends and the smoking behaviour of the brother. However, on these variables the preparators' score was opposite to the trend within the precontemplation subtypes.

\section{DISCUSSION}

This study investigated the existence of subgroups within the precontemplation stage of adolescent smoking acquisition, by assessing differences between the various potential subgroups regarding cognitive predictors of smoking behaviour. Usually, the precontemplating group is very large in an adolescent population, as was confirmed by the present study: $90 \%$ of the total sample was in acquisition precontemplation. Relatively few individuals are in acquisition contemplation and acquisition preparation, indicating that adolescents move through these stages rapidly. The large group of adolescents situated in acquisition precontemplation might be too diverse to provide accurate health education messages. Based on earlier research on immotive and progressive subgroups within adult cessation precontemplation (Crittenden et al., 1994; Dijkstra et al., 1997; Dijkstra et al., 1998; Norman et al., 2000; Velicer et al., 1995) and research on susceptibility to smoking (Choi et al., 1997; Pierce et al., 1995; 1996), three subtypes within the acquisition precontemplation stage were identified in the present study. The subtypes are labelled as committers, immotives and progressives.

The results of the present study indicate that the group of smoking acquisition precontemplators should not be viewed as one homogenous group. Progressives have concrete plans to start smoking in the future. These concrete plans are not apparent in immotives, who only have vague plans or no plans at all to start smoking in the future. Committers not only have no plans, but they are also committed to never smoke. They have firmly decided to remain nonsmokers. Known cognitive predictors of future smoking behaviour have consistently been found to differ between these subgroups. Scores on pros and cons of smoking, social norm, perceived pressure, perceived smoking behaviour of the social environment, emotional self-efficacy, opportunity self-efficacy and self-efficacy in situations with friends all differed between these subgroups, in a way corresponding with the hypotheses.

The conciseness and theoretical background of the SCC makes it a useful tool for studying adolescent smoking acquisition. Viewing adolescent smoking acquisition as a dynamic process rather than a static dichotomous characteristic is a valid and fruitful starting-point that enables investigation of cognitive processes along this continuum. In the present study, despite the use of constructs that are different than proposed by Prochaska and colleagues (1983), scores on the dynamic constructs of the TTM differed between the various stages of smoking acquisition. In this respect, the results replicate the findings of Pallonen and colleagues (1998). Moreover, the present study has added a new aspect to this issue, in that contemplation and preparation did not consistently differ from the progressive subgroup within precontemplation. Accordingly, the findings do not support the necessity of differentiating between the acquisition contemplation and acquisition preparation stage of change with regard to adolescent smoking. The absence of differences between these stages might be 
explained by the relatively small number of individuals that was situated in these stages. Further research is needed to assess the relevance of the distinction between the acquisition stages of contemplation and preparation. Also, the results found in this study should be validated by means of longitudinal data.

Whereas Velicer and colleagues (1995) and Norman and colleagues (2000) used a hypothesis-generating cluster analysis method to identify subgroups within cessation precontemplators, and Dijkstra and colleagues $(1997 ; 1998)$ used a hypothesis-testing method similar to that used in the present study to identify subtypes, the present study is the first to identify the immotive and progressive subtypes within acquisition precontemplation. The identification of the committer subgroup was inspired by explorative work by Pierce and colleagues (1995; 1996). They have named this concept 'susceptibility' (Pierce et al., 1995) although an analogous concept has also been tested as a 'strong commitment' (Choi et al., 1997). The difference between these two concepts is that, unlike commitment, the concept of susceptibility contains an expectational component that is related to self-efficacy (Pierce et al., 1996): a firm decision not to smoke 'when a friend offers a cigarette' is an inclusion criterion in the susceptibility algorithm. Consequently, self-efficacy T-scores in this study would have been artificially high within the 'non-susceptible' group because similar concepts would have been used both as independent and dependent variables.

The use of the subgroups described in the present study has important benefits. Firstly, presenting prevalence rates using subgroups of smoking acquisition precontemplation provide more detailed information on specific characteristics of the population under study. Secondly, since smoking initiation is believed to be a process of change, effect rates of smoking prevention interventions would be far more useful and informative if the outcome measure is a stage construct which includes movements between subtypes within a heterogeneous stage. Thirdly, a more detailed cognitive profile with regard to relevant determinants of smoking initiation enables the development of more precise stage-matched interventions.

Progressives can be characterised as being ready to move to the next stage. Thus, progressives can not be considered as typical precontemplators. With regard to proximal determinants of smoking behaviour, acquisition progressives can be viewed as similar to nonsmoking contemplators and preparators. They perceive many pros and few cons of smoking. Many negative social influences are perceived by these individuals and they have relatively low self-efficacy to remain a nonsmoker. Health education messages should therefore take into account that, although progressive adolescents could be labelled as precontemplators according to their intentions to start smoking, their cognitive characteristics show that individuals in this subgroup are on the edge of starting to smoke. With regard to some cognitive characteristics (pros of smoking, social norm of others, social pressure of friends, and smoking behaviour of the brother) adolescents in the progressive stage seemed more likely to take up regular smoking than those in preparation. One possible explanation for this finding may be that once the decision to start smoking in the near future is made, beliefs and influences are perceived to be less salient. Another conclusion may be that the groups of progressives and preparators do not systematically differ. The fact that no coherent image of differences between these groups is demonstrated, may support the latter explanation. 
Adolescents committed to nonsmoking differ from all other groups in that their perceptions of the cons of smoking outweigh the pros. All other smoking-related cognitions of the committing subtype can also be labelled as protective. These perceptions could be confirmed and strengthened by health education messages. Most of the nonsmoking adolescents in our sample were residing in the immotive subgroup. In this subtype, the protective cognitive characteristics of adolescents of the committer subtype seem to be changing into the risky cognitive characteristics of the progressive subtype. Smoking prevention research could identify the immotive subgroup, which should be considered as a group that is at a critical stage of smoking acquisition.

The findings of the present study show that recognition of subtypes within precontemplation is a promising perspective in studying adolescent smoking acquisition, both for theory construction and for smoking prevention practice. Future studies aimed at testing the existence of subgroups within smoking acquisition precontemplation are desirable and valuable in order to validly apply the SCC to adolescent smoking acquisition. The SCC for adult smoking cessation may have limited usefulness in explaining and predicting the uptake of smoking behaviour by adolescents. Perhaps focusing on subgroups within acquisition precontemplation will be more productive than examining stages in which few adolescents can be categorised. 


\title{
Chapter 3
}

\section{Four motivational stages of smoking initiation: Predictive validity}

\begin{abstract}
The present study tested the use and predictive validity of a stage model of adolescent smoking initiation. The model aims to identify adolescents who are currently not smoking, but who are cognitively predisposed to start smoking in the future. Research on subtypes within the precontemplation stage of adolescent smoking initiation and the concept of susceptibility to smoking led to the construction of a motivational stage model of four distinct stages: committer, immotive, progressive, and contemplator. Using longitudinal data on a large international sample of European adolescents $(n=7117)$, the model proved to have value in predicting smoking initiation at twelve months follow-up. The Odds Ratio to take up regular smoking behaviour appeared to double with each forward stage transition. Implications of the findings are discussed.
\end{abstract}

A manuscript based on this chapter has been submitted for publication as:

Kremers, S. P. J., De Vries, H., Mudde, A. N., \& Candel, M. Four motivational stages of smoking initiation: predictive validity and predictors of transitions. 
Recent trends indicate that the age of smoking initiation is falling, while smoking prevalence rates among adolescents are rising (Warren et al., 2000). Once an adolescent has started to smoke regularly, smoking is likely to become a long-term addiction (Pierce \& Gilpin, 1996). In contrast, if an individual does not start smoking during adolescence, he/she is unlikely ever to do so (USDHHS, 1994). Although prevention of adolescent smoking initiation is an essential component of efforts to reduce the overall prevalence of smoking (Tyas \& Pederson, 1998), the effect of prevention programs greatly depends on the identification of groups at risk and on reliable predictors of smoking onset (Collins et al., 1987; Conrad, Flay \& Hill, 1992).

Traditionally, smoking onset by adolescents has been studied in terms of recent smoking behaviour. Consequently, the population under study is usually categorised into two or more behavioural categories of smoking (e.g., nonsmokers, experimenters, and regular smokers; e.g., Mayhew et al., 2000; Robinson et al., 1997). However, nonsmoking adolescents can also be categorised into different groups, based on their cognitive characteristics (Kremers, Mudde \& De Vries, 2001a; Pierce et al., 1996; Stern et al., 1987). It may be possible to identify adolescents who are currently not smoking, but who are cognitively predisposed or motivated to start smoking in the future.

Although the Stages of Change Construct (SCC; Prochaska \& DiClemente, 1983) was originally developed to study adult smoking cessation within the Transtheoretical Model of Change, it has also been applied to adolescent smoking initiation (Elder et al., 1990; Kelley et al., 1999; Pallonen, 1998; Pallonen et al., 1998; Stem et al., 1987; Werch \& DiClemente, 1994). The SCC of smoking initiation can be regarded as the mirror image of the cessation model (Stern et al., 1987). It distinguishes three motivational stages (Pallonen et al,, 1998), defined as precontemplation (no intentions to start smoking in the next 6 months), contemplation (thinking about starting to smoke in the next 6 months) and preparation (thinking about starting to smoke in the next 30 days). To date, no longitudinal tests of the SCC of smoking initiation have been performed (Werch \& Anzalone, 1995).

Pierce and colleagues (1995) introduced the concept of commitment to nonsmoking, labelled 'non-susceptibility'. The decision to start smoking may be influenced by the absence of a firm commitment not to smoke (Choi, Gilpin, Farkas \& Pierce, 2001; Choi et al., 1997; Huang, Unger \& Rohrbach, 2000; Jackson, 1998; Pierce et al., 1996; Unger et al., 1997; Unger, Rohrbach, Howard-Pitney, Olson \& Mouttapa, 2001). Longitudinal research has shown that susceptibility to smoking was strongly associated with moving towards both experimentation (Pierce et al., 1996) and established smoking (Choi et al., 1997; 2001).

Kremers et al. (2001a) integrated the concepts of stages of change and susceptibility in a cross-sectional study. The results of that study indicated that the group of smoking initiation precontemplators should not be viewed as one homogenous group. Three subtypes within precontemplation were identified: progressives, immotives, and committers. Progressives had concrete plans to start smoking in the future. Such concrete plans were not apparent in immotives, who only had vague plans or no plans at all to start smoking in the future. Committers not only 
had no plans, but they were also committed to never start smoking. They had firmly decided to remain nonsmokers. Known cognitive predictors of future smoking behaviour were consistently found to differ between these subgroups. Progressives had cognitive characteristics indicating that they were most at risk of starting to smoke, while committers had characteristics indicating that they were least at risk. The study further showed that the groups of acquisition contemplators and acquisition preparators were small, and that these groups did not differ from each other with regard to cognitive characteristics. Consequently, a stage model could be constructed with four stages within the adolescent presmoking stage: committers, immotives, progressives, and contemplators (Figure 3.1).

Figure 3.1. Models of motivational stages of adolescent smoking initiation; the threestage model following the Stage of Change construct and the four-stage model tested in the present study

Stages of change

Four-stage model

(present study)

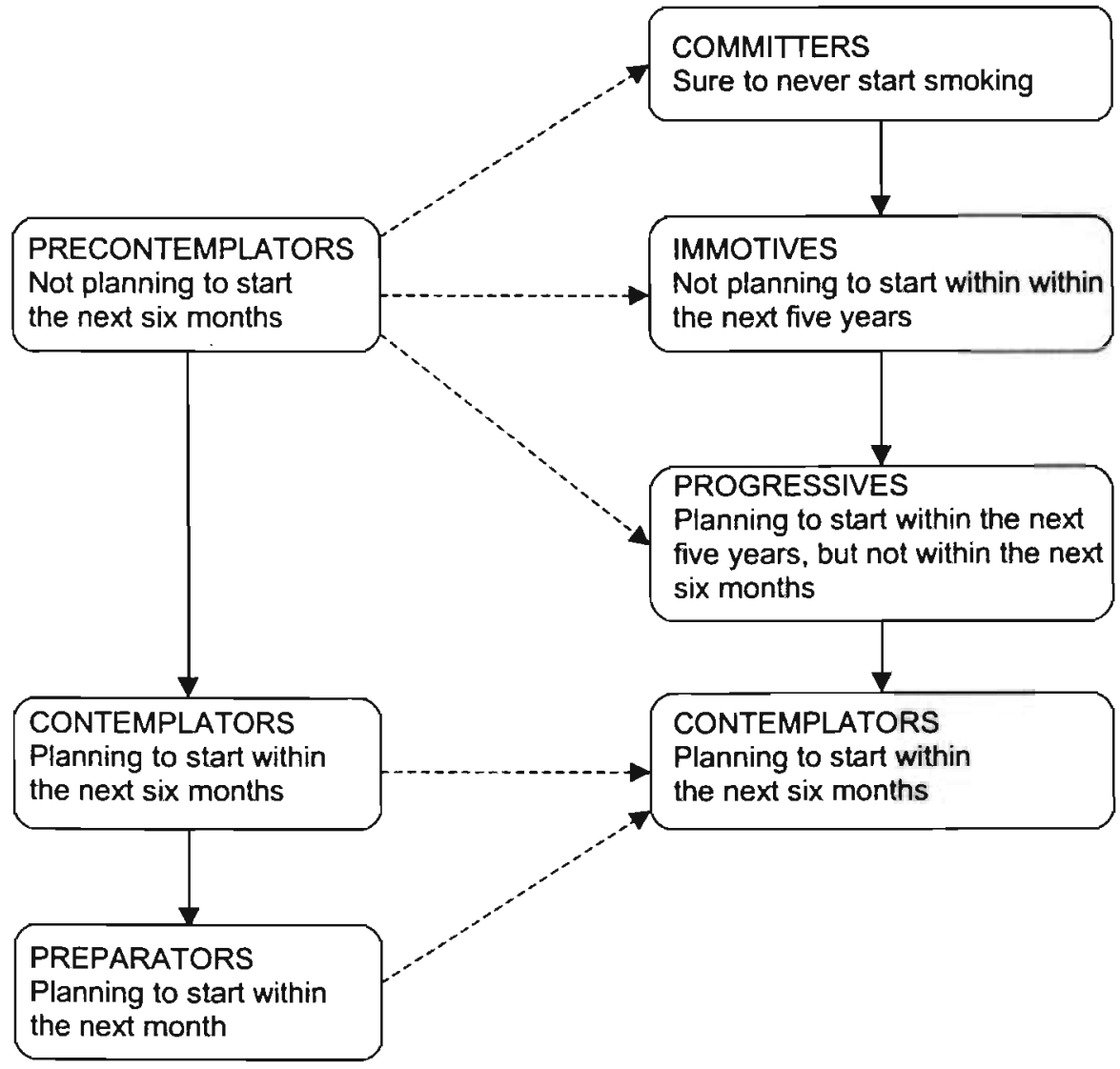


Cross-sectional comparison of groups within different stages of change can be considered a first step in the development of a stage model (Weinstein et al., 1998; e.g., De Vries \& Backbier, 1994; DiClemente et al., 1991; Dijkstra et al., 1996; Prochaska \& DiClemente, 1984). If adolescents in two different stages do not differ on central psychological constructs, there may be little reason to distinguish between these stages (Dijkstra et al., 1998). The vast majority of studies investigating stage theories have used cross-sectional designs (Sutton, 2000). The study by Kremers et al. (2001a) accomplished this first step with regard to the motivational stages of smoking initiation. However, finding significant differences between people in different stages cannot conclusively be interpreted as support for the model (Sutton, 2000). The purpose of the present study was to further test the four-stage model of smoking initiation using a prospective longitudinal design.

A second step in the testing of a stage model incorporates the predictive validity of the stages. Stage assignment at one point in time should be predictive of smoking behaviour measured at a later point in time (De Vries \& Mudde, 1998; Dijkstra et al., 1998; Weinstein et al., 1998). The goal of the present study was to examine the predictive validity of the various stages of the four-stage model. It was expected that, 12 months after the baseline measurement, more contemplators than progressives would be smoking regularly, more progressives than immotives would be smoking regularly and more immotives than committers would be smoking regularly.

\section{METHODS}

\section{Participants and recruitment}

In the present study, a large international sample of European adolescents $(n=10170)$ was followed longitudinally. A baseline measurement was conducted in August/September 1998 and a follow-up measurement was performed 12 months later. The sample consisted of the control group of a larger, ongoing prospective study of the ESFA smoking prevention project (European Smoking prevention Framework Approach; De Vries et al., submitted; Kremers, Mudde \& De Vries, 2000). Six member states of the European Union (Finland, Denmark, the United Kingdom, the Netherlands, Spain, and Portugal) participate in this project. Data were collected at schools, using a self-administered questionnaire.

Of the sample, $9.1 \%$ lived in Denmark, $15.1 \%$ in Finland, $23.7 \%$ in the Netherlands, $14.3 \%$ in Portugal, $9.1 \%$ in Spain, and $28.7 \%$ in the United Kingdom. The mean age of the respondents at baseline was 13.3 years $(\mathrm{SD}=0.7)$, and $50.5 \%$ were males. Due to missing or incomplete data on key variables, 290 cases (3.7\%) were excluded from the analysis.

\section{Attrition}

A logistic regression analysis was conducted to compare participating subjects with the dropouts (i.e., those not participating in the second measurement) using data of the first measurement as predictors of drop out. Independent variables were gender, age, country, and regular smoking behaviour. The indicators for regular smoking behaviour are described in the Measures section. 
Dropouts $(\mathrm{n}=2233 ; 22 \%)$ were found to be older $(\mathrm{OR}=1.32,95 \%$ CI $=1.24-$ 1.41 ), less often from Finland $(\mathrm{OR}=0.32,95 \% \mathrm{CI}=0.27-0.38)$, the Netherlands (OR $=0.23,95 \% \mathrm{CI}=0.20-0.27)$ or Spain $(\mathrm{OR}=0.62,95 \% \mathrm{CI}=0.53-0.73)$ when compared to the United Kingdom, and more often smoking regularly ( $O R=1.66,95 \%$ $\mathrm{Cl}=1.39-1.99)$. No differences were found for gender.

\section{MEASURES}

\section{Current smoking status}

Adolescents were asked to pick a statement that best described them, out of a set of specific smoking related statements. Responses were cross-validated using an algorithm consisting of concepts measuring current smoking and lifetime smoking. A primary measure of regular use is smoking, on average, at least once a week or with greater frequency (Flay, 1993; Robinson et al., 1997; Sussman, Dent, Burton, Stacy \& Flay, 1995; USDHHS, 1994). Consequently, smoking behaviour was classified into four stages:

(1) Never smokers were defined as those who reported never having smoked a cigarette, not even one puff ( $n=4874 ; 63.7 \%)$.

(2) Experimenters were defined as those who reported having tried smoking or having experimented with cigarettes, but not smoking weekly ( $\mathrm{n}=2243$; $29.3 \%)$.

(3) Regular smokers were defined as those who reported smoking at least once a week $(\mathrm{n}=389 ; 5.1 \%)$.

(4) Quitters were defined as those who reported to have quit smoking after having smoked at least once a week $(n=141 ; 1.8 \%)$.

\section{Stages of smoking initiation}

Regular smokers and quitters at baseline were excluded from the analysis. Subsequently, respondents were classified as a result of an item that assessed the adolescents' plans to smoke in the future. The item was stated as: 'Which of the following statements best describes you?' Answering categories included 'I am sure I will never start smoking', 'I think that I will never start smoking', 'I think that I will start smoking within the next five years', and 'I think that I will start smoking within the next six months'. Respondents were classified as contemplators $(n=77 ; 1.1 \%)$ if they planned to start within the next six months. Within the group who did not intend to start smoking within the next six months (precontemplators), three stages were distinguished: those who intended to start smoking within the next five years (progressives, $n=221 ; 3.1 \%$ ), those who did not intend to start within the next five years but lacked a firm decision never to start smoking (immotives, $n=4336 ; 60.9 \%$ ). and those who indicated they were sure to never start smoking and definitely not intending to smoke in the next year and definitely not intending to smoke in the future (committers, $n=2483 ; 34.9 \%$ ). The latter two indicators of the stage of committers were derived from two items on the adolescents' intentions to smoke that are in line with the instrument by Pierce et al. (1995) in order to identify adolescents susceptible to smoking. The items were stated as follows: 'Do you intend to smoke in the next 
year?' and 'Do you intend to smoke in the future?' Answering categories were 'definitely', 'probably', 'possibly', 'I don't know', 'possibly not', 'probauly not', and 'definitively not'.

\section{Demographic variables}

Demographic variables included in the study were country, gender and age. For more information on the distribution of the demographic variables over the population under study we refer to our cross-sectional study (Kremers et al., 2001a).

\section{Statistical analysis}

Three sets of analyses were performed. Firstly, percentages of transitions from the various stages were assessed. Secondly, Odds Ratios were computed in order to test the predictive validity of the stages with regard to the transition towards regular smoking behaviour. These Odds Ratios were corrected for the covariates gender, age, country, and experimenting behaviour, using logistic regressions. Each stage was tested against every other stage, implying that three of the four stages were used as reference category once.

\section{RESULTS}

\section{Transitions at 12 months follow-up}

Table 3.1 shows the transitions from stages at the baseline measurement to those at the 12 months follow-up measurement. Of the committers at baseline, $60.8 \%$ were still committers at follow-up. About one-third of the committers at baseline had progressed to the immotive stage, and less than one percent had progressed to the progressive or contemplation stage. Less than 4 percent of the committers at baseline had initiated regular smoking behaviour during the 12 months follow-up period.

Table 3.1. Transitions from stages at baseline (T1) to those at 12 months follow-up (T2) $(n=7117)$

\begin{tabular}{|c|c|c|c|c|c|}
\hline $\mathrm{T} 2$ & $\begin{array}{l}\text { Committers } \\
n=2322 \\
32.6 \%\end{array}$ & $\begin{array}{l}\text { Immotives } \\
n=3768 \\
52.9 \%\end{array}$ & $\begin{array}{l}\text { Progressives } \\
n=143 \\
2.0 \%\end{array}$ & $\begin{array}{l}\text { Contemplators } \\
n=98 \\
1.4 \%\end{array}$ & $\begin{array}{l}\text { Smokers } \\
n=786 \\
11.0 \%\end{array}$ \\
\hline T1 - & & & & & \\
\hline $\begin{array}{l}\text { Committers } \\
n=2483 \\
34.9 \%\end{array}$ & $\begin{array}{l}1509 \\
60.8 \%\end{array}$ & $\begin{array}{l}837 \\
33.7 \%\end{array}$ & $\begin{array}{l}21 \\
0.8 \%\end{array}$ & $\begin{array}{l}19 \\
0.8 \%\end{array}$ & $\begin{array}{l}97 \\
3.9 \%\end{array}$ \\
\hline $\begin{array}{l}\text { Immotives } \\
n=4336 \\
60.9 \%\end{array}$ & $\begin{array}{l}791 \\
18.2 \% \\
\end{array}$ & $\begin{array}{l}2805 \\
64.7 \%\end{array}$ & $\begin{array}{l}100 \\
2.3 \% \\
\end{array}$ & $\begin{array}{l}68 \\
1.6 \% \\
\end{array}$ & $\begin{array}{l}572 \\
13.2 \%\end{array}$ \\
\hline $\begin{array}{l}\text { Progressives } \\
n=221 \\
3.1 \%\end{array}$ & $\begin{array}{l}18 \\
8.1 \%\end{array}$ & $\begin{array}{l}104 \\
47.1 \%\end{array}$ & $\begin{array}{l}20 \\
9.0 \% \\
\end{array}$ & $\begin{array}{l}3 \\
1.4 \%\end{array}$ & $\begin{array}{l}76 \\
34.4 \%\end{array}$ \\
\hline $\begin{array}{l}\text { Contemplators } \\
n=77 \\
1.1 \%\end{array}$ & $\begin{array}{l}4 \\
5.2 \%\end{array}$ & $\begin{array}{l}22 \\
28.6 \%\end{array}$ & $\begin{array}{l}2 \\
2.6 \%\end{array}$ & $\begin{array}{l}8 \\
10.4 \%\end{array}$ & $\begin{array}{l}41 \\
53.2 \%\end{array}$ \\
\hline
\end{tabular}


Of the immotives at baseline, $64.7 \%$ were still immotives at follow-up. About two percent had moved to the progressive stage, while $1.6 \%$ had progressed to contemplation, and $13.2 \%$ had started smoking. Eighteen percent of the immotives at baseline had committed themselves to nonsmoking at follow-up. Of the progressives at baseline, $9 \%$ were still progressives at follow-up. One percent had progressed to contemplation. One-third of the progressives at baseline had made the move to smoking behaviour in the year of follow-up. Almost half of the progressives at baseline $(47.1 \%)$ had regressed to immotives at follow-up, and $8.1 \%$ had committed themselves to nonsmoking. Of the contemplators at baseline, $10.4 \%$ were still contemplators at follow-up. Almost three percent had regressed to the stage of progressives, $28.6 \%$ had regressed to the immotive stage and $5.2 \%$ had regressed to committers. More than half of the contemplators at baseline $(53.2 \%)$ had started smoking at follow-up.

\section{Predictive validity of the stages}

Table 3.2 shows the Odds Ratios for each stage with regard to progression to regular smoking behaviour. Age, gender, country, and experimenting behaviour at baseline were entered as covariates in the computation of Odds Ratios. The most important Odds Ratios are those that compare a particular stage with the one directly preceding it. In these cases (depicted in bold in Table 3.2), the preceding stage was used as the reference category in the regression analysis. The Odds Ratio of the reference category was set at 1.00 .

Table 3.2 shows that the Odds Ratios that compared a stage with the one directly preceding it were always approximately 2 . Compared to that of committers, the Odds Ratio of immotives was 2.32 ( $\mathrm{CI}=1.83-2.93)$. The Odds Ratio of progressives to smoke regularly at follow-up was $2.10(\mathrm{CI}=1.54-2.88)$, when compared to that of immotives. The Odds Ratio that compared contemplators with progressives was $1.96(\mathrm{CI}=1.11-3.44)$. Since all $95 \%$ confidence intervals were larger than 1.00 , it may be concluded that all differences found were statistically significant.

Table 3.2. Odds Ratios (OR) and their 95\% confidence intervals (Cl) of transition towards smoking behaviour. Committers, Immotives and progressives were each tested as reference stage $(n=7117)$

\begin{tabular}{lllll}
\hline & \multicolumn{3}{l}{ Reference stage } \\
\cline { 3 - 4 } & & Committers & Immotives & Progressives \\
\hline Immotives & OR & 2.32 & & \\
& $95 \% \mathrm{Cl}$ & $\mathbf{1 . 8 3}-2.93$ & & \\
& & & \\
\hline Progressives & OR & 4.88 & 2.10 & \\
& $95 \% \mathrm{Cl}$ & $3.36-7.11$ & $1.54-2.8 \mathrm{~B}$ & \\
& & & & \\
\hline Contemplators & OR & 9.53 & & \\
& $95 \% \mathrm{Cl}$ & $5.58-16.27$ & $2.52-6.67$ & $1.14-3.44$
\end{tabular}

Note. Reference stage: OR set at 1.00. Odds Ratios corrected for age, gender, country and experimenting behaviour. Odds Ratios that compare one stage with one directly preceding it are depicted in bold. 
The Odds Ratio of contemplators at baseline for smoking regularly at follow-up was 9.53 , compared to the reference category of committers. The $95 \%$ confidence interval was relatively large (5.58-16.27). The Odds Ratio of progressives was $4.88(95 \% \mathrm{CI}=$ 3.36-7.11), when compared to committers. The Odds Ratio of contemplators was 4.13 $(\mathrm{CI}=2.52-6.76)$, when compared to the reference category of immotives.

\section{DISCUSSION}

The present study investigated the predictive validity of a motivational stage model of adolescent smoking initiation. The model combines the Stages of Change construct (Prochaska \& DiClemente, 1983) from the Transtheoretical model with the concept of susceptibility to smoking (Pierce et al., 1995). The new stage model consists of four distinct stages: committers, immotives, progressives, and contemplators. The fourstage model proved to have value in predicting smoking initiation at twelve months follow-up.

Adolescents in the committer stage at baseline were found to be least at risk of making the transition towards regular smoking behaviour in the twelve months followup period. Immotives were more at risk than committers, but less than adolescents in the progressive stage. Contemplators ran the highest risk of being smokers at followup. The Odds Ratio to take up regular smoking behaviour appeared to double with each forward stage transition. Studies on the concept of susceptibility to smoking have also shown that committed adolescents were about twice as likely to move towards smoking than non-committed adolescents (Choi et al., 1997; 2001; Jackson, 1998; Pierce et al, 1996; Unger et al., 1997). The present study has shown that the group of susceptible adolescents can be divided into stages of immotives, progressives and contemplators, for which a similar risk factor of 2 is apparent for each transition.

The conciseness and theoretical background of the SCC makes it a useful tool to study adolescent smoking initiation. Viewing adolescent smoking initiation as a dynamic process rather than a static dichotomous characteristic is a valid and fruitful starting point. However, studies on the concept of susceptibility and on subtypes within the precontemplation stage have proven that the SCC cannot be simply mirrored in order to be validly applied to adolescent smoking initiation. Thus, the present study offers an explanation for recent failures of smoking prevention efforts based on the SCC (e.g., Aveyard et al., 1999). The external validity of the model with respect to its transfer to other topics than smoking cessation has also been questioned by other authors (Clarke \& Eves, 1997; Lauby et al., 1998; Lechner et al., 1998; Whitelaw et al., 2000). In our view, the time framing of the distinct stages of the SCC should be critically and specifically examined for the various possible health behaviours and target groups. Our model has maintained the time frame of 6 months as an indicator of concrete motivation to smoke in the near future. We have added the time frame of 5 years, in order to represent the motivation to be a smoker in the distant future (as an adult). The distinction between immotives and committers is based on the firmness of the intention not to smoke, rather than on a specific time frame.

The identification of the committer stage was inspired by the explorative work of Pierce et al. $(1995 ; 1996)$. An analogous concept to that of susceptibility has also 
been tested as a 'strong commitment' to nonsmoking (Choi et al., 1997). The difference between these two concepts is that, unlike commitment, the concept of susceptibility contains an expectational component that is related to self-efficacy (Pierce et al., 1996): a firm decision not to smoke 'when a friend offers a cigarette' is an inclusion criterion in the susceptibility algorithm. We did not include the expectational component in our definition of the commitment stage. Instead, in line with the Transtheoretical model and other theories of health behaviour (e.g., Ajzen, 1988; Bandura, 1977; De Vries et al., 1988), we view self-efficacy as a possible determinant of stage transition within the model.

The results of the present study should be viewed in the light of a dropout that proved to be selective with regard to age, country and regular smoking behaviour of the respondents. However, since all regular smokers at baseline were excluded from the analysis and the results were corrected for factors including age and country, the external validity was probably not affected. Moreover, the cross-cultural sample of the present study increased the external validity of its results.

The present study indicates that a useful theory on the adolescent smoking initiation process should incorporate motivational stages of change. However, the finding of a more or less 'gradual' increase of the Odds Ratio to start smoking regularly does not undeniably support an underlying stage model. A gradual pattern of transitions may also suggest a linear process (Sutton, 2001; Weinstein et al., 1998). It is important to note that more research is needed on the relationship between early behavioural stages of smoking initiation (i.e., initial trying and experimenting) and the motivational stages of change. Further, prospective studies should test the assumption that different predictors are involved in different stages (De Vries \& Mudde, 1998; Weinstein et al., 1998). Future studies should also include experimental studies of matched and mismatched interventions to test the four-stage model as proposed in the present study. Experiments provide better tests of stage ideas than do correlational research designs (Weinstein et al., 1998). Since the groups of progressives and contemplators have been found to be relatively small, the practical use of distinguishing between these two stages should also receive attention. 


\section{Part 2}

\section{Behavioural stages of smoking initiation}

To cease smoking is the easiest thing l ever did. l ought to know, l've done it a thousand times.

Mark Twain 


\section{Chapter 4}

\section{'Kicking the initiation': Do adolescent ex-smokers differ from other groups within the initiation continuum?}

\section{ABSTRACT}

Current research on the continuum of smoking initiation has largely focussed on stages of progressing frequency of smoking. To gain more insight into reasons why some adolescents do, and others do not proceed to advanced levels of smoking behaviour, a continuum is examined in which two categories of ex-smoking are proposed. Standardised scores on psychosocial predictors of smoking among adolescent nonsmoking deciders and quitters were compared cross-sectionally with those of the categories of never smokers, triers, experimenters and regular smokers $(n=23317)$. Never smokers, triers, experimenters and regular smokers had significantly different characteristics with regard to psychosocial predictors of smoking $(p<.01)$, with scores of never smokers indicating that they were least at risk of smoking in the future, and those of regular smokers indicating that they were most at risk. Scores of nonsmoking deciders showed that they were less at risk than triers and experimenters, and more at risk than never smokers. Quitters seemed to have less risky psychosocial characteristics than experimenters and more risky characteristics than nonsmoking deciders. It is concluded that studying transitions of smoking behaviour based on six possible stages (i.e., never smoking, nonsmoking deciding, trying, experimenting, regular smoking and quitting) might lead to more valid insights into predictors of adolescent smoking behaviour.

Published as:

Kremers, S. P. J., Mudde, A. N., \& De Vries, H. (200lc). "Kicking the initiation": Do adolescent ex-smokers differ from other groups within the initiation continuum? Preventive Medicine, 33, 5, 392-401. 


\section{INTRODUCTION}

Several authors have postulated that the process of adolescent smoking initiation comprises distinct stages (Flay, 1993; Flay et al., 1983; Leventhal \& Cleary, 1980; Mayhew et al., 2000; Pallonen et al., 1998; Stern et al., 1987). An important contribution to the understanding of the continuum towards patterns of regular smoking among adolescents was made by Flay and colleagues (Flay, 1993; Flay et al., 1983; 1998), who proposed a model of smoking initiation. The never smoking (preparatory) stage, the trial stage and the experimental stage take an individual to the stage of regular smoking. Adolescents in the preparatory stage have never smoked even one puff. The second stage involves initial trying. Depending on physiological effects and social reinforcements after the use of the first few cigarettes, an adolescent advances to the experimental stage, which involves repeated, but irregular use over an extended period of time. Regular smoking involves smoking on a regular basis, perhaps weekly (Flay, 1993; Flay et al., 1983; 1998; USDHHS, 1994).

However, not all adolescents advance beyond trying or experimenting. Approximately $50 \%-67 \%$ of persons who try smoking do not proceed to regular patterns of use (USDHHS, 1994; CDC, 1998). Apparently, they stop smoking before there is a necessity to 'kick the habit'. At present, there is a lack of understanding of why some adolescents do, and others do not advance beyond trying or experimenting (Flay et al., 1998). It may therefore be useful to study this group of 'nonsmoking deciders' as a separate category of smoking behaviour. In addition, the subject of adolescent smoking cessation is receiving more and more scientific interest (Houston et al., 1998). A significant number of adolescents who smoke regularly report that they would want to quit (Stone \& Kristeller, 1992). Although some youngsters actually succeed in their attempt to quit, most of them do not (USDHHS, 1994). Quitting becomes more difficult as smokers progress through the continuum (CDC, 1998). Thus, it is worthwhile to study this group of quitters, consisting of ex-regular smokers, as a separate stage within the smoking initiation continuum.

Flay has acknowledged that adolescents may quit after trying, experimenting or regular smoking, by postulating that the probability of advancing from one stage to another is always less than one (Flay, 1993). In empirical settings, however, nonsmoking deciders and quitters have usually been categorised in any of the three stages preceding regular smoking (Mayhew et al., 2000). In the most recent empirical study on different stages of adolescent smoking by Flay and colleagues (1998), exsmokers were divided over the groups of triers and experimenters. Adolescents who decided to be nonsmokers after having tried smoking were categorised as triers or experimenters, depending on the number of cigarettes smoked in their life. Adolescents who quit smoking after having smoked regularly were categorised as experimenters (Figure 4.1).

It might be impossible to validly test Flay's theory of smoking initiation (Flay et al., 1983) empirically by adopting a four-stage model, because the groups of triers and experimenters are heterogeneous with regard to current smoking behaviour. These groups might therefore be heterogeneous with regard to psychosocial predictors of smoking behaviour. The present study is the first to empirically examine the full 
theoretical model by Flay, including the two suggested stages that were previously labelled as 'no longer smoking' (USDHHS, 19984).

Figure 4.1. The four-stage model and six-stage model of smoking initiation towards regular use. Full arrows indicate possible pathways of initiation. Broken lines indicate possible reclassification pathways

\section{Four-stage model}

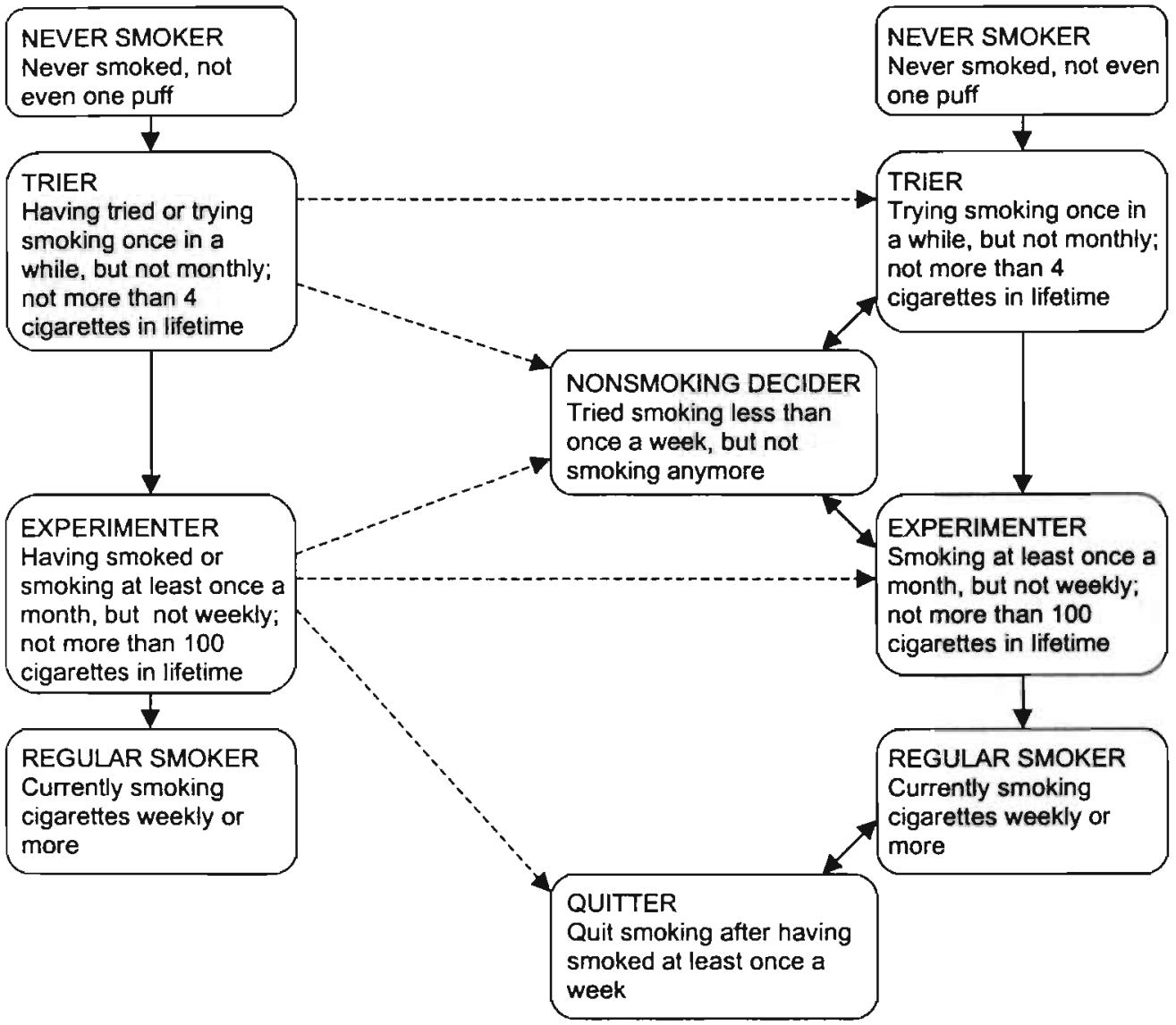

The objective of the present cross-sectional study was to examine psychosocial characteristics of nonsmoking deciders and quitters as distinct categories within the initiation continuum, using a large sample of adolescents divided over six European countries. The differences between the various categories within the initiation continuum were assessed with regard to psychosocial predictors of smoking behaviour. The rationale was that if scores on psychosocial predictors of smoking behaviour differed per category within the continuum, the various categories would 
prove to be distinguishable. While Flay and colleagues (1998) showed that psychosocial predictors of smoking differed per stage of smoking initiation, using the four-stage model, we tried to replicate their findings and explore the consequences of adopting a model which adds two stages of current nonsmoking to the four-stage model.

Four distinct hypotheses were tested in the present study. First, we hypothesised that never smokers, triers, experimenters and regular smokers would have significantly different scores on psychosocial predictors of smoking, with never smokers having scores indicating they were least at risk of smoking in the future and regular smokers having scores indicating they were most at risk (Hypothesis 1). The second hypothesis reflected the four-stage model assumption that nonsmoking deciders can be categorised as triers or experimenters. We hypothesised that nonsmoking deciders would be clearly distinguishable from these two groups, in that their scores on psychosocial characteristics would indicate they were less at risk than triers, and thereby also less than experimenters (Hypothesis 2). Our third hypothesis reflected the four-stage model assumption that quitters can be categorised as experimenters. We hypothesised that quitters would not be comparable to experimenters, in that their scores on psychosocial characteristics would indicate they were less at risk of smoking in the future (Hypothesis 3). Finally, we hypothesised that the three categories of current nonsmokers (never smokers, nonsmoking deciders and quitters) are clearly distinguishable from each other, in that the scores of never smokers on psychosocial characteristics would indicate the lowest risk of future smoking behaviour, while those of quitters would indicate the highest risk (Hypothesis 4).

\section{METHODS}

\section{Participants}

Data for the present study were gathered cross-sectionally among seventh-graders in an international sample of 23531 adolescents. This study is part of a larger, ongoing prospective study of the ESFA project (European Smoking prevention Framework Approach) (De Vries et al., 1999; 2000; Kremers et al., 2000). Seven sites in six European Union member states (Finland, Denmark, the United Kingdom, the Netherlands, Barcelona (Spain), Madrid (Spain) and Portugal) participate in this project. Data were collected at schools, using self-administered questionnaires. Due to missing or incomplete data on key variables on smoking behaviour, 214 cases $(0.9 \%)$ were excluded from analyses.

Of the remaining 23317 adolescents, $7.6 \%$ lived in Denmark, $12.0 \%$ in Finland, $17.0 \%$ in the Netherlands, $13.1 \%$ in Portugal, $8.6 \%$ in Barcelona, $13.8 \%$ in Madrid and $27.9 \%$ lived in the United kingdom. The mean age of the respondents was 13.3 years $(\mathrm{SD}=0.7)$, and $50.1 \%$ were male.

\section{Translation and pretesting}

The questionnaire that was used in the present study was translated in the seven languages by native speaking experts on the subject of adolescent smoking behaviour. In each language, the questionnaire was pretested in a representative sample of 
adolescents, using qualitative research methods. Intensive collaboration between the several sites within the project optimised the internal validity of the questionnaire.

\section{Smoking behaviour}

Adolescents were asked to select the statement that best described them from a set of specific smoking-related statements that paralleled the definitions depicted in the sixstage model in Figure 4.1. Responses were cross-validated using a four-item algorithm, consisting of concepts measuring current smoking and lifetime smoking (for more information, see Kremers, Mudde \& De Vries, 2001b). In agreement with the definition of triers as adolescents who are smoking their first few cigarettes, lifetime smoking data were additionally used to define triers as those who had not smoked more than four cigarettes in their life. Thus, adolescents who reported to be trying smoking once in a while but had smoked more than four cigarettes in their life were classified as experimenters. In line with the WHO and USDHHS operationalisation of established smoking (USDHHS, 1994; WHO, 1998), adolescents who reported smoking monthly but who had smoked more than 100 cigarettes in their life were classified as regular smokers. A similar cut-off point to distinguish between experimenters and regular smokers has been the result of a review on the development of adolescent smoking behaviour (Mayhew et al., 2000).

\section{Demographics}

Demographics included in the study were country, gender, age, religious background, and ethnicity. Two Northern European countries (Finland and Denmark), two Western European countries (The Netherlands and the United Kingdom), and two Southern European countries (Portugal and Spain) participated in this study. Barcelona and Madrid were distinguished as two separate locations in Spain, because of language differences. We also asked respondents whether they had a religious background. Ethnicity was classified as either native or immigrant.

\section{Psychosocial predictors}

Based on the results of recent research and reviews on determinants of adolescent smoking behaviour (Conrad et al., 1992; Petraitis et al., 1995; Tyas \& Pederson, 1998; USDHHS, 1994), psychosocial predictors of smoking assessed in the present study were attitudes, social influences, self-efficacy expectations, and intention.

\section{Attitudes}

Twelve items on smoking-related beliefs were measured. One item, referring to sociability of smoking, was excluded from the analyses because of ambiguous translations into several languages. Separate principal component analyses were performed to identify factors. Subsequently, alpha factoring with direct oblimin rotation was used to discover common factors (Tabachnick \& Fidell, 1996). This revealed two stable factors, viz., pros of smoking and cons of smoking (Table 4.1). The item assessing the belief that smoking would help to be slim did not load uniquely on any factor and was therefore removed from the analysis. Consequently, both subscales consisted of 5 items. Scales of pros and cons of smoking consisted of sumscores. 
Table 4.1. Factors within the concepts of attitude, social norm, social pressure, and self-efficacy

\begin{tabular}{|c|c|c|c|}
\hline Items & Factors & & \\
\hline $\begin{array}{l}\text { Attitude } \\
(-3,+3)\end{array}$ & $\begin{array}{l}\text { Pros of smoking } \\
(\alpha=64)\end{array}$ & $\begin{array}{l}\text { Cons of smoking } \\
(\alpha=.69)\end{array}$ & \\
\hline My friends will pay more attention to me & .46 & & \\
\hline I seem more confident in company & .53 & & \\
\hline It is easier to be part of the crowd & .49 & & \\
\hline It helps to calm my nerves & .56 & & \\
\hline It will make me feel relaxed & .55 & & \\
\hline It helps me to be slim & & & \\
\hline It is bad for my health & & .60 & \\
\hline I will be somy that I ever started smoking & & .48 & \\
\hline It is stupid of me & & .70 & \\
\hline It tastes horrible & & .43 & \\
\hline I consider my behaviour to be wrong & & .66 & \\
\hline $\begin{array}{l}\text { Social norm } \\
(-3,+3)\end{array}$ & $\begin{array}{l}\text { Parents \& teachers } \\
(\alpha=.72)\end{array}$ & $\begin{array}{l}\text { Peers \& siblings } \\
(\alpha=.74)\end{array}$ & \\
\hline Father & .78 & & \\
\hline Mother & .83 & & \\
\hline Teachers & .46 & & \\
\hline Brother & & .42 & \\
\hline Sister & & .41 & \\
\hline Best friend & & .74 & \\
\hline Friends & & .79 & \\
\hline People in same school year & & .67 & \\
\hline $\begin{array}{l}\text { Social pressure } \\
(0,4)\end{array}$ & $\begin{array}{l}\text { Peers } \\
(\alpha=.78)\end{array}$ & $\begin{array}{l}\text { Family \& teachers } \\
(\alpha=.76)\end{array}$ & \\
\hline Best friend & .68 & & \\
\hline Friends & .86 & & \\
\hline People in same school year & 67 & & \\
\hline Father & & .75 & \\
\hline Mother & & .72 & \\
\hline Brother & & .59 & \\
\hline Sister & & .54 & \\
\hline Teachers & & .50 & \\
\hline $\begin{array}{l}\text { Self-efficacy } \\
(-3,+3)\end{array}$ & $\begin{array}{l}\text { Friends } \\
(\alpha=.94)\end{array}$ & $\begin{array}{l}\text { Opportunities } \\
(\alpha=.93)\end{array}$ & $\begin{array}{l}\text { Emotions } \\
(\alpha=.96)\end{array}$ \\
\hline When with others who smoke & .85 & & \\
\hline When with friends who smoke & .90 & & \\
\hline When you are offered a cigarette & .90 & & \\
\hline When friends offer you a cigarelte & .91 & & \\
\hline When you are at the shops with friends & .83 & & \\
\hline When you are watching TV & & .93 & \\
\hline When you are doing homework & & .95 & \\
\hline When you are on the way home from school & & .84 & \\
\hline When you feel upset & & & .91 \\
\hline When you feel depressed & & & .93 \\
\hline When you feel nervous & & & .94 \\
\hline When you are worried & & & .92 \\
\hline
\end{tabular}

Note. Highest loadings per item (>.40) are shown. 


\section{Social influences}

Three components of social influence were assessed in the present study. Perccived behaviour of the social environment was measured by asking whether the mother, father and best friend smoked or not. These variables were used as separate items in the analyses. Social norm was operationalised by 8 items. Two meaningful factors were suggested by factor analysis: 'social norm of parents and teachers' and 'social norm of peers and siblings' (Table 4.1). The 'parents and teachers' subscale consisted of 3 items, while the 'peers and siblings' subscale contained 5 items. The third component within the concept of social influence analysed in this study was pressure to smoke. This concept was operationalised by 8 items. For example: Have you ever felt pressure to smoke from your best friend? Answering possibilities were very often (4), often (3), sometimes (2), a few times (1), and never (0). Factor analysis indicated two stable factors: 'pressure from peers' and 'pressure from family and teachers' (Table 4.1).

\section{Self-efficacy}

Self-efficacy expectations were measured by 12 items on a 7-point scale, derived from a validated instrument by Lawrance (1988). The items referred to the respondents' perception of their ability to refrain from smoking when they were in certain situations with friends, when they were subject to certain emotions and when they had certain opportunities to smoke. Factor analysis did indeed reveal the 'friends', 'emotion', and 'opportunity' subscales, although the item 'when you are at the shops with friends', which was originally intended as an opportunity item, turned out to be more closely correlated with the friends subscale (Table 4.1).

\section{Intention}

Intention to smoke was measured by one item on a 7-point scale. The item assessed the adolescents' intention to smoke within a year. Answering categories ranged from 'definitely not' through 'probably not', 'possibly not', 'I don't know', 'possibly', and 'probably' to 'definitely'.

\section{Statistical analyses}

Two sets of analyses were conducted in this study. First, the behavioural categories of smoking initiation were compared with regard to demographic variables using chisquare analyses for the discrete variables and an F-tests for age. In the case of significant differences between the categories, demographic variables were involved in the analyses as covariates. Secondly, contrasts between the various categories of smoking behaviour were analysed. To allow comparison of the scores on the various psychosocial concepts between the groups, standardised scores (mean z-scores) were computed for each concept. The analyses of contrasts were executed for both the fourstage model and the six-stage model. Inflated type I error because of multiple testing was controlled by applying a Bonferroni correction (Tabachnick \& Fidell, 1996). Additionally, the critical significance level was set at $p<.01$ because of the large sample size in the present study. 
Table 4.2. Demographics for the four-stage and six-stage models of adolescent smoking behaviour $(\mathrm{n}=23317$ )

\begin{tabular}{|c|c|c|c|c|c|}
\hline \%of total & $\begin{array}{l}\text { Never } \\
\text { smoker } \\
14681 \\
63.0 \\
\end{array}$ & $\begin{array}{l}\text { Trier } \\
\\
4631 \\
19.9 \\
\end{array}$ & $\begin{array}{l}\text { Experi- } \\
\text { menter } \\
2705 \\
11.6 \\
\end{array}$ & $\begin{array}{l}\text { Regular } \\
\text { smoker } \\
1300 \\
5.6 \\
\end{array}$ & $\begin{array}{l}\text { Test of } \\
\text { significance } \\
\text { within } \\
\text { 4-stage } \\
\text { model }\end{array}$ \\
\hline $\begin{array}{l}\text { Gender } \\
\text { Male }(n=11587) \\
\text { Female }(n=11538)\end{array}$ & $\begin{array}{l}63.0 \\
63.1\end{array}$ & $\begin{array}{r}19.9 \\
19.8\end{array}$ & $\begin{array}{l}12.1 \\
11.1\end{array}$ & $\begin{array}{l}5.0 \\
6.1\end{array}$ & $\chi^{2}=23.5^{\circ \times 10}$ \\
\hline $\begin{array}{l}\text { Mean age } \\
\text { (SD) }\end{array}$ & $\begin{array}{l}13.2 \\
(0.6)\end{array}$ & $\begin{array}{l}13.3 \\
(0.7)\end{array}$ & $\begin{array}{l}13.4 \\
(0.7)\end{array}$ & $\begin{array}{l}13.6 \\
(0.8)\end{array}$ & $F=161.7^{* \cdots *}$ \\
\hline $\begin{array}{l}\text { Country } \\
\text { Denmark }(n=1764) \\
\text { Finiand }(n=2802) \\
\text { The Netherlands }(n=3956) \\
\text { Portugal }(n=3064) \\
\text { Spain-Barcelona }(n=2008) \\
\text { Spain-Madrid }(n=3212) \\
\text { United Kingdom }(n=6511)\end{array}$ & $\begin{array}{l}54.0 \\
60.5 \\
57.7 \\
71.3 \\
63.5 \\
70.5 \\
61.8\end{array}$ & $\begin{array}{l}23.2 \\
13.7 \\
26.1 \\
16.1 \\
23.1 \\
14.5 \\
21.2\end{array}$ & $\begin{array}{l}16.0 \\
16.1 \\
10.9 \\
7.9 \\
10.5 \\
10.4 \\
11.6\end{array}$ & $\begin{array}{l}6.9 \\
9.6 \\
5.3 \\
4.7 \\
2.9 \\
4.6 \\
5.4\end{array}$ & $\chi^{2}=579.7^{* * *}$ \\
\hline $\begin{array}{l}\text { Ethnicity } \\
\text { Native }(n=20293) \\
\text { Immigrant }(n=3024)\end{array}$ & $\begin{array}{l}63.5 \\
59.1\end{array}$ & $\begin{array}{l}19.5 \\
22.6\end{array}$ & $\begin{array}{l}11.5 \\
12.3\end{array}$ & $\begin{array}{l}5.5 \\
6.0\end{array}$ & $x^{2}=24.2^{* *}$ \\
\hline $\begin{array}{l}\text { Religlous background } \\
\text { Non-religious }(n=11898) \\
\text { Religious ( } n=11419)\end{array}$ & $\begin{array}{l}60.7 \\
65.1\end{array}$ & $\begin{array}{l}19.8 \\
19.9\end{array}$ & $\begin{array}{l}12.6 \\
10.6\end{array}$ & $\begin{array}{l}6.9 \\
4.3\end{array}$ & $\chi^{2}=106.6^{* * *}$ \\
\hline
\end{tabular}

\begin{tabular}{|c|c|c|c|c|c|c|c|}
\hline \%of total & $\begin{array}{l}14681 \\
63.0\end{array}$ & $\begin{array}{l}757 \\
3.2\end{array}$ & $\begin{array}{l}1399 \\
6.0\end{array}$ & $\begin{array}{l}\text { Regular } \\
\text { smoker } \\
\\
1300 \\
5.6\end{array}$ & $\begin{array}{l}\text { Non- } \\
\text { smoking } \\
\text { decider }\end{array}$ & $\begin{array}{l}469 \\
2.0\end{array}$ & $\begin{array}{l}\text { Test of } \\
\text { significance } \\
\text { within } \\
6 \text {-stage } \\
\text { model }\end{array}$ \\
\hline $\begin{array}{l}\text { Gender } \\
\text { Male }(n=11587) \\
\text { Female }(n=11538)\end{array}$ & $\begin{array}{l}63.0 \\
63.1\end{array}$ & $\begin{array}{l}3.0 \\
3.5\end{array}$ & $\begin{array}{l}6.0 \\
6.0\end{array}$ & $\begin{array}{l}5.0 \\
6.1\end{array}$ & $\begin{array}{l}20.8 \\
19.6\end{array}$ & $\begin{array}{l}2.2 \\
1.8\end{array}$ & $x^{2}=37.6$ \\
\hline $\begin{array}{l}\text { Mean age } \\
\text { (SD) }\end{array}$ & $\begin{array}{l}13.2 \\
(0.6)\end{array}$ & $\begin{array}{l}13.3 \\
(0.7)\end{array}$ & $\begin{array}{l}13.4 \\
(0.7)\end{array}$ & $\begin{array}{l}13.6 \\
(0.8)\end{array}$ & $\begin{array}{l}13.3 \\
(0.7)\end{array}$ & $\begin{array}{l}13.4 \\
(0.7)\end{array}$ & $F=97.4$ \\
\hline $\begin{array}{l}\text { Country } \\
\text { Denmark }(n=1764) \\
\text { Finland }(n=2802) \\
\text { The Netherlands }(n=3956) \\
\text { Portugal }(n=3064) \\
\text { Spain-Barcelona }(n=2008) \\
\text { Spain-Madrid }(n=3212) \\
\text { United Kingdom }(n=6511)\end{array}$ & $\begin{array}{l}54.0 \\
60.5 \\
57.7 \\
71.3 \\
63.5 \\
70.5 \\
61.8\end{array}$ & $\begin{array}{l}4.7 \\
6.0 \\
3.7 \\
1.6 \\
2.9 \\
2.3 \\
2.7\end{array}$ & $\begin{array}{l}9.6 \\
8.2 \\
5.4 \\
4.2 \\
6.2 \\
5.3 \\
5.5\end{array}$ & $\begin{array}{l}6.9 \\
9.6 \\
5.3 \\
4.7 \\
2.9 \\
4.6 \\
5.4\end{array}$ & $\begin{array}{l}22.9 \\
13.1 \\
26.0 \\
16.6 \\
23.3 \\
14.8 \\
22.4\end{array}$ & $\begin{array}{l}2.0 \\
2.5 \\
1.9 \\
1.5 \\
1.1 \\
2.6 \\
2.1\end{array}$ & $x^{2}=694.4^{+\cdots+}$ \\
\hline $\begin{array}{l}\text { Ethniclty } \\
\text { Native }(n=20293) \\
\text { Immigrant }(n=3024)\end{array}$ & $\begin{array}{l}63.5 \\
59.1 \\
\end{array}$ & $\begin{array}{l}3.3 \\
2.9 \\
\end{array}$ & $\begin{array}{l}6.0 \\
5.9 \\
\end{array}$ & $\begin{array}{l}5.5 \\
6.0 \\
\end{array}$ & $\begin{array}{l}19.7 \\
23.8 \\
\end{array}$ & $\begin{array}{l}2.0 \\
2.3 \\
\end{array}$ & $x^{2}=34.8^{+\cdots+4}$ \\
\hline $\begin{array}{l}\text { Religlous background } \\
\text { Non-religious }(n=11898) \\
\text { Religious }(n=11419)\end{array}$ & $\begin{array}{l}60.7 \\
65.1\end{array}$ & $\begin{array}{l}3.7 \\
2.8\end{array}$ & $\begin{array}{l}6.5 \\
5.6\end{array}$ & $\begin{array}{l}6.9 \\
4.3\end{array}$ & $\begin{array}{l}20.1 \\
20.3\end{array}$ & $\begin{array}{l}2: 1 \\
1.9\end{array}$ & $x^{2}=111.7^{* \cdots}$ \\
\hline
\end{tabular}

Note. ${ }^{* *}=p<.001$. 


\section{Demographic variables}

Table 4.2 shows the percentages of the demographic variables that were classified in each of the smoking behaviour categories. We will first focus on the four-stage model. Overall, $63.0 \%$ of the respondents were classified as never smokers, while $19.9 \%$ were classified as triers, $11.6 \%$ were classified as experimenters and $5.6 \%$ were classified as regular smokers. Although fewer girls were experimenting with smoking, they were more often smoking on a regular basis than boys. The age of the respondents ranged from 10 to 16 years; $93.6 \%$ of the sample was 12 or 13 years of age. The mean age showed a slight increase through the successive categories of smoking behaviour. The prevalence of never smokers was largest in Portugal and smallest in Denmark. While the lowest percentage of regular smokers was observed in Barcelona, the largest percentage was found in Finland. Immigrant adolescents experimented and smoked regularly more often than native respondents. More non-religious than religious adolescents were smoking regularly.

While the trier category was larger than the experimenter category in the fourstage model $(19.9 \%$ and $11.6 \%$, respectively), there were fewer triers than experimenters in the six-stage model $(3.2 \%$ and $6.0 \%$, respectively). More than $20 \%$ $(\mathrm{n}=4711)$ of the respondents were found to be nonsmoking deciders in the six-stage model. The group of nonsmoking deciders included $82 \%(n=3874)$ adolescents who were triers in the four-stage model. The Netherlands was found to have relatively high numbers of nonsmoking deciders. Immigrant adolescents were more often found to be nonsmoking deciders than native adolescents. Two percent of the sample were classified as quitters in the six-stage model. In Madrid, relatively large numbers of adolescents were found to be quitters (2.6\%). All demographic variables differed significantly between the various smoking categories. Therefore, these variables were included in the analyses as covariates.

\section{Psychosocial predictors}

Table 4.3 presents the mean z-scores of each tested category of adolescent smoking behaviour. All psychosocial predictor variables were coded in such a way that low scores refer to a low level of perception of the particular concept and high scores to a high level. For example, a low z-score on cons of smoking implies the perception of few negative consequences of smoking; a high z-score on pressure to smoke implies the perception of much pressure. The z-scores of never smokers and regular smokers are identical for both models because these groups are common to the four-stage model and the six-stage model.

Overall, the results show that the scores of never smokers on each of the psychosocial characteristics tested indicated they were least at risk to smoke in the future, while regular smokers were most at risk. The $\mathrm{z}$-score of regular smokers on the intention to smoke next year and the smoking behaviour of the best friend was highest of all scores, indicating that these concepts can be regarded as the best explanatory variables for regular smoking. Smoking behaviour of the father was found to be the least discriminating variable. 
Table 4.3. Standardised scores (mean=0; $S D=1$ ) of the psychosocial predictors per stage of adolescent smoking behaviour In the four-stage and the six-stage models ${ }^{1}$. Contrasts are deplcted for each hypothesls (H1, H2, H3, and H4) ${ }^{2}$.

\begin{tabular}{|c|c|c|c|c|c|c|c|c|c|c|c|}
\hline Concept & Model & $\begin{array}{l}\text { Never } \\
\text { Emoker }\end{array}$ & Trier & $\begin{array}{l}\text { Experi- } \\
\text { menter }\end{array}$ & $\begin{array}{l}\text { Regular } \\
\text { smoker }\end{array}$ & $\begin{array}{l}\text { Non- } \\
\text { smoking } \\
\text { decider }\end{array}$ & Quitter & $\begin{array}{l}\text { Contrasts } \\
N, T, E, R^{3} \\
\text { (H1) }\end{array}$ & $\begin{array}{l}\text { Contrasts } \\
D, T \\
(H 2)\end{array}$ & $\begin{array}{l}\text { Contrasts } \\
Q, E \\
\text { (H3) }\end{array}$ & $\begin{array}{l}\text { Contrasts } \\
N, D, Q \\
(\mathrm{H} 4)\end{array}$ \\
\hline Cons of smoking & $\begin{array}{l}4 \\
6\end{array}$ & $\begin{array}{l}0.19 \\
0.19 \\
\end{array}$ & $\begin{array}{l}0.02 \\
-0.37\end{array}$ & $\begin{array}{l}-0.46 \\
-0.69 \\
\end{array}$ & $\begin{array}{l}-1.18 \\
-1.18 \\
\end{array}$ & 0.06 & -0.35 & $\begin{array}{l}N>T>E>R \\
N>T>E>R\end{array}$ & $D>T$ & $Q>E$ & $N>D>C$ \\
\hline Pros of smoking & $\begin{array}{l}4 \\
6 \\
\end{array}$ & $\begin{array}{l}-0.21 \\
-0.21 \\
\end{array}$ & $\begin{array}{l}0.12 \\
0.33 \\
\end{array}$ & $\begin{array}{l}0.45 \\
0.58 \\
\end{array}$ & $\begin{array}{l}0.98 \\
0.98 \\
\end{array}$ & 0.10 & 0.46 & $\begin{array}{l}N<T<E<R \\
N<T<E<R\end{array}$ & $\mathrm{D}<\mathrm{T}$ & $Q=E$ & $N<D<Q$ \\
\hline Pressure from peers & $\begin{array}{l}4 \\
6 \\
\end{array}$ & $\begin{array}{l}-0.25 \\
-0.25\end{array}$ & $\begin{array}{l}0.15 \\
0.39\end{array}$ & $\begin{array}{l}0.58 \\
0.66 \\
\end{array}$ & $\begin{array}{l}1.04 \\
1.04\end{array}$ & 0.16 & 0.61 & $\begin{array}{l}N<T<E<R \\
N<T<E<R\end{array}$ & $\mathrm{D}<\mathrm{T}$ & $Q=E$ & $N<D<Q$ \\
\hline $\begin{array}{l}\text { Pressure from family } \\
\text { and teachers }\end{array}$ & $\begin{array}{l}4 \\
6 \\
\end{array}$ & $\begin{array}{l}-0.09 \\
-0.09 \\
\end{array}$ & $\begin{array}{l}-0.01 \\
0.09 \\
\end{array}$ & $\begin{array}{l}0.19 \\
0.29 \\
\end{array}$ & $\begin{array}{l}0.61 \\
0.61 \\
\end{array}$ & -0.01 & 0.14 & $\begin{array}{l}N<T<E<R \\
N<T<E<R\end{array}$ & $\mathrm{D}=\mathrm{T}$ & $Q=E$ & $\mathrm{~N}<\mathrm{D}<\mathrm{Q}$ \\
\hline $\begin{array}{l}\text { Social norm parents } \\
\text { and teachers }\end{array}$ & $\begin{array}{l}4 \\
6 \\
\end{array}$ & $\begin{array}{l}-0.11 \\
-0.11 \\
\end{array}$ & $\begin{array}{l}0.04 \\
0.17 \\
\end{array}$ & $\begin{array}{l}0.22 \\
0.29 \\
\end{array}$ & $\begin{array}{l}0.54 \\
0.54 \\
\end{array}$ & 0.03 & 0.24 & $\begin{array}{l}N<T<E<R \\
N<T, E<R\end{array}$ & $\mathrm{D}<\mathrm{T}$ & $Q=E$ & $N<D<Q$ \\
\hline $\begin{array}{l}\text { Social norm peers } \\
\text { and siblings }\end{array}$ & $\begin{array}{l}4 \\
6 \\
\end{array}$ & $\begin{array}{l}-0.20 \\
-0.20 \\
\end{array}$ & $\begin{array}{l}0.12 \\
0.40 \\
\end{array}$ & $\begin{array}{l}0.41 \\
0.56 \\
\end{array}$ & $\begin{array}{l}0.95 \\
0.95 \\
\end{array}$ & 0.09 & 0.33 & $\begin{array}{l}N<T<E<R \\
N<T<E<R\end{array}$ & $\mathrm{D}<\mathrm{T}$ & $Q<E$ & $N<D<Q$ \\
\hline $\begin{array}{l}\text { Smoking behaviour } \\
\text { father }\end{array}$ & $\begin{array}{l}4 \\
6 \\
\end{array}$ & $\begin{array}{l}-0.09 \\
-0.09 \\
\end{array}$ & $\begin{array}{l}0.10 \\
0.05\end{array}$ & $\begin{array}{l}0.15 \\
0.19 \\
\end{array}$ & $\begin{array}{l}0.34 \\
0.34\end{array}$ & 0.10 & 0.20 & $\begin{array}{l}N<T, E<R \\
N<T, E<R\end{array}$ & $\mathrm{D}=\mathrm{T}$ & $Q=E$ & $N<D, Q$ \\
\hline $\begin{array}{l}\text { Smoking behaviour } \\
\text { mother }\end{array}$ & $\begin{array}{l}4 \\
6 \\
\end{array}$ & $\begin{array}{l}-0.11 \\
-0.11 \\
\end{array}$ & $\begin{array}{l}0.12 \\
0.09\end{array}$ & $\begin{array}{l}0.19 \\
0.19 \\
\end{array}$ & $\begin{array}{l}0.46 \\
0.46\end{array}$ & 0.13 & 0.24 & $\begin{array}{l}N<T, E<R \\
N<T, E<R\end{array}$ & $\mathrm{D}=\mathrm{T}$ & $Q=E$ & $N<D, Q$ \\
\hline $\begin{array}{l}\text { Smoking behaviour best } \\
\text { friend }\end{array}$ & $\begin{array}{l}4 \\
6 \\
\end{array}$ & $\begin{array}{l}-0.24 \\
-0.24 \\
\end{array}$ & $\begin{array}{l}0.01 \\
0.22\end{array}$ & $\begin{array}{l}0.42 \\
0.58\end{array}$ & $\begin{array}{l}1.75 \\
1.75 \\
\end{array}$ & 0.00 & 0.43 & $\begin{array}{l}N<T<E<R \\
N<T<E<R\end{array}$ & $\mathrm{D}<\mathrm{T}$ & $Q=E$ & $N<D<Q$ \\
\hline Self-efficacy emotions & $\begin{array}{l}4 \\
6 \\
\end{array}$ & $\begin{array}{l}0.25 \\
0.25 \\
\end{array}$ & $\begin{array}{r}-0.04 \\
-0.31 \\
\end{array}$ & $\begin{array}{l}-0.43 \\
-0.61 \\
\end{array}$ & $\begin{array}{l}-1.62 \\
-1.62 \\
\end{array}$ & -0.03 & -0.32 & $\begin{array}{l}N>T>E>R \\
N>T>E>R\end{array}$ & $\mathrm{D}>\mathrm{T}$ & $Q>E$ & $N>D>Q$ \\
\hline Self-efficacy friends & $\begin{array}{l}4 \\
6\end{array}$ & $\begin{array}{l}0.30 \\
0.30\end{array}$ & $\begin{array}{l}-0.10 \\
-0.48\end{array}$ & $\begin{array}{l}-0.58 \\
-0.83\end{array}$ & $\begin{array}{l}-1.66 \\
-1.66 \\
\end{array}$ & -0.06 & -0.43 & $\begin{array}{l}N>T>E>R \\
N>T>E>R\end{array}$ & $D>T$ & $Q>E$ & $N>D>Q$ \\
\hline Self-efficacy opportunity & $\begin{array}{l}4 \\
6 \\
\end{array}$ & $\begin{array}{l}0.17 \\
0.17 \\
\end{array}$ & $\begin{array}{l}-0.02 \\
-0.18\end{array}$ & $\begin{array}{l}-0.25 \\
-0.38 \\
\end{array}$ & $\begin{array}{l}-1.14 \\
-1.14 \\
\end{array}$ & 0.00 & -0.17 & $\begin{array}{l}N>T>E>R \\
N>T>E>R\end{array}$ & $\mathrm{D}>\mathrm{T}$ & $Q>E$ & $N>D>Q$ \\
\hline $\begin{array}{l}\text { Intention to smoke } \\
\text { within a year }\end{array}$ & $\begin{array}{l}4 \\
6 \\
\end{array}$ & \begin{tabular}{|l|}
-0.36 \\
-0.36 \\
\end{tabular} & $\begin{array}{l}0.08 \\
0.64 \\
\end{array}$ & $\begin{array}{l}0.78 \\
1.11 \\
\end{array}$ & $\begin{array}{l}2.01 \\
2.01 \\
\end{array}$ & 0.04 & 0.54 & $\begin{array}{l}N<T<E<R \\
N<T<E<R\end{array}$ & $\mathrm{D}<\mathrm{T}$ & $Q<E$ & $N<D<Q$ \\
\hline
\end{tabular}

Note. Standardised scores are corrected for gender, age, country, ethnicity and religion. Level of significance for the contrasts was set at $p<.01$. $\mathrm{N}=$ Never Smoker, $\mathrm{T}=$ Trier, $\mathrm{E}=$ Experimenter, $\mathrm{R}=$ Regular Smoker, $\mathrm{D}=$ Nonsmoking Decider, $\mathrm{Q}=\mathrm{Quitter}$. 
The contrasts show that the separate categories within the four-stage model differed significantly $(p<.01)$ for almost every psychosocial characteristic tested in the present study. This pattern of consistently differing categories was not found for the concepts of smoking behaviour of the father, and smoking behaviour of the mother. In these cases, the score for triers was not significantly different from that for experimenters.

Considering Hypothesis 1 with regard to the six-stage model, the categories of never smokers, triers, experimenters, and regular smokers differed from each other in 10 of the 13 psychosocial determinants tested, with scores of never smokers indicating the lowest level of risk of future smoking and those of regular smokers indicating the greatest risk, and with scores of experimenters indicating greater risk than those of triers. With respect to the concepts of social norm of parents and teachers, and smoking behaviour of the father and mother, the score for triers was not significantly different from that for experimenters.

With regard to Hypothesis 2, the contrasts between nonsmoking deciders and triers were studied. The scores of nonsmoking deciders were found to indicate less risk of future smoking than those of triers on each psychosocial concept tested, except for the concepts of pressure from family and teachers, smoking behaviour of the father, and smoking behaviour of the mother.

Hypothesis 3 concerned the comparison of the z-scores of quitters with those of experimenters. Scores of quitters were found to indicate significantly less risk than those of experimenters on 6 of the 13 psychosocial characteristics tested. These characteristics were cons of smoking, social norm of peers and siblings, the three scales within the concept of self-efficacy, and intention. The scores of the quitters on 5 other psychosocial determinants also indicated less risk than those of experimenters, but the differences were not significant at the level of $p<.01$. Quitters scored more risky than experimenters on smoking behaviour of the father and smoking behaviour of the mother, but the differences were not significant.

With regard to hypothesis 4 , the scores of never smokers on every determinant tested were found to indicate significantly less risk of future smoking than those of nonsmoking deciders. Scores of nonsmoking deciders indicated lower levels of risk than those of quitters on every concept tested, except for smoking behaviour of the father and smoking behaviour of the mother.

Finally, the scores on the psychosocial variables of those groups of adolescents that remained in the categories of triers and experimenters in the six-stage model were found to indicate greater risk than those of the groups of triers and experimenters in the four-stage model. This pattern was found for every concept in the group of triers, except for the smoking behaviour of the father and the smoking behaviour of the mother. In the group of experimenters, only the concept of smoking behaviour of the mother did not show a shift towards a more risky score when the nonsmoking deciders and quitters were added to the four-stage model. In this case, the z-score of the sixstage model was identical to that of the four-stage model. 


\section{DISCUSSION}

The main research question of the present study was to examine whether nonsmoking deciders and quitters should be viewed as distinct categories within the initiation continuum. The results show that the scores of nonsmoking deciders on psychosocial predictors of smoking indicated that they were less at risk to smoke in the future than triers and experimenters, and more at risk than never smokers. The results for the category of quitters were less clear. Scores of quitters seemed to indicate that they were less at risk to smoke in the future than experimenters and more at risk than nonsmoking deciders, although the results were not consistent over all psychosocial concepts tested. Additionally, the present study supports the usefulness of distinguishing different behavioural categories of adolescent smoking behaviour.

Flay's smoking initiation continuum (Flay et al., 1983) is used as a framework in a review of predictors of transition through the stages of adolescent smoking (Mayhew et al., 2000). The review presents an adapted model, in which the category of never smoking was re-labelled as 'nonsmoking', while the trying category was re-labelled as 'tried'. Consequently, quitters were classified together with never smokers in the 'nonsmoking' stage, and adolescents who had 'tried but quit' (i.e., nonsmoking deciders) were classified together with current triers in the 'tried' stage. The present study has indicated that defining adolescent smoking stages without distinguishing different stages of current nonsmoking will result in heterogeneous groups with regard to psychosocial characteristics, and thus cannot lead to reliable conclusions on predictors of transitions.

A considerable number of respondents in our sample viewed themselves as being in a stage of deciding not to be a smoker. One-fifth of our sample had made the decision not to smoke after having tried smoking, but before starting to smoke on a regular basis. Whereas the four-stage model might suggest that this large group is progressing towards regular smoking behaviour, the nonsmoking deciders have actually decided not to start smoking regularly. The adoption of nonsmoking deciders as a separate category enables one to gain more detailed insight into the decisions to start smoking among the population under study. Moreover, viewing nonsmoking deciders as a separate category within the initiation continuum might lead to a better understanding of why some adolescents advance beyond experimenting and others do not.

One out of every fifty respondents reported to have quit regular smoking. This group presumably becomes larger as adolescents grow older. It is conceivable that results with regard to psychosocial characteristics of this group may become more consistent as the group size increases. Future studies should thus focus on the differential characteristics of quitters. In this respect, the level of nicotine dependency might be an important concept (Shadel, Shiffman, Niaura, Nichter \& Abrams, 2000). Nicotine dependency might also be an important concept when advanced stages of regular smoking (e.g., daily smoking, or amount of cigarettes per day) are considered. The present study focussed on the early stages of the initiation continuum including weekly smoking, which is generally viewed as a primary measure of regular use (Flay, 1993; (USDHHS, 1994; Sussman et al., 1995). 
The method used in the present study, i.e., examining differences on standardised scores of psychosocial concepts, is similar to the methodology that is commonly used in order to distinguish the several 'stages of change' within the Transtheoretical Model (e.g., De Vries \& Backbier, 1994; De Vries \& Mudde, 1998; Dijkstra et al., 1996; Kremers et al., 2001a; Pallonen et al., 1998; Velicer et al., 1999; Velicer, Rossi, Prochaska \& DiClemente, 1996). The advantage of this procedure is that scores of the several concepts are easily compared.

Whereas Flay and colleagues (1998) used self-reported information on lifetime smoking and smoking behaviour in the past week to define stages of smoking behaviour, we used a self-perceptive item which was cross-validated by four items on current and lifetime smoking. This procedure of classifying respondents into categories of smoking behaviour is believed to be more reliable than using information of the past week's smoking behaviour, considering the intermittent and irregular nature of adolescent smoking behaviour (Lloyd, Lucas, Holland, McGrellis \& Amold, 1998). Measures like 'any time in the last 7 days' are not strictly measures of weekly smoking, though they have often been used as such (Mayhew et al., 2000). To date, no acceptable measure of the smoking uptake process exists (Choi et al., 1997). However, a valid and reliable measure of smoking stages is of paramount importance to the future of adolescent smoking research if we want empirical findings to reliably inform theory development (Mayhew et al., 2000; USDHHS, 2000). Our theory-driven assessment of adolescent smoking behaviour might be a useful instrument in order to study the adolescent smoking initiation continuum. However, longitudinal research within several cultures is needed to examine the predictive validity, cross-cultural validity and test-retest reliability of the six-stage model.

The cross-sectional design of the present study implies that no conclusions can be drawn about the predictive value of the various categories. However, crosssectional studies can be useful in generating hypotheses (Conrad et al., 1992). The present study has generated several possible hypotheses for future studies on adolescent smoking, smoking prevention efforts, and the evaluation of prevention programs. One topic that could be studied is the transition to regular smoking, based on five possible preceding stages: never smoking, trying, experimenting, nonsmoking deciding and quitting. The hypothesis would be that each category will have different rates and predictors of transition. Furthermore, smoking prevention activities could take the groups of current nonsmokers into account. If the target group is segmented into more homogenous groups with regard to relevant cognitive characteristics, the effects of prevention programs tailored to specific groups may improve (De Vries \& Brug, 1999). Results of the present study lead to the hypothesis that nonsmoking deciders do not need information on the pros and cons of smoking, or on self-efficacy. Instead, the information for this group should include reinforcement of their current beliefs. Triers and experimenters on the other hand, do need information on the cons of smoking, as well as self-efficacy enhancing information. Finally, adopting a model of smoking initiation that includes nonsmoking deciders and quitters may lead to an improved outcome measure of prevention studies. For instance, the category of nonsmoking deciders enables evaluation of prevention programs in terms of the promotion of nonsmoking decisions. 


\section{Chapter 5}

\section{Operationalising Flay's stage model of adolescent smoking initiation: A longitudinal test}

\section{ABSTRACT}

Although the stage model by Flay et al. is viewed as the leading model on the process of adolescent smoking initiation, a dearth of longitudinal research on the model has been observed. The present study is the first to operationalise the model including two stages of nonpersistent smoking behaviour that were previously unlabelled. An instrument was developed that distinguished six distinct stages of smoking initiation (i.e., never smoker, trier, experimenter, regular smoker, nonsmoking decider, and quitter). The results indicated the applicability of the instrument in a large crosscultural population of early European adolescents $(n=7899)$. Stage transitions had taken place in the expected sequence and progression to daily smoking at 12 months follow-up was successfully predicted. The theory-driven assessment of the process of adolescent smoking initiation may contribute to the development of a generally accepted model of smoking initiation.

Submitted for publication as:

Kremers S. P. J., Mudde, A. N., \& De Vries, H. Operationalizing Flay's stage model of adolescent smoking initiation: A longitudinal test. 


\section{INTRODUCTION}

Observations of smoking behaviour in the late 1960s and early 1970s (e.g., Dunn, 1973; Salber et al., 1968) have led to the construction of a stage model of adolescent smoking initiation in the early 1980s (Flay et al., 1983; Hirschman et al., 1984; Leventhal \& Cleary, 1980). The basic stages of smoking initiation were suggested by Leventhal and Cleary (1980) and elaborated by Flay et al. (1983). In Flay's stage model, the never smoked (preparatory) stage, the trial stage, the experimental stage and the regular smoking stage take an individual to the stage of nicotine dependence and addiction. Adolescents in the preparatory stage have never smoked even one puff. The second stage involves initial trying. Following the use of the first few cigarettes an adolescent advances to the experimental stage, which involves repeated, but irregular use. Regular smoking involves smoking on a regular, at least weekly, basis. The final stage, nicotine dependence and addiction, is characterised by a physiological craving for nicotine (Flay, 1993; Flay et al., 1983; 1998; USDHHS, 1994).

The stage model should be interpreted as stochastic, in that the probability of advancing from one stage to another is always less than one (Flay, 1993). Indeed, research by Chassin et al. (Chassin et al., 1990; 1991; 2000) on the natural history of cigarette smoking from adolescence to adulthood has shown that a group of adolescent 'nonpersistent smokers' can be distinguished. Adolescents in this stage of the initiation process have decided to be nonsmokers after having tried or experimented with smoking. For these adolescents, smoking may represent only a period of adolescent rebellion, rather than a persistent smoking behaviour (Chassin et al., 1991; 2000). In addition, the subject of adolescent smoking cessation has been receiving more and more scientific interest (Houston et al., 1998; Sussman, Dent, Severson, Burton \& Flay, 1998). Since quitting becomes more difficult as adolescents progress through the continuum (CDC, 1998), smoking cessation after having smoked regularly may be viewed as a separate stage within the model of initiation.

Measurement strategies in adolescent smoking research have rarely been developed on the basis of theory on the smoking initiation continuum. Instead, measurement strategies have often driven stage definitions (Mayhew et al., 2000). For example, triers have been defined as those adolescents 'having tried smoking only once' (Murray et al., 1983), or smoking 'no more than once per month' (Rowe et al., 1996). Experimenters have been defined as those smoking 'less than weekly' (Santi et al., 1994), or those having smoked 'one to one-hundred cigarettes in lifetime but not in the last 30 days' (Wang et al., 1997). Often, existing data-sets are used. Based on the available data, stages of initiation are defined. However, a valid and reliable operationalisation of stages is paramount to the future of adolescent smoking research (Mayhew et al., 2000). Only then can empirical findings inform theory development and guide the development of prevention efforts (Mayhew et al., 2000). As a result of a dearth of research into the developmental stages of smoking initiation (Werch \& Anzalone, 1995), no acceptable measure of the smoking uptake process currently exists (Choi et al., 1997). Although the stage model by Flay et al. has face validity (Robinson et al., 1997) and has been accepted as the leading theory on the process of smoking initiation by the Surgeon General (USDHHS, 1994), the model has never 
been tested as such in longitudinal research. One longitudinal study (Flay et al., 1998) has used the stage model to assess determinants of stage transitions.

One reason for the lack of empirical tests of the model by Flay et al. may be that stage definitions are sometimes unclear, contradictory and unfalsifiable. For instance, the trying stage has been defined as trying the first 'few' cigarettes (e.g., Mayhew et al., 2000, p. S63; USDHHS, 1994, p. 126), but also as the first two or three cigarettes (e.g., Flay, 1993), though it has been operationalised as having smoked 'all or part of one cigarette' (Flay et al., 1998). Based on the theory by Flay et al., we developed a measuring instrument that focuses on the stages of adolescent smoking initiation towards regular smoking behaviour. Following current scientific knowledge and accepted standards with respect to the natural process of smoking initiation, stage definitions were operationalised (Figure 5.1).

Figure 5.1. Model of adolescent smoking initiation

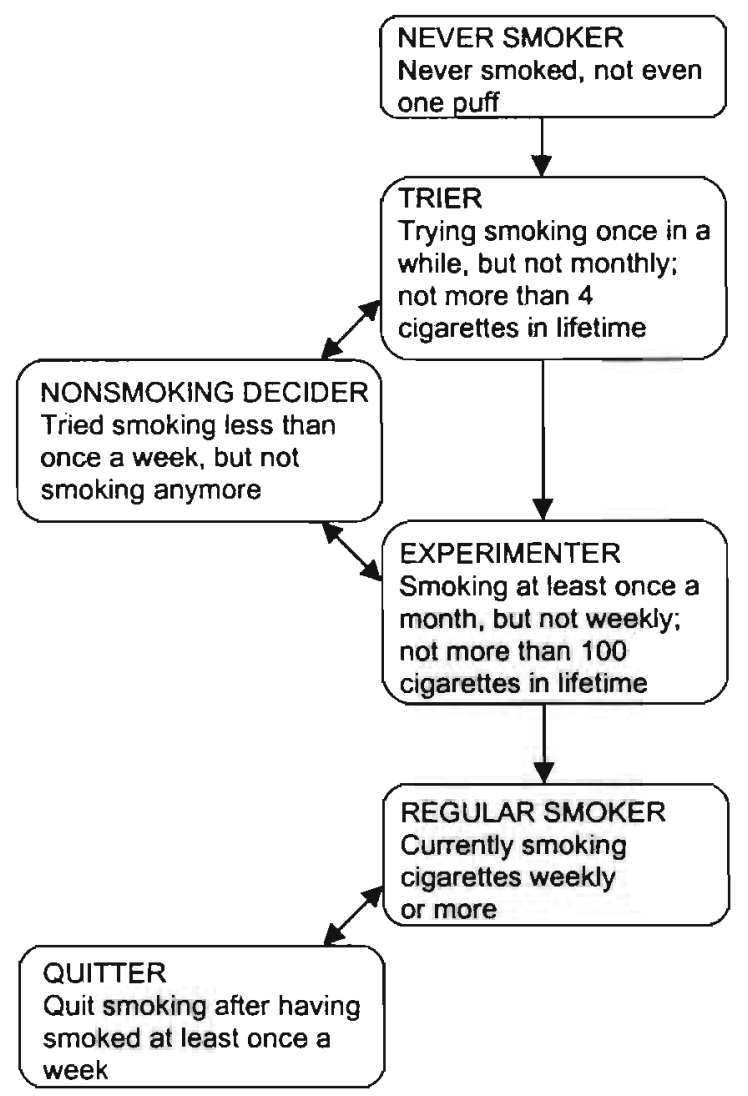


In contrast to the algorithm used by Flay et al. (1998), this instrument identifies two additional categories of current nonsmokers: nonsmoking deciders (i.e., nonpersistent triers and experimenters) and quitters (i.e., ex-regular smokers) (see also Kremers, Mudde \& De Vries, in press). Stage definitions incorporate a dimension of frequency of smoking, and a dimension of the quantity of cigarettes smoked (see also Chassin et al., 2000). Since weekly smoking is generally viewed as a measure of regular smoking behaviour (Robinson et al., 1997; Sussman et al., 1995; USDHHS, 1994), and monthly smoking is an accepted measure to distinguish between levels of early initiation (Eckhardt, Woodruff \& Elder, 1994; Rowe et al., 1996; Wang, Fitzhugh, Eddy \& Westerfield, 1996) these definitions of frequency have been applied in the model. Early research on the process of smoking initiation identified the salience of smoking the first four cigarettes (Salber et al., 1968). A study on the addiction to nicotine suggested that over $90 \%$ of individuals who smoke four cigarettes go on to use them regularly (Russell, 1990). The number of four cigarettes was used in our stage definition to distinguish between initial trying and further experimentation. Following the definition of regular/established smoking as having smoked 100 cigarettes or more (Mayhew et al., 2000; WHO, 1998), we limited the experimental stage to smoking the first 100 cigarettes in a lifetime. Note that the model concentrates on the process that leads to the initiation of regular smoking behaviour. The final stage, nicotine dependence and addiction, is not defined in this model.

Kremers, Mudde and De Vries (2001c) have shown that the six categories within the initiation continuum differed with regard to their cognitive characteristics. This finding provided preliminary evidence of the validity of the instrument. However, finding significant differences between people in different stages cannot conclusively be interpreted as support for the model (Sutton, 2000). After cross-sectional comparisons of cognitive characteristics, a second step in the testing of a stage model may incorporate a longitudinal examination of the stage sequences (Weinstein et al., 1998). The most informative component of examining stage sequences is a test of the predictive validity of the stages. That is, stage assignment at one point in time should be predictive of behaviour measured at a later point in time (De Vries \& Mudde, 1998; Dijkstra et al., 1998; Pierce et al., 1996).

The main goal of the present study was to longitudinally test our operationalisation of Flay's stage model of adolescent smoking initiation (Flay, 1993; Flay et al., 1983; USDHHS, 1994). First, the development and use of our measuring instrument are described. Then, we examined the applicability of the measure for groups with various demographic characteristics within our sample, and we focused on transitions within the model in order to examine stage sequences. Finally, we tested the ability of the stage model to predict progress to daily smoking behaviour during a 12 months follow-up period. Since our model focuses on the early stages of initiation (i.e., stages leading up to regular, at least weekly, smoking behaviour) the model should ideally be tested for its ability to predict established, daily, smoking behaviour. It was hypothesised that the four stages of increasing smoking behaviour at baseline (i.e., never smoked, trying, experimenting and regular smoking) would be clearly distinguishable in terms of the likelihood of daily smoking at follow-up, with never smokers to be least likely and regular smokers to be most likely to smoke daily at follow-up (hypothesis 1). A similar pattern was hypothesised for the three groups of 
nonsmokers at baseline (i.e., never smokers, nonsmoking deciders and quitters), with never smokers expected to be least likely and quitters expected to be most likely to smoke daily at follow-up (hypothesis 2). Two further hypotheses compared the categories of ex-smokers with the immediately preceding stages of smoking behaviour. We expected triers and experimenters to be more likely to smoke daily at follow-up than nonsmoking deciders (hypothesis 3). Parallel to this hypothesis, we expected regular smokers at baseline to be more likely to be smoking daily at followup than quitters (hypothesis 4).

\section{METHOD}

\section{Participants}

For the present study, data was gathered longitudinally in an international sample of 10,132 adolescents. The sample consisted of the control group of a larger, ongoing prospective study of the ESFA project (European Smoking prevention Framework Approach; De Vries et al., submitted). Six member states of the European Union (Finland, Denmark, the United Kingdom, the Netherlands, Spain, and Portugal) participate in this project. Data were collected at schools, using self-administered questionnaires.

Of the sample, $9.1 \%$ lived in Denmark, $15.1 \%$ in Finland, $23.7 \%$ in the Netherlands, $14.3 \%$ in Portugal, $9.1 \%$ in Spain, and $28.7 \%$ in the United kingdom. The mean age of the respondents was 13.3 years at baseline (SD -0.7 ), and $50.5 \%$ were males.

\section{Attrition analyses}

A logistic regression analysis was conducted to compare participating subjects with dropouts (i.e., those not participating in the second measurement) using data of the first measurement as predictors of drop-out. Independent variables were gender, age, country, and regular smoking behaviour. The indicators for regular smoking behaviour are described in the Measures section.

Dropouts $(\mathrm{n}=2233 ; 22 \%)$ were found to be older $(\mathrm{OR}=1.32,95 \% \mathrm{CI}=1.24$ 1.41 ), less often from Finland ( $\mathrm{OR}=0.32,95 \% \mathrm{CI}=0.27-0.38$ ), the Netherlands (OR $=0.23,95 \% \mathrm{CI}=0.20-0.27)$ or Spain $(\mathrm{OR}=0.62,95 \% \mathrm{CI}=0.53-0.73)$ than from the United Kingdom, and more often smoking regularly ( $\mathrm{OR}=1.66,95 \% \mathrm{Cl}=1.39-1.99)$. No differences were found for gender.

\section{Translation and pretesting}

The questionnaire used in the present study was translated into all six languages by native speaking experts on the subject of adolescent smoking behaviour. In each language, the questionnaire was pretested in a representative sample of adolescents, using qualitative research methods (Vroom, 1994). Close collaboration between the various sites within the ESFA project optimised the internal validity of the questionnaire. 


\section{Stages of smoking initiation}

The algorithm to categorise smoking behaviour was based on 5 items. Assignment of the adolescents to the various stages of smoking initiation was based on a selfdescriptive item and a question on lifetime smoking behaviour. Responses were crossvalidated using an algorithm consisting of four items. This section provides details on the self-descriptive and lifetime smoking items. For more information on the algorithm, see Kremers, Mudde \& De Vries (2001b).

The self-descriptive item was phrased: 'Which of the following statements best describes you? (tick only one answer).' The answering categories were based on statements regarding frequency of smoking behaviour, following the model of smoking initiation depicted in Figure 5.1. 'I have never smoked, not even one puff' resulted in categorisation as a never smoker. 'I try smoking once in a while' and 'I smoke less than once a month' resulted in categorisation as a trier. 'I do not smoke weekly, but at least once a month' resulted in categorisation as an experimenter. 'I do not smoke daily, but at least once a week' and 'I smoke at least once a day' resulted in categorisation as a regular smoker. Further, "I have tried smoking once in a while, but I don't smoke anymore' and 'I have quit smoking, I have always smoked less than once a week' resulted in categorisation as a nonsmoking decider. 'I have quit smoking after having smoked at least once a week' resulted in categorisation as a quitter.

Combining of the self-descriptive item with lifetime smoking behaviour resulted in a categorisation into 6 stages. The lifetime smoking question was phrased as follows: 'When you add up all the cigarettes that you have ever smoked during your life, how many have you smoked?". The answering categories ranged from ' 0 ', through 'between 0 and 1', '1-4', '5-24', '25-49', '50-99', '100-149', and '150-199', to ' 200 or more'. A pretest of an earlier version of this item showed that adolescents who had only smoked one or two puffs were not inclined to answer ' $1-4$ '. Therefore, the option of 'between 0 and 1' was added. Furthermore, we decided to gradually increase the answering categories and not to use the option ' 100 or more' as the final answering category. The amounts of 4 and 100 cigarettes were used as cut-off points.

\section{Missing data and inconsistencies}

Smoking initiation stage at baseline was unknown in 53 cases, and data on an additional 68 cases were missing at follow-up. Consequently, a total of 121 cases (1.5\%) were excluded from the analyses of transitions. Further, a longitudinal validation of the smoking behaviour identified 435 cases $(5.6 \%)$ that reported incongruent smoking behaviour at follow-up compared to the baseline measurement. These cases were reclassified to the most 'progressed' smoking behaviour category. For example, 26 adolescents who were regular smokers at baseline claimed to be experimenters at follow-up. These adolescents were reclassified as regular smokers. More than $50 \%$ of the incongruent respondents $(n=219)$ were nonsmoking deciders at baseline who claimed to be never smokers at follow-up. These respondents were reclassified as nonsmoking deciders at follow-up. 


\section{Demographics}

Demographics included in the study were country, gender, age, religion and ethnicity. Two Northern European countries (Finland and Denmark), two Western European countries (The Netherlands and the United Kingdom) and two Southern European countries (Portugal and Spain) participated in this study. We also asked respondents for their religious background. Classification used the following categories: 'no religion', 'Christian', 'Islam' and 'other religion'. Ethnicity was classified as either native or immigrant.

\section{Daily smoking}

Since we wanted to examine the validity of our operationalisation of the stage model, we treated the measure of daily smoking independently from the measuring instrument of the uptake process. Daily smoking was defined as smoking an average of one cigarette or more per day. This means that adolescents who were classified as daily smokers should have smoked at least 7 cigarettes during an average week. The item was formulated as follows: 'On average, how many cigarettes do you smoke during a week?' Answering categories were arranged on a continuous scale.

\section{Statistical analysis}

Logistical regression was used to identify the predictive value of each stage with regard to daily smoking at the 12 months follow-up. Daily smokers at baseline were removed from the analysis, based on the independent measure of daily smoking. Missing demographic data were recoded into the modus. All variables were entered into the regression model. The probability of smoking daily at follow-up was compared between each baseline stage and the baseline stage that was hypothesised to carry a lower risk of smoking daily at follow-up. The stage with the lowest hypothesised probability of smoking daily at follow-up was used as a reference category (OR set at 1.00), implying that all Odds Ratios were expected to be larger than 1. We also examined two-way interactions between the smoking initiation continuum and each demographic. Inflated type I error because of multiple testing was controlled for by applying a Bonferroni correction to the interaction analyses (Tabashnick \& Fidell, 1996).

\section{RESULTS}

\section{Prevalence rates by demographics}

Table 5.1 shows the prevalence rates of the various stages within each demographic factor assessed in the present study. An overall pattern was observed in that the proportion of adolescents in the stage of never smokers decreased, whereas the proportion of adolescents in progressed stages of the initiation continuum (i.e., regular smoking and quitting) increased. This pattern appeared to be true for each country, gender, age-group, religion and origin, indicating initial face validity with regard to the applicability of the instrument in the demographic subpopulations assessed.

Table 5.1 shows that the highest prevalence rates of regular smoking at baseline were found in Finland, followed by Denmark, the United Kingdom, the Netherlands, 
Portugal and Spain. At follow-up, this order of prevalence rates still existed, although there appeared to be a large increase in regular smoking prevalence in Spaln. In each country, prevalence rates of regular smoking behaviour had at least doubled during the follow-up period. The youngest age category smoked least frequently and the oldest age group smoked most frequently. A small difference was detectable between smoking rates among boys and girls at baseline (see also De Vries, Wetzels, Kremers \& Mudde, submitted). This difference had increased at follow-up; $15.6 \%$ of the girls and $11.8 \%$ of the boys in the sample smoked regularly. It was found, for instance, that boys more frequently decided to be nonsmokers after initial experimentation than girls. Islamic adolescents were found to be nonsmoking deciders more often than adolescents in the other religious categories. Native adolescents were more often found to be trying and experimenting than immigrants, while immigrants were more often found to have quit experimental and regular smoking than natives.

Table 5.1. Prevalence rates by demographics at baseline (T1) and 12 months follow-up (T2) ( $n=7899)$

\begin{tabular}{|c|c|c|c|c|c|c|c|c|c|c|c|c|}
\hline & \multicolumn{2}{|c|}{$\begin{array}{l}\text { Never } \\
\text { smoker }\end{array}$} & \multicolumn{2}{|c|}{ Trier } & \multicolumn{2}{|c|}{\begin{tabular}{|l|}
$\begin{array}{l}\text { Experimen- } \\
\text { ter }\end{array}$ \\
\end{tabular}} & \multicolumn{2}{|c|}{\begin{tabular}{|l|} 
Regular \\
smoker
\end{tabular}} & \multicolumn{2}{|c|}{\begin{tabular}{|l|}
$\begin{array}{l}\text { Nonsmoking } \\
\text { decider }\end{array}$ \\
\end{tabular}} & \multicolumn{2}{|c|}{ Quitter } \\
\hline Overall & $\begin{array}{l}T 1 \\
63.3 \\
\end{array}$ & $\begin{array}{l}\mathrm{T} 2 \\
46.6\end{array}$ & $\begin{array}{l}\mathrm{T} 1 \\
3.4\end{array}$ & $\begin{array}{l}\mathrm{T} 2 \\
2.9\end{array}$ & \begin{tabular}{|l|} 
T1 \\
5.4 \\
\end{tabular} & $\begin{array}{l}\mathrm{T} 2 \\
6.8 \\
\end{array}$ & \begin{tabular}{|l|}
$\mathrm{T} 1$ \\
5.2 \\
\end{tabular} & $\begin{array}{l}\mathrm{T} 2 \\
13.7 \\
\end{array}$ & \begin{tabular}{|l|}
$T 1$ \\
20.9 \\
\end{tabular} & $\begin{array}{l}\mathrm{T} 2 \\
26.2 \\
\end{array}$ & $\begin{array}{l}\mathrm{T} 1 \\
1.9 \\
\end{array}$ & $\begin{array}{l}\mathrm{T} 2 \\
3.8 \\
\end{array}$ \\
\hline $\begin{array}{l}\text { Country } \\
\text { Denmark } \\
(n=633)\end{array}$ & 54.5 & 38.5 & 4.0 & 3.1 & 8.6 & 10.7 & 6.8 & 16.9 & 24.9 & 28.0 & 1.3 & 2.8 \\
\hline $\begin{array}{l}\text { Finland } \\
(n=1347)\end{array}$ & 63.2 & 44.2 & 5.1 & 4.4 & 7.8 & 8.5 & 9.7 & 22.8 & 12.0 & 13.8 & 2.2 & 6.3 \\
\hline $\begin{array}{l}\text { The Netheriands } \\
(n=2145)\end{array}$ & 61.4 & 48.0 & 3.7 & 2.2 & 4.3 & 6.1 & 3.9 & 11.1 & 24.9 & 29.1 & 1.8 & 3.4 \\
\hline $\begin{array}{l}\text { Portugal } \\
(n=1018)\end{array}$ & 76.4 & 57.7 & 1.3 & 3.1 & 3.1 & 4.6 & 2.9 & 6.6 & 15.1 & 25.7 & 1.2 & 2.4 \\
\hline $\begin{array}{l}\text { Spain } \\
(n=730)\end{array}$ & 65.4 & 43.7 & 3.3 & 1.6 & 5.9 & 7.4 & 1.8 & 11.0 & 22.5 & 34.9 & 1.1 & 1.4 \\
\hline $\begin{array}{l}\text { United Kingdom } \\
(n=2026)\end{array}$ & 63.3 & 44.6 & 2.7 & 2.8 & 4.8 & 6.3 & 5.5 & 13.8 & 23.5 & 28.1 & 2.6 & 4.4 \\
\hline $\begin{array}{l}\text { Gender } \\
\text { Boy }(n=3970) \\
\text { Girl }(n=3929)\end{array}$ & $\begin{array}{l}62.9 \\
63.7 \\
\end{array}$ & $\begin{array}{l}47.8 \\
45.4 \\
\end{array}$ & $\begin{array}{l}3.4 \\
3.3 \\
\end{array}$ & $\begin{array}{l}2.2 \\
3.6 \\
\end{array}$ & $\begin{array}{l}5.6 \\
5.1\end{array}$ & $\begin{array}{l}6.3 \\
7.4\end{array}$ & $\begin{array}{l}4.8 \\
5.7 \\
\end{array}$ & $\begin{array}{l}11.8 \\
15.6 \\
\end{array}$ & $\begin{array}{l}21.5 \\
20.2 \\
\end{array}$ & $\begin{array}{l}28.3 \\
24.1\end{array}$ & $\begin{array}{l}1.8 \\
2.0 \\
\end{array}$ & $\begin{array}{l}3.6 \\
3.9\end{array}$ \\
\hline $\begin{array}{l}\text { Age } \\
<13 \text { years }(n=4052) \\
13 \text { years }(n=3449) \\
>13 \text { years }(n=398)\end{array}$ & $\begin{array}{l}67.7 \\
59.4 \\
52.3 \\
\end{array}$ & $\begin{array}{l}51.2 \\
42.3 \\
37.3 \\
\end{array}$ & $\begin{array}{l}2.9 \\
3.9 \\
3.1 \\
\end{array}$ & $\begin{array}{l}2.5 \\
3.4 \\
2.3\end{array}$ & $\begin{array}{l}4.4 \\
6.4 \\
6.2 \\
\end{array}$ & $\begin{array}{l}6.3 \\
7.5 \\
6.5\end{array}$ & \begin{tabular}{|l|}
2.7 \\
7.3 \\
13.1 \\
\end{tabular} & $\begin{array}{l}9.5 \\
17.8 \\
20.4\end{array}$ & $\begin{array}{l}20.9 \\
20.7 \\
21.6 \\
\end{array}$ & $\begin{array}{l}27.6 \\
24.4 \\
27.5\end{array}$ & $\begin{array}{l}1.4 \\
2.2 \\
3.6 \\
\end{array}$ & $\begin{array}{l}2.8 \\
4.6 \\
6.0\end{array}$ \\
\hline $\begin{array}{l}\text { Roligion } \\
\text { Christian }(n=5271) \\
\text { Islam }(n=186) \\
\text { Other }(n=191) \\
\text { No religion }(n=2251)\end{array}$ & $\begin{array}{l}65.7 \\
51.6 \\
62.3 \\
58.8 \\
\end{array}$ & $\begin{array}{l}48.3 \\
36.8 \\
44.1 \\
43.7 \\
\end{array}$ & $\begin{array}{l}3.3 \\
2.2 \\
3.2 \\
3.6 \\
\end{array}$ & $\begin{array}{l}3.1 \\
1.6 \\
3.2 \\
2.4 \\
\end{array}$ & $\begin{array}{l}5.4 \\
4.3 \\
4.2 \\
5.5 \\
\end{array}$ & $\begin{array}{l}6.9 \\
5.4 \\
4.8 \\
7.1 \\
\end{array}$ & $\begin{array}{l}5.5 \\
2.2 \\
6.8 \\
4.8 \\
\end{array}$ & $\begin{array}{l}13.7 \\
13.0 \\
12.4 \\
13.8 \\
\end{array}$ & \begin{tabular}{|l|}
18.3 \\
37.6 \\
20.0 \\
25.4 \\
\end{tabular} & $\begin{array}{l}24.4 \\
40.0 \\
30.1 \\
29.1 \\
\end{array}$ & \begin{tabular}{|l}
1.8 \\
2.2 \\
2.6 \\
2.0 \\
\end{tabular} & $\begin{array}{l}3.7 \\
3.2 \\
5.4 \\
3.9 \\
\end{array}$ \\
\hline $\begin{array}{l}\text { Ethnicity } \\
\text { Native }(n=7167) \\
\text { Immigrant }(n=732)\end{array}$ & $\begin{array}{l}63.6 \\
60.0\end{array}$ & $\begin{array}{l}46.9 \\
44.1 \\
\end{array}$ & $\begin{array}{l}3.5 \\
2.5\end{array}$ & $\begin{array}{l}2.9 \\
2.5 \\
\end{array}$ & $\begin{array}{l}5.5 \\
3.6 \\
\end{array}$ & $\begin{array}{l}6.9 \\
5.9 \\
\end{array}$ & $\begin{array}{l}5.2 \\
5.5 \\
\end{array}$ & $\begin{array}{l}13.7 \\
13.3 \\
\end{array}$ & \begin{tabular}{|l|}
20.4 \\
25.7 \\
\end{tabular} & $\begin{array}{l}25.9 \\
29.7\end{array}$ & $\begin{array}{l}1.8 \\
2.8 \\
\end{array}$ & $\begin{array}{l}3.7 \\
4.5 \\
\end{array}$ \\
\hline
\end{tabular}




\section{Transitions in smoking behaviour}

Table 5.2 presents the transitions in smoking behaviour that occurred in the 12 months follow-up period. The overall percentages differ slightly from those in Table 5.1, since only complete cases (i.e., those without missing data on the first and second measurements) were used to construct Table 5.2. All possible cells in this Table proved to be filled, with the transition from never smoker to quitter found to be least likely (only $0.8 \%$ of the respondents made this transition during the 12 months followup period).

More than a quarter of the never smokers at baseline were found to have tried smoking in the 12 months follow-up period. Almost $59 \%$ of the adolescents who had tried their first cigarette in the 12 months follow-up period had decided not to be smokers $(n=768)$ at the time of the second measurement. Less than 4 percent had progressed to the level of regular smoking within the follow-up period.

Almost 62 percent of the nonsmoking deciders at baseline had stuck to their decision at follow- up. Since more than half of the quitters at baseline had relapsed into regular smoking at follow- up, the nonsmoking deciding stage proved to be more stable than the quitting stage. Almost 10 percent of the triers at baseline were still in the trying stage at follow-up. Fifty percent of triers at baseline had decided to be nonsmokers, while $40.2 \%$ had progressed. Almost $21 \%$ were smoking regularly at follow-up. Of the experimenters at baseline, almost one quarter were still experimenting at follow-up. One third had quit experimenting (i.e., were now nonsmoking deciders), while another third were smoking regularly at follow-up. Of the regular smokers at baseline, $18.7 \%$ had quit smoking.

Table 5.2. Transitions from stages at baseline (T1) to 12 months follow-up (T2) $(n=7778)$

\begin{tabular}{|c|c|c|c|c|c|c|c|c|}
\hline $\mathbf{T} 1$ & $\mathrm{T2}$ & $\begin{array}{l}\text { Never } \\
\text { smoker }\end{array}$ & $\begin{array}{l}\text { Nonsmoking } \\
\text { decider }\end{array}$ & Trier & $\begin{array}{l}\text { Experimen- } \\
\text { ter }\end{array}$ & $\begin{array}{l}\text { Regular } \\
\text { smoker }\end{array}$ & Quitter & $\begin{array}{l}\text { Total } \\
\text { T1 }\end{array}$ \\
\hline $\begin{array}{l}\text { Never } \\
\text { smoker }\end{array}$ & $\begin{array}{l}\mathrm{n} \\
\%\end{array}$ & $\begin{array}{l}3628 \\
73.5\end{array}$ & $\begin{array}{l}768 \\
15.6\end{array}$ & $\begin{array}{l}130 \\
2.6\end{array}$ & $\begin{array}{l}190 \\
3.9\end{array}$ & $\begin{array}{l}179 \\
3.6\end{array}$ & $\begin{array}{l}39 \\
0.8\end{array}$ & $\begin{array}{l}4934 \\
63.4\end{array}$ \\
\hline $\begin{array}{l}\text { Nonsmoking } \\
\text { decider }\end{array}$ & $\begin{array}{l}n \\
\%\end{array}$ & & $\begin{array}{l}1002 \\
61.9\end{array}$ & $\begin{array}{l}69 \\
4.3\end{array}$ & $\begin{array}{l}201 \\
12.4\end{array}$ & $\begin{array}{l}276 \\
17.0\end{array}$ & $\begin{array}{l}72 \\
4.4\end{array}$ & $\begin{array}{l}1620 \\
20.8\end{array}$ \\
\hline Trier & $\begin{array}{l}n \\
\%\end{array}$ & & $\begin{array}{l}132 \\
50.0\end{array}$ & $\begin{array}{l}26 \\
9.8\end{array}$ & $\begin{array}{l}44 \\
16.7\end{array}$ & $\begin{array}{l}55 \\
20.8\end{array}$ & $\begin{array}{l}7 \\
2.7\end{array}$ & $\begin{array}{l}264 \\
3.4\end{array}$ \\
\hline $\begin{array}{l}\text { Experimen- } \\
\text { ter }\end{array}$ & $\begin{array}{l}n \\
\%\end{array}$ & & $\begin{array}{l}140 \\
33.9\end{array}$ & & $\begin{array}{l}95 \\
23.0\end{array}$ & $\begin{array}{l}142 \\
34.4\end{array}$ & $\begin{array}{l}36 \\
8.7\end{array}$ & $\begin{array}{l}413 \\
5.3\end{array}$ \\
\hline Quitter & $\begin{array}{l}n \\
\%\end{array}$ & & & & & $\begin{array}{l}83 \\
56.8\end{array}$ & $\begin{array}{l}63 \\
43.2\end{array}$ & $\begin{array}{l}146 \\
1.9\end{array}$ \\
\hline $\begin{array}{l}\text { Regular } \\
\text { smoker }\end{array}$ & $\begin{array}{l}n \\
\%\end{array}$ & & & & & $\begin{array}{l}326 \\
81.3\end{array}$ & $\begin{array}{l}75 \\
18.7\end{array}$ & $\begin{array}{l}401 \\
5.2\end{array}$ \\
\hline Total T2 & $\begin{array}{l}n \\
\%\end{array}$ & $\begin{array}{l}3628 \\
46.6\end{array}$ & $\begin{array}{l}2042 \\
26.3\end{array}$ & $\begin{array}{l}225 \\
2.9\end{array}$ & $\begin{array}{l}530 \\
6.8\end{array}$ & $\begin{array}{l}1061 \\
13.6\end{array}$ & $\begin{array}{l}292 \\
3.8\end{array}$ & 7778 \\
\hline
\end{tabular}

Note. All empty cells are structural zero's, i.e., by defenition, no value but zero is possible. 


\section{Prediction of daily smoking at follow-up}

Daily smokers at baseline $(n=309 ; 3.9 \%)$ were removed from the analysis. Of this removed group, 245 adolescents were classified as regular smokers in the model, 18 were quitters, 24 were experimenters, 2 were triers, 14 were nonsmoking deciders, and 7 were classified as never smokers. Of the remaining sample, 627 adolescents (8.4\%) reported smoking daily at the follow-up measurement. Overall, data on the daily smoking variable were missing in 222 cases $(2.8 \%)$. These cases were removed from the analyses. Table 5.3 present the results of the tests of the four hypotheses with regard to progression to daily smoking at follow-up. The Odds Ratios presented in Table 5.3 were corrected for country, gender, age, religion and ethnicity.

Hypothesis 1 concerned the stages of increasing smoking behaviour (i.e., never smoking, trying, experimenting, regular smoking) that were expected to lead to increased risks of daily smoking at follow-up. Less than three percent of never smokers at baseline had become daily smokers at the 12 months follow-up measurement. Less than nineteen percent of triers at baseline had progressed to daily smoking behaviour at follow-up. The Odds Ratio of smoking daily at follow-up of triers at baseline compared to never smokers at baseline was $6.84(95 \% \mathrm{CI}=4.77$ 9.81). Of the experimenters at baseline, $28.4 \%$ had progressed to levels of daily smoking. Compared to the reference category of triers, their Odds Ratio was almost twice as large $(\mathrm{OR}=1.78 ; 95 \% \mathrm{CI}=1.20-2.63)$. The Odds Ratio of smoking daily at follow-up was more than twice as large when regular smokers at baseline were compared to experimenters at baseline (OR $=2.55 ; 1.71-3.81)$. Almost half of all regular smokers who did not smoke daily at baseline had progressed to levels of daily smoking at follow-up. Since all confidence intervals excluded 1.00, hypothesis 1 was confirmed.

Table 5.3. Odds Ratio of progression to daily smoking in the 12 months follow-up period $(n=7360)$

\begin{tabular}{|c|c|c|c|c|c|c|c|}
\hline & \multirow{2}{*}{$\begin{array}{l}\text { daily } \\
\text { smoking } \\
\text { follow- } \\
\text { up }\end{array}$} & & \multicolumn{5}{|c|}{ Reference stage } \\
\hline & & & \begin{tabular}{|l} 
Never \\
smoking
\end{tabular} & Trying & $\begin{array}{l}\text { Experimen- } \\
\text { ting }\end{array}$ & $\begin{array}{l}\text { Nonsmoking } \\
\text { deciding }\end{array}$ & Quitting \\
\hline $\begin{array}{l}\text { Never } \\
\text { smoklng }\end{array}$ & $2.9 \%$ & & & & & & \\
\hline Trying & $18.6 \%$ & $\begin{array}{l}\text { OR } \\
95 \% \mathrm{Cl}\end{array}$ & $\begin{array}{l}\text { (i) } 6.84 \\
4.77-9.81\end{array}$ & & & $\begin{array}{l}\text { (3) } 1.26 \\
0.89-1.80\end{array}$ & \\
\hline $\begin{array}{l}\text { Experimen- } \\
\text { ting }\end{array}$ & $28.4 \%$ & $\begin{array}{l}\text { OR } \\
95 \% \mathrm{Cl}\end{array}$ & & $\begin{array}{l}\text { (1) } 1.78 \\
1.20-2.63\end{array}$ & & $\begin{array}{l}\text { (3) } 2.37 \\
1.56-3.60\end{array}$ & \\
\hline $\begin{array}{l}\text { Regular } \\
\text { smoking }\end{array}$ & $49.4 \%$ & $\begin{array}{l}\text { OR } \\
95 \% \mathrm{Cl}\end{array}$ & & & $\begin{array}{l}\text { (1) } 2.55 \\
1.71-3.81\end{array}$ & & $\begin{array}{l}\text { (क) } 5.74 \\
4.01-8.22\end{array}$ \\
\hline $\begin{array}{l}\text { Nonsmoking } \\
\text { deciding }\end{array}$ & $13.3 \%$ & $\begin{array}{l}\text { OR } \\
95 \% \mathrm{Cl}\end{array}$ & $\begin{array}{l}(2) 5.41 \\
4.32-6.79\end{array}$ & & & & \\
\hline Quitting & $29.1 \%$ & $\begin{array}{l}\mathrm{CF} \\
95 \% \mathrm{Cl}\end{array}$ & & & & $\begin{array}{l}\text { (2) } 2.25 \\
1.71-2.95\end{array}$ & \\
\hline
\end{tabular}

Note. $\mathrm{OR}=$ Odd́s Ratio, corrected for country, gender, age, ethnicity, and religion; $\mathrm{Cl}=\mathrm{Confidence} \mathrm{Interval;}$

${ }^{(1)}=$ Test of hypothesis $1 ;{ }^{(2)}=$ Test of hypothesis $2 i^{(3)}=$ Test of hypothesis $3 i^{(4)}=$ Test of hypothesis 4 
Hypothesis 2 concerned the three levels of current nonsmoking in the model (i.e., never smoking, nonsmoking deciding, and quitting). Nonsmoking deciders at baseline were expected to be smoking more frequently than never smokers at baseline. Quitters were expected to be most likely to smoke daily of all nonsmokers at baseline. More than $13 \%$ of the nonsmoking deciders at baseline smoked daily at follow-up. Their Odds Ratio compared to never smokers was $5.41(95 \% \mathrm{CI}=4.32-6.79)$. The Odds Ratio of smoking daily at follow-up was more than twice as high for quitters as for nonsmoking deciders $(\mathrm{OR}=2.25 ; 95 \% \mathrm{CI}=1.71-2.95)$. More than one quarter of the quitters at baseline smoked daily at follow-up. This confirmed hypothesis 2 .

Hypothesis 3 stated that more triers and experimenters at baseline were expected to be smoking daily than baseline nonsmoking deciders. Although more triers than nonsmoking deciders were smoking daily at follow-up $(18.6 \%$ vs. $13.3 \%)$, the confidence interval of the Odds Ratio that compared triers with nonsmoking deciders $(\mathrm{OR}=1.26)$ did not exclude $1.00(95 \% \mathrm{CI}=0.89-1.80)$. Thus, the Odds Ratio of triers at baseline to be smoking daily at follow- up, corrected for demographics, was not conclusively higher than that of nonsmoking deciders at baseline. Thus, hypothesis 3 was not confirmed. Experimenters did have a significantly higher Odds Ratio than nonsmoking deciders $(\mathrm{OR}=2.37 ; 95 \% \mathrm{CI}=1.56-3.60)$.

Hypothesis 4 compared regular smokers at baseline with quitters at baseline. The Odds Ratio of regular smokers was 5.74 , compared to quitters $(95 \% \mathrm{CI}=4.01-8.22)$. This confirmed hypothesis 4 . None of the two-way interactions between the smoking initiation continuum and the demographics were significant.

\section{DISCUSSION}

The behavioural stage approach to adolescent smoking initiation that was introduced two decades ago (Flay et al., 1983; Leventhal \& Cleary, 1980) has formed the basis of research with respect to the natural process of smoking initiation (Chassin et al., 1990; 1991; 2000; Chassin, Presson, Rose \& Sherman, 1996; Chassin, Presson, Sherman \& Edwards, 1992; Fergusson \& Horwood, 1995), and determinants of adolescent smoking initiation (Flay et al., 1998; Novak \& Clayton, 2001; Robinson et al., 1997). In turn, these studies have informed the development of an instrument to test Flay's stage model of smoking initiation (Flay, 1993; Flay et al., 1983; USDHHS, 1994). In the present study, the face validity of the results indicated the applicability of the measuring instrument in a cross-cultural population of early European adolescents. Stage transitions were found to have taken place in the expected sequence and three of the four hypotheses with regard to progression to daily smoking during 12 months of follow-up were confirmed. Our theory-driven assessment of the developmental process of adolescent smoking behaviour may contribute to the development of a generally accepted measure of the stages of smoking initiation.

The proportions of nonsmoking deciders, regular smokers, and quitters increased, while the proportions of never smokers decreased during the 12 months follow-up period. The proportions of adolescents in the trial and experimental stages remained rather small. These patterns were observed irrespective of country, gender, and religion, and for both immigrants and natives. Note that the prevalence rates found 
in the present study cannot be viewed as representative of the various national populations. For example, the Finnish sample only consisted of schools in Helsinki, while the Spanish sample consisted only of schools in Barcelona. However, the cultural differences between the various sites remain. Stage transitions were found to have occurred in the expected direction. Moreover, movement to distant stages was less likely than movement to nearby stages. On the other hand, the interpretation of Table 5.2 alters if the columns would have been studied instead of the rows. The incidence of regular smokers at follow-up, for instance, is to a large extent due to the never smokers and nonsmoking deciders at baseline. This 'vertical' interpretation of the results would have led to different conclusions. We chose to base our conclusions on the conditional probability of an individual to reside in a cetrain stage at follow-up, since this method is not biased by group size at baseline.

The process of transition towards regular smoking appears to develop slowly for most early adolescents (Baugh, Hunter, Webber \& Berenson, 1982; Colder et al., 2001; Leventhal, Gleming \& Glynn, 1988). Only $4.4 \%$ of those who tried their first cigarette during the 12 months follow-up had progressed to the level of regular smoking behaviour. In agreement with the findings by Ary \& Biglan (1988), over 74\% of those who had tried their first cigarette before the baseline measurement still had not progressed to regular smoking during the 12 months follow-up period. Since the stage of nonsmoking deciding proved to be more stable than the stage of quitting, the assumption that relapse is more prevalent as adolescents progress through the continuum (CDC, 1998) was confirmed.

Many determinant studies found that earlier smoking status accounted for most of the variance in changes in smoking status at follow-up (e.g., Collins et al., 1987; Engels et al., 1999; Graham, Marks \& Hansen, 1991; Sutton, 1994; Urberg, Cheng \& Shyu, 1991). In agreement with these findings, the present study showed that increased levels of smoking behaviour at baseline were highly predictive of progression to daily smoking at follow-up. With regard to nonsmokers at baseline, the level of smoking experience proved to have predictive value. No statistically significant differences were found between triers and nonsmoking deciders with regard to the risk of progressing to daily smoking at follow-up. The level of current smoking behaviour of triers seemed to outweigh the level of past smoking experience of nonsmoking deciders. Both stages had an increased risk of progressing towards daily smoking, viz., about 6 times higher than that of never smokers. However, once an adolescent progressed from either one of these stages to the stage of experimentation, the risk of daily smoking was found to double.

The method we used to test the applicability and predictive validity of our instrument has been applied earlier in validation studies (e.g., Dijkstra et al., 1998; Pierce et al., 1996). However, several potential limitations of the present study should be considered. Seventy-eight percent of our original subjects had completed the follow-up questionnaire. Although this retention rate is relatively high (see e.g., Ary \& Biglan, 1988; Chassin, Presson, Sherman, Montello \& McGrew, 1986; Josephson \& Rosen, 1978), the attrition may have reduced the generalisability. In particular, regular smokers were found to have dropped out more frequently than non-regular smokers. Adolescents with problem behaviours (e.g., those who smoked cigarettes at baseline) have often been found to be underrepresented at later moments (e.g., Ary \& Biglan, 
1988; Chassin et al., 1992; Flay et al., 1998). The loss of relatively more smokers for the follow-up measurement might have influenced the validity of the results found for regular smokers in the present study. Another potential limitation is the missing values on the measures of smoking behaviour. Although the percentage of missing cases for our measure of the initiation continuum was relatively small $(1.5 \%)$, the percentage of cases that were not analysed as a result of a missing value on the measure of daily smoking was about twice as large. However, repeated analyses in which respondents with missing values were recoded as smokers did not result in different findings, indicating the reliability of the results found (Tabashnick \& Fidell, 1996).

Adolescent smoking behaviour, with its intermittent and irregular nature, does not allow assessment by a single item on recent smoking behaviour (Lloyd et al., 1998). 'Smoking in the past 7 days' does not necessarily indicate weekly smoking behaviour, though it has often been used as such (Mayhew et al., 2000). We believe that our measure of the stage model provides more reliable data than information extracted from a report on smoking behaviour over a defined period before completing the questionnaire. Note that the dependent variable used in the logistic regressions of the present study is assumed to be less reliable than the measure of the smoking initiation continuum. The reliability may be indicated by the inconsistencies between the reported behaviour on our instrument and the measure of daily smoking. One-fifth of the adolescents who reported to be smoking daily were not classified as regular smokers in the model. However, since it would be inappropriate to validate a measure with an indicator that is the result of the same instrument, we treated the measure of daily smoking independently from the measure of the initiation continuum.

Since our sample consisted of early adolescents, we focused our model on the process that leads to the stage of regular smoking (see also Fergusson \& Horwood, 1995). The fact that the final stage of the original model (the stage of nicotine dependence and addiction) was not defined in the model used in the present study may be viewed as a deficit. Indeed, we feel that studies focusing on higher levels of smoking behaviour should validate the definition of the stage of nicotine dependence as the final stage. There is a growing body of literature suggesting that adolescent smokers are exposed to nicotine early in their initiation process (see Eissenberg \& Balster, 2000 for a review; Shadel et al., 2000). Other methods than those we used in the present study are needed to validly define the stage of nicotine dependency. In this respect, promising methodologies are the use of biological samples (e.g., saliva cotinine, Bauman et al., 1989; McNeill, Jarvis \& West, 1987), the use of cigarette-bycigarette, or puff-by-puff records (Eissenberg \& Balster, 2000), or the use of a modified version of the Fagerström Tolerance Questionnaire for adolescents (Prokhorov et al., 2000; Prokhorov, Pallonen, Fava, Ding \& Niaura, 1996).

Several authors refer to a continuum as opposed to a stage model in the sense that a continuum would imply a linear development of behaviour (Sutton, 2000; Weinstein et al., 1998). Although some authors have suggested that behavioural change may take place continuously over time (Willet, 1997), we do not assume such a linear development with respect to the smoking initiation continuum. Smoking initiation is a complex process rather than a continuous progression where trying a cigarette inevitably leads to the level of daily smoking (Hirschman et al., 1984). We do believe that there may be a certain amount of heterogeneity in developmental trajectories of 
smoking initiation (Chassin et al., 2000; Colder et al., 2001; Wills, Vaccaro, McNamara \& Hirky, 1996). However, stage models can be considered accurate and useful if a substantial majority follows the specified sequence (Weinstein et al., 1998). Thus, interventions can be tailored to adolescents in a particular stage (De Vries \& Brug, 1999; Werch, 2001).

Instead of studying the determinants of regular smoking from a dichotomous starting point (i.e., 'not smoking regularly' versus 'smoking regularly'), the transitions through the various stages of smoking initiation should be studied. This would allow reliable conclusions to be drawn that are not confounded by the behavioural heterogeneity of the 'nonsmoking' group, in which never smokers, triers, experimenters, nonsmoking deciders and quitters are lumped together (Ary \& Biglan, 1988; Robinson et al., 1997). Concepts that have often been concluded to be psychosocial 'predictors' of regular smoking might actually have been psychosocial 'results' of stage transitions that were not assessed. Remarkably, only a handful of studies have even addressed this issue (Ary \& Biglan, 1988; Chassin, Presson, Sherman, Corty \& Olhavsky, 1984; Flay et al., 1998; Novak \& Clayton, 2001; Robinson et al., 1997). Longitudinal studies that focused only on never smokers to predict smoking onset resulted in a pessimistic view with regard to the predictability of adolescent smoking initiation (Engels et al., 1999). We hypothesise that different causal factors are important at different stages (e.g., Flay et al., 1983; Flay, 1993; Leventhal \& Cleary, 1980; USDHHS, 1994; Weinstein et al., 1998). Future studies should address this issue.

Finally, theories on adolescent smoking initiation might be improved by integrating motivational levels of smoking acquisition within the behavioural stages of initiation (Choi et al., 2001). Intentional concepts like 'susceptibility to smoking' and the 'stages of change' have been shown to have a certain value in explaining and predicting adolescent smoking behaviour (Choi et al., 1997; Kremers et al., 2001b; Pallonen et al., 1998; Pierce et al., 1996; Stem et al., 1987). Insights into the interplay between motivations and trial behaviour might improve our understanding of why certain adolescents do and others do not progress beyond trying and experimenting. 


\section{Part 3}

\section{Integration of motivational and behavioural stages}

Musica è guardare più lontano

[Music is looking further]

Eros Ramazzotti 


\section{Model of Unmotivated Smoking Initiation of Children and Adolescents (MUSICA): Development and testing of a stage model of smoking behaviour}

\section{ABSTRACT}

The main goal of the present study was to examine the usefulness of integrating motivational and behavioural stages of adolescent smoking initiation. An integrative model was developed that combines features of the Stages of Change Construct (Prochaska \& DiClemente, 1983), the concept of susceptibility to smoking (Pierce et al., 1995), and Flay's behavioural stage model (Flay et al., 1983). The developed integrative Model of Unmotivated Smoking Initiation of Children and Adolescents (MUSICA) postulates that youngsters experiment with smoking while they are in an unmotivated state as regards their plans for smoking regularly in the future. The study showed that more than $97 \%$ of a cross-cultural population of early adolescents resided in one of the seven stages distinguished by the MUSICA. The stages showed the expected differences with regard to cognitive characteristics. Moreover, the Odds Ratio of starting to smoke regularly during the twelve months follow-up period increased with advanced stage assignment at baseline. Unique predictors of stage progression from the various stages were identified, but effect sizes of predictors of transitions were found to be small. Implications of the results are discussed. 
Since Leventhal and Cleary (1980) suggested the existence of stages of smoking onset, there have been basically two lines of psychological research attempting to spell them out (Werch \& Anzalone, 1995). Whereas the first line focuses on behavioural stages of smoking initiation, the second line emphasises motivational stages.

The basic behavioural stages of smoking initiation were described and elaborated by Flay and colleagues (1983; 1993; 1998; Mayhew et al., 2000), and adopted in the Surgeon General's report (USDHHS, 1994). According to this model, adolescents in the never smoking stage have never smoked even one puff. The second stage, initial trying, involves the consumption of the first few cigarettes. In the experimental stage, adolescents smoke repeatedly, but irregularly over an extended period of time. Regular smoking involves smoking on a regular, at least weekly, basis (Flay et al., 1983; 1993; 1998; USDHHS, 1994). Recently, Kremers et al. (2001c) tested a behavioural six-stage model of adolescent smoking initiation. In addition to the four stages described above, the model identifies two distinct groups of current nonsmokers: nonsmoking deciders (i.e., nonpersistent triers and experimenters) and quitters (i.e., ex-regular smokers). It was shown to be necessary to distinguish between these six categories on the basis of the cognitive characteristics of the adolescents in the various behavioural stages (Kremers et al., 2001c). Expanding the cross-sectional results, the six-stage model proved to have predictive validity with regard to daily smoking behaviour at 12 months follow-up (Kremers, Mudde \& De Vries, submitted).

Another line of research that has tried to cover the initiation continuum of smoking focuses merely on motivational stages of initiation. This focus is represented by an application of the Stages of Change Construct (SCC; Prochaska \& DiClemente, 1983) to smoking initiation (Elder et al., 1990; Kelley et al., 1999; Pallonen, 1998; Pallonen et al., 1998; Stern et al., 1987; Werch \& DiClemente, 1994), and the introduction and application of the concept of 'susceptibility to smoking' (Choi et al., 1997; 2001; Huang et al., 2000; Jackson, 1998; Pierce et al., 1995; 1996; Unger et al., $1996 ; 2001)$. The SCC of smoking initiation can be viewed as a mirror image of the stages of smoking cessation. The concept of susceptibility identifies those adolescents who have firmly committed themselves to nonsmoking. These adolescents are labelled 'non-susceptible' to smoking. Kremers and colleagues (2001a) combined features of both concepts in order to categorise a population into motivational stages of smoking initiation. The study identified three subtypes within the stage of acquisition precontemplation: progressives, immotives, and committers. Progressives had concrete plans to start smoking in the future, operationalised as having plans to start smoking within the next 5 years. These concrete plans were not apparent in immotives, who had only vague plans or no plans at all to start smoking in the future. Committers had firmly decided not to start smoking. The groups of contemplating and preparating adolescents were found to be small in the explorative cross-sectional study. Moreover, these groups did not differ from each other with regard to cognitive characteristics. Consequently, the stages of contemplation and preparation were combined in a prospective study (Kremers, De Vries \& Mudde, submitted). The four motivational stages proved to have validity with regard to the prediction of future smoking behaviour. 
Choi et al. (2001) have shown that the probability of future smoking behaviour among adolescents is related to both previous smoking experience and motivations regarding future smoking. It may be useful to integrate the behavioural and motivational lines of research in order to gain more insights into the process of adolescent smoking initiation (Kremers, Mudde \& De Vries, submitted; see also Werch \& Anzalone, 1995).

The integration of the four behavioural stages (i.e., never smoked, nonsmoking deciding, trying, and experimenting) and the four motivational stages (i.e., committed, immotive, progressive, and contemplating) would result in a framework of sixteen possible categories that may induce an adolescent to develop regular smoking behaviour (see Figure 6.1).

Figure 6.1. Integrated smoking initiation framework

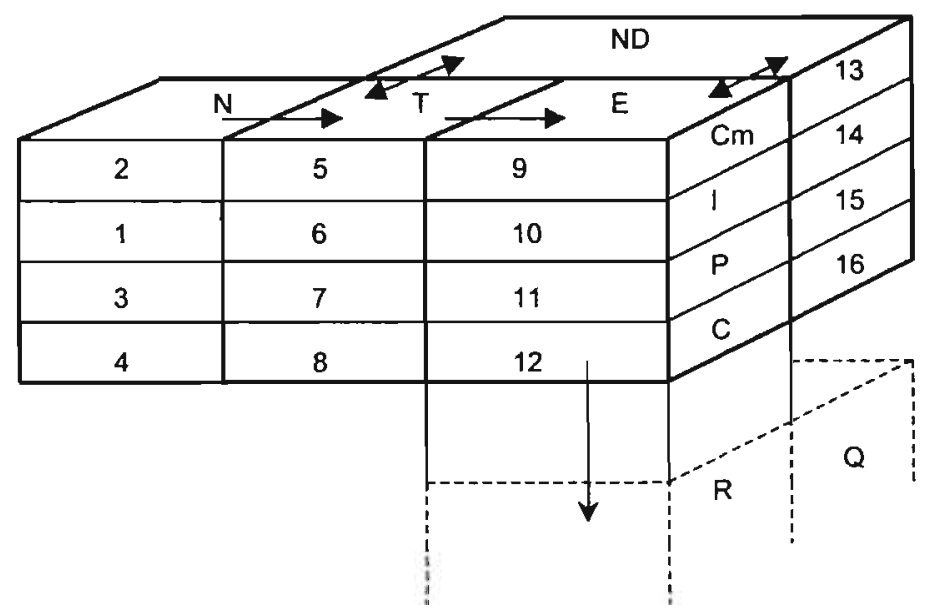

Explanation of symbols:

Behavioural stages: $\mathrm{N}=$ Never smoker, $\mathrm{ND}=$ Nonsmoking Decider, $\mathrm{T}=$ Trier, $\mathrm{E}=$ Experimenter,

$\mathrm{R}=$ Regular smoker, $\mathrm{Q}=$ Quitter.

Motivational stages: $\mathrm{Cm}=$ Committer $, \mathrm{I}=\mathrm{Immotive}, \mathrm{P}=$ Progressive, $\mathrm{C}=$ Contemplator .

Since each individual comes to a point where they start thinking about smoking or nonsmoking, each individual enters the framework as an immotive never smoker (category 1). Any nonsmoking (i.e., not regularly smoking) adolescent population can be categorised in this framework. For example, someone can be a never smoker who is making concrete plans about starting to smoke regularly within the next six months (contemplating never smoker; category 4), or they may have tried smoking but are not smoking anymore (nonsmoking decider) and committed themselves to nonsmoking (committer; category 13). 
Both inductive and deductive procedures were applied in the present stuviy to develop and test an integrated stage model of adolescent smoking initiation. First, inductively, we aimed to study a large international sample of adolescents, using Figure 6.1 as a framework (Study A). The population was categorised in this framework to allow us to observe a pattern in the prevalence rates. Then, the categories that fell within the observed pattern were compared with regard to their cognitive characteristics. Categories should differ from each other with regard to social cognitive characteristics, in that adolescents in more advanced categories should have more risky characteristics (Hypothesis A1). Only then, categories could be viewed as qualitatively distinct stages (see also Weinstein et al., 1998).

The results of the inductive process led to the formulation of a stage model of adolescent smoking initiation, which was then tested deductively, following Weinstein et al.'s (1998) guidelines on testing stage models (Study B). The following hypotheses were tested:

B1. The proportion of adolescents that progress to more advanced stages within the model increase with advanced stage assignment at baseline.

B2. Advanced stage assignment at baseline leads to an increased risk of regular smoking behaviour at follow-up.

B3. Transitions from the various stages are predicted by different cognitive characteristics.

Hypothesis 1 was tested by studying transitions from stage at baseline to the various stages at follow-up. The predictive validity of the various stages with regard to regular smoking behaviour at follow-up were studied in order to test hypothesis 2 . Finally, hypothesis 3 was tested by studying differential cognitive predictors of transitions from the various stages. Consequences of adapting the stage model of smoking initiation are discussed and directions for future research will be proposed.

\section{METHODS}

\section{Participants and recruitment}

In the present study, a large international sample of European adolescents $(n=10170)$ was followed longitudinally. The sample consisted of the control group of a larger, ongoing prospective study of the ESFA smoking prevention project (European Smoking prevention Framcwork Approach; De Vries et al., 1999; 2000; submitted; Kremers et al., 2000). Six European Union member states (Finland, Denmark, the United Kingdom, the Netherlands, Spain, and Portugal) participate in this project. Data were collected at schools, using a self-administered questionnaire.

A logistic regression analysis was used to compare participating subjects and dropouts (i.e., those not participating in the second measurement) with data of the first measurement as predictors of dropout $(n=2233)$. Dropout appeared to be selective with regard to country, age and smoking behaviour. The results of the attrition analyses have been discussed in more detail elsewhere (Kremers, De Vries, Mudde \& 
Candel, submitted). Of the longitudinal sample, $9.1 \%$ lived in Denmark, $15.1 \%$ in Finland, $23.7 \%$ in the Netherlands, $14.3 \%$ in Portugal, $9.1 \%$ in Spain, and $28.7 \%$ in the United Kingdom. The mean age of the respondents at baseline was 13.3 years (SD= 0.7 ), and $50.5 \%$ were males. Due to missing or incomplete data on key variables 327 cases $(4.1 \%)$ were excluded from the analyses.

\section{Smoking behaviour}

Adolescents were asked to select the statement that best described them from a set of specific statements referring to the frequency of current smoking behaviour (for more information, see Kremers et al., 2001c). Never smokers were defined as those who had never smoked even one puff. Triers were those adolescents who indicated that they smoked once in a while, but less than monthly. Experimenters were defined as smoking monthly, but less than weekly. Regular smokers were those adolescents who indicated they smoked at least weekly. Nonsmoking deciders were defined as those nonsmokers who had tried smoking in the past, but not on a weekly basis. Quitters were those adolescents who indicated that they had smoked at least weekly in the past, but who were not smoking anymore. Responses were cross-validated using a four-item algorithm, consisting of concepts measuring current smoking and lifetime smoking. In agreement with the definition of triers as adolescents who are smoking their first few cigarettes, lifetime smoking data were additionally used to define triers as those who had not smoked more than four cigarettes in their life. Thus, adolescents who reported to be trying smoking less than monthly but had smoked more than four cigarettes in their life were classified as experimenters. In line with the WHO and USDHHS operationalisation of established smoking (USDHHS, 1994; WHO, 1998), adolescents who reported smoking monthly but who had smoked more than 100 cigarettes in their life were classified as regular smokers.

\section{Motivational stages of smoking acquisition}

Respondents were classified as acquisition contemplators if they planned to start smoking at some point within the next six months. Progressives were defined as those adolescents who planned to start smoking within the next five years. Immotives were those who did not intend to start within the next five years but lacked a firm decision never to start smoking. Respondents who indicated they were sure that they would never start smoking and definitely did not intend to smoke in the next year and definitely did not intend to smoke in the future were labelled as committers (see also Kremers et al., 2001a).

\section{Social cognitive characteristics}

Social cognitive models that try to explain and predict adolescent smoking behaviour share a common feature in that they consist of attitudinal, social and efficacy constructs (Petraitis et al., 1995). The present study examined indicators of each of these constructs, using several validated instruments (see also Kremers et al., 2001a for the exact items). Ten items on smoking related beliefs were included in the analyses in order to assess attitude towards smoking. Smoking related beliefs were assessed using items with bipolar answering categories. For example: If I smoke (or were to smoke) it will make me feel very relaxed (3) to it will make me feel very 
stressed $(-3)$. Two scales of five items were constructed, indicating the pros of smoking $(\alpha=.65)$ and the cons of smoking ( $\alpha=.68)$. The items on the pros of smoking refer to expected positive outcomes of smoking, while the cons of smoking refer to expected negative outcomes of smoking. Scales of pros and cons of smoking consisted of sumscores. Three components of social influence were assessed in the present study: social pressure to smoke, social norm, and perceived behaviour of the social environment. Pressure to smoke from people in the environment was operationalised by seven items with five answering categories. For example: Have you ever felt pressure to smoke from your mother? Answering options were very often (4), often (3), sometimes (2), a few times (1), and never (0). Subscales were constructed for parents (sumscore of father and mother; $\alpha=78$ ), siblings (sumscore of brother(s) and sister(s); $\alpha=.60$ ), and friends (sumscore of best friend, friends in general and people in same school year; $\alpha=.78$ ). Social norm was assessed using seven items with seven answering categories on the respondent's perceptions of whether important others think they should smoke or not. For example: My best friend thinks that I definitely should smoke (3) to definitely should not smoke (-3). Subscales were constructed for parents (sumscore of father and mother; $\alpha=78$ ), siblings (sumscore of brother(s) and sister(s); $\alpha=.41$ ), and friends (sumscore of best friend, friends in general and people in same school year; $\alpha=80$ ). The third component of the concept of social influence analysed in the present study was perceived behaviour of the social environment. Perceived behaviour was measured by asking whether an important other smoked or not. For example: Does your father smoke? $($ no $=0$, yes $=1$ ). Subscales were constructed for parents (sumscore of father and mother; $\alpha=48$ ), siblings (sumscore of brother(s) and $\operatorname{sister}(\mathrm{s}) ; \alpha=.28$ ), and friends (sumscore of friends in general and people in same school year; $\alpha=.62$ ). Self-efficacy expectations were measured by twelve items on a seven-point scale, derived from a validated instrument by Lawrance (1988). The items refer to the respondents' perception of their ability to refrain from smoking when they are in certain situations with friends (four items; $\alpha=.94$ ), when they have the opportunity to smoke (four items, $\alpha=.93$ ) and when they have certain emotions (four items; $\alpha=.96$ ). For example: When a friend offers you a cigarette, are you sure you will not smoke? Answering categories ranged from 'I am sure I won't smoke (3) to 'I am sure I will smoke' (-3).

\section{Statistical analyses}

After regular smokers and quitters at baseline had been removed from the data set, four sets of analyses were performed. Firstly, prevalence rates within the initiation categories at baseline were assessed. Secondly, cognitive characteristics were examined with regard to each category at baseline, using standardised $\mathrm{T}$ scores for each concept with a mean of 50 and a standard deviation of 10 . The $\mathrm{T}$ scores were corrected for age, gender and country and Tukey HSD contrasts were examined. Thirdly, transitions within the model were studied, using the categories at baseline as the input and the categories at 12 months follow-up as the output. Odds Ratios were computed in order to test the predictive validity of the stages with regard to regular smoking behaviour at follow-up. The probability of smoking regularly at follow-up was compared between each baseline stage and the baseline stage that was 
hypothesised to precede it. The latter stage was used as a reference (Odds Ratio = 1.00). Using logistic regressions, the Odds Ratios were corrected for the covariates gender, age and country. Finally, predictors of transitions were studied using separate analyses of variance in order to identify unique predictors of transitions. Stage transition status 12 months later was used as the independent grouping variable and the cognitive characteristics as the dependent variables. Because of the large differences in group sizes between the various groups, we used the magnitude of the effect size (omega-squared; $\omega^{2}$ ) as a source of information, since it is insensitive to group sizes (Tabashnick \& Fidell, 1996). Effect size interpretations were based on Cohen's (1988; p. 285) descriptive guidelines. A large effect size is about $14 \%$ or more of the variance $\left(\omega^{2}=.14\right)$, a medium effect size is about $6 \%$ of the variance $\left(\omega^{2}=.06\right)$, and a small effect size is about $1 \%$ of the variance $\left(\omega^{2}=.01\right)$.

\section{RESULTS}

\section{Study A. Development of an integrated model}

\section{Prevalence rates within the integrated framework}

Regular smokers $(n=410 ; 5.2 \%)$ and quitters $(n=149 ; 1.9 \%)$ at baseline were removed from the data set. Further, 295 respondents $(4.0 \%)$ were removed as a result of missing values with regard to their category within the framework.

Figure 6.2. Prevalences in the smoking initiation framework at baseline (T1) and 12 months follow-up (T2) (N=7083)

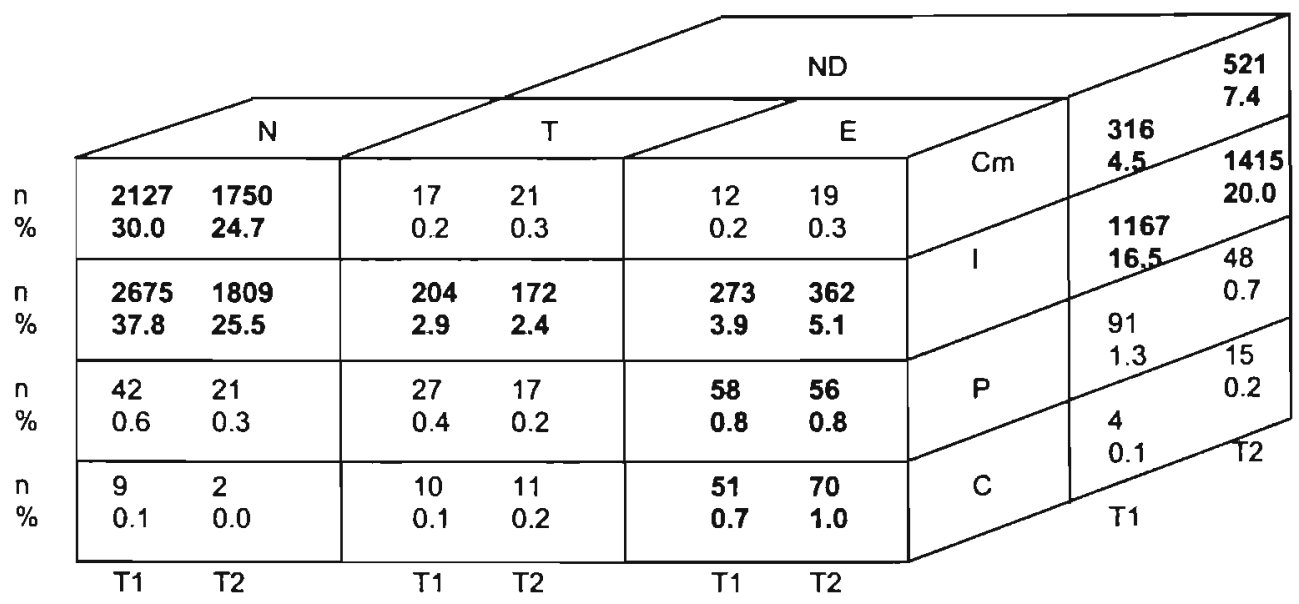

Explanation of symbols:

$N=$ Never smoker, $N D=$ Nonsmoking Decider, $T=$ Trier,$E=$ Experimenter.

$\mathrm{Cm}=$ Committer, $\mathrm{I}=$ Immotive, $\mathrm{P}=$ Progressive, $\mathrm{C}=$ Contemplator .

Note. Categories that contain 50 or more respondents at both measurements are depicted in bold. 
Figure 6.2 shows the prevalence rate of each category within the integrated model. All categories contained respondents, but the prevalence rates differed considerably. The largest category was that of immotive never smokers $(37.8 \%$ of the total population at baseline; $25.5 \%$ at follow-up). This finding indicates that a large part of the sample had never tried smoking and had not even thought about smoking in the future. The second largest group was that of committed never smokers (30.0\% at baseline; $24.7 \%$ at follow-up). These adolescents had never tried even one puff, and they had firmly decided never to do so. Within the trier and experimenter stages, most adolescents were found to be immotive. At baseline, $16.5 \%$ of the total sample was categorised as immotive nonsmoking decider. At follow-up, the prevalence rate of adolescents in this category was $20.0 \%$. A considerable amount of nonsmoking deciders committed themselves to nonsmoking ( $4.5 \%$ at baseline; $7.4 \%$ at follow-up). Overall, relatively few adolescents were found within the stages of progressives and contemplators.

There was a pattern with regard to prevalence rates in that a limited number of categories within the integrated framework seemed to represent a substantial part of the population with regard to their progression to regular smoking behaviour. Eight of the 16 categories contained 50 or more respondents at both measurements, representing $97.0 \%$ of the total population at baseline and $97.9 \%$ of the population at follow-up. These categories were: committed never smokers (1), immotive never smokers (2), immotive triers (3), immotive experimenters (4), progressive experimenters (5), contemplating experimenters (6), immotive nonsmoking deciders (7), and committed nonsmoking deciders (8). Although the category of progressive nonsmoking deciders exceeded the total of 50 respondents at baseline, and almost contained 50 respondents at follow-up, this category was not included since the progressive motivational stage did not appear to characterise nonsmoking deciders. Relative percentages of progressives within the nonsmoking decider stage were $5.8 \%$ at baseline and $2.4 \%$ at follow-up, while these relative percentages were $14.7 \%$ and $11.0 \%$ respectively for progressives within the experimenter stage at baseline and follow-up.

\section{Cognitive characteristics of the eight categories}

As stated in the introduction, the selected categories needed to differ from each other with regard to cognitive characteristics in order to represent qualitatively distinct stages. Hypothesis A1 stated that all stages would differ from each other with regard to social cognitive characteristics. Table 6.1 shows the standardised $T$ scores for attitude, social norm and self-efficacy within each stage. A high $T$ score indicates that a respondent had a high score on the particular concept (i.e., perceived many pros of smoking, perceived a high social norm towards smoking, or had a high self-efficacy to refrain from smoking). Tukey-HSD contrasts were computed.

Overall, the results indicate that adolescents had more risky cognitive characteristics once they were situated more closely to the regular smoking category in the model. On most concepts, committers scored less risky than immotives, both in never smokers and nonsmoking deciders. More advanced behavioural stages within the immotive state were found to have more risky social cognitive characteristics. 
Table 6.1. Standardised T scores on cognitive characteristics of eight categories $(n=6871)$

\begin{tabular}{|c|c|c|c|c|c|c|c|c|c|}
\hline$n$ & $\begin{array}{l}\mathrm{CmN} \\
2127\end{array}$ & $\begin{array}{l}\text { IN } \\
2675 \\
\end{array}$ & $\begin{array}{l}\pi \\
204 \\
\end{array}$ & $\begin{array}{ll}\mathrm{IE} \\
273 \\
\end{array}$ & $\begin{array}{l}\mathrm{PE} \\
58 \\
\end{array}$ & $\begin{array}{l}\text { CE } \\
51 \\
\end{array}$ & $\begin{array}{ll}\text { IND } \\
1167 \\
\end{array}$ & $\begin{array}{l}\text { CmND } \\
316 \\
\end{array}$ & Tukey HSD contrasts \\
\hline $\begin{array}{l}\text { Pros of } \\
\text { smoking }\end{array}$ & 46.9 & 50.0 & 53.7 & 56.2 & 60.9 & 61.0 & 52.1 & 51.1 & $\begin{array}{l}\text { CmN<CmND,IN, IND, IT,IE<PE,CE } \\
\text { CmND<IT, IE } \\
\text { IN }<I N D, I T, I E \\
\text { IND }<I E\end{array}$ \\
\hline $\begin{array}{l}\text { Cons of } \\
\text { smoking }\end{array}$ & 53.1 & 49.5 & 45.7 & 42.0 & 37.1 & 36.8 & 48.8 & 52.7 & $\mathrm{CmN}, \mathrm{CmND}>\mathrm{IN}, \mathrm{IND}>\mathrm{IT}>\mid \mathrm{E}>\mathrm{PE}, \mathrm{CE}$ \\
\hline $\begin{array}{l}\text { Social norm } \\
\text { parents }\end{array}$ & 47.5 & 50.9 & 50.9 & 53.2 & 55.6 & 52.2 & 51.3 & 49.3 & $\begin{array}{l}\text { CmN<CmND<IN,IND,IT,IE,PE,CE } \\
\text { IN<IE,PE,CE } \\
\text { IND<IE }\end{array}$ \\
\hline $\begin{array}{l}\text { Social norm } \\
\text { siblings }\end{array}$ & 47.5 & 50.6 & 52.5 & 53.2 & 57.5 & 53.6 & 51.5 & 49.7 & $\begin{array}{l}\text { CmN<CmND,IN,IND,IT,IE,CE }<P E \\
\text { CmND<IND, IT, IE,PE,CE } \\
\text { IN }<\text { IE,PE,CE } \\
\text { IND }<P E, C E\end{array}$ \\
\hline $\begin{array}{l}\text { Social norm } \\
\text { peers }\end{array}$ & 46.7 & 50.3 & 54.9 & 55.6 & 57.3 & 58.0 & 52.4 & 49.6 & $\mathrm{CmN}<\overline{\mathrm{C} m N D, I N<\mid N D<I T, I E, P E, C E}$ \\
\hline $\begin{array}{l}\text { Social } \\
\text { pressure } \\
\text { parents }\end{array}$ & 49.3 & 49.8 & 50.4 & 51.1 & 56.3 & 56.5 & 50.9 & 49.3 & $\begin{array}{l}\text { CmN,CmND,IN,IND, IT,IE<PE, CE } \\
C m N<I N D \\
I N<I N D\end{array}$ \\
\hline $\begin{array}{l}\text { Social } \\
\text { pressure } \\
\text { siblings }\end{array}$ & 48.9 & 49.6 & 51.0 & 53.0 & 61.4 & 60.0 & 51.0 & 49.9 & $\begin{array}{l}\text { CmN,CmND,IN,IND,IT,IE<PE,CE } \\
\text { CmN<IND,IE } \\
\text { CmND<IE } \\
\text { IN }<I N D, I E \\
\end{array}$ \\
\hline $\begin{array}{l}\text { Social } \\
\text { pressure } \\
\text { peers }\end{array}$ & 47.3 & 48.5 & 55.2 & 56.9 & 61.5 & 59.2 & 53.7 & 53.3 & $\begin{array}{l}\mathrm{CmN}<\mathrm{IN}<\mathrm{CmND}, \mathrm{IND}, \mathrm{IT}, \mathrm{IE}<\mathrm{PE}, \mathrm{CE} \\
\mathrm{IND}<\mathrm{IE}\end{array}$ \\
\hline $\begin{array}{l}\text { Perceived } \\
\text { behaviour } \\
\text { parents }\end{array}$ & 48.4 & 49.6 & 50.6 & 52.7 & 52.0 & 54.8 & 52.3 & 51.6 & $C m N<I N<C m N D, I N D, I T, I E, P E, C E$ \\
\hline $\begin{array}{l}\text { Perceived } \\
\text { behaviour } \\
\text { siblings }\end{array}$ & 48.4 & 49.5 & 52.0 & 52.8 & 58.1 & 55.0 & 52.3 & 50.3 & $\begin{array}{l}\mathrm{CmN}<|\mathrm{IN}<\mathrm{CmND}<| \mathrm{ND}, \Pi, \mid \mathrm{I}, \overline{\mathrm{PE}}, \mathrm{CE} \\
\mathrm{IND}<\mathrm{PE}, \mathrm{CE}\end{array}$ \\
\hline $\begin{array}{l}\text { Perceived } \\
\text { behaviour } \\
\text { peers }\end{array}$ & 48.3 & 48.4 & 54.3 & 58.9 & 60.3 & 61.5 & 52.3 & 51.6 & $\begin{array}{l}\mathrm{CmN}, \mathrm{IN}<\mathrm{CmND}, \mathrm{IND}<\mathrm{IT}, \mathrm{IE}, \mathrm{PE}, \mathrm{CE} \\
\mathrm{IT}<\mathrm{PE}, \mathrm{CE}\end{array}$ \\
\hline $\begin{array}{l}\text { Self-efficacy } \\
\text { friends }\end{array}$ & 54.8 & 49.2 & 43.1 & 41.5 & 36.4 & 33.6 & 46.9 & 53.2 & $\mathrm{CmN}, \mathrm{CmND}>\mathrm{IN}>\mathrm{IND}>\mathrm{IT}, \mathrm{IE}>\mathrm{PE}, \mathrm{CE}$. \\
\hline $\begin{array}{l}\text { Self-efficacy } \\
\text { opport. }\end{array}$ & 53.2 & 49.2 & 45.4 & 45.3 & 42.2 & 43.1 & 48.2 & 52.4 & $\mathrm{CmN}, \mathrm{C} m \mathrm{ND}>\mathrm{IN}>\mathrm{IND}>\mathrm{IT}, \mathrm{IE}>\mathrm{PE}, \mathrm{CE}$ \\
\hline $\begin{array}{l}\text { Self-efficacy } \\
\text { emotions }\end{array}$ & 54.0 & 49.2 & 44.7 & 44.3 & 38.1 & 37.1 & 47.4 & 52.7 & $\mathrm{CmN}, \mathrm{CmND}>\mathrm{IN}>\mathrm{IND}>\mathrm{IT}, \mathrm{IE}>\mathrm{PE}, \mathrm{CE}$ \\
\hline
\end{tabular}

Notes. T scores corrected for age, gender, and country. Tukey HSD contrasts: $p<.05$

$\mathrm{CmN}=$ Committed never smokers; IN = Immotive never smokers; IT = Immotive triers; IE = Immotive experimenters; PE = Progressive experimenters; $\mathrm{CE}=$ Contemplating experimenters; IND = Immotive nonsmoking deciders; $\mathrm{CmND}=$ Committed nonsmoking deciders . 
However, whereas progressive and contemplating experimenters scored more risky than immotive experimenters on most concepts, no expected differences were found between the progressives and the contemplators. On 6 of the 14 concepts, contemplators scored less risky than progressives (i.e., social norm parents, social norm siblings, perceived pressure from siblings, perceived pressure from peers, perceived behaviour of siblings, and opportunity self-efficacy), while they were expected to score more risky. With regard to the perceived social norm of the siblings, the difference reached statistical significance $(p<.05)$. On 8 concepts, the results showed the expected direction (contemplators scored more risky than progressives), but none of the differences were significant at a level of $p<.05$. While one would have expected that contemplating experimenters would score consistently and significantly riskier than progressives, hypothesis Al was rejected. In other words, the categories of progressive and contemplating experimenters could not be viewed as representing qualitatively distinct stages. As a result, these two categories were aggregated into one stage ('contemplating experimenters'), representing those adolescents that have formed concrete plans about their future smoking behaviour.

\section{Model of Unmotivated Smoking Initiation of Children and Adolescents (MUSICA)}

The results with regard to the prevalence of the various categories within the integrated framework as well as the results concerning the differences in means suggested seven meaningful stages of smoking initiation. These stages were: committed never smokers (1), immotive never smokers (2), immotive triers (3), immotive experimenters (4), contemplating experimenters (5), immotive nonsmoking deciders (6), and committed nonsmoking deciders (7).

It was expected that youngsters do not display initial trial behaviour while they are in an immotive motivational state, since they have no clear intention to start smoking in the future (note 3). However, it was found in Study A that the majority of triers, experimenters and nonsmoking deciders were immotives, implying that their motivation to take up smoking was low. Consequently, there seems to be a contradiction with respect to the term 'immotive' in smoking initiation. At the one hand, the term 'immotive' suggests a situation of no motivational action. At the other hand, these adolescents do change their behaviour. These adolescents are displaying initial trial behaviour, while they are 'stuck' in an unmotivated state. In other words, immotive triers, experimenters and nonsmoking deciders are not motivationally engaged in their behavioural change process. This finding forms the basis of the Model of Unmotivated Smoking Initiation of Children and Adolescents (MUSICA). The MUSICA is depicted in Figure 6.3.

All individuals start in the stage of immotive never smoking. They can leave this stage by committing themselves to nonsmoking (committed never smokers) or by trying smoking (immotive triers). In this stage, they may stop trying before having smoked more than four cigarettes (immotive nonsmoking deciders) or continue to experiment with smoking (immotive experimenters). The nonsmoking deciders can firmly decide to remain nonsmokers (committed nonsmoking deciders) or relapse into previous trial behaviour (immotive triers or experimenters). Thus, initial smoking behaviour is postulated to occur in an unmotivated (immotive) state with regard to 
starting to smoke regularly in the future (note 4). Individuals may pass the stages within the 'unmotivated cycle' several times before committing themselves to nonsmoking, or before contemplating regular smoking. When immotive experimenters form concrete plans to smoke at some point within the next five years, they are labelled contemplators. Contemplating experimenters can either regress to the immotive stage or progress to the stage of regular smoking (i.e., starting to smoke at least weekly). Note that the model concentrates on the process that leads to the initiation of regular smoking behaviour. Distinct stages of advanced smoking behaviour (i.e., daily smoking, dependency), as well as stages of smoking cessation are not included in this model.

Figure 6.3. Model of Unmotivated Smoking Initiation of Children and Adolescents (MUSICA)

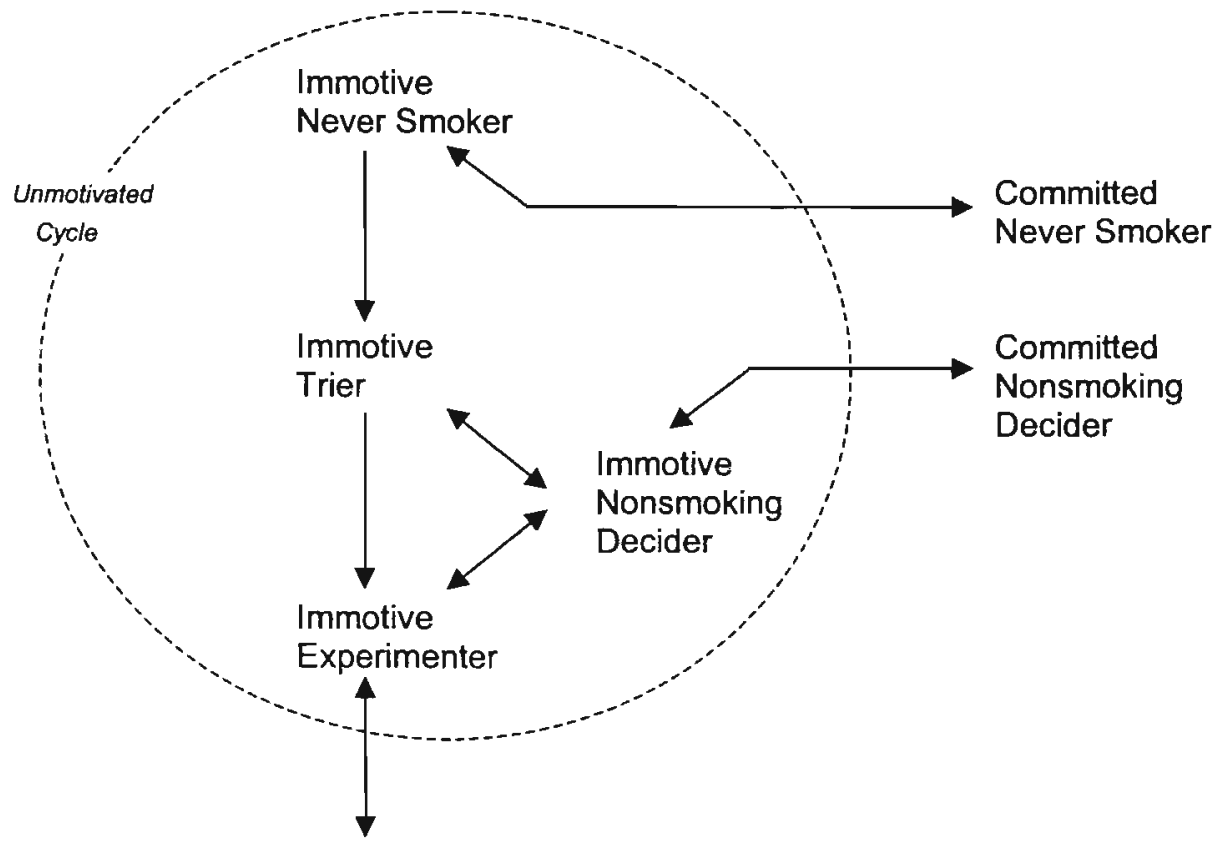

Contemplating

Experimenter

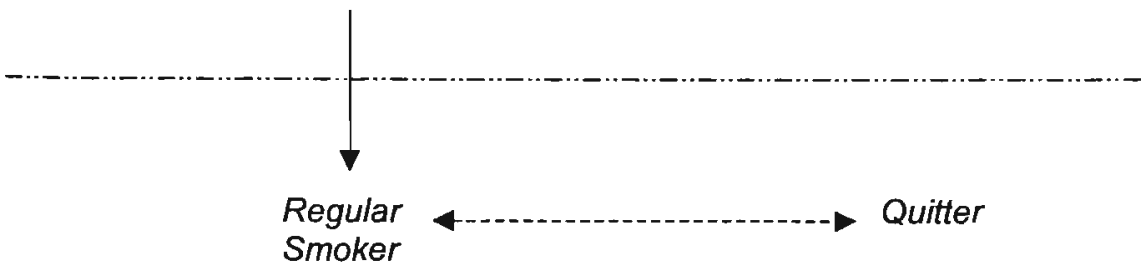




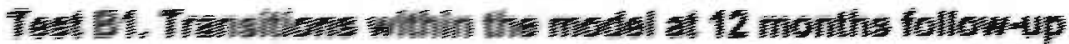

About $2 \%$ of the respondenta that could be chassifete within the MUSICA at baseline could not be elasaified within the model at forlow-yn $(\mathrm{n}=142$. These cases were

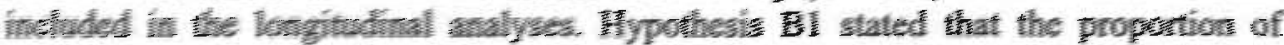
adolescente that progres towarls more alvanced stages woulu increase with advancad.

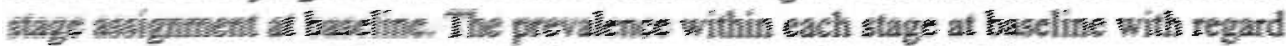
to atage aesignment at 12 monthe follow-sp are derieted in Thute 6.2 .

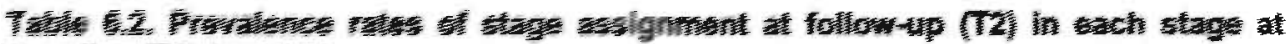

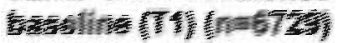

\begin{tabular}{|c|c|c|c|c|c|c|c|c|c|c|}
\hline \multicolumn{10}{|c|}{ Elages T2 } & \multirow{2}{*}{ 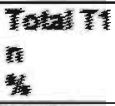 } \\
\hline Glargon & Cnll & In & $\pi$ & IE. & $\overline{C E}$ & 160 & Crate & $F$ & 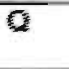 & \\
\hline Emk & 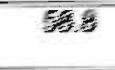 & 238 & 1,1 & 16 & 68 & 8.7 & E.t & 2.1 & 0.4 & $\begin{array}{l}200 \mathrm{~g} \\
31,2\end{array}$ \\
\hline Iftis & 195 & 498 & 2.8 & 3.2 & 1.9 & 15.5 & 2.6 & 4.6 & 1.0 & $\begin{array}{l}2621 \\
39.0\end{array}$ \\
\hline If & & & 7 & 13 & 21 & 43.8 & 9.2 & 19.4 & 2.0 & $\begin{array}{l}196 \\
2.9\end{array}$ \\
\hline $\mathbb{I E}$ & & & & 19.3 & 5.3 & 23.9 & 8.7 & 33.7 & 9.1 & $\begin{array}{l}264 \\
3.9 \\
\end{array}$ \\
\hline CE & & & & 10.8 & 7.8 & 22.5 & 4.9 & 44.1 & 9.8 & $\begin{array}{l}102 \\
1.5 \\
\end{array}$ \\
\hline IND & & & 4.1 & 9.7 & 4.0 & 46.7 & 12.5 & 18.0 & 5.0 & $\begin{array}{l}1139 \\
16.9\end{array}$ \\
\hline CmND & & & 2.3 & 6.2 & 0.3 & 34.4 & 43.8 & 10.1 & 2.9 & $\begin{array}{l}308 \\
4.6 \\
\end{array}$ \\
\hline Total T2 & $\begin{array}{ll}n & 1745 \\
\% & 25.9 \\
\end{array}$ & $\begin{array}{l}1794 \\
26.7 \\
\end{array}$ & $\begin{array}{l}168 \\
2.5 \\
\end{array}$ & $\begin{array}{l}338 \\
5.0\end{array}$ & $\begin{array}{l}119 \\
1.8 \\
\end{array}$ & $\begin{array}{l}1356 \\
20.2 \\
\end{array}$ & $\begin{array}{l}498 \\
7.4 \\
\end{array}$ & $\begin{array}{l}572 \\
8.5 \\
\end{array}$ & $\begin{array}{l}139 \\
2.1 \\
\end{array}$ & 6729 \\
\hline
\end{tabular}

Explanation of abbreviations:

$\mathrm{CmN}=$ Committed never smokers; IN = Immotive never smokers; IT = Immotive triers; IE = Immotive experimenters; $\mathrm{CE}=$ Contemplating experimenters; IND = Immotive nonsmoking deciders; $\mathrm{CmND}=$ Committed nonsmoking deciders; $R=$ Regular smokers; $Q=$ Quitters.

Note. All empty cells are structural zero's, i.e., by defenition, no value but zero is possible.

Overall, Table 6.2 shows that the proportion of adolescents that progressed towards more advanced stages increased with advanced stage assignment at baseline, confirming hypothesis B1. About $59 \%$ of the adolescents that were committed never smokers at baseline were still in this category at follow-up. Respondents that left this stage mostly progressed to being immotive about their future smoking behaviour $(23.3 \%)$. Whereas about half of the immotive never smokers at baseline had remained in this category at follow-up (49.8\%), about one-fifth of them committed themselves to never smoking at follow-up. One-fifth of the immotive triers smoked regularly at follow-up, while about one-third of the immotive experimenters did so. A small percentage of the adolescents that were contemplating experimenters at baseline was still in the same behavioural stage at follow-up (7.8\%). About $44 \%$ of the contemplators at baseline smoked regularly at follow-up. A large proportion of immotive nonsmoking deciders at baseline was still immotive at follow-up (43.8\%). 
More than $12 \%$ had committed themselves to nonsmoking and $18 \%$ smoked regularly. About $44 \%$ of the committed nonsmoking deciders at baseline were still committed to nonsmoking at follow-up. One-tenth of them smoked regularly at follow-up.

\section{Test B2. Probability of regular smoking at follow-up}

Hypothesis B2 stated that advanced stage assignment at baseline would lead to an increased risk of regular smoking behaviour at follow-up. Table 6.3 presents the results of pairwise comparisons of the Odds Ratios of the transition towards regular smoking behaviour during the follow-up period. The Odds Ratios of the reference stages were set at 1.00 , while the OR of a stage that can immediately follow it was computed, correcting for the covariates gender, age and country.

The results on the diagonal show that the Odds Ratio of smoking regularly at follow-up always significantly exceeded 1.00 when higher levels of smoking initiation were compared to lower levels. This result indicates an increased chance to start smoking regularly as adolescents progress through the MUSICA, confirming hypothesis B2 of the present study. The largest pairwise difference was that of immotive never smokers and immotive triers. The Odds Ratio of regular smoking at follow-up was found to be more than 4 times as high for immotive triers than for immotive never smokers. Further significant differences were found in comparisons between committers and immotives within the behavioural stages of never smoking and nonsmoking deciding. In each of these behavioural stages, the Odds Ratio of immotives was found to be about twice as high as that of committers $(O R=2.30$ for never smokers; $O R=1.95$ for nonsmoking deciders). A significant decrease by the same factor was found when immotive nonsmoking deciders were compared with immotive experimenters $(\mathrm{OR}=0.54)$. Further, an increase by a factor of 2 was found comparing the Odds Ratio of experimenting contemplators with that of experimenting immotives $(\mathrm{OR}=1.93)$. The result of the comparison of immotive triers and immotive nonsmoking deciders was not statistically significant.

Table 6.3. Likelihood (Odds Ratio) of regular smoking at follow-up ( $n=6729$ )

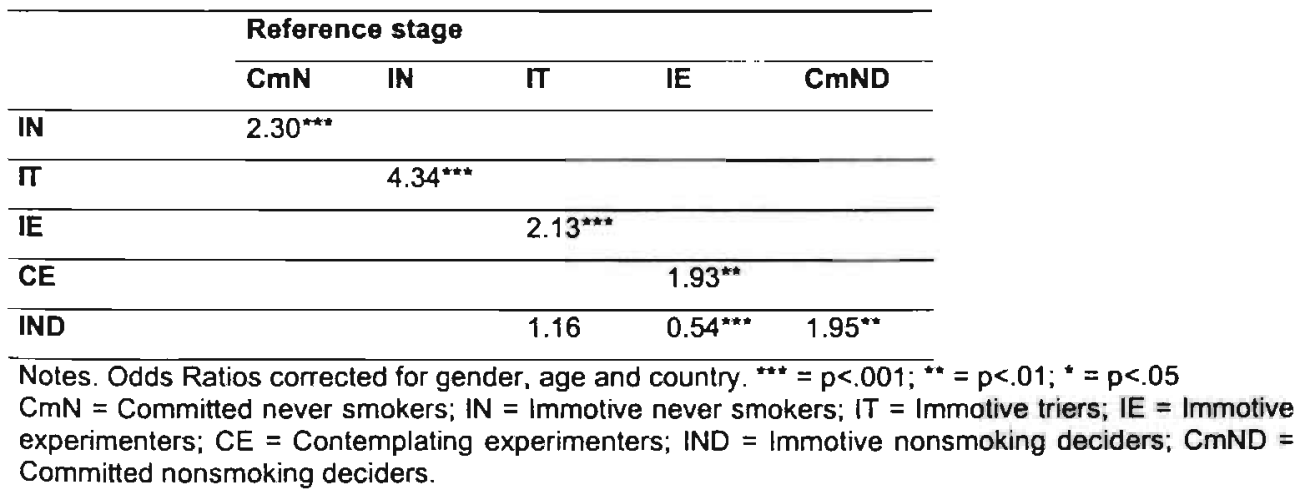


Table 6.4. Predictors of progression during the 12 months follow-up period ( $n=6729$ ). All effect sizes $\left(\omega^{2}\right)$ equal to or larger than .01 are shown.

\begin{tabular}{|c|c|c|c|c|c|c|c|c|}
\hline $\mathbf{N}$ & & $\begin{array}{l}\mathrm{CmN} \\
2099 \\
\end{array}$ & $\begin{array}{l}\text { IN } \\
2621 \\
\end{array}$ & $\begin{array}{l}\pi \\
196 \\
\end{array}$ & $\begin{array}{l}\mathrm{IE} \\
264 \\
\end{array}$ & $\begin{array}{l}C E \\
102 \\
\end{array}$ & $\begin{array}{l}\text { IND } \\
1139 \\
\end{array}$ & $\begin{array}{l}\mathrm{CmND} \\
308 \\
\end{array}$ \\
\hline & & mean $\omega^{2}$ & mean $\omega^{2}$ & mean $\omega^{2}$ & mean $\omega^{2}$ & mean $\omega^{2}$ & mean $\omega^{2}$ & mean $\omega^{2}$ \\
\hline $\begin{array}{l}\text { Pros } \\
\text { of smoking }\end{array}$ & $\begin{array}{l}\text { S/R } \\
P\end{array}$ & & & $\begin{array}{ll}53.1 & .01 \\
55.0 & \end{array}$ & $\begin{array}{ll}55.6 & .01 \\
57.8 & \end{array}$ & & & \\
\hline $\begin{array}{l}\text { Cons } \\
\text { of smoking }\end{array}$ & $\begin{array}{l}\text { S/R } \\
P\end{array}$ & & & $\begin{array}{ll}47.4 & .03 \\
43.3 & \end{array}$ & & & $\begin{array}{ll}49.6 & .01 \\
48.0 & \end{array}$ & \\
\hline $\begin{array}{l}\text { Social norm } \\
\text { parents }\end{array}$ & $\begin{array}{l}\text { S/R } \\
P\end{array}$ & & & & & $\begin{array}{ll}51.5 & .03 \\
55.8 & \end{array}$ & & $\begin{array}{ll}47.9 & .01 \\
49.9 & \end{array}$ \\
\hline $\begin{array}{l}\text { Social norm } \\
\text { siblings }\end{array}$ & $\begin{array}{l}\text { S/R } \\
P\end{array}$ & & & $\begin{array}{ll}51.8 & .01 \\
54.3 & \end{array}$ & & & & $\begin{array}{ll}47.7 & .02 \\
50.8 & \end{array}$ \\
\hline $\begin{array}{l}\text { Social norm } \\
\text { peers }\end{array}$ & $\begin{array}{l}\text { S/R } \\
P\end{array}$ & & & & & $\begin{array}{ll}56.3 & .01 \\
58.5 & \end{array}$ & & \\
\hline $\begin{array}{l}\text { Social } \\
\text { pressure } \\
\text { parents }\end{array}$ & $\begin{array}{l}\text { S/R } \\
\mathrm{P}\end{array}$ & & & & & & & \\
\hline $\begin{array}{l}\text { Social } \\
\text { pressure } \\
\text { siblings }\end{array}$ & $\begin{array}{l}\text { S/R } \\
P\end{array}$ & & & & & & & \\
\hline $\begin{array}{l}\text { Social } \\
\text { pressure } \\
\text { peers }\end{array}$ & $\begin{array}{l}\text { S/R } \\
P\end{array}$ & & $\begin{array}{ll}47.8 & .01 \\
49.4 & \end{array}$ & & & & & \\
\hline $\begin{array}{l}\text { Perceived } \\
\text { behaviour } \\
\text { parents }\end{array}$ & $\begin{array}{l}S / R \\
P\end{array}$ & $\begin{array}{ll}47.7 & .01 \\
49.2 & \end{array}$ & & & $\begin{array}{ll}50.9 & .02 \\
54.3 & \end{array}$ & & & \\
\hline $\begin{array}{l}\text { Perceived } \\
\text { behaviour } \\
\text { siblings }\end{array}$ & $\begin{array}{l}S / R \\
P\end{array}$ & & $\begin{array}{ll}48.9 & .01 \\
50.5 & \end{array}$ & & $\begin{array}{ll}50.9 & .02 \\
54.3 & \end{array}$ & & & \\
\hline $\begin{array}{l}\text { Perceived } \\
\text { behaviour } \\
\text { peers }\end{array}$ & $\begin{array}{l}S / R \\
P\end{array}$ & & $\begin{array}{ll}47.7 & .01 \\
49.3 & \end{array}$ & $\begin{array}{ll}52.6 & .06 \\
58.5 & \end{array}$ & & & $\begin{array}{ll}50.8 & .02 \\
54.1 & \end{array}$ & \\
\hline $\begin{array}{l}\text { Self-efficacy } \\
\text { friends }\end{array}$ & $\begin{array}{l}\text { S/R } \\
P\end{array}$ & $\begin{array}{ll}55.2 & .01 \\
54.0 & \end{array}$ & & & & & & \\
\hline $\begin{array}{l}\text { Self-efficacy } \\
\text { opportunities }\end{array}$ & $\begin{array}{l}\text { S/R } \\
P\end{array}$ & & & & & & & \\
\hline $\begin{array}{l}\text { Self-efficacy } \\
\text { emotions }\end{array}$ & $\begin{array}{l}S / R \\
P\end{array}$ & $\begin{array}{ll}54.4 & .01 \\
53.3 & \end{array}$ & & & & & & $\begin{array}{ll}53.8 & .01 \\
52.2 & \end{array}$ \\
\hline
\end{tabular}

Explanation of abbreviations:

$\mathrm{CmN}=$ Committed never smokers; $\mathbb{I N}=$ Immotive never smokers; IT = Immotive triers; IE = Immotive experimenters; $\mathrm{CE}=$ Contemplating experimenters; $\mathrm{IND}=$ Immotive nonsmoking deciders; $\mathrm{CmND}=$ Committed nonsmoking deciders.

$\mathrm{S} / \mathrm{R}=$ Stable or Regressed $\mathbf{P}=$ Progressed . 


\section{Test B3. Predictors of transitions}

Hypothesis B3 stated that different social cognitive characteristics would predict transitions from the various stages. The results with regard to longitudinal predictors of stage transitions are shown in Table 6.4. This Table shows all effect sizes $\left(\omega^{2}\right)$ of the cognitive concepts at baseline predicting forward transition (progression) that were equal to or larger than .01 (explained variance $=1 \%$ ).

Unique predictors of progression from the various stages were identified, confirming hypothesis B3. On the whole, however, effect sizes were small. The smoking behaviour of parents and self-efficacy appeared to play a role in progression from the committed never smoker stage. Among immotive never smokers, the pressure and behaviour of peers was predictive, as well as the smoking behaviour of siblings. The smoking behaviour of peers proved to have a medium effect size $\left(\omega^{2}=.06\right)$ in predicting progression from the trying stage. Attitude towards smoking (both pros and cons) also proved to predict stage transition from the immotive trying stage. Whereas friends were the most important models in the immotive never smoking and trying stages, parents and siblings proved to be important models in the progression from the immotive experimental stage. Perceived social norm of parents and peers proved to be important in the contemplation stage. Cons of smoking and peer smoking behaviour were the concepts that predicted progression from the immotive nonsmoking decider stage. Perceived social norm of parents and siblings, as well as emotional self-efficacy, predicted progression from the committed nonsmoking decider stage.

\section{DISCUSSION}

The main goal of the present study was to examine the usefulness of integrating motivational and behavioural stages of smoking initiation. Acknowledging the need for a model of smoking initiation to incorporate both motivational and behavioural stages, an integrative framework was developed that combined features of the Stages of Change Construct (Prochaska \& DiClemente, 1983; Stern et al., 1987), the concept of susceptibility to smoking (Pierce et al., 1995; 1996) and Flay's behavioural initiation model (Flay et al., 1983; Flay, 1993; Flay et al., 1998; USDHHS, 1994). Cross-sectional observations and examinations of a cross-cultural population were used to develop an integrative stage model that aimed to describe the developmental process of smoking initiation. The Model of Unmotivated Smoking Initiation of Children and Adolescents (MUSICA) originated from this process. The MUSICA postulates that youngsters experiment with smoking while they are in an unmotivated state with regard to starting to smoke regularly in the future. The study has shown that the seven stages distinguished in the model included substantial percentages of respondents in the population under study and that the stages showed the expected differences with regard to cognitive characteristics. Advanced stage assignment at baseline resulted in an increase of Odds Ratio of starting to smoke regularly during the twelve months follow-up period. Moreover, unique predictors of stage transitions were identified. However, effect sizes of predictors of transitions were found to be small.

Three findings in the present study add to the current state of scientific knowledge of the process of smoking initiation. First of all, an integration of 
motivational and behavioural dimensions has been shown to improve our understanding of the process of smoking initiation. Second, initial smokling behaviour has been found to be an unmotivated action with regard to future smoking behaviour. Youngsters appear to experiment with smoking without many rational plans to smoke in the future. Initial trial behaviour may thus be viewed as a behaviour that corresponds with the adolescent nature. Smoking is tried at the critical moments that individuals encounter during this turbulent period in their life (Engels et al., 1999). Third, the time frame of the Stages of Change Construct (Prochaska \& DiClemente, 1983) was found to be inapplicable to smoking initiation. The ability of the SCC to segment populations and tailor compatible interventions to them are attractive features (Whitelaw et al., 2000). However, although there are found to be motivational stages in the uptake of smoking behaviour, nonsmoking adolescents appear not to follow the time frame of the SCC algorithm. Variations in experimental behaviour and strength of intention are features that need to be added to the SCC algorithm for smoking initiation.

The MUSICA can be constructed using only two questions: one item that assesses the behavioural stage and one item measuring the motivational stage. The operationalisation of the items used in the present study is described elsewhere (Kremers et al., 2001a; 2001c). Importantly, the MUSICA focuses solely on the process that leads to the initiation of regular smoking. Although we acknowledge the relevance of studying stages of advanced smoking (and quitting) behaviour, the present study aimed to provide a detailed view of the early stages. The methods used to test the model have also been used in other studies. Examining cognitive characteristics within distinct groups is common practice in studies of the stages of change (e.g., Dijkstra et al., 1997; Pallonen at al., 1998; Velicer et al., 1999). Studying Odds Ratios of significant behavioural transitions has been applied to test the predictive validity of both the concept of susceptibility (Pierce et al., 1996) and the behavioural initiation continuum (Kremers, Mudde \& De Vries, submitted).

The present study did find a pattern with regard to the importance of social cognitive concepts. Self-efficacy was found to be a predictor of transition out of the committer stage. The smoking behaviour of parents was particularly predictive of progression from committed never smoking, whereas family norms were predictors of progression from committed nonsmoking deciding. Whereas peers appeared to be important models in immotive never smokers and triers, parents were important models with regard to the progression from the immotive experimenter stage. The social norms within the family then predicted whether the adolescents progressed from contemplating experimenters to the stage of regular smoking. However, the magnitude of the effect sizes of the above predictors needs to be regarded as small. Other sound longitudinal analyses have also failed to identify strong social cognitive predictors of adolescent smoking initiation (e.g., Collins et al., 1987; De Vries, Engels, Kremers, Wetzels \& Mudde, submitted; Engels et al., 1999; Graham et al., 1991). The predictive value of the cognitive characteristics, after previous use has been entered in the equation, has been found not to exceed an explained variance of $10 \%$ (Engels et al., 1999; De Vries et al., submitted). Some authors have explained low predictability of smoking initiation in terms of a long interval between two waves (e.g., Collins et al., 1987; De Vries et al., 1995; Guy, Smith \& Bentler, 1994; Pederson \& Lefcoe, 1987; 
Stein, Newcomb \& Bentler, 1996). However, another, more pessimistic, explanation is supported by the findings of the present study. Since initial smoking was found to occur in an immotive state, this may imply that smoking initiation does not require much cognitive energy. The predictability of adolescent smoking initiation, especially early trial behaviour, using social cognitive concepts, may thus be limited.

The results of the present study need to be viewed in the light of a selective dropout. Furthermore, three of the fourteen social cognitive scales could not be assessed on a reliable scale (i.e., $\alpha<.60$ ), and we used adolescents' self-reports on smoking behaviour. Several studies have found little discrepancy between self-reports and biochemical assessments of adolescent smoking behaviour (Komro et al., 1993; Stacy et al., 1990). In their review of the influence of the use of biological measures on the reporting of smoking behaviours among adolescents, Dolcini and colleagues (Dolcini et al., 1996) concluded that under optimum measurement conditions, the validity of adolescents' self-reported smoking is good, and shows a high level of concordance with biological indicators. Measuring conditions are optimised by assuring strict confidentiality of responses (Dolcini et al., 1996; Hansen, Mallotte \& Fielding, 1985; Murray \& Perry, 1987), which was done in the present study.

The present study may be viewed as a step towards an integrated model of smoking initiation, though the model needs to be tested further. Many possibly relevant hypotheses were not examined in the present study. For instance, some individuals may pass a stage much quicker than another. Individuals may even pass a certain stage in a split second. However, it is also conceivable that individuals might completely bypass a certain stage. The possibility of individual bypassing of stages is not assessed in our study. Additionally, the first cigarette (or even the first puff) may have a greater impact than the third of fourth (Hirschman et al., 1984). Further, we did not find a difference in the probability of taking up regular smoking between immotive triers and nonsmoking deciders. This result indicates that the stage of nonsmoking deciders might have to be subdivided into those who enter this stage as triers and those who enter it as experimenters. It is conceivable that ex-experimenters take up their previous behaviour more easily than ex-triers, who do not have the level of smoking experience that experimenters have. Qualitative research, using puff-by-puff or cigarette-by-cigarette records, might be a good method to assess these issues (Eissenberg \& Balster, 2000). 


\section{Chapter 7}

\section{General Discussion}

\section{ABSTRACT}

The purpose of this chapter is to summarise the findings and discuss the results of the various studies that have been described in this thesis. Several methodological issues are discussed, including the reliance on self-reports of smoking behaviour, the definitions of the various stages, generalisations that have been made and strategies of analysis that have been applied. Implications of the results are also discussed. Alternative explanations of the results of previous determinant studies are provided, and implications for smoking prevention practice are outlined. Finally, some directions for future research are indicated and additional concepts are proposed for inclusion in adolescent smoking research. 


\section{Part 1 Motivational stages of adolescent smoking initiation}

In part 1 of the thesis, the Stages of Change Construct (Prochaska \& DiClemente, 1983) of smoking acquisition was the major topic. This study started from the observation that the group of acquisition precontemplators was found to include over $90 \%$ of the total nonsmoking adolescent population in previous research (e.g., Aveyard et al., 1999; Kelley et al., 1999; Pallonen et al., 1998). This means that almost every early adolescent appears to state he or she does not want to start smoking within a period of 6 months. However, early adolescence is known as the period in which most adolescents take up smoking (USDHHS, 1994). It was hypothesised that the group of smoking acquisition precontemplators could be heterogeneous, and that heterogeneity could be expressed in the cognitive characteristics of adolescents residing in this stage. This hypothesis led to a search for subtypes within the precontemplation stage of adolescent smoking acquisition. Our search was inspired by two different lines of research. One was the search for subtypes within the precontemplation stage of smoking cessation. This line of research had already resulted in the identification of the subgroups of immotives and progressives (Dijkstra et al., 1997; Norman et al., 2000; Velicer et al., 1995). Immotives were found to be further removed from action than progressives. Whereas immotives lacked concrete plans to stop smoking, progressives did have some concrete motivation to quit. It was hypothesised that these two subgroups could also be identifiable in the mirror image situation of smoking initiation precontemplation. Another line of research had investigated the concept of susceptibility to smoking (Pierce et al., 1995). Smoking onset had been found to be influenced by the lack of a firm decision not to smoke (e.g., Pierce et al., 1996; Unger et al., 1997). Adolescents who were not committed to nonsmoking were more likely to start smoking than those who were committed. Consequently, we hypothesised that this group of committers would be further removed from starting to smoke than immotives. In our search for subtypes, we questioned the validity of applying the stages of change construct as such to smoking initiation. In particular, the time frame and the strength of intention were regarded as crucial features.

Chapter 2 reports on a study in which three subgroups within the precontemplation stage ('committers', 'immotives' and 'progressives') were compared to each other with regard to demographics and cognitive characteristics using a crosssectional research design. For this purpose, psychosocial characteristics were selected that had been found in previous studies to be associated with smoking behaviour. The concepts were based on the ASE model (De Vries et al., 1988). In line with the findings of earlier studies, it was found that the percentage of adolescents in the precontemplation stage of smoking acquisition was over $90 \%$ of our total sample of European adolescents. Further, the subgroups of committers, immotives, and progressives proved to differ from each other on each cognitive characteristic that we tested. Differences in self-efficacy expectations were greatest, while differences in parental smoking behaviour were found to be smallest between the several stages. The results on the other two motivational acquisition stages within the SCC, contemplation and preparation, were less supportive of an underlying stage process. These categories were small, and did not appear to differ with regard to cognitive characteristics. 
In the study reported on in Chapter 3, we used the results of the cross-sectional study as a starting point for a longitudinal investigation of a potential stage model. We proposed a four-stage model consisting of the stages committer, immotive, progressive and contemplator. The latter stage combined the stages of contemplation and preparation. The results established the sequential order in the stage model. The stages were predictive of regular smoking behaviour one year later. Of all groups, it was that of committers at baseline who were least likely to start smoking within the 12 months follow-up period, followed by immotives, progressives and contemplators. Corrected for demographic background variables and experimenting behaviour, the Odds Ratio of starting to smoke appeared to double with each stage transition. It was concluded that motivational stages should be taken into account in the examinination of the smoking initiation process, but that more research was needed on the relationship between early behavioural stages of smoking initiation (i.e., initial trying and experimenting) and the motivational stages of change.

\section{Part 2 Behavioural stages of adolescent smoking initiation}

In part 2 of the present thesis, the focus was on the investigation of behavioural stages of smoking initiation. Based on the work by Leventhal and Cleary (1980), a model of the stage process of smoking initiation had been constructed by Flay and colleagues (1983; Flay, 1993; USDHHS, 1994). Although this model has been adopted in the Surgeon General's report, and has considerable face validity, it had never been validated as such, except for one determinant study (Flay et al., 1998). Some reasons for this lack of validation studies were identified. First, the model does not define stages of quitting behaviour. Adolescents may (successfully or unsuccessfully) decide to quit smoking both during the initiation process and during the stage of regular smoking. These stages of 'deciding not to be a smoker' and 'quitting' were not labelled in Flay's stage model of the smoking initiation process. Further, the definitions of the various stages were sometimes unclear, and operationalisations of these stages were inconsistent across the various studies in which the model was applied. As a result of these observations, we investigated the adaptation and initial validation of Flay's behavioural model of smoking initiation.

Chapter 4 reports the findings of our study of the usefulness of distinguishing two stages of quitting. The first cessation stage was labelled 'nonsmoking deciders', and included those adolescents who had tried or experimented with smoking, but had decided not to smoke before they started to smoke on a regular basis. The second cessation stage was labelled 'quitters', and included those adolescents who stopped smoking after having smoked regularly. Thus, a six-stage model of smoking initiation was created, consisting of never smokers, triers, experimenters, regular smokers, nonsmoking deciders, and quitters. The six stages were compared in a cross-sectional design with regard to psychosocial characteristics. This model was compared with a four-stage model, in which the two cessation stages were included in the stages of trying and experimenting, depending on the number of cigarettes smoked. The latter was similar to the model used in the only validation study that was available at that time (Flay et al., 1998). Relevant cognitive features were studied as indicators of the risk of future smoking behaviour. The study proved the relevance of distinguishing the two categories of ex-smoking, in that the adolescents in these groups differed 
qualitatively from those in the current smoking groups. Thus, nonsmoking deciders differed from triers and experimenters in that they had less risky cognitive characteristics. Moreover, quitters had less risky cognitive characteristics than regular smokers. However, the hypothesis that quitters would also be clearly distinct from experimenters could not be confirmed with the cognitive characteristics that we used in this cross-sectional study. We assumed that other factors, like addiction to nicotine, would differentiate between these groups.

In Chapter 5, we tested the six-stage behavioural model of smoking initiation. In order to make the model testable, we proposed an operationalisation of the various stages, including a measuring instrument based on these stage definitions. We then tested the model with regard to stage sequences and the power to predict future daily smoking behaviour. Stage transitions proved to have occurred as expected. Moreover, daily smoking at twelve months follow-up was successfully predicted. The levels of increasing smoking behaviour at baseline (i.e., never smoking, trying, experimenting, and regular smoking) appeared to result in an increase of smoking daily at follow-up. Also, the levels of current nonsmoking at baseline (i.e., never smokers, nonsmoking deciders, and quitters) appeared to result in an increased risk of daily smoking at follow-up. Moreover, quitters at baseline were less likely to be daily smokers at follow-up than regular smokers at baseline, and nonsmoking deciders were less likely to be daily smokers than experimenters. However, nonsmoking deciders at baseline did not have the hypothesised smaller chance of being daily smokers at follow-up than triers. The level of current smoking behaviour of triers and the level of past smoking experience of nonsmoking deciders appeared to compensate each other. Both stages had an increased risk of progressing towards daily smoking, which was about six times that of never smokers. Once an adolescent progressed from either one of these stages to the stage of experimentation, the risk of daily smoking was found to double. The behavioural model by Flay and colleagues was concluded to have potential for the study of adolescent smoking and its determinants. However, we ended Chapter 5 by signalling the possibility of integrating motivational levels of smoking acquisition within the behavioural stages of initiation. Motivational stages as studied in part 1 of the thesis have been shown to be valuable for explaining and predicting adolescent smoking behaviour. Insights into the interplay between motivations and trial behaviour could improve our understanding of why certain adolescents do and others do not progress beyond the early stages of the smoking initiation process.

\section{Part 3 Integration of motivational and behavioural stages}

Part 3 of the thesis built on the observations in parts 1 and 2. Both the motivational and behavioural stages of smoking initiation proved to have the potential to provide a better understanding of the stage process of smoking onset. It was hypothesised that integrating the motivational and behavioural stages of initiation would yield a more complete picture of the processes that play a role in the eventual uptake of regular smoking behaviour. A framework that fully acknowledged all motivational and behavioural stages assessed in parts 1 and 2 was composed in the study reported on in Chapter 6. Observations of prevalence rates for the various categories of the framework and a tentative hypothesis of the usefulness of distinguishing the various categories led to the proposal of an integrated Model of Unmotivated Smoking 
Initiation of Children and Adolescents (MUSICA). The MUSICA postulates that the first behavioural stages of initiation occur in an unmotivated state with regard to future smoking behaviour: the 'unmotivated cycle'. Youngsters try and experiment with cigarettes without having concrete, rational plans to start smoking in the future. They may decide to quit trying or experimenting, which may however often be followed by renewed experimental behaviour. Once individuals have firmly and rationally committed themselves to nonsmoking, their risk to start smoking regularly in the future is assumed to be considerably reduced. Once individuals have progressed to the contemplation stage, in which they make concrete plans about their future smoking behaviour, they are assumed to be highly likely to start smoking on a regular basis.

The stages of the MUSICA proved to include more than $97 \%$ of all respondents in our cross-cultural sample. The early adolescents in the various stages proved to differ with regard to their social cognitive characteristics in that those in the more advanced stages had more risky characteristics with regard to the likelihood of future smoking behaviour. Longitudinal examination showed that advanced stage assignment at baseline led to an increased probability of smoking regularly at follow-up. As hypothesised, social cognitive predictors of stage progression were found to differ between the various stages. Self-efficacy was found to be a predictor of transition out of the committer stage. The smoking behaviour of parents was particularly predictive of progression from committed never smoking, whereas family norms were predictors of progression from committed nonsmoking deciding. Peers were found to be important models in immotive never smokers and triers, while parents were important models with regard to the progression from the immotive experimenter stage. The social norms within the family predicted whether the adolescents progressed from contemplating experimenter to the stage of regular smoking. However, overall effect sizes of the cognitive predictors were small, which may have been caused by the relatively long interval between the two measurements. However, the MUSICA offers an alternative explanation. Since smoking initiation is postulated to be a low cognitive energy, unmotivated, action, social cognitive concepts may not be able to explain much of the variance in smoking behaviour in prospective designs.

\section{METHODOLOGICAL ISSUES}

This section discusses some shortcomings of the studies and some methodological choices. The first methodological issue concerns the validity of self-reports of adolescent smoking, the second that of the stage definitions and their operationalisations and the third the statistical methods used to test the hypotheses.

\section{Self-reports of smoking behaviour}

Surveys of smoking behaviour rely heavily on self-reports. The reliability and validity of self-reports among adolescents have been extensively investigated, as have possibilities to increase the reliability and validity of self-reported cigarette use. Just as in adult smoking research, several authors have tried to validate adolescent self-reports by biochemical measures like $\mathrm{CO}$ rates in the breath and cotinine levels in the blood. However, the intermittent and irregular cigarette use among adolescents cannot be 
reliably validated with biochemical measures (Klesges, Klesges \& Cigrang, 1992). Biochemical measures cannot trace smoking that took place more than 24 hours before the measurement, nor can they distinguish between low levels of smoking and inhaling environmental smoke ('passive smoking').

An attempt to increase the validity of self-reported cigarette use was the introduction of a bogus pipeline procedure (Jones \& Sigall, 1971). The bogus pipeline procedure is based on the announcement of a possible biochemical validation after the completion of the questionnaire, without actually using such a validation. Although early research into the bogus pipeline procedure found increased self-reporting (e.g., Evans, Hansen \& Mittelmark, 1977), later research has put this procedure under question (Hansen et al., 1985; Sussman et al., 1995). Freier, Griffith and Chasnoff (1991) suggested that a major problem in the use of a bogus pipeline is the false positive rate. Infrequent users may believe that their tobacco use will be detected by some biochemical device, and may report relatively elevated rates of use. Hansen and colleagues (1985) found that their potential participants frequently responded negatively to a bogus pipeline procedure, with many refusing to participate. Additionally, the use of a bogus pipeline procedure involves deception of the participants, and there are serious ethical considerations about the appropriateness of employing deception in research, especially among children and adolescents (Baumrind, 1985).

Although research has shown that adolescents can report accurately, this is only the case when sufficient assurance of confidentiality is given. Williams, Eng, Botvin, Hill and Wynder (1979) found that $98 \%$ of the adolescents who reported never to have smoked had non-detectable plasma cotinine levels. Hansen and colleagues (1985) did not find differences in self-reports between bogus pipeline and confidentiality conditions. In a review of the influence of biochemical measures on the reporting of smoking behaviours among adolescents, Dolcini and colleagues (1996) concluded that, under ideal measurement conditions, the validity of adolescents' self-reports about smoking is good and shows a high level of agreement with biochemical measures. Measuring conditions can be optimised by assuring strict confidentiality of the responses (Dolcini et al., 1996; Hansen et al., 1985; Murray \& Perry, 1987). Confidentiality procedures were carefully applied in the studies reported on in this thesis.

\section{Stage definitions}

We have based our stage definitions on previous research in a large variety of contexts. For example, we examined early research in the area of smoking behaviour as well as the latest developments in the area of cognitive susceptibility to smoking. Similarly, we have assessed standards in the Stages of Change Construct as well as those set by the World Health Organization. However, the validity of these standards has hardly been assessed. One such standard is the WHO standard of 100 cigarettes to define established smoking (WHO, 1998). Another cut-off point is that of 'an intention to start smoking within the next 5 years', which we have used to define those adolescents who have at least some concrete plans regarding their future smoking behaviour. Although a period of five years may represent the total period of 
adolescence for the 13-year-olds in our sample, this cut-off point must be regarded as arbitrary.

A comment can be made on the use of the term 'stage' in the present thesis. Some authors have argued that a stage can only be labelled as such when it implies a sequential order; one needs to pass through a stage in order to reach the next (Bandura, 1997; Weinstein et al., 1998). In the present thesis, however, various stages have been labelled as such even though they do not need to be passed through to reach another stage. For example, the motivational stage of 'committing' does not need to be passed in order to reach any other stage. The behavioural stage of nonsmoking deciding also lacks a sequential nature. Similarly, in the Model of Unmotivated Smoking Initiation of Children and Adolescents, the committed never smoking stage, the immotive nonsmoking decider stage and the committed nonsmoking decider stage do not need to be passed to reach the stage of regular smoking behaviour. Moreover, the immotive experimenter stage does not need to be passed in order to reach the stage of committed nonsmoking deciding. Thus, strictly speaking, the MUSICA as a whole cannot be viewed as a stage model. Consequently, some authors prefer to use the term 'phase' instead of 'stage' in such cases (Bolman \& De Vries, 1998; Kremers et al., 2001c (note $5)$. On the other hand, it seems unrealistic to insist on strict assumptions for stage models of addictive behaviours (Sutton, 2001). Recently, it has been argued that a number of less restrictive stage models could be specified (Sutton, 2001). The MUSICA incorporates more than one endpoint. The model postulates that adults may be in the stage of (1) committed never smoker, (2) committed nonsmoking decider, (3) regular smoker or (4) quitter. Since each category implies the need for a sequential order to reach at least one of the endpoints within the model (i.e., the immotive nonsmoking decider stage needs to be passed to reach the committed nonsmoking decider stage, and the immotive experimenter stage needs to be passed to reach the regular smoker stage), the term 'stage' is used in the present thesis.

Many possibly relevant hypotheses have not been studied in the present thesis. For instance, the stage of immotives might include relevant subtypes. Since this stage is the largest stage of all, the prospect of providing finer discriminations continues to make identification of subtypes within this group desirable (see also Crittenden et al., 1994). As discussed in Chapter 6, another hypothesis that has not been assessed is the existence of subtypes within the behavioural stages of initiation. For example, it is conceivable that the first cigarette that is tried (or even the first puff) has greater impact than the third of fourth (Hirschman et al., 1984). Moreover, the stage of nonsmoking deciders might be divided into those who enter this stage as triers and those who enter it as experimenters. It is conceivable that ex-experimenters resume their previous behaviour more easily than ex-triers, who do not have the level of smoking experience that experimenters have. Additionally, since the studies focussed on the process towards the initiation of regular smoking behaviour, the validity of the Action and Maintenance stage within the SCC of smoking initiation was not tested.

Some researchers have proposed overall theories of drug use or problem behaviours (Flay \& Petraitis, 1994; Jessor \& Jessor, 1977; Werch \& DiClemente, 1991). Instead of focusing on a specific deviant behaviour, they assume several drug use behaviours to be explained by the same theory. We have not assumed such a level 
of generalisability of the stage models across the various drugs; our focus has been solely on adolescent smoking initiation.

\section{Generalisations and inferences}

Several remarks need to be made with regard to conclusions that have been drawn in the present thesis. First of all, we have studied a population of early adolescents (mean age 13.3 years at baseline). The results are generalised across the 'smoking initiation process' as a whole (e.g., within the MUSICA). However, it is unsure whether the same results would have been found in younger or older individuals. Secondly, although a cross-cultural data set was used, cross-cultural differences were not studied in depth. In contrast, we have assumed generalisability across cultures. Country was viewed as a possible confounder instead of a topic of research. Comparisons between countries would have been troubled by the fact that the samples in the various countries could not be viewed as representative for the total population of the particular country (see also De Vries et al., submitted). Thirdly, our social cognitive concepts were directed towards 'smoking'. For example, attitudes were assessed with regard to smoking behaviour in general. In contrast, inferences on the low capacity of these concepts to predict stage transition were made with regard to smoking initiation. Consequently, the operationalisation of the items on attitude, social influence and selfefficacy towards initial trial behaviour might have resulted in higher predictive value of these concepts (see also Ajzen \& Fishbein, 1980). However, practical problems would have occurred when this line of reasoning would have been strictly applied, since adolescents in different behavioural stages would have required different operationalisations of proximal concepts (e.g., never smokers would require other questions than triers, etcetera).

\section{Strategies of Analysis}

Our research focussed on the testing of hypotheses derived from our assumption of underlying stage processes of smoking initiation, and we have chosen our analytic strategies accordingly. Thus, we did not use analytic strategies that are merely hypothesis-generating, rather than hypothesis-testing. For instance, some studies have applied cluster analysis to generate subgroups of individuals (e.g., Norman et al., 2000; Velicer et al., 1995). This strategy was not applied in Chapter 2, since we examined the possibility to identify specific subtypes, based on information with regard to the strength of intentions not to smoke. With our strategy, we were able to test whether the motivational stages could serve as a 'surveillance measure' (see Pierce et al., 1995). Additionally, cluster analysis implies methodological problems with regard to the interpretation of the results (Blashfield, 1980; Isenhart, 1997). Similarly, we did not use analytic strategies that make no assumptions of developmental processes. Individual growth curve modelling, for example, allows the assessment of individual change to be represented by straight-line, curvilinear or discontinued trajectories (Willet, 1997). On the other hand, we agree with the postulation that change should not be viewed as the difference between 'before and after'. Therefore, more waves of data would have been more informative than the two that we have used for the present research. Moreover, it would have been more informative when shorter intervals would have been used between the measurements. Since adolescence is a 
period in which many changes occur within a short period of time, a twelve months interval might be too long to monitor salient transitions properly. A three months interval, or even shorter, would have been more appropriate.

The analytical methods we used to study predictors of stage transitions were based on univariate techniques. Since multivariate analyses result in the deletion of factors that might help to predict smoking behaviour but are 'overlapped' by other factors, studies that aim to identify unique predictors of transitions benefit from univariate analyses of the data (Tabachnick \& Fidell, 1996). When factors are correlated, they have shared or overlapping variance. If this correlation is substantial, both factors might 'knock each other out of the solution', or one factor might be knocked out, depending on the analytical strategy. This would lead to incorrect conclusions about variables relevant for the prediction of smoking behaviour. Moreover, the presentation of univariate results leaves room for accurate comparisons across studies (Engels et al., 1999; Tyas \& Pederson, 1998).

On the other hand, if applied correctly (i.e., the dependent variable is continuous or a polychoric correlation matrix is analysed) structural equations modelling is a multivariate technique that may provide information on how and why variables predict onset. For example, a distal variable may be important, as evidenced by its indirect effect, even though its univariate correlation with smoking behaviour may be small (Conrad et al., 1992). Since our major interest was to examine the validity of stage models the aim of finding unique predictors of stage transition instead of gaining detailed insights into processes of proximal and distal influences of determinants, we have emphasised univariate analyses in our studies.

Studies of relevant predictors of smoking behaviour are often (if not always) based on null hypothesis significance tests. Once p-values are lower than .05 , variables are labelled as 'significantly predictive'. However, null hypothesis significance tests are highly dependent on sample size. With large samples, a small difference between two groups will easily exceed the .05 criterion. However, such a significant result does not give any information on the practical relevance of the particular variable. Since there is always some correlation between two variables, a large enough sample will always lead to a significant result (see also Cohen, 1994). Since we used a large set of data, we have tried to be cautious in our interpretation of statistically significant results. Moreover, where possible, we have tried to avoid the interpretation of $p$ values. Instead, we have tried to use exploratory data analysis, a standardisation in measurements, confidence intervals and effect sizes to interpret our data (see also Cohen, 1994; Tukey, 1962). The conclusions on the effect sizes in the present study are based on Cohen's (1988) descriptive guidelines. The effect size values served as operational definitions of the qualitative adjectives 'small', 'medium', and 'large'. Of course, like all statistical conventions (e.g., the $\mathrm{p}<.05$ level), these definitions are arbitrary. Cohen (1988) indicated that the definitions of effect size conventions 'will be found reasonable by reasonable people'. However, since the guidelines are relative and general, they may not be reasonably descriptive in the area of adolescent smoking initiation.

The conclusions drawn from the studies in the present thesis need to be interpreted in the light of the fact that the ultimate tests of stage theories are experiments with matched and mismatched interventions (see also Weinstein et al., 
1998). Two specific types of experiments can provide such tests: treatments can be matched to stage, or treatments can be sequenced in an experimental setting.

\section{IMPLICATIONS OF THE FINDINGS}

\section{Predictability of smoking initiation with social cognitive constructs}

The studies in the present thesis have shown that adolescent smoking uptake behaviour might not be the result of rational considerations in the extent that social cognitive models assume. In other words, the 'predictability' of smoking initiation is low, when constructs of social cognitive models are used.

A great deal is known about social cognitive factors that are associated with smoking behaviour (Conrad et al., 1992; Petraitis et al., 1995; Tyas \& Pederson, 1998). However, we know a lot less about factors that predict smoking behaviour. Most studies of the relations between predictor variables and smoking behaviour have used cross-sectional designs. This kind of research implicitly postulates that factors associated with smoking behaviour at a particular point in time are also predictive of smoking at a later point in time. However, cross-sectional research cannot distinguish causes of behaviour from the results of behaviour.

Additionally, most longitudinal studies on adolescent smoking initiation cannot distinguish between predictors and determinants. Most studies of the factors that influence adolescent smoking have lumped stages of initiation (e.g., never smoking, trying and experimenting) together (Robinson et al., 1997). In these studies, the identification of social cognitive predictors of regular smoking behaviour could be explained by two different processes. Cognitions lead to stage transition (1) and stage transition leads to cognitive changes (2). Since many adolescents in advanced behavioural stages will eventually take up regular smoking, it remains unclear whether the predictive value of cognitions reflects the consequences of behavioural transitions within the aggregated stages (e.g., from never smoking to trying), or whether it reflects the influence of cognitions on the transition under study (Engels et al., 1999; Stacy, Bentler \& Flay, 1994; Sutton, 1992). When initiation stages are lumped together in determinant studies, a consequence of a stage transition may be read as a determinant of regular smoking behaviour. Studies that minimised the possible effects of earlier stage transitions, for example those examining a sample of never smokers, found small effects of cognitions on behaviour (Collins et al., 1987; De Vries et al., submitted; Engels et al., 1999; Graham et al., 1991).

Inverse cognition-behaviour relationship: An alternative explanation of social cognitive differences between stages

If social cognitive constructs do not predict smoking initiation, how can it be explained that the various stages differ with regard to social cognitive characteristics? Social cognitive differences between the various stages might be explained by other processes than the influence of cognitions on behaviour. Although Bandura (1977) described the concept of reciprocal determinism in his Social Cognitive Theory, most theories and empirical studies focus on the one-way influence of cognitions on behaviour (see Flay \& Petraitis, 1994 for a review). However, from the social learning 
perspective, psychological functioning is a 'continuous reciprocal interaction between personal, behavioural, and environmental determinants' (Bandura, 1977; p. 194). Thus, the effects of behaviour on the person might be as important as the effects of the person on behaviour.

An example of an inverse cognition-behaviour relationship is the concept of attribution (Weiner, 1985; 1986), while other examples include the false consensus effect (Holmes, 1968; Marks \& Miller, 1987; Mullen et al., 1985; Sherman et al., 1983) and dissonance reduction (Bem, 1972; Festinger, 1957). The inverse relationship between behaviour and cognitions in these examples and its application to adolescent smoking initiation is discussed below.

Weiner's attributional model $(1985,1986)$ indicates that when behavioural outcomes are negative, unexpected or important, a causal search is started, resulting in causal ascriptions that try to explain the outcomes. A person attributing success to a stable cause (e.g., ability) will have a higher expectancy of success when having to perform the same behaviour again, compared to someone who attributes success to an unstable cause (e.g., luck). After failure, this effect is reversed (Kok et al., 1992). Expectancies of success resemble Bandura's ideas of self-efficacy in the sense that both concepts are based on a cognitive appraisal of past behavioural experiences (Bandura, 1986, p. 349; Weiner, 1986, p. 181). In adolescence, many individuals are confronted with offers of cigarettes. Failure to refuse an offer may lead to lower selfefficacy expectations with regard to future offers.

Empirical investigations have consistently identified strong relationships between peer behaviour and individual behaviour (peer group homogeneity). Hence, peer influences are considered to be a major determinant of adolescent smoking initiation (Bauman \& Ennett, 1996). However, peer influences were in most cases not found to be an important factor in sound longitudinal studies (Bauman \& Ennett, 1996; De Vries et al., submitted; Engels et al., 1999; Kandel, 1978). Distorted perception of peer smoking has been proposed as an explanation for these findings (Bauman \& Ennett, 1996; Engels, Knibbe, De Vries, Drop \& Van Breukelen, 1999). Some studies have shown that smoking adolescents tend to overestimate the smoking behaviour of their friends and agemates. This well-established principle has been labelled false consensus effect or projection (Bauman \& Ennett, 1996). When projection occurs, the behaviour considered to be the friends' is the consequence rather than the cause of the adolescent's behaviour.

An inverse attitude-behaviour relationship has been assumed to occur in low involvement conditions (Chaffee \& Roser, 1986; Ray et al., 1973; see Figure 7.1).

Figure 7.1. Hierarchies of effects model

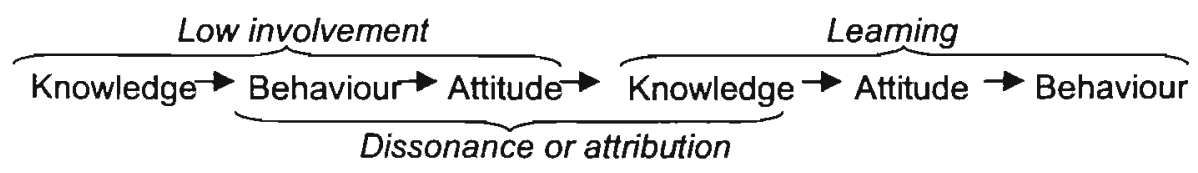


Involvement can be viewed as the most important feature of the concept of motivation (see e.g., Petty \& Cacioppo, 1986), and may refer to “... the complexity or extensiveness of cognitive and behavioural processes characterising the overall... decision process" (Houston \& Rothschild, 1978, p. 185). If individuals are not motivated for or involved in a particular behaviour, they might not tend to put much energy in their decision process. Instead, they are likely to act without using much rational consideration, and to form their attitudes about the behaviour after it has occurred (Ray et al., 1973). Consequently, low involvement behaviour is essentially unpredictable (Chaffee \& Roser, 1986). Several mechanisms have been proposed over the years that might account for such attitude change (Chaiken \& Stangor, 1987), including self-perception (Bem, 1972; Fazio \& Zanna, 1981; Fazio, Zanna \& Cooper, 1977; Higgins \& Rholes, 1978), dissonance reduction (Fazio et al., 1977; Festinger, 1957), impression management (Riess, Kalle \& Tedeschi, 1981) and ego enhancement (Steele \& Liu, 1983). Others have indicated that next to involvement, the opportunity to pursue cognitive elaborations is an important feature (Fazio \& Towles-Schwen, 1999). When individuals are not involved, or when they do not have the opportunity to deliberate, they will act in a more spontaneous matter.

In short, the finding that smoking initiation occurs in an unmotivated (low involvement) state might indicate the formation of attitudes after a behavioural transition is made in the smoking uptake process. Crucial events, in which smoking suddenly becomes an important topic (e.g., someone offers a cigarette), may put an individual in a position to decide without having the motivation or the opportunity to deliberate.

\section{Relative importance of distal concepts}

Smoking-specific cognitions fluctuate more with trial behaviour than distal concepts. This might explain that proximal influences have traditionally been conceptualised as better predictors of future behaviour than distal ones. However, as argued in the previous section, these fluctuations may be partly attributable to the consequence of stage transitions rather than to the cause of these transitions. This finding might lead to the hypothesis that a larger relative influence should be attributed to distal factors than has previously been conceptualised in social cognitive models. Distal factors like selfesteem (Stacy, Sussman, Dent, Burton \& Flay, 1992), proneness to deviance (Chassin et al, 1984; Chassin, Presson \& Sherman, 1989), parenting styles (Steinberg, 1999) and genetic factors like inherited vulnerability to nicotine addiction (Koopmans, Slutske, Heath, Neale \& Boomsma, 1999) might be more relevant causes of smoking onset than previously assumed. These influences might bypass proximal factors in their influence on behaviour. In their review of prospective research on predictors of adolescent smoking behaviour, Conrad, Flay and Hill (1992) concluded that "Selfesteem received fairly consistent support [as a predictor of initiation] from the reviewed longitudinal studies. This is better than we would have expected from our reading of previous cross-sectional studies". These findings could be explained by a reinterpretation of the causal value of proximal concepts, as described above. Furthermore, it is conceivable that distal concepts may explain differences in stage transition impact on proximal concepts. The studies in the present thesis are limited in that the possibly relevant distal concepts mentioned above were not assessed. 


\section{Smoking prevention efforts}

Peer influences, smoking attitudes, and self-efficacy are the main factors commonly dealt with in theoretically based prevention programmes for adolescents (e.g., De Vries et al., 1988; Glynn, 1989; Peterson, Kealey, Mann, Marek \& Sarason, 2000). However, prevention interventions have produced disappointing results. Effects of smoking prevention programmes have been found to be poor (Ausems, Mesters, De Vries \& Van Breukelen, submitted; Best, Thomson, Santi \& Brown, 1988; De Vries, 1989; De Vries et al., in preparation; Dijkstra et al., 1999; Rundall \& Bruvold, 1988) or absent (e.g., Aveyard et al., 1999; Peterson et al., 2000). With one exception (Botvin, Baker, Dusenbury, Botvin \& Diaz, 1995), no long-term intervention effects have been observed to date. Consequently, the question arises whether smoking prevention interventions could actually be expected to have considerable success.

The Elaboration Likelihood Model (ELM) of persuasion describes the process of attitude change as a result of persuasive communication (Petty \& Cacioppo, 1986). Basically, two different persuasion processes are distinguished in the ELM: attitude change via the 'central route' and attitude change via the 'peripheral route' (Cialdini, Petty \& Cacioppo, 1981; Petty \& Cacioppo, 1981; 1984). The important distinction between the two routes is the amount of cognitive effort an individual spends on the content of the persuasive message. Whereas the central route involves a careful and thoughtful scrutiny of the information presented, the peripheral route involves simple cues in the persuasion context (e.g., attractive pictures, music). An important key to the route to persuasion consists of motivational factors (Verplanken, 1989). If individuals are unmotivated, persuasive information may be unlikely to lead to careful and thoughtful central route considerations. The finding that most adolescents are immotive with regard to future smoking behaviour leads to pessimism with regard to the potential of primary smoking prevention interventions. Moreover, it may explain the absence of success of earlier smoking prevention efforts.

On the other hand, the studies have yielded findings that might imply the potential of secondary prevention of smoking. Many adolescents appear to decide not to be a smoker after initial trial behaviour. Research has shown that adolescents who have had direct experience with a behaviour are more likely to process information via the central route (Verplanken, 1989). Moreover, stronger relationships between attitudes and future behaviour have been found when attitudes had been formed by direct experience (see, e.g., Fazio, 1985; Fazio, Chen, McDonel \& Sherman, 1982; Fazio \& Zanna, 1981; Manstead, Proffitt \& Smart, 1983; Regan \& Fazio, 1977). Adolescents in more advanced stages might be more receptive for provided 'rational' information than adolescents that do not have behavioural experience with smoking.

Instead of preventing trial behaviour, interventions might profit from following the principle of the hierarchies of effects (Chaffee \& Roser, 1986; Ray et al., 1973; Figure 7.1). Interventions in children should aim to provide information (knowledge). These interventions, as well as those in early adolescence, should emphasise the use of peripheral cues. Such interventions acknowledge the low involvement hierarchy of effects. This strategy is similar to that often applied for commercial purposes (e.g., Jain, 1978). Tobacco companies use the strategy of applying attractive peripheral cues in order to achieve the opposite effect of health promotion efforts. 
Many adolescents will try smoking, and this trial behaviour may be viewed as a 'natural' action in the adolescent period. Although this represents an important step toward the eventual uptake of regular smoking behaviour, this behaviour will result in smoking-specific cognitions (i.e., dissonance hierarchy). These cognitions, which are more finely tuned and specific than in the stage of never smoking, will either lead to a 'weak' decision not to smoke regularly (immotive nonsmoking deciders), or to the contemplation of regular smoking behaviour (contemplating experimenters). Interventions should support the first decision by trying to convince adolescents in the immotive nonsmoking decider stage to commit themselves to nonsmoking. Committers might be helped to fulfil their goal by helping them to furnish the goal with implementation intentions (Gollwitzer, 1993; see also the section on 'Future Perspectives').

Interventions aimed at adolescents in the contemplating experimenter stage should aim at regression. Rational information may lead to more central processing (i.e., learning hierarchy) in this situation than in any other stage in the initiation continuum. However, the fact that adolescents seem to pass through this stage rather quickly may form a major challenge to intervention designers.

\section{FUTURE PERSPECTIVES}

\section{Tests of the stage models}

The studies in the present thesis have led to the development and testing of various developmental models of smoking initiation, which should be tested further by the empirical application of the conclusions derived from it. If the conclusions are shown to be true, the theory is corroborated. If the conclusions are shown to be false, this should be taken as a signal that the theory is not entirely correct (in logical terms, the theory is falsified) (Popper, 1963). Observations that are not in agreement with the hypotheses that can be inferred from the model should be interpreted as limiting the validity of the theory. We have described the instruments that are used in this thesis. We do not need to argue that replication studies should be tested using sound instruments and methodologies. Experimental studies of matched and mismatched interventions may be the ultimate test.

\section{Studying the impact of social influences in the various stages}

Resisting social influences is often used as a social psychological basis for developing health promotion interventions. The social influence paradigm assumes that many adolescent health behaviours are to a great extent the result of social influences. This assumption is based on studies showing high correlation between an adolescent's behaviour and peer behaviours. Next to the process of projection (see section on inverse cognition-behaviour relationship), another alternative explanation for peer group homogeneity is the process of selection. The peer selection paradigm states that adolescents that engage in smoking behaviour seek out friends who also smoke (Bauman \& Ennett, 1996; Engels, Knibbe, Drop \& De Haan, 1997).

Many social influence studies were unable to control for friend selection as an alternative explanation since assessment of selection effects requires specific designs, 
measures and analytical methods. Information of respondents is required at different time points, as well as data on social networks (Ennett \& Bauman, 1994). To date, no study accurately separated social influence and selection processes. New social network analysis techniques (Snijders, in press) have recently been developed to overcome shortcomings of previous studies. Social network simulation techniques may be better at revealing projection and selection effects than current approaches, since they take better account of reciprocity of relationships and other endogenous network effects.

Projection and selection effects might differ between the various stages of smoking initiation. For instance, social influences could be more important in the early stages of initiation (USDHHS, 1994). Insights into the processes of projection and selection or their determinants might help to explain why some adolescents advance beyond experimenting and others do not. Thus, studying projection and selection in a developmental context might help to distinguish between the differential impact of the alternative explanations of social influence and the 'real' effects of social influence in each stage of smoking initiation. This will enable us to gain a better understanding of the relevance of addressing social influences in interventions.

\section{Inclusion of additional concepts in research on smoking initiation models}

The studies reported on in the present thesis have shown the importance of including concepts in research on adolescent smoking initiation that have not, or rarely, been included so far.

As a result of the postulations of the Model of Unmotivated Smoking Initiation of Children and Adolescents (MUSICA), involvement is a concept that needs to be investigated in the context of adolescent smoking acquisition. The concept of involvement was first introduced in psychology (Sherif \& Cantril, 1947), then in consumer behaviour (Krugman, 1965) and more recently in other areas like leisure behaviour (Bloch \& Bruce, 1984; Reid \& Crompton, 1993). Involvement is an unobservable state of motivation, arousal or interest (Rothschild, 1984). Its consequences are types of searching, information processing and decision making (Reid \& Crompton, 1993). The work of Laurent and Kapferer (1985) has made it clear that involvement is a multidimensional concept that can be measured in order to construct an involvement profile (IP). Future research should aim to apply the IP to the subject of adolescent smoking behaviour. The IP of smoking might contribute to our understanding of the causal relationships between social cognitive concepts and smoking initiation behaviour.

The present thesis has indicated that smoking initiation is not exclusively the result of rational, concious, considerations. Smoking initiation behaviour incorporates both concious and unconcious processes. Therefore, studies of the smoking initiation process might profit from the application of dual-process models (see Chaiken \& Trope, 1999). These models postulate that behaviour is the result of a simultaneous influence of conscious and non-conscious processes. The application of dual-process models to smoking initiation might help to gain insight into the circumstances under which smoking initiation is a conscious (motivated) or unconscious (unmotivated) action (see also Bargh \& Chartrand, 1999). 
Future studies need to address the concept of time as a predictor of future smoking behaviour. The concept of 'duration dependence' postulates that time spent in a current stage determines the probability of a subsequent stage transition (Featherman \& Petersen, 1986). Measuring the amount of time an adolescent spends in a particular stage might suggest which adolescents are more at risk to reach the level of daily smoking than others. Consequently, future research should include survival analysis and hazard models that treat time as the outcome variable (Mayhew et al., 2000; Willet \& Singer, 1991). Predictors can be studied with regard to their impact on the time before a transition occurs.

Recently, the importance of studying the influence of addiction to nicotine on adolescent smoking uptake has been acknowledged (Eissenberg \& Balster, 2000). The sensory and pharmacological effects of nicotine are initially aversive, but tolerance appears to develop rapidly and the skill to avoid overdosage is quickly acquired (Russell, 1990). The change in the role of nicotine from being aversive to rewarding and reinforcing may be a factor in the initiation process (Russell, 1990). Unfortunately, there are no data that conclusively reveal exposure to nicotine and its physiological and subjective addictive effects in adolescents in early stages of smoking behaviour (Eissenberg \& Balster, 2000). Such data may reveal early stage addiction as a predictor of future tobacco use. The use of an adapted version of the Fagerström questionnaire of addiction (Prokhorov et al, 1996; 2000) may be a useful instrument.

Although the concept of implementation intentions (Gollwitzer, 1993; 1996) has only been used in research on 'getting started' with healthy behaviours (e.g., starting to exercise regularly, adopting a healthy diet), the principles underlying this concept might also be applicable to 'not getting started' with smoking. Like the concept of action plans, introduced by Leventhal and colleagues in 1965 (Leventhal, Singer \& Jones, 1965), implementation intentions are different from a commitment to achieve a certain goal (e.g., 'commitment to nonsmoking') in that they specify the when, where, and how of responses leading to goal attainment (Gollwitzer, 1993). Their structure is "When situation $x$ arises, I will perform response $y$ !", which links anticipated situations with goal-directed responses (Gollwitzer, 1999). Consequently, it is not the person's self that is linked to the desired behaviour (as with commitment to nonsmoking); rather, the person commits himself or herself to respond in a specific situation in a certain manner (Gollwitzer, 1999). It is interesting to note that studies have shown that the strength of commitment to perform a particular behaviour influences the effect of implementation intentions. For example, Orbell, Hodgkins and Sheeran (1997) reported that the beneficial effects of implementation intentions on compliance in performing breast self-examination were observed only in those women who strongly intended to perform the behaviour during the next month. This result suggests that implementation intentions do not work in adolescents who are immotive with regard to smoking behaviour. But they might be effective in helping committers to reach their goal of nonsmoking. Future studies should test this hypothesis.

Studies on adolescents' implicit attitudes on smoking might yield more information on the hypothesised cognitive adjustments after stage transitions within the initiation process. A recent study by Swanson, Rudman and Greenwald (2001) showed that smoking students differed considerably from nonsmoking students with regard to reported attitudes on smoking. However, these students did not differ from 
each other with regard to implicit attitudes, as revealed by an Implicit Association Test (IAT). Thus, smokers appear to adjust their cognitions explicitly, but they may not be able to resolve the behaviour-attitude inconsistency at the implicit level (Swanson et al., 2001). This result supports the conclusion of low predictive value of explicit cognitions in sound smoking initiation research.

\section{Conclusion}

Several conclusions can be drawn from the studies reported on in this thesis. The main conclusions are outlined below:

(1) The studies have shown that smoking initiation is not a linear process in which the first cigarette inevitably leads to a second, and a second leads to a third, etcetera (see also Hirschman et al., 1984). Neither can it be described as a dichotomous behavioural event ('to smoke or not to smoke').

(2) The dynamic stage approach of the Stages of Change Construct (Prochaska \& DiClemente, 1983) and the behavioural smoking initiation process (Flay et al., 1983) proved to have potential in describing and predicting adolescent smoking onset. However, refinement of the original models proved to be necessary. With regard to the Stages of Change Construct, the time frame of the original algorithm needed to be adjusted, and the dimension of 'strength of intention' or 'commitment' was added in order to improve the SCC's applicability to smoking initiation. With regard to the behavioural initiation model, the explicit labeling of stages of ex-smoking proved to have surplus value.

(3) Integration of the motivational and behavioural approaches showed that smoking initiation consists of both behavioural and motivational stages. Additionally, integration of both dimensions showed that youngsters appear to be largely unmotivated with regard to future smoking behaviour when they initially try smoking and experiment with cigarettes. The latter finding resulted in the Model of Unmotivated Smoking Initiation of Children and Adolescents (MUSICA). This model may contribute to an explanation of why smoking initiation stage transition is difficult to predict with social cognitive concepts. It was hypothesised that (a) initial trial behaviour largely occurs in the absence of a deliberate and motivated decision, and (b) cognitive adjustments are a result of stage transition.

(4) Studies on smoking initiation should not be exclusively based on social cognitive models. Examination of concepts like projection, selection, involvement and implicit attitudes may help us to gain insights into the 'true' causal influence of traditional social cognitive concepts on smoking initiation. Dual-process models may be useful both in the study of smoking initiation and in the implementation of interventions. 
1. In addition to the notion of Fishbein and Ajzen's concept of intention, the ASE model has also adopted the principles underlying the stages of change suggested by the Transtheoretical model (Prochaska \& DiClemente, 1983). These stages are elaborated in the sections on stage models.

2. This thesis argues that, even in a longitudinal design, the term 'determinant' is often incorrectly used. The term 'predictor' would be a better description of the concept analysed.

3. The term 'immotive' originates from smoking cessation studies. People in this stage are considered to be 'stuck' in low readiness (Dijkstra et al., 1997). They are assumed to be likely to retain their status quo (see also Levesque, Gelles \& Velicer, 2000).

4. In general, four sources of motivation are distinguished in psychology. Next to (1) cognitive sources and (2) social sources of motivation, (3) biological factors (e.g., the need for food, water, sex) and (4) emotional factors (e.g., panic, anger, love, hatred) are distinguished (Petri, 1986). In the present social psychological perspective, the term 'unmotivated' refers to the absence of cognitive and social drives. It does not reflect the biological and emotional sources of motivation.

5. For reasons of consistency, the term 'phase' has been replaced by the term 'stage' in Chapter 4 of the present thesis, in contrast to the original publication (Kremers et al., 2001c). 


\section{References}

Aarts, H., \& Dijksterhuis, A. (2000). The automatic activation of goal-directed behaviour: The case of travel habit. Journal of Environmental Psychology, 20, 75-82.

Ajzen, I. (1988). Attitudes, Personality, and Behaviour. Milton Keynes: Open University Press.

Ajzen, I., \& Fishbein, M. (1980). Understanding attitudes and predicting social behaviour. Englewood Cliffs, NJ: Prentice-Hall.

Allison, K. R. (1992). Academic stream and tobacco, alcohol, and cannabis use among Ontario high school students. International Journal of the Addictions, 27, 561-570.

Andersen, B. L., Cacioppo, J. T., \& Roberts, D. C. (1995). Delay in seeking a cancer diagnosis: Delay stages and psychophysiological comparison processes. British Journal of Social Psychology, 34, 33-52.

Ary, D. V., \& Biglan, A. (1988). Longitudinal changes in adolescent cigarette smoking behaviour: Onset and cessation. Journal of Behavioural Medicine, 11, 361-382.

Ausems, M., Mesters, I., De Vries, H., \& Van Breukelen, G. (submitted). Promising shortterm effects of a randomized computer-based out-of-school smoking prevention trial aimed at Dutch elementary schoolchildren.

Aveyard, P., Cheng, K. K., Almond, J., Sherratt, E., Lancashire, R., Lawrence, T., Griffin, C., \& Evans, O. (1999). Cluster randomised controlled trial of expert system based on the transtheoretical ('stages of change') model for smoking prevention and cessation in schools. British Medical Journal, 319, 948-953.

Bagozzi, R. P., \& Yi, Y. (1989). The degree of intention formation as a moderator of the attitude-behaviour relationship. Social Psychology Quarterly, 52, 266-279.

Bandura, A. (1977). Social Learning Theory. Englewood Cliffs, New York: Prentice Hall.

Bandura, A. (1986). Social foundations of thought and action: A social cognitive theory. New York: Prentice-Hall.

Bandura, A. (1997). The anatomy of stages of change. American Journal of Health Promotion, 12, 8-10.

Bargh, J. A., \& Chartrand, T. L. (1999). The unbearable automaticity of being. American Psychologist, 54, 462-479.

Barnea, Z., Rahav, G., \& Teichman, M. (1987). The reliability and consistency of self-reports on substance use in a longitudinal study. British Journal of Addiction, 82, 891-898.

Baugh, J. G., Hunter, S. M., Webber, L. S., \& Berenson, G. S. (1982). Developmental trends of first cigarette smoking experience of children: The Bogalusa Heart Study. American Journal of Public Health, 72, 1161-1164.

Bauman, K. E., \& Ennett, S. T. (1996). On the importance of peer influence for adolescent drug use: Commonly neglected considerations. Addiction, 91, 185-198.

Bauman, K. E., Koch, G. G., Bryan, E. S., Haley, N. J., Downtown, M. I., \& Orlandi, M. A. (1989). On the measurement of tobacco use in adolescents. Validity of sclf-reports of smokeless tobacco use and validity of cotinine as an indicator of cigarette smoking. American Journal of Epidemiology, 130, 327-337.

Baumrind, D. (1985). Familial antecedents of adolescent drug use: A developmental perspective. In: C. L. Jones \& R. J. Battjes (Eds.), Etiology of drug abuse: Implications for prevention. Rockville, MD: National Institute of Drug Abuse.

Bem, D. J. (1972). Self-perception theory. In: L. Berkowitz (Ed.), Advances in experimental social psychology (vol. 6). New York: Academic Press.

Best, J. A., Thomson, S. J., Santi, S. M., \& Brown, K. S. (1988). Preventing cigarette smoking among school children. Annual Review of Public Health, 9, 161-201. 
Biglan, A., Duncan, T. E., Ary, D. V., \& Smolkowski, K. (1995). Peer and parental influences on adolescent tobacco use. Journal of Behavioural Medicine, 18, 315-330.

Blashfield, R. K. (1980). Propositions regarding the use of cluster analysis in clinical research. Journal of Consulting and Clinical Psychology. 48, 456-459.

Bloch, P. H., \& Bruce, G. D. (1984). The leisure experience and consumer products: An investigation of underlying satisfactions. Journal of Leisure Research, 16, 74-78.

Bolman, C., \& De Vries, H. (1998). Psycho-social determinants and motivational phases in smoking behaviour of cardiac patients. Preventive Medicine, 27, 738-747.

Bonaguro, J. A., \& Bonaguro, E. W. (1987). Self-concept, stress symptomatology, and tobacco use. Journal of School Health, 57, 56-58.

Borgatta, E. F., \& Evans, R. R. (Eds.), Smoking, health and behaviour. Chicago: Aldine.

Botvin, G. J., Baker, E., Dusenbury, L., Botvin, E. M., \& Diaz, T. (1995). Long-term followup results of a randomized drug abuse prevention trial in a white middle-class population. Journal of the American Medical Association, 273, 1106-1112.

Botvin, G. J., Baker, E., Goldberg, C. J., Dusenbury, L., \& Botvin, E. M. (1992). Correlates and predictors of smoking among black adolescents. Addictive Behaviours, 17, 97 103.

Byrne, D. G., Byme, A. E., \& Reinhart, M. I. (1995). Personality, stress and the decision to commence cigarette smoking in adolescence. Joumal of Psychosomatic Research, 39 , 53-62.

Camp, D. E., Klesges, R. C., \& Relyea, G. (1993). The relationship between body weight concerns and adolescent smoking. Health Psychology, 12, 24-32.

Catania, J. A., Kegeles, S. M., Coates, T. J. (1990). Towards an understanding of risk behaviour: An AIDS risk reduction model (ARRM). Health Education Quarterly, 17. 53-72.

Centers for Disease Control and Prevention (1993). Smoking-attributable mortality and years of potential life lost - United States, 1990. Morbidity and Mortality Weekly Report, 42, 645-648.

Centers for Diseasc Control and Prevention (1998). Selected cigarette smoking initiation and quitting behaviors among high school students--United States, 1997. Morbidity and Mortality Weekly Report, 47, 386-389.

Chaffee, S. H., \& Roser, C. (1986). Involvement and the consistency of knowledge, attitudes, and behaviors. Communication Research, 13, 373-399.

Chaiken, S., \& Stangor, C. (1987). Attitudes and attitude change. Annual Review of Psychology, 38, 575-630.

Chaiken, S., \& Trope, Y (Eds.). (1999). Dual-process theories in social psychology. New York: Guilford Press.

Chassin, L., Presson, C. C., Pitts, S. C., \& Sherman, S. J. (2000). The natural history of cigarette smoking from adolescence to adulthood in a Midwestern community sample: Multiple trajectories and their psychosocial correlates. Health Psychology, 19, 223231.

Chassin, L., Presson, C. C., Rose. J., \& Sherman, S. J. (1991). The natural history of cigarette smoking from adolescence to adulthood: Demographic predictors of continuity and change. Health Psychology, 15, 478-484.

Chassin, L., Presson, C. C., Rose, J. S., \& Sherman, S. J. (1996). The natural history of cigarette smoking from adolescence to adulthood: demographic predictors of

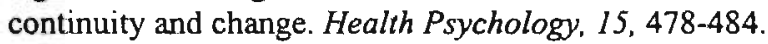

Chassin, L., Presson, C. C., \& Sherman, S. J. (1989). 'Constructive' vs. 'destructive' deviance in adolescent health-related behaviors. Journal of Youth and Adolescence, 18, 245262. 
Chassin, L., Presson, C. C., Sherman, S. J., Corty, E., \& Olhavsky, R. W. (1984). Predicting the onset of cigarette smoking in adolescents: A longitudinal study. Journal of Applied Social Psychology, 14, 224-243.

Chassin, L., Presson, C. C., Sherman, S. J., \& Edwards, D. A. (1990). The natural history of cigarette smoking: Predicting young-adult smoking outcomes from adolescent smoking patterns. Health Psychology, 9, 701-716.

Chassin, L., Presson, C. C., Sherman, S. J., \& Edwards, D. A. (1992). The natural history of adolescent smoking and young adult social roles. Journal of Health and Social Behaviors, 33, 328-347.

Chassin, L., Presson, C. C., Sherman, S. J., Montello, D., \& McGrew, J. (1986). Changes in peer and parent influence during adolescence. Longitudinal versus cross-sectional perspectives on smoking initiation. Developmental Psychology, 22, 327-334.

Chassin, L., Presson, C. C., Todd, M., Rose, J. S., \& Sherman, S. J. (1998). Matemal socialization of adolescent smoking: the intergenerational transmission of parenting and smoking. Developmental Psychology, 34, 1189-1201.

Choi, W. S., Gilpin, E. A., Farkas, A. J., \& Pierce, J. P. (2001). Determining the probability of future smoking among adolescents. Addiction, 96, 313-323.

Choi, W. S., Pierce, J. P., Gilpin, E. A., Farkas, A. J., \& Berry, C. C. (1997). Which adolescent experimenters progress to established smoking in the United States. American Journal of Preventive Medicine, 13, 385-391.

Cialdini, R. B., Petty, R. E., \& Cacioppo, J. T. (1981). Attitude and attitude change. Annual Review of Psychology, 32, 357-404.

Clarke P., \& Eves, F. (1997). Applying the transtheoretical model to the study of exercise on prescription. Joumal of Health Psychology, 2, 195-207.

Cohen, J. (1977). Sources of peer group homogeneity. Sociology of Education, 50, 227-241.

Cohen, J. (1988). Statistical power analysis for the behavioral sciences. Hillsdale, New York: Erlbaum.

Cohen, J. (1994). The earth is round (p <.05). American Psychologist, 49, 997-1003.

Colder, C.R., Mehta, P., Balanda, K., Campbell, R.T., Mayhew, K.P., Stanton, W.R., Pentz, M.A., \& Flay, B.R. (2001). Identifying trajectories of adolescent smoking: An application of latent growth mixture model. Health Psychology, 20, 127-135.

Collins, L. M., Sussman, S., Mestel Rauch, J., Dent, C. W., Anderson Johnson, C., Hansen, W. B., \& Flay, B. R. (1987). Psychosocial predictors of young adolescent cigarette smoking: A sixteen-month three-wave longitudinal study. Journal of Applied Social Psychology, 17, 554-573.

Conrad, K. M., Flay, B. R., \& Hill, D. (1992). Why children start smoking cigarettes: Predictors of onset. British Journal of Addiction, 87, 1711-1724.

Crittenden, K. S., Manfredi, C., Lacey, L., Warnecke, R., \& Parsons, J. (1994). Measuring readiness and motivation to quit smoking among women in public health clinics. Addictive Behaviors, 19, 497-507.

De Vries, H. (1989). Smoking prevention in Dutch adolescents. Dissertation. Maastricht.

De Vries H., Ariza C., Bakker M., Holm K., Mudde A. N., Lehtovuori R., Kremers S. P. J., Vitoria P. D., \& Fresnillo L. (1999). European Smoking prevention Framework Approach. Special session presented at the $2^{\text {nd }}$ European Conference on Tobacco or Health, Las Palmas, Gran Canaria, February 23-27.

De Vries, H., \& Backbier, E. (1994). Self-efficacy as an important determinant of quitting among pregnant women who smoke: The $\phi$-pattern. Preventive Medicine, 23, 167-174.

De Vries, H., Backbier, E., Dijkstra, M., Van Breukelen, G., Parcel, G. S., \& Kok, G. J. (1994). A Dutch social influence smoking prevention approach for vocational school students. Health Education Research, 9, 365-374. 
De Vries, H., Backbier, E., Kok, G., \& Dijkstra M. (1995). The impact of social influences in the context of attitude, self-efficacy, intention and previous behaviour as predictors of smoking onset. Journal of Applied Social Psychology, 25, 237-257.

De Vries, H., \& Brug, J. (1999). Computer-tailored interventions motivating people to adopt health promoting behaviours; introduction to a new approach. Patient Education and Counseling, 36, 99-105.

De Vries, H., Dijkstra, M., \& Kuhlman, P. (1988). Self-efficacy: The third factor besides attitude and subjective norm as a predictor of behavior intention. Health Education Research, 3, 273-282.

De Vries, H., Engels, R. C. M. E., Kremers, S. P. J., Wetzels, J. J. L., \& Mudde, A. N. (submitted). Parental and friends' smoking status as predictors of smoking onset: Findings from six European countries.

De Vries, H., \& Kok, G. J. (1986). From determinants of smoking behaviour to the implications for a prevention programme. Health Education Research, 1, 85-94.

De Vries, H., Lechner, L., \& Kremers, S. P. J. (in preparation). Advantages and disadvantages of using multiplicative functions for assessing attitudes and social norms.

De Vries, H., \& Mudde, A. N. (1998). Predicting stage transitions for smoking cessation applying the attitude-social influence-efficacy model. Psychology and Health, 13, 369-385.

De Vries, H., Mudde, A. N., Dijkstra, A., \& Willemsen, M. C. (1998). Differential beliefs, perceived social influences, and self-efficacy expectations among smokers in various motivational phases. Preventive Medicine, 27, 681-689.

De Vries, H., Mudde, A. N., Kremers, S. P. J., Charlton, A., Pais Clemente, M., Storm, H., Navarro Gonzalez, A., Nebot, M., Prins, T., \& Vartiainen, E. (submitted). ESFA: the European Smoking Prevention Framework Approach; goals, methods and first findings.

De Vries H., Mudde A. N., Kremers, S. P. J., Leijs I., Uiters E. (2000). The European Smoking prevention Framework Approach (ESFA): An example of integral prevention. Poster presented at the 11 th Conference on Tobacco OR Health, Chicago, August 6-11. Abstacts vol. I, p. 14.

De Vries, H., Mudde, A. N., Kremers, S. P. J., Wetzels, J. J. L., Uiters, E., Ariza, C., Vitoria, P. D., Fielder, A., Holm, K., Jansen, K., Lehtovuori, R., Candel, M. (in preparation). The European Smoking Prevention framework Approach (ESFA): short-term findings.

De Vries, H., Wetzels, J. J. L., Kremers, S. P. J., \& Mudde, A.N. (submitted). Differences in perceptions on smoking between boys and girls.

DiClemente, C. C., \& Prochaska, J. O. (1982). Self-change and therapy change of smoking behavior: A comparison of processes of change in cessation and maintenance. Addictive Behaviors, 7, 133-142.

DiClemente, C. C., Prochaska, J. O., Fairhurst, S. K., Velicer, W. F., Velasquez, M. M., \& Rossi, J. S. (1991). The processes of smoking cessation: An analysis of precontemplation, contemplation, and preparation stages of change. Journal of Consulting and Clinical Psychology, 59, 295-304.

Dijkstra, A., Bakker, M., \& De Vries, H. (1997). Subtypes within a precontemplating sample of smokers: A preliminary extension of the stages of change. Addictive Behaviors, 22 , 327-337.

Dijkstra, A., De Vries, H., \& Bakker, M. (1996). The pros and cons of quitting, self-efficacy and the stages of change in smoking cessation. Journal of Consulting and Clinical Psychology, 64, 758-763. 
Dijkstra, A., De Vries, H., Roijackers, J., \& Mudde, A. N. (1997). Psycho-social determinants of stage transition. Paper presented at the $11^{\text {th }}$ European Health Psychology Society Conference, Bordeaux.

Dijkstra, A., De Vries, H., Rooijackers, J., \& Van Breukelen, G. (1998). Tailored interventions to communicate stage-matched information to smokers in different motivational stages. Journal of Consulting and Clinical Psychology, 66, 549-557.

Dijkstra, A., Roijackers, J., \& De Vries, H. (1998). Smokers in four stages of readiness to change. Addictive Behaviors, 23, 339-350.

Dijkstra, M., Mesters, I., De Vries, H., Van Breukelen, \& Parcel, G. S. (1999). Effectiveness of a social influence approach and boosters to smoking prevention. Health Education Research, 14, 791-802.

Dolcini, M. M., Adler, N. E., \& Ginsberg, D. (1996). Factors influencing agreement between self-reports and biological measures of smoking among adolescents. Journal of Research on Adolescence, 6, 515-542.

Doll, R. (1998). Uncovering the effects of smoking: Historical perspective. Statistical Methods in Medical Research, 7, 87-117.

Doll, R., \& Hill, A. B. (1950). Smoking and carcinoma of the lung. Preliminary report. British Medical Journal, 739-748.

Doll, R., Peto, R., Wheatley, K., Gray, R., \& Sutherland, I. (1994). Mortality in relation to smoking: 40 years' observations on male British doctors. British Medical Journal, $309,901-911$.

Dunn, W. L., Jr. (Ed.), Smoking behavior: Motives and incentives. Washington, D. C.: V. H. Winston.

Dutch Foundation on Smoking and Health (1999). Annual Report. The Hague, The Netherlands.

Dutch Foundation on Smoking and Health (2000). Annual Report. The Hague, The Netherlands.

Eckhardt, L., Woodruff, S. I., \& Elder, J. P. (1994). A longitudinal analysis of adolescent smoking and its correlates. Journal of School Heallh, 64, 67-72.

Eiser, J. R., Morgan, M., Gammage, P., Brook, N., \& Kirby, R. (1991). Adolescent health behaviour and similarity-attraction: Friends share smoking habits (really), but much else besides. British Journal of Social Psychology, 30, 339-348.

Eissenberg, T., \& Balster, R. L. (2000). Initial tobacco use episodes in children and adolescents: current knowledge, future directions. Drug and Alcohol Dependence, 59 (Suppl. 1), S41-S60.

Elder, J. P., De Moor, C., Young, R. L., Wildey, M., Molgaard, C., \& Golbeck, A. (1990). Stages of adolescent tobacco-use acquisition. Addictive Behaviors, 15, 449-454.

Engels, R. C. M. E., Knibbe, R. A., De Vries, H., Drop, M. J., \& Van Breukelen, G. J. P. (1999). Influences of parental and best friends' smoking and drinking on adolescent use: A longitudinal study. Journal of Applied Social Psychology, 29, 338-362.

Engels, R. C. M. E., Knibbe, R. A., \& Drop, M. J. (1999). Predictability of smoking in adolescence: Between optimism and pessimism. Addiction, 94, 115-124.

Engels, R. C. M. E, Knibbe, R. A., Drop, M. J., \& De Haan, J. T. (1997). Homogeneity of smoking behavior in peer groups: Influence or selection? Health Education and Behavior, 24, 801-811.

Evans, R. I. (1983). Deterring smoking in adolescence: Evolution of a research program in applied social psychology. International Review of Applied Psychology, 32, 71-83.

Evans, R. I., Hansen, W. B., \& Mittelmark, M. B. (1977). Increasing the validity of se]freports of smoking behaviour in children. Journal of Applied Psychology, 62, 521-532. 
Evans, R. I., Rozelle, R. M., \& Maxwell, S. E. (1981). Social modelling films to deter smoking in adolescents: results of a three-year field investigation. Jouriuli of Applied Psychology, 66, 391-414.

Evans, R. I., Rozelle, R. M., Mittelmark, M. B., Hansen, W. B., Bane, A. L., \& Havis, J. (1978). Deterring the onset of smokng in children: Knowledge of immediate physiological effects and coping with peer pressure, media pressure and parent modeling. Journal of Applied Social Psychology, 8, 126-135.

Farkas, A. J., Gilpin, White, \& Pierce, J. P. (2000). Association between household and workplace smoking restrictions and adolescent smoking. Journal of the American Medical Association, 284, 717-722.

Fazio, R. H. (1985). How do attitudes guide behavior? In: R. M. Sorrentino, \& E. T. Higgins (Eds.), The handbook of motivation and cognition: foundations of social behavior. New York: Guilford.

Fazio, R. H., Chen, J., McDonel, E. C., \& Sherman, S. J. (1982). Attitude accessibility, attitude-behavior consistency and the strength of the object-evaluation association. Journal of Experimental Social Psychology, 18, 339-357.

Fazio, R. H., \& Towles-Schwen, T. (1999). The MODE-model of attitude-behavior processes. In: S. Chaiken \& Y. Trope (Eds.), Dual Process Theories in Social Psychology. New York: Guilford.

Fazio, R. H., \& Zanna, M. P. (1981). Direct experience and the attitude-behavior consistency. In: L. Berkowitz (Ed.), Advances in Experimental Social Psychology (vol. 14). New York: Academic Press.

Fazio, R. H., Zanna, M. P., \& Cooper, J. (1977). Dissonance and self-perception: an integrative view of each theory's proper domain of application. Journal of Experimental Social Psychology, 13, 464-479.

Featherman, D. L., \& Petersen, T. (1986). Markers of aging: modeling the clocks that time us. Research on Aging, 8, 339-365.

Fergusson, D. M., \& Horwood, L. J. (1995). Transitions to cigarette smoking during adolescence. Addictive Behaviors, 20, 627-642.

Festinger, L. (1957). A theory of cognitive dissonance. Stanford, CA: Stanford University Press.

Fishbein, M., \& Ajzen, I. (1975). Belief, attitude, intention, and behavior: an introduction to theory and research. Reading, MA: Addison-Wesley.

Fisher, L. A., \& Bauman, K. E. (1988). Influence and selection in the friend-adolescent relationship: Findings from studies of adolescent smoking and drinking. Journal of Applied Social Psychology, 18, 289-314.

Flay, B. R. (1993). Youth tobacco use: risks, patterns, and control. In: Slade J., Orleans C. T., Eds, Nicotine addiction: principles and management. New York: Oxford University Press.

Flay, B. R., D'Avernas, J. R., Best, J, A., Kersell, M. W., \& Ryan, K. B. (1983). Cigarette smoking: why young people do it and ways of preventing it. In: P. McGrath, \& P. Firestone (Eds.), Pediatric and Adolescent Behavioral Medicine. New York: SpringerVerlag.

Flay, B. R., Hu, F. B., \& Richardson, J. (1998). Psychosocial predictors of different stages of cigarette smoking among High School students. Preventive Medicine, 27, A9-A18.

Flay, B. R., \& Petraitis, J. (1994). The theory of triadic influence: A new theory of health behavior with implications for preventive interventions. Advances in Medical Sociology, 4, 19-44.

Freier, M. C., Griffith, D. R., \& Chasnoff, I. J. (1991). In utero drug exposure: developmental follow-up and matemal-infant interaction. Seminars in Perinatology, 15, 310-316. 
Friedman, L. S., Lichtenstein, E., \& Biglan. (1985). Smoking onset among teens: An empirical analysis of initial situations. Addictive Behaviors, 10, 1-13.

Gagné, C., \& Godin, G. (2000). The theory of planned behavior: Some measurement issues concerning belief-based variables. Journal of Applied Social Psychology, 30, $2173-$ 2193.

Gebhardt, W. A. (1997). Health Behaviour Goal Model. Leiden: University of Leiden.

Glynn, T. J. (1989). Essential elements of school-based smoking prevention programs. Journal of School Health, 59, 181-188.

Gollwitzer, P. M. (1993). Goal achievement: The role of intentions. In W. Stroebe, \& M. Hewstone (Eds.), European Review of Social Psychology. Chichester: Wiley.

Gollwitzer, P. M. (1996). The volitional benefits of planning. In: P. M. Gollwitzer, \& J. A. Bargh (Eds.), The psychology of action: Linking cognition and motivation to behavior. New York: Guilford.

Gollwitzer, P. M. (1999). Implementation Intentions. Strong effects of simple plans. American Psychologist, 54, 493-503.

Graham, J. W., Marks, G., \& Hansen, W. B. (1991). Social influence processes affecting adolescent substance use. Journal of Applied Psychology, 76, 291-298.

Guy, S. M., Smith, G. M., \& Bentler, P. M. (1994). Consequences of adolescent drug use and personality factors on adult drug use. Journal of Drug Education, 24, 109-132.

Haglund, M. (2000). Regional Summary for the European Region. In: Corrao, M. A., Guindon, G. E., Sharma, N., \& Shokoohi, D. F. (Eds.), Tobacco Control Country Profiles. Georgia: The American Cancer Society, Inc.

Hansen, W. B., Mallotte, K. C., \& Fielding, J. E. (1985). The bogus pipeline revisited: The use of the threat as a means of increasing self-reports of tobacco use. Joumal of Applied Psychology, 70, 789-792.

Heal, L. (1985). Methodology for community integration research. In: R. H. Bruininks, K. C. Lakin (Eds.), Living and Learning in the Least Restrictive Environment. Baltimore: Paul H. Brooks.

Heath, A. C., Madden, P. A., Grant, J. D., McLaughlin, T. L., Todorov, A. A., \& Bucholz, K. K. (1999). Resiliency factors protecting against teenage alcohol use and smoking: influences of religion, religious involvement and values, and ethnicity in the Missouri Adolescent Female Twin Study. Twin Research, 2, 145-155.

Higgins, E. T., \& Rholes, W. S. (1978). "Saying is believing": effects of message modification on memory and liking for the person described. Journal of Experimental and Social Psychology, 14, 363-378.

Hirschman, R. S., Leventhal, H., \& Glynn, K. (1984). The development of smoking behavior: Conceptualization and supportive cross-sectional survey data. Journal of Applicd Social Psychology, 14, 184-206.

Holmes, D. S. (1968). Dimensions of projection. Psychological Bulletin, 69, 248-268.

Houston, T., Kolbe, L. J., \& Eriksen, M. P. (1998). Tobacco-use cessation in the ' 90 s--not "adults only" anymore. Preventive Medicine, 27, A1-2.

Houston, M. J., \& Rothschild, M. L. (1978). Conceptual and methodological perspectives in involvement. In: S. Jain (Ed.), Research frontiers in marketing: dialogues and directions. Chicago: American Marketing Association.

Hovland, C. I., Janis, I. L., \& Kelley, H. H. (1953). Communication and persuasion. New Haven: Yale University Press.

Huang, T. T., Unger, J. B., \& Rohrbach, A. (2000). Exposure to, and perceived usefulness of, school-based tobacco prevention programs: associations with susceptibility to smoking among adolescents. Journal of Adolescent Health, 27, 248-254. 
International Association of Athletics Federations (2000). LAAF handbook 2000-2001. Available from: URL: http://www.iaaf.org/InsidelAAF/index.asp.

Isenhart, C. E. (1997). Pretreatment readiness for change in male alcohol dependent subjects: Predictors of one-year follow-up status. Journal of Studies on Alcohol, 58, 351-357.

Jackson, C. (1998). Cognitive susceptibility to smoking and initiation of smoking during childhood: a longitudinal study. Preventive Medicine, 27, 129-134.

Jackson, C., Bee-Gates, D. J., \& Henriksen, L. (1994). Authorative parenting, child competencies, and initiation of cigarette smoking. Health Education Quarterly, 21, 103-116.

Jain. S. (1978). Research frontiers in marketing: dialogues and directions. Chicago: American Marketing Association.

Jessor, R., \& Jessor, S. L. (1977). Problem behavior and psychosocial development: $A$ longitudinal study of youth. New York: Academic Press.

Jones, E. E., \& Sigall, H. (1971). Bogus pipeline: A new paradigm for measuring affect and attitude. Psychological Bulletin, 76, 349-364.

Josephson, E., \& Rosen, M. (1978). Panel loss in a high school drug study. In D. B. Kendel (Ed.), Longitudinal Research on Drug Use: Empirical Studies and Methodological Issues. New York: Wiley.

Kandel, D. B. (1978). Homophily, selection, and socialization in adolescent friendships. American Joumal of Sociology, 84, 427-437.

Kandel, D. B., \& Faust, R. (1975). Sequence and stages in patterns of adolescent drug use. Archives of General Psychiatry, 32, 923-932.

Kaufman, N., \& Feiden, K. L. (1999). Meeting overview and summary. Nicotine \& Tobacco Research, 1, S5-S13.

Kelley, R. M., Denny, G., Young, M. (1999). Modified stages of acquisition of gateway drug use: a primary prevention application of the stages of change model. Journal of Drug Education, 29, 189-203.

Kelly, G. (1955). The psychology of personal constructs. New York: Norton.

Klesges, L. M., Klesges, R. C., \& Cigrang, J. A. (1992). Discrepancies between self-reported smoking and carboxyhemoglobin: an analysis of the second national health and nutrition survey. American Journal of Public Health, 82, 1026-1029.

Kok, G. J., Den Boer, D-J., De Vries, H., Gerards, F., Hospers, H. J., \& Mudde, A. N. (1992). Self-efficacy and attribution theory in health education. In: R. Schwarzer (Ed.), Selfefficacy. Thought control of action. Washington: Hemisphere Publishing Corporation.

Komro, K. A., Kelder, S. H., Perry, C. L., \& Klepp, K. I. (1993). Effects of a saliva pipeline procedure on adolescent self-reported smoking behavior and youth smoking prevention outcomes. Preventive Medicine, 22, 857-865.

Koopmans, J. R., Slutske, W. S., Heath, A. C., Neale, M. C., \& Boomsma, D. I. (1999). The genetics of smoking initiation and quantity smoked in Dutch adolescent and young adult twins. Behavior Genetics, 29, 383-393.

Kremers, S. P. J., De Vries, H., Mudde, A. N., \& Candel, M. (submitted). Four motivational stages of smoking initiation: predictive validity and predictors of transitions.

Kremers, S. P. J., Mudde, A. N., \& De Vries, H. (2000). Measuring the effectiveness of ESFA: Towards best practices in smoking prevention research. In: L. Norheim, \& $\mathrm{M}$. Waller, editors. Best Practices: A selection of papers on Quality and Effectiveness in Health Promotion. Helsinki: Finnish Centre for Health Promotion.

Kremers, S. P. J., Mudde, A. N., \& De Vries, H. (200la). Subtypes within the precontemplation stage of adolescent smoking aquisition. Addictive Behaviors, 26, $237-251$. 
Kremers S. P. J., Mudde A. N., \& De Vries H. (200lb). Categorisation of adolescent smoking behaviour: A measure of the initiation continuum. Available from: URL: http://www.personeel.unimaas.nl/Hein.deVries/publications.htm.

Kremers, S.P. J., Mudde, A. N., \& De Vries, H. (2001c). "Kicking the initiation": Do adolescent ex-smokers differ from other groups within the initiation continuum? Preventive Medicine, 33, 392-401.

Kremers S. P. J., Mudde, A. N., \& De Vries, H. (submitted). Operationalizing Flay's stage model of adolescent smoking initiation: a longitudinal test.

Krugman, H. (1965). The impact of television in advertising: Leaming without involvement. Public Opinion Quarterly, 29, 349-356.

Lacity, M., \& Jansen, M. A (1994). Understanding qualitative data: A framework of text analysis methods. Journal of Management Information System, 11, 137-160.

Lauby, J., Semaan, S., Cohen, A., Leviton, L., Gielen, A., Pulley, L., Walls, C., \& O’Campo, P. (1998). Self-efficacy, decisional balance and Stages of Change for condom use among women at risk of HIV infection. Health Education Research, 13, 343-356.

Laurent, G, \& Kapferer, J. N. (1985). Measuring consumer involvement profiles. Journal of Marketing Research, 22, 41-53.

Lawrance, L. (1988). Validation of a self-efficacy scale to predict adolescent smoking. Health Education Research, 4, 351-360.

Lechner, L. (1997). Social psychological determinants of health risk behaviors related to cancer and CVD. Dissertation. Maastricht.

Lechner, L., Brug, J., De Vries, H., van Assema, P., \& Mudde, A. N. (1998). Stages of change for fruit, vegetable and fat intake: consequences of misconception. Health Education Research, 13, 1-11.

Lettieri, D. J., Sayers, M., \& Pearson, H. W. (Eds.) (1980). Theories on drug abuse. Selected contemporary perspectives. Rockville, MD: National Institute of Drug Abuse.

Leventhal, H., (1968). Experimental studies of anti-smoking communications. In: E. F. Borgatta, \& R. R. Evans (Eds.), Smoking, health, and behavior. Chicago: Aldine.

Leventhal, H., \& Cleary, P. D. (1980). The smoking problem: a review of the research and theory in behavioral risk modification. Psychological Bulletin, 88, 370-405.

Leventhal, H., Gleming, R., \& Glynn, K. (1988). A cognitive developmental approach to smoking intervention. In: S. Maes, C. D. Spielberger, P. B. Defares, \& I. G. Sarason (Eds.), Topics in health psychology: proceedings of the first annual expert conference in health psychology. New York: John Wiley \& Sons, Inc.

Leventhal, H., Singer, R., \& Jones, S. (1965). Effects of fear and specificity of recommendation upon attitudes and behavior. Journal of Personality and Social Psychology, 2, 20-29.

Levesque, D. A., Gelles, R. J., \& Velicer, W. F. (2000). Development and validation of a stages of change measure for men in batterer treatment. Cognitive Therapy and Research, 24, 175-199.

Levin, M. L., Goldstein, H., \& Gerhardt, P. R., (1950). Cancer and tobacco smoking. Journal of the American Medical Association, 143, 336-338.

Lewin, K. (1951). Field theory in social science. New York: Harper.

Lloyd, B., Lucas, K., Holland, J., McGrellis, S., \& Amold S. (1998). Smoking in adolescence. Images and identities. New York: Routledge.

Lo, S. K., Blaze-Temple, D., Binns, C. W., \& Ovenden, C. (1993). Adolescent cigarette consumption: the influence of attitudes and peer drug use. International Joumal of the Addictions, 28, 1515-1530. 
Lynch, B. S., Bonnie R. J. (1994). Growing up tobacco free: Preventing nicotine addiction in children and youths. Washington, D.C: Institute of Medicine, National Academy Press.

Manstead, A. S. R., Proffitt, C., \& Smart, J. L. (1983). Predicting and understanding mothers' infant-feeding intention and behavior: testing the theory of reasoned action. Journal of Personality and Social Psychology, 44, 657-671.

Marks, G., \& Miller, N. (1987). Ten years of research on the false-consensus effect: An empirical and theoretical review. Psychological Bulletin, 102, 72-90.

Martin, S. G. (1995). Prostitutes and AIDS: A five stage model for attitude and behavior change. Dissertation. Berkeley.

Mayhew, K. P., Flay, B. R., \& Mott, J. A. (2000). Stages in the development of adolescent smoking. Drug and Alcohol Dependence, 59 (Suppl. I), S61-S81.

McAllister, A. L., Perry, C. L., \& Maccoby, N. (1979). Adolescent smoking: onset and prevention. Pediatrics, 63, 650-658.

McCool, J. P., Cameron, L. D., Petrie, K. J. (2001). Adolescent perceptions of smoking imagery in film. Social Science and Medicine, 52, 1577-1587.

McDermott, R. J., Sarvela, P. D., Hoalt, P. N., Bajracharya, S. M., Marty, P. J., \& Emery, E. M. (1992). Multiple correlates of cigarette use among high school students. Journal of School Health, 62, 146-150.

McDowell, I., \& Newell, C. (1987). Measuring Health: A guide to rating scales and questionnaires. Oxford: Oxford University Press.

McGuire, W. J. (1984). Public communication as a strategy to inducing health-promoting behavioral change. Preventive Medicine, 13, 299-319.

McNeill, A. D., Jarvis, M. J., Stapleton, J. A., Russell, M. A., Eiser, J. R., Gammage, P., \& Gray, E. M. (1988). Prospective study of factors predicting uptake of smoking in adolescents. Journal of Epidemiology and Community Health, 43, 72-78.

McNeill, A. D., Jarvis, M., \& West, R. (1987). Subjective effects of cigarette smoking in adolescents. Psychopharmacology, 92, 115-117.

Mills, C. A., \& Porter, M. M. (1950). Tobacco-smoking habits and cancer of the mouth and respiratory system. Cancer Research, 10, 539-542.

Mudde, A. N., Kremers, S. P. J., \& De Vries, H. (1999). Baseline model-testing in the ESFAproject. Poster session presented at the $13^{\text {th }}$ Conference of the European Health Psychology Society, Florence.

Mullen, B., Atkins, J. L., Champion, D. S., Edwards, C., Hardy, D., Story, J. E., \& Vanderklok. (1985). The false consensus effect: A meta-analysis of 155 hypothesis tests. Journal of Experimental Social Psychology, 21, 262-283.

Murray, D., \& Perry, C. L. (1987). The measurement of substance use among adolescents. When is the 'bogus pipeline' method needed? Addictive Behaviors, 12, 225-233.

Murray, M., Swan, A. V., Johnson, D., \& Bewley, B. R. (1983). Some factors associated with increased risk of smoking by children. Child Psychiatry, 24, 223-232.

Norman, G. J., Velicer, W. F., Fava, J. L., Prochaska, J. O. (2000). Cluster subtypes within stage of change in a representative sample of smokers. Addictive Behaviors, 25, 2, 183-204.

Novak, S. P., \& Clayton, R. R. (2001). The influence of school environment and selfregulation on transitions between stages of cigarette smoking: A mulitlevel analysis. Health Psychology, 20, 196-207.

Oakley, A., Brannen, J., \& Dodd, K. (1992). Young people, gender and smoking in the United Kingdom. Healih Promotion International, 7, 75-88.

Orbell, S., Hodgkins, S., \& Sheeran. P. (1997). Implementation intentions and the theory of planned behavior. Personality and Social Psychology Bulletin, 23, 945-954. 
Page, R. M., \& Gold, R. S. (1983). Assessing gender differences in college cigarette smoking intenders and nonintenders. Journal of School Health, 53, 531-535.

Pallonen, U. E. (1998). Transtheoretical measures for adolescent and adult smokers: Similarities and differences. Preventive Medicine, 27, A29-A38.

Pallonen, U. E., Prochaska, J. O., Velicer, W. F., Prokhorov, A. V., \& Smith, N. F. (1998). Stages of acquisition and cessation for adolescent smoking: An empirical integration. Addictive Behaviors, 23, 303-324.

Pavlov, I. P. (1927). Conditioned reflexes. Oxford: Ox ford University Press.

Pederson, L. L., \& Lefcoe, N. M. (1987). Short- and long-term prediction of self reported cigarette smoking in a cohort of late adolescents: Report of an 8-year follow-up of public school students. Preventive Medicine, 16, 432-447.

Perry, C. L., Murray, D. M., \& Klepp, K. I. (1987). Predictors of adolescent smoking and implications for prevention. Morbidity and Mortality Weekly Report, 36, 41S-47S.

Peterson, A. V., Kealey, K. A., Mann, S. L., Marek, P. M., \& Sarason, I. G. (2000). Hutchinson Smoking Prevention Project: Long-term randomized trial in school-based tobacco use prevention. Results on smoking. Journal of the National Cancer Institute, 92, 1979-1991.

Peto, R., Darby, S., Deo, H., Silcocks, P., Whitley, E., \& Doll, R. (2000). Smoking, smoking cessation, and lung cancer in the UK since 1950: combination of national statistics with two case-control studies. British Medical Journal, 321, 323-329.

Peto, R., Lopez, A., Boreham., Thun, \& Heath. (1994). Mortality from tobacco in developed countries: indirect estimation from national vital statistics. Oxford: Oxford University Press.

Petraitis, J., Flay, B. R., \& Miller, T. Q. (1995). Reviewing theories of adolescent substance use: Organizing pieces in the puzzle. Psychological Bulletin, 117, 67-86.

Petri, H. L. (1986). Motivation: Theory and Research. Belmont, CA: Wadsworth.

Petty, R. E., \& Cacioppo, J. T. (1981). Attitudes and persuasion: classic and contemporary approaches. Dubuque, IA: Brown.

Petty, R. E., \& Cacioppo, J. T. (1984). The effects of involvement on responses to argument quantity and quality: central and peripheral routes to persuasion. Journal of Personality and Social Psychology, 46, 69-81.

Petty, R. E., \& Cacioppo, J. T. (1986). Communication and persuasion, central and peripheral routes to attitude change. New York: Springer-Verlag.

Pierce, J. P., Choi, W. S., Gilpin, E. A., Farkas, A. J., \& Merritt, R. K. (1996). Validation of susceptibility as a predictor of which adolescents take up smoking in the United States. Health Psychology, 15, 355-361.

Pierce, J. P., Farkas, A. J., Evans, N., \& Gilpin, E. (1995). An improved surveillance measure for adolescent smoking? Tobacco Control, 4, S47-S56.

Pierce, J. P., \& Gilpin, E. A. (1996). How long will today's new adolescent smoker be addicted to cigarettes? American Journal of Public Health, 86, 253-256.

Popper, K. R. (1963). Conjectures and refutations: The growth of scientific knowledge. London: Routledge \& Kegan Paul Limited.

Prochaska, J. O., \& DiClemente, C. C. (1983). Stages and processes of self-change of smoking: Toward an integrative model of change. Journal of Consulting and Clinical Psychology, 51, 295-304.

Prochaska, J. O., \& DiClemente, C. C. (1984). Self-change processes, self-efficacy and decisional balance across five stages of smoking cessation. Advances in Cancer Control: Epidemiology and Research, 131-140.

Prochaska, J. O., DiClemente, C. C., \& Norcross, J. C. (1993). In search of how people change: Applications to addictive behaviors. American Psychologist, 47, 1102-1114. 
Prochaska, J. O., DiClemente, C. C., Velicer, W. F., Ginpil, S., \& Norcross, J. C. (1985). Predicting change in smoking status for self-changers. Addictive Behaviors, 10, 395406.

Prochaska, J. O., Velicer, W. F., DiClemente, C. C., \& Fava, J. (1988). Measuring processes of change: Applications to the cessation of smoking. Journal of Consulting and Clinical Psychology, 56, 520-528. 1988

Prochaska, J. O., Velicer, W. F., Guadagnoli, E., Rossi, J. S., \& DiClemente C. C. (1991). Patterns of change: Dynamic typology applied to smoking cessation. Multivariate Behavioral Research, 26, 83-107.

Prochaska, J. O., Velicer, W. F., Rossi, J. S., Goldstein, M. G., Marcus, B. H., Rakowski, W., Fiore, C., Harlow, L. L., Redding, C. A., Rosenbloom, D., \& Rossi, S. R. (1994). Stages of change and decisional balance for 12 problem behaviors. Health Psychology, 13, 39-46.

Proescholdbell, R. J., Chassin, L., \& McKinnon, D. P. (2000). Home smoking restrictions and adolescent smoking. Nicotine and Tobacco Research, 2, 159-167.

Prokhorov, A. V., \& Alexandrov, A. A. (1992). Tobacco smoking in Moscow school students. British Journal of Addiction, 87, 1469-1476.

Prokhorov, A. V., De Moor, C., Pallonen, U. E., Hudmon, K. S., Koehly, L., \& Hu, S. (2000). Validation of the modified Fagerström Tolerance Questionnaire with salivary cotinine among adolescents. Addictive Behaviors, 25, 429-433.

Prokhorov, A. V., Pallonen, U. E., Fava, J. Ding, L., \& Niaura, R. (1996). Measuring nicotine dependence among high-risk adolescent smokers. Addictive Behaviors, 21, 117-127.

Ray, M. L., Sawyer, A. G., Rothschild, M. L., Heeler, R. M., Strong, E. C., \& Reed, J. E. (1973). Marketing communications and the hierarchy-of-effects. In: P. Clarke (Ed.), New models for mass communication research: Vol. 2. Beverly Hills: Sage.

Reid, I. S., \& Crompton, J. L. (1993). A taxonomy of leisure purchase decision paradigms based on level of involvement Journal of Leisure Research, 25, 182-202.

Regan, D. T., \& Fazio, R. H. (1977). On the consistency between attitudes and behavior: look to the method of attitude formation. Journal of Experimental Social Psychology, 13. 28-45.

Reppucci, J. D., Revenson, T. A., \& Aber, M. (1991). Unrealistic optimism among adolescent smokers and nonsmokers. Journal of Primary Prevention, 11, 227-236.

Riess, M. R., Kalle, R. J., \& Tedeschi, J. T. (1981). Bogus pipeline attitude assessment, impression management, and misattribution in induced compliance setting. Journal of Social Psychology, 115, 247-258.

Rigby, A. S. (1999). Getting past the statistical referee: moving away from P-values and towards interval estimation. Health Education Research, 14, 713-715.

Robinson, L. A., Klesges, R. C., Zbikowski, S. M., \& Glaser, R. (1997). Predictors of risk for different stages of adolescent smoking in a biracial sample. Journal of Consulting and Clinical Psychology, 65, 653-662.

Rosenthal, R. (1990). How are we doing in soft psychology? American Psychologist, 45, 775777.

Rothschild, M. L. (1984). Perspectives on involvement: Current problems and future directions. Advances in Consumer Research, 11, 216-217.

Rowe, D. C., Chassin, L., Presson, C. C., \& Edwards, D. (1992). An 'epidemic' model of adolescent cigarette smoking. Journal of Applied Social Psychology, 22, 261-285.

Rowe, D. C., Chassin, L., Presson, C., \& Sherman, S. J. (1996). Parental smoking and the 'epidemic' spread of cigarette smoking. Journal of Applied Social Psychology, 26, 437-454. 
Rundall, T. G., \& Bruvold, W. H. (1988). A meta-analysis of school-based smoking and alcohol use prevention programs. Health Education Quarterly, 15, 317-334.

Russell, M. A. H. (1990). The nicotine addiction trap: a 40-year sentence for four cigarettes. British Journal of Addiction, 85, 293-300.

Safer, M. A., Tharps, Q. J., Jackson, T. C., \& Leventhal, H. (1979). Determinants of three stages of delay in seeking care at a medical clinic. Medical Care, 17, 11-29.

Salber, E. J., Freeman, H. E., \& Abelin, T. (1968). Needed research on smoking: Lessons from the Newton study. In E. F. Borgatta, \& R. R. Evans (Eds.), Smoking, health and behavior. Chicago: Aldine.

Santi, S. M., Cargo, M., Brown, K. S., Best, J. A., \& Cameron, R. (1994). Dispositional riskfactors for smoking-stage transitions: a social influences program as an effect modifier. Addictive Behaviors, 19, 269-285.

Schrek, R., Baker, L. A., Ballard, G. P., \& Dolgoff, S. (1950). Tobacco smoking as an etiologic factor in disease: Cancer. Cancer Research, 10, 49-58.

Schwarzer, R. (1992). Self-efficacy in the adoption and maintenance of health behaviors: Theoretical approaches and a new model. In: R. Schwarzer (Ed.), Self-efficacy: Thought control of action. Washington, DC: Hemisphere.

Schwarzer, R., \& Fuchs, R. (1996). Self-efficacy and health behaviours. In: M. Conner and P. Norman (Eds.), Predicting health behaviour. Buckingham: Open University Press.

Shadel, W. G., Shiffman, S., Niaura, R., Nichter, M., \& Abrams, D. B. (2000). Current models of nicotine dependence: what is known and what is needed to advance understanding of tobacco etiology among youth. Drug and Alcohol Dependence, 59 (Suppl 1), 9-22.

Sherif, M., \& Cantril, H. (1947). The psychology of ego involvement. New York: Wiley.

Sherman, S. J. (1982). Smoking intention in adolescents: Direct experience and predictability. Personality and Social Psychology Bulletin, 8, 376-383.

Sherman, S. J., Presson, C. C., Chassin, L., Corty, E., \& Olshavsky, R. (1983). The false consensus effect in estimates of smoking prevalence: Underlying mechanisms. Personality and Social Psychology Bulletin. 9, 197-208.

Siegel, M., Biener, L., \& Rigotti, N. A. (1999). The effect of local tobacco sales on adolescent smoking initiation. Preventive Medicine, 29, 334-342.

Skinner, B. F. (1938). The behaviour of organisms: An experimental analysis. New York: Appleton Century Crofts.

Snijders, T. A. B. (in press). The Statistical Evaluation of Social Network Dynamics. Sociological Methodology.

Stacy, A. W., Bentler, P. M., \& Flay, B. R. (1994). Attitudes and health behavior in diversc populations: Drunk driving, alcohol use, binge eating, marijuana use, and cigarette use. Health Psychology, 13, 73-85.

Stacy, A. W., Flay, B. R, Sussman, S., Brown, K. S., Santi, S., \& Best, J. A. (1990). Validity of alternative self-report indices of smoking among adolescents. Psychological Assessment, 2, 442-446.

Stacy, A. W., Sussman, S., Dent, C. W., Burton, W., \& Flay, B. R. (1992). Moderators of peer social influence in adolescent smoking. Personality and Social Psychology Bulletin, 92, 163-172.

Stein, J. A., Newcomb, M. D., \& Bentler, P. M. (1996). Initiation and maintenance of tobacco smoking: Changing personality correlates in adolescence and young adulthood. Journal of Applied Social Psychology, 26, 160-187.

Steinberg, L. (1999). Adolescence. Boston: McGraw-Hill.

Steele, C. M., \& Liu, T. J. (1983). Dissonance processes as self-affirmation. Journal of Personality and Social Psychology: 45, 5-19. 
Stern, R. A., Prochaska, J. O., Velicer, W. F., \& Elder, J. P. (1987). Stages of adolescent cigarette smoking acquisition: Measurement and sample profiles. Addictive Behaviors, 12, 319-329.

Stone S. L., Kristeller J. L. (1992). Attitudes of adolescents toward smoking cessation. American Journal of Preventive Medicine, 8, 221-225.

Sussman, S., Dent, C. W., Burton, D., Stacy, A. W., \& Flay, B. R. (1995). Developing schoolbased tobacco use prevention and cessation programs. Thousand Oaks, Califomia: Sage Publications.

Sussman, S., Dent, C. W., Flay, B. R., Hansen, W. B., \& Johnson, C. A. (1987). Psychosocial predictors of cigarette smoking onset by white, black, Hispanic, and Asian adolescents in Southern California. Morbidity and Mortality Weekly Report, 36, 11S-17S.

Sussman, S., Dent, C. W., Severson, H., Burton, D., \& Flay, B. R. (1998). Self-initiated quitting among adolescent smokers. Preventive Medicine, 27, A19-A28.

Sutton, S. R. (1992). Is taking up smoking a reasoned action? Addiction, 87, 21-24.

Sutton, S. R. (1994). The past predicts the future: interpreting behaviour-behaviour relationships in psychological models of health behaviours. In D. R. Rutter, \& L. Quine (Eds.), Social Psychology and Health: European Perspectives (pp. 71-88). Aldershot: Avebury.

Sutton, S. R. (2000). Interpreting cross-sectional data on stages of change. Psychology and Health, 15, 163-171.

Sutton, S. R. (2001). Back to the drawing board? A review of applications of the transtheoretical model to substance use. Addiction, 96, 175-186.

Svyantek D. J., \& Ekeberg S. E. (1995). The earth is round (so we can probably get there from here). American Psychologist, 50, 1101.

Swanson, J. E., Rudman, L. A., \& Greenwald, A. G. (2001). Using the Implicit Association Test to investigate attitude-behaviour consistency for stigmatised behaviour. Cognition and Emotion, 15. 207-230.

Tabachnick, B. G., \& Fidell, L. S. (1996). Using Multivariate Statistics, Third Edition. New York: HarperCollins Publishers.

Thomton, W., Douglas, G. A., \& Houghton, S. J. (1999). Transition through stages of smoking: the effect of gender and self-concept on adolescent smoking behavior. Journal of Adolescent Health, 25, 284-289.

Trafimow D. (2000). Habit as both a direct cause of intention to use a condom and as a moderator of the attitude-intention and subjective norm-intention relations. Psychology and Health, 15, 383-393.

Triandis, H. C. (1977). Interpersonal Behavior. Monterey, CA: Brooks/Cole.

Triandis, H. C. (1980). Values, attitudes, and interpersonal behavior. In: H. E. Howe Jr \& M. M. Page (Eds.), Nebraska Symposium on Motivation, 1979. Lincoln, NE: University of Nebraska Press.

Trochim, W. M. K. (2001). Introduction to validity. Available through: URL: http://trochim.human.comell.edu/kb.

Tuakli, N., Smith, M. A., \& Heaton, C. (1990). Smoking in adolescence: Methods for health eductation and smoking cessation. Journal of Family Practice, 31, 369-374.

Tucker, L. A. (1984). Psychological differences between adolescent smoking intenders and nonintenders. Journal of Psychology, 118, 37-43.

Tukey, J. W. (1962). The future of data-analysis. Annals of Mathematical Statistics, 33, 1-67.

Turner, C. F., Lester, J. T., \& Gfroerer, J. C. (1992). Survey Measurement of Drug Use: methodological studies, NIDA, DHHS Publication no. (ADM) 92-1929. Washington: National Institute on Drug Abuse. 
Tyas, S. L., \& Pederson, L. L. (1998). Psychosocial factors related to adolescent smoking: a critical review of the literature. Tobacco Control, 7, 409-420.

Unger, J. B., Johnson, C. A., Stoddard, J. L, Nezami, E., \& Chou, C. P. (1997). Identification of adolescents at risk for smoking initiation: Validation of a measure of susceptibility. Addictive Behaviors, 22, 81-91.

Unger, J. B., Rohrbach, L. A., Howard-Pitney, B., Olson, R. A., \& Mouttapa, M. (2001). Peer influences and susceptibility to smoking among California adolescents. Substance Use and Misuse, 36, 551-571.

Urberg, K. A., Cheng, C. H., \& Shyu, S. J. (1991). Grade changes in peer influence on adolescent cigarette smoking: A comparison of two measures. Addictive Behaviors, 16, $21-28$.

U.S. Department of Health and Human Services (1994). Preventing Tohacco Use among Young People: A Report of the Surgeon General. Atlanta, Georgia: U.S. Department on Health and Human Services.

U.S. Department of Health and Human Services (2000). Reducing tobacco use: A Report of the Surgeon General. Atlanta, Georgia: U.S. Department on Health and Human Services, Centers for Disease Control and Prevention.

Vaidya, S. G., Vaidya, J. S., \& Naik, U. D. (1999). Sports sponsorship by cigarette companies influences the adolescent children's mind and helps initiate smoking: results of a national study in India. Journal of the Indian Medical Association, 97, 354-359.

Velicer, W. F., Hughes, S. L., Fava, J. L., Prochaska, J. O., \& DiClemente, C. C. (1995). An empirical typology of subjects within stages of change. Addictive Behaviors, 20, 299320.

Velicer, W. F., Norman, G. J., Fava, J. L., \& Prochaska, J. O. (1999). Testing 40 predictions from the Transtheoretical model. Addictive Behaviors, 24, 455-469.

Velicer, W. F., Prochaska, J. O., Fava, J. L., Norman, G. J., \& Redding, C. A. (1998). Smoking cessation and stress management: Applications of the Transtheoretical Model of behavior change. Homeostasis, 38, 216-233.

Velicer W. F., Rossi J. S., Prochaska J. O., \& DiClemente C. C. (1996). A criterion measurement model for health behavior change. Addictive Behaviors, 2l, 555-584.

Verplanken, B. (1989). Persuasive communication of technological risks. A test of the elaboration likelihood model. Dissertation. Leiden.

Verplanken, B., \& Aarts, H. (1999). Habit, attitude, and planned behaviour: Is habit an empty construct or an interesting case of goal-directed automaticity? European Review of Social Psychology, 10, 101-134.

Virgili, M., Owen, N., \& Severson, H. H. (1991). Adolescents' smoking behavior and risk perceptions. Journal of Substance Abuse, 3, 315-324.

Vroom, B. (1994). De tekst getest. Handleiding voor het pretesten van schriftclijk materiaal. [The text tested. Manual for pretesting written material]. Assen: Van Gorcum.

Wang, M. Q., Fitzhugh, E. C., Eddy, J. M., Fu, Q., \& Turner, L. (1997). Social influences on adolescents' smoking progress: a longitudinal analysis. American Journal of Health Behavior, 21, 111-117.

Wang, M. Q., Fitzhugh, E. C., Eddy, J. M., \& Westerfield, R. C. (1996). Attitudes and beliefs of adolescent experimental smokers: a smoking prevention perspective. Journal of Alcohol and Drug Education, 41, 1-12.

Wang, M. Q., Fitzhugh, E. C., Westerfield, R. C., \& Eddy, J. M. (1994). Predicting smoking status by symptoms of depression for U.S. adolescents. Psychological Reports, 75, 911-914. 
Warren, C. W., Riley, L., Asma, S., Eriksen, M. P., Green, L., Blanton, C., Loo, C., Batchelor, S., \& Yach, D. (2000). Tobacco use by youth: a surveillance report from the Global Youth Survey project. Bulletin of the World Health Organization, 78, 868-876.

Weiner, B. (1985). An attributional theory of achievement motivation and emotion. Psychological Review, 92, 548-573.

Weiner, B. (1986). An attributional theory of motivation and emotion. New York: Springer.

Weinstein, N. D. (1988). The Precaution Adoption Process. Health Psychology, 7, 355-386.

Weinstein, N. D., Rothman, A. J., \& Sutton, S. R. (1998). Stage theories of health behavior: Conceptual and methodological issues. Health Psychology, 17, 290-299.

Weinstein, N. D., \& Sandman, P. M. (1992). A model of the precaution adoption process: evidence from home radon testing. Health Psychology, 11, 170-180.

Werch, C. E. (2001). Expanding the stages of change: A program matched to the stages of change of alcohol acquisition. American Journal of Health Promotion, 12, 34-37.

Werch, C. E., \& Anzalone, D. (1995). Stage theory and research on tobacco, alcohol, and other drug use. Journal of Drug Education, 25, 81-98.

Werch, C. E., Anzalone, D., Castellon-Vogel, E., Carlson, J., Brokiewics, L., \& Felker, J. (1995). Factors associated with the stages of alcohol use among inner city school youth. Journal of School Health, 65, 255-258.

Werch, C. E., Carlson, J. M., Pappas, D. M., Dunn, M., \& Williams, T. (1997). Risk factors related to urban youth stage of alcohol initiation. American Journal of Health Behavior, 21, 377-387.

Werch, C. E., \& DiClemente, C. C. (1994). A multi-component stage-model for matching drug prevention strategies and messages to youth stage of use. Health Education Research, 9, 37-46.

Werch, C. E., Meers, B. W., \& Farrell, J. (1993). Stages of drug use acquisition among college students: Implications for the prevention of drug abuse. Journal of Drug Education, 23, 375-386.

Werch, C. E., Ross, C., Anzalone, D., \& Meers, B. W. (1994). Stage of alcohol and drug use among young adults. Health Values, 18, 41-49.

Whitelaw, S., Baldwin, S., Bunton, R., \& Flynn. (2000). The status of evidence and outcomes in Stages of Change research. Health Education Research, 15, 707-718.

Willet, J. B. (1997). Measuring change: what individual growth modeling buys you. In: E. Amsel, \& K. Renninger (Eds.), Change and Development: Issues of Theory, Method and Application (pp. 213-241). New Jersey: Erlbaum.

Willet, J. B., \& Singer, J. D. (1991). How long did it take? Using survival analysis in educational and psychological research. In: L. Collins, \& J. Hom (Eds.), Best methods for the analysis of change: Recent advances, unanswered questions, future directions. Washington, DC: American Psychological Association.

Williams, C. L., Eng, A., Botvin, G. J., Hill, E., \& Wynder, P. L. (1979). Validation of students' self-reported cigarette smoking status with plasma cotinine levels. American Journal of Public Health, 69, 1272-1274.

Wills, T., Vaccaro, D., McNamara, G., \& Hirky (1996). Escalated substance use: A longitudinal grouping analysis from early to middle adolescence. Journal of Abnormal Psychology, 105, 166-180.

Windle, M., \& Windle, R. C. (2001). Depressive symptoms and cigarette smoking among middle adolescents: Prospective associations and intrapersonal and interpersonal influences. Journal of Consulting and Clinical Psychology, 69, 215-226.

World Health Organization. (1998). Guidelines for controlling and monitoring the tobacco epidemic. Geneva: WHO monograph nr. WM 290 98GU. 
Wynder, E. L., \& Graham, E. A. (1950). Tobacco smoking as a possible etiologic factor in bronchogenic carcinoma. Journal of the American Medical Association, 143, 329-336.

Young, M., \& Werch, C. E. (1990). Relationship between self-esteem and substance use among students in fourth through twelfth grade. Wellness Perspectives: Research, Theory and Practice, 7, 31-44.

Zhu, B. P., Liu, M., Shelton, D., \& Giovino, G. A. (1996). Cigarette smoking and its risk factors among elementary school students in Beijing. American Joumal of Public Health, 86, 368-375. 


\section{Summary}

Adolescence is the period in which many people start smoking. However, adolescents do not become smokers overnight. As with many other behaviours, a process of change precedes the actual adoption of smoking behaviour. Smoking behaviour becomes a habit and an addiction, which may cause severe damage to one's health. Therefore, it is important to know why adolescents start smoking, which is why determinant studies are conducted. The results of such determinant studies can be used to develop interventions that aim to prevent smoking. Many studies have measured smoking behaviour in a 'rough-and-ready' fashion. There is no accepted measure of adolescent smoking behaviour, so it is difficult to compare outcomes of different studies. Moreover, models that form the basis of determinant studies assume that smoking behaviour develops in a linear process. The introduction of so-called 'stage models' in smoking behaviour research raises questions with regard to the quality of existing determinant studies, which can only result in useful information if the behaviour in question is measured accurately. The studies in the present thesis are a consequence of the latter observation. They were intended to refine existing models of the process of smoking initiation, to test them and to integrate them.

Part 1 of the thesis focuses on the 'Stages of Change Construct', a construct that originated from the popular Transtheoretical Model. This construct particularly describes the motivational stages that people pass through as they change their behaviour. The principles derived from the model have been applied to many behaviours, one of which is smoking initiation by adolescents. Studies applying this model to the subject of smoking initiation showed that a large majority of adolescents reside in the so-called precontemplation stage, the stage in which people plan to start smoking within the next six months. When early adolescents are asked whether they want to start smoking, a large majority answers 'no'. Nevertheless, a considerable proportion of this group will eventually take up smoking. This raises the question whether this group of non-intenders can be divided into a number of subgroups that differ from each other. This hypothesis was exploratively tested in the study described in Chapter 2.

Based on studies of subgroups within the precontemplation stage of smoking cessation, as well as on research regarding the concept of 'susceptibility to smoking', the study of Chapter 2 tested whether the group of precontemplators could be divided into committers, immotives and progressives. Committed adolescents are sure they will never start smoking. Immotives think they will never start smoking, at least not within the next five years. Progressives have concrete plans with regard to their future smoking behaviour: they do not want to start within the next six months, but they think they will do so within the next five years. The three subgroups proved to differ with regard to their cognitions and their perception of smokers in the social environment. The results on the other two motivational stages from the Transtheoretical model, contemplation (planning to start smoking within six months) and preparation (planning to start smoking within a month), were ambiguous. Both groups were found to be small and the results on the cognitive characteristics of both groups were inconsistent.

Chapter 3 describes a study in which the groups of contemplators and preparators were aggregated, resulting in a four-stage model to describe the 
motivational development in the process of smoking initiation. The four-stage model included the stages of committers, immotives, progressives and contemplators. The model was tested in a longitudinal design using the motivational state at baseline to predict weekly smoking at follow-up. The follow-up measurement took place twelve months after the baseline measurement. It was expected that committed adolescents would be least likely to start smoking, followed by immotives, progressives and contemplators. The motivational stages were found to have predictive value with regard to smoking behaviour at follow-up. The chance of starting to smoke during the 12 months follow-up was found to increase by a factor of 2 when a more advanced stage was compared with a stage that was further removed from the adoption of the behaviour. These results were interpreted as support for the underlying four-stage model.

Part 2 of this thesis focuses on a model describing the process of smoking initiation mainly from a behavioural perspective. Since the beginning of the 1980 s, the stages of never smoked, trying, experimenting and regular smoking have been distinguished. At first sight, the distinction between these stages seems valid. The model was presented in the American Surgeon General's report as the leading model of the smoking initiation process. However, the model has never been thoroughly tested as such. One of the reasons for this lack of tests may be that the model only specifies stages of progressing smoking behaviour. Thus, the model does not operationalise the stages in which an adolescent can decide to stop smoking. Previous research has shown that there is a considerable group of adolescents who decide to quit after having tried smoking several times. Moreover, there is increased scientific interest in the subject of adolescent smoking cessation, a subject that had previously been applied exclusively to adult smoking. Chapter 4 describes a study aimed at identifying two groups of ex-smokers: nonsmoking deciders (who have quit smoking after trying or experimenting) and quitters (who have quit after having smoked regularly). The study found that nonsmoking deciders and quitters should be viewed as separate groups. Nonsmoking deciders had less risky social cognitive characteristics than triers and experimenters. Quitters had less risky characteristics than regular smokers. The results of the comparison between quitters and experimenters were less clear. The concept of 'nicotine addiction' might be more useful in showing differences between these two groups than social cognitive concepts. It was concluded that the nonsmoking deciders and quitters should not be forcibly included within the four stages of progressing smoking behaviour, as is often done in research applying behavioural models of smoking initiation.

Chapter 5 is based on the conclusions of Chapter 4. The six-stage model that was constructed on the basis of earlier findings consisted of the following stages: never smoked, trying, experimenting, nonsmoking deciding, regular smoking and quitting. Since the original model has often been operationalised in different ways, this chapter starts with an account of the operationalisation of the various stages. This operationalisation was based on existing knowledge and norms prevailing in the field. The results of the longitudinal study showed that the stages had predictive value with regard to daily smoking during the 12 months between the baseline and follow-up measurements. Adolescents who resided in more advanced stages were more likely to smoke daily at follow-up. However, nonsmoking deciders were not, as had been 
expected, less likely to start smoking daily than triers. The smoking experience of nonsmoking deciders appeared to compensate the current smoking behaviour of triers. Both groups had a probability to start smoking daily that was around six times as high as that of never smokers. This probability was doubled again when adolescents resided in the experimenter stage at baseline. Adolescents smoking regularly (weekly) at baseline were twice as likely as experimenters at baseline to smoke daily at follow-up. The probability for quitters to smoke daily at follow-up was half that of regular smokers. Chapter 5 ends with the observation that the integration of motivational and behavioural stages might improve our understanding of the process of smoking initiation.

Part 3 attempts to integrate the two lines of research described above. The results of the studies reported on in Parts 1 and 2 show that both motivational and behavioural stages are valuable to obtain insights into the process of smoking initiation. The study described in this part examined whether integrating these two lines of research would result in a more complete picture of the processes that play a role in the eventual uptake of regular smoking behaviour. A framework including all motivational and behavioural stages was constructed, and the prevalence of each of the categories of the framework was studied. This led to the selection of eight stages that appeared to cover a substantial part of the total population. These stages were compared in terms of cognitive characteristics. Stages were found to show the expected differences on one or more social cognitive characteristics, except for the stages of progressing and contemplating experimenters. As a result, these stages were aggregated into one stage, representing the experimenters who contemplate smoking. Subsequently, an integrated Model of Unmotivated Smoking Initiation of Children and Adolescents (MUSICA) was developed. The MUSICA postulates that the first stages of smoking initiation occur in the so-called 'unmotivated cycle'. Youngsters try smoking and experiment with cigarettes without having concrete, rational, plans to smoke in the future. Decisions to stop smoking will often be followed by repeated trial behaviour. The behaviour displayed in the unmotivated cycle is viewed as typical behaviour in adolescence. When individuals commit themselves to nonsmoking, they become considerably less likely to smoke in the future. When individuals make plans to start smoking in the future, they become considerably more likely to actually initiate regular smoking behaviour.

The tests described in Chapter 6 showed that early adolescents in the various stages differed with regard to their social cognitive characteristics in that adolescents in the more advanced stages had riskier social cognitive characteristics with regard to future smoking behaviour. Longitudinal examination showed that advanced stage assignment at baseline led to an increased probability of smoking regularly at followup. As hypothesised, social cognitive predictors of stage progression appeared to differ between the various stages. Self-efficacy was found to be a predictor of transition out of the committer stage. The smoking behaviour of parents was particularly predictive of progression from committed never smoking, whereas family norms were predictors of progression from committed nonsmoking deciding. Whereas peers appeared to be important models in immotive never smokers and triers, parents were important models with regard to the progression from the immotive experimenter stage. Social norms within the family predicted whether one progressed from contemplating 
experimenter to the stage of regular smoking. However, overall effect sizes of the cognitive predictors were small, which could be caused by the relatively long interval between the two measurements. However, the MUSICA offers an alternative explanation. Since smoking initiation is postulated to be a low cognitive energy, unmotivated, action, social cognitive concepts may not be able to explain much of the variance in smoking behaviour in prospective designs. Instead of being the result of rational considerations, initial trial behaviour may often take place in crucial events after which cognitive adjustments are made. Consequently, models that assume rational considerations will have low predictive value.

It is concluded that studies of adolescent smoking initiation need to distinguish both motivational and behavioural stages of smoking initiation. More research on the hypotheses that follow from this thesis is necessary. The studies in the present thesis may stimulate research into smoking initiation from a point of view that is less dependent on traditional, rational, social cognitive concepts. Social cognitive concepts are useful to put respondents 'on their marks' within a stage model, but they have shortcomings in predicting the start of smoking behaviour. 


\section{Samenvatting}

De adolescentie is een periode waarin velen beginnen met roken. Echter, iemand is niet van de ene op de andere dag een roker. Net zoals bij veel ander gedrag gaat er een proces van verandering vooraf aan het uiteindelijk definitief uitvoeren van het rookgedrag. Rookgedrag ontwikkelt zich tot een gewoonte en een verslaving die ernstige schade kan aanrichten aan de gezondheid. Vandaar dat het van belang is te onderkennen waarom adolescenten beginnen met roken. Hiertoe wordt zogenaamd determinantenonderzoek uitgevoerd. Als gevolg van de resultaten van determinantenonderzoek kunnen interventies worden ontwikkeld die tot doel hebben het beginnen met roken te voorkomen. Vaak wordt in determinantenonderzoek het gedrag 'voor de vuist weg' gemeten. Er bestaat geen algemeen geaccepteerde maat voor rookgedrag van adolescenten. Vandaar dat onderzoeken onderling moeilijk vergelijkbaar zijn. Bovendien gaan de modellen die ten grondslag liggen aan determinantenonderzoek vaak uit van het idee dat rookgedrag zich 'lineair' ontwikkelt. De opkomst van zogenaamde 'stadium modellen' in het onderzoek naar rookgedrag van pubers roept vragen op met betrekking tot de kwaliteit van bestaande determinantenonderzoeken. Detemninantenonderzoek levert alleen bruikbare informatie op als het gedrag in kwestie op een goede manier wordt gemeten. De studies in dit proefschrift zijn het gevolg van deze laatste constatering. Het doel van de studies was om bestaande modellen van het proces van beginnen met roken aan te passen op basis van observaties, daarna te testen, en te integreren.

Deel 1 van dit proefschrift concentreerde zich op de 'stadia van gedragsverandering'; een construct dat afkomstig is uit het populaire 'Transtheoretische model'. Dit construct beschrijft met name de motivationele stadia die mensen doorlopen als zij hun gedrag veranderen. Op vele gedragingen zijn de principes die afkomstig zijn uit deze theorie al toegepast. Zo ook op beginnen met roken door jongeren. Uit de studies die met dit model naar dit onderwerp zijn gedaan, bleek dat een overgrote meerderheid van de jongeren zich bevindt in de zogenaamde precontemplatiefase. Dit is de fase waarin men niet van plan is om binnen 6 maanden te gaan beginnen met roken. Als je vroege adolescenten vraagt of ze willen beginnen met roken, antwoordt een grote meerderheid met 'nee'. Echter, toch begint een aanzienlijk deel van deze groep uiteindelijk toch met roken. Het zou dus wel eens zo kunnen zijn dat de groep 'nee'-zeggers onder te verdelen is in een aantal subgroepen die onderling van elkaar verschillen. Deze laatste hypothese is exploratief getest in Hoofdstuk 2.

Op basis van kennis die afkomstig is uit onderzoek naar subgroepen binnen de precontemplatiefase van stoppen met roken, en op basis van onderzoek naar de vatbaarheid voor beginnen met roken is in Hoofdstuk 2 getest of de groep precontemplatoren onder te verdelen was in vastberaden, ongemotiveerde en progressieve jongeren. Vastberaden jongeren zijn er zeker van dat ze nooit zullen gaan roken. Ongemotiveerden denken dat ze nooit zullen beginnen met roken, in ieder geval niet in de eerstkomende vijf jaar. Progressieven hebben concrete plannen met betrekking tot hun toekomstig rookgedrag. $\mathrm{Zij}$ willen niet binnen zes maanden gaan roken, maar denken dat wel te gaan doen binnen vijf jaar. De drie subgroepen bleken inderdaad van elkaar te verschillen op basis van hun cognities en perceptie van hun 
sociale omgeving. De resultaten met betrekking tot de twee andere motivationele stadia uit het Transtheoretische model, overweging (van plan zijn te gaan roken binnen zes maanden) en voorbereiding (van plan zijn te gaan roken binnen een maand), waren niet eenduidig. Ten eerste bleken de groepen klein van omvang te zijn. Daarnaast waren de resultaten met betrekking tot de cognitieve karakteristieken van beide groepen inconsistent.

In Hoofdstuk 3 zijn de groepen van overwegers en voorbereiders samengevoegd, zodat een vierfasen model ontstond dat de motivationele ontwikkeling in het proces van beginnen met roken beschrijft. Dit vierfasenmodel bestond uit de fasen vastberaden, ongemotiveerd, progressief, en overwegend. Het model is getest in een longitudinaal design waarbij de motivationele fase op de voormeting werd gebruikt om beginnen met wekelijks roken op de nameting te voorspellen. De nameting vond 12 maanden na de voormeting plaats. Er werd verwacht dat vastberaden jongeren de kleinste kans hadden op het beginnen met roken, gevolgd door respectievelijk ongemotiveerden, progressieven en overwegers. De motivationele stadia bleken voorspellende waarde te hebben voor het rookgedrag op de nameting. De kans van beginnen met roken gedurende de 12 maanden bleek toe te nemen met een factor 2, wanneer een meer gevorderd stadium werd vergeleken met een stadium dat verder verwijderd was van het uitvoeren van het gedrag. Deze resultaten werden geïnterpreteerd als zijnde een ondersteuning van het onderliggende vierfasen model.

In Deel 2 van dit proefschrift stond een model centraal dat het proces van beginnen met roken voornamelijk vanuit een gedragsmatig perspectief beschrijft. Sinds het begin van de jaren 80 worden de stadia van nooit gerookt, proberen, experimenteren en regelmatig roken onderscheiden. Op het eerste gezicht lijkt het onderscheid tussen de stadia in dit model gegrond. Het model is gepresenteerd door het Amerikaanse ministerie van Volksgezondheid als een toonaangevend model van beginnen met roken. Echter, dit gedragsmatige model is nooit uitgebreid als zodanig getest. Een van de oorzaken hiervoor is dat het model alleen de fasen van toenemend rookgedrag specificeert. Het model beschrijft dus niet de fasen waarbij een jongere kan besluiten om niet meer te roken. In eerder onderzoek is aangetoond dat de groep jongeren die besluit om niet meer door te gaan, nadat ze enkele malen roken hebben uitgeprobeerd, aanzienlijk is. Bovendien is de laatste tijd steeds meer wetenschappelijke aandacht voor het stoppen met roken door jongeren. Dit onderwerp werd voorheen vrijwel uitsluitend op volwassenen toegepast.

Hoofdstuk 4 richtte zich op het identificeren van twee groepen ex-rokers: nietroken beslissers (gestopt met roken na proberen of experimenteren) en stoppers (gestopt na regelmatig te hebben gerookt). In dit hoofdstuk bleek dat niet-roken beslissers en stoppers als aparte groepen moeten worden gezien. De niet-roken beslissers hadden minder riskante sociaal cognitieve eigenschappen dan probecrders en experimenteerders. Stoppers scoorden minder riskant dan regelmatig rokers. De resultaten met betrekking tot de vergelijking tussen stoppers en experimenteerders waren minder duidelijk. Waarschijnlijk zal een concept als 'nicotineverslaving' duidelijker verschillen tussen deze twee groepen kunnen aantonen dan sociaal cognitieve concepten. Geconcludeerd werd dat de niet-roken beslissers en stoppers niet dienen te worden 'geforceerd' binnen de vier stadia van toenemend rookgedrag, zoals regelmatig in onderzoeken met een gedragsmatig model gebeurt. 
Hoofdstuk 5 is gebaseerd op de conclusies van Hoofdstuk 4. Het zesfasen model dat als gevolg van de bevindingen werd geconstrueerd, bestond uit de fasen: nooit gerookt, proberen, experimenteren, niet-roken beslissen, regelmatig roken en stoppen. Aangezien het oorspronkelijke gedragsmatige model vaak wisselend werd geoperationaliseerd, begon dit hoofdstuk met een uiteenzetting van de operationalisatie van de verschillende stadia. De operationalisatie was gebaseerd op de bestaande kennis en normen binnen het vakgebied. De resultaten van de longitudinale studie toonden aan dat de stadia voorspellende waarde hadden met betrekking tot dagelijks gaan roken gedurende de 12 maanden tussen voor- en nameting. Adolescenten die zich bevonden in een meer geavanceerd stadium bij de voormeting hadden een verhoogde kans om dagelijks te roken bij de nameting. Echter, de niet-roken beslissers hadden niet de verwachte lagere kans om dagelijks te roken bij de nameting dan probeerders. De rookervaring van niet-roken beslissers bleek even zwaar te wegen als het huidig rookgedrag van de probeerders. Beide groepen hadden een kans om dagelijks te gaan roken die zes keer zo hoog lag als die van nooit-rokers. Deze kans werd nog eens verdubbeld als adolescenten zich bij de voormeting in de experimenteerfase bevonden. Diezelfde verdubbeling werd gevonden wanneer regelmatig rokers werden vergeleken met experimenteerders. De kans om dagelijks te roken bij de nameting was half zo groot voor stoppers in vergelijking met regelmatig rokers. Hoofdstuk 5 eindigde met de signalering dat de integratie van motivationele en gedragsmatige stadia het inzicht in het proces van beginnen met roken zou kunnen vergroten.

In Deel 3 is getracht beide onderzoekslijnen, zoals hierboven beschreven, te integreren. In deel 1 en 2 bleek dat zowel de motivationele als gedragsmatige stadia toegevoegde waarde hebben wat betreft het verkrijgen van inzicht in het proces van beginnen met roken. Er werd gekeken of het combineren van beide onderzoekslijnen een completer beeld zou geven van de processen die een rol spelen bij het uiteindelijk beginnen met regelmatig rookgedrag. Een raamwerk dat alle motivationele en gedragmatige stadia bevat werd geconstrueerd. De prevalentie binnen elk van de categorieën van het raamwerk werd bestudeerd. Dit leidde tot de selectie van acht stadia die een substantieel deel van de populatie bleken te bevatten: ongemotiveerd nooit-roker, ongemotiveerd probeerder, ongemotiveerd experimenteerder, ongemotiveerd niet-roken beslisser, vastberaden nooit-roker, vastberaden niet-roken beslisser, progressief experimenteerder en overwegend experimenteerder. Deze stadia werden vergeleken met betrekking tot cognitieve karakteristieken. De stadia bleken van elkaar te verschillen in de verwachte richting, met uitzondering van de progressieve en overwegend experimenteerders. Deze twee stadia werden samengevoegd tot één stadium dat de experimenteerders representeert die overwegen om te roken in de toekomst. Dit leidde tot de formulering van een geïntegreerd stadium Model van Ongemotiveerd Beginnen met Roken door Kinderen en Adolescenten - Model of Unmotivated Smoking Initiation of Children and Adolescents (MUSICA), bestaande uit zeven stadia. De MUSICA stelt dat de eerste stadia van beginnen met roken plaatsvinden in de zogenaamde 'ongemotiveerde cyclus'. Jongeren proberen sigaretten uit en experimenteren met roken zonder concrete, rationele, plannen te hebben met betrekking tot hun toekomstig rookgedrag. Beslissingen om te stoppen met uitproberen zullen vaak worden gevolgd door herhaald probeer- of experimenteergedrag. Het gedrag binnen de ongemotiveerde cyclus wordt 
gezien als natuurlijk gedrag in de puberteit. Wanneer jongeren vastberaden beslissen om een niet-roker te zijn, is hun kans om te roken in de toekomst duidelijk verminderd. Wanneer jongeren plannen gaan maken om met roken te beginnen in de toekomst, is de kans om uiteindelijk regelmatig te gaan roken sterk vergroot.

De adolescenten in de verschillende stadia van de MUSICA verschilden met betrekking tot hun sociaal cognitieve eigenschappen. Adolescenten in meer gevorderde stadia scoorden riskanter dan adolescenten in minder gevorderde stadia. Voorts toonden longitudinale analyses aan dat gevorderde stadia een hogere kans hadden om te gaan roken in de periode tussen de voor- en de nameting. Zoals verwacht, waren verschillende sociaal cognitieve factoren verantwoordelijk voor transitie uit de verschillende stadia. Bij alle gevonden voorspellers scoorden diegenen die in stadium vooruit waren gegaan (progressie) riskanter dan diegenen die niet vooruit waren gegaan (geen progressie). Het gedrag en waargenomen druk van vrienden alsmede het gedrag van broers en zussen bleken progressie van ongemotiveerd nooit rokers te voorspellen. Het gedrag van vrienden werd meer saillant bij de ongemotiveerd probeerders. Bovendien voorspelden attitudes over roken progressie vanuit dit stadium. Waargenomen sociale normen van ouders en vrienden voorspelden progressie van ongemotiveerd experimenteerders. Het rookgedrag van vrienden en waargenomen nadelen van roken waren concepten die progressie van ongemotiveerd niet-roken beslissers voorspelden. Progressie vanuit de vastberaden stadia werd voorspeld door eigen-effectiviteit ten aanzien van het weigeren van sigaretten. Bij nooit-rokers bleek bovendien het rookgedrag van de ouders voorspellende waarde te hebben. Bij nietroken beslissers waren normen binnen de familie van belang. Echter, de voorspellende waarde van de sociaal cognitieve concepten bleek beperkt. Dit zou te maken kunnen hebben met de relatief lange periode tussen de meting van de voorspellers en de meting van het gedrag. Het MUSICA-model biedt een alternatieve verklaring voor deze vinding. Omdat beginnen met roken een 'ongemotiveerde' actie blijkt, zou de cognitieve energie die wordt gebruikt bij een dergelijke beslissing laag verondersteld kunnen worden. In plaats van het gevolg te zijn van rationele overwegingen, zou probeer- en experimenteergedrag vaak kunnen plaatsvinden in cruciale gebeurtenissen waarna cognitieve aanpassingen worden gemaakt. Dientengevolge zullen modellen die uitgaan van rationele beslissingen weinig voorspellende waarde hebben.

Concluderend kan worden gesteld dat in onderzoek naar beginnen met roken door adolescenten onderscheid dient te worden gemaakt tussen zowel motivationele als gedragsmatige stadia. Meer onderzoek zal moeten worden verricht naar de hypothesen die uit het huidige proefschrift volgen. De studies in het huidige proefschrift zullen wellicht een aanzet zijn om het beginnen met roken door adolescenten vanuit een invalshoek te bestuderen die minder afhankelijk is van traditionele, rationele, sociaal cognitieve concepten. Sociaal cognitieve concepten zijn nuttig om respondenten 'op hun plaatsen' te zetten binnen een stadium model, maar schieten tekort om de start van rookgedrag te voorspellen. 


\section{Acknowledgements}

I would like to thank all the people who have contributed to this $\mathrm{PhD}$ project. Hein, thank you for your faith, guidance and support. I am sure that we will find ways to keep up some level of cooperation in the future. Aart, I have learned a lot from you. Sharing a room with you for these three years is the best learning experience that I could have imagined. And above that, it was a lot of fun!

I thank the members of the scientific committee: Nanne de Vries, Hans Brug, Rutger Engels, Ronald Knibbe and Wayne Velicer, for the time and energy they spent on reading my thesis. Further, I thank Jan Klerkx for his corrections of my English writing, and Silvia Smits for the cover design of this thesis.

Next, I would like to express my gratitude to MEMIC, MailMerge and all ESFA team-members that I have worked with: Goof, Kerstin, Judith, Kris, Helga, Esmée, Ellen, Ingrid, Marjolein, Miep, Anne, Julie, Max, Liz, Riku, Heikki, Klavs, Karin, Daniëlle, Noortje, Paulo, Carlota, Filipa, Lourdes, Carles, Zoa, Jeanette, Elleke, Margien, and Kirsten. As a team, we made ESFA work! I would especially like to thank two ESFA-colleagues. Martijntje, thank you very much for offering me the opportunity to work with you. On Gran Canaria, it even felt nice to pretend for a few hours that I was married to you. In that sense, the ESFA project will always be special for me, since I have not only pretended to love someone within the project. Joyce, I enjoy every minute with you. Thank you for your work in the project, and for your endurance and support during the many hours that I spent on this thesis. And thanks for the beautiful person that you are.

I thank Geo and Rob for their willingness to back me up at the defence of this thesis. Rob, if Herman, Herman (David), Charles, Elvis (David), or Kit are really dead or unavaiable as your paranymphs, you know where to find me. Geo, you have been a real friend since we met during our studies. Although our weekly visits to Maastricht restaurants started off as a joke, I now really appreciate the fun and function of these dinners. I hope that we will continue this journey for a long time. And when we have visited every restaurant in Maastricht, let's do a test-retest! Further, I would like to thank all colleagues of the Department of Health Education and Promotion. Especially, I thank Marja for her support in the final stages of this $\mathrm{PhD}$ project.

De lui in Valkenswaard wil ik bedanken voor het vele Dommelsch Bier dat we samen met veel plezier hebben genuttigd. Billy, Botske, Leo, Mirjan, Rinette, Sjengen, Snelle en Steffen: ik denk dat ik nog wel eens langskom. Verder bedank ik PSV voor de twee kampioenschappen en de drie supercups die we tijdens mijn promotie-project hebben mogen vieren.

Tenslotte wil ik in het bijzonder ons mam, ons pap, Bart en Paul bedanken voor alle steun door de jaren heen. 


\section{Curriculum Vitae}

Stef Kremers was born on July 25, 1973 in Hardinxveld-Giessendam. In 1992, he received his VWO diploma at the Hertog Jan College in Valkenswaard. In that same year he started studying Health Sciences at the Universiteit Maastricht. In February 1998, he graduated, specialising in Health Education and Promotion. The first three months after graduating, he worked as a research-assistant at the Department of Health Education and Promotion at the Universiteit Maastricht. In June 1998, he started working as a researcher on the ESFA project; an international smoking prevention project (financed by the European Community) of which Maastricht was the research center. From December 2000 till August 2001, he was research manager of the ESFA project. Since September 2001, he has been working as a post-doc researcher at the Department of Health Education and Promotion at the Universiteit Maastricht. In this function, financed by the Netherlands Heart Foundation, he studies determinants of obesity inducing behaviours, and he guides the development and implementation of evidence-based weight gain prevention interventions. He is a committed nonsmoking decider. 

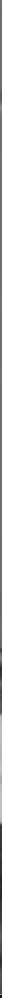